\title{
It has been done elsewhere, it can be done everywhere : impact of smoke-free legislation on smoking
}

Citation for published version (APA):

Nagelhout, G. E. (2012). It has been done elsewhere, it can be done everywhere : impact of smoke-free legislation on smoking. [Doctoral Thesis, Maastricht University]. Datawyse / Universitaire Pers Maastricht. https://doi.org/10.26481/dis.20121010gn

Document status and date:

Published: 01/01/2012

DOI:

10.26481/dis.20121010gn

Document Version:

Publisher's PDF, also known as Version of record

\section{Please check the document version of this publication:}

- A submitted manuscript is the version of the article upon submission and before peer-review. There can be important differences between the submitted version and the official published version of record.

People interested in the research are advised to contact the author for the final version of the publication, or visit the DOI to the publisher's website.

- The final author version and the galley proof are versions of the publication after peer review.

- The final published version features the final layout of the paper including the volume, issue and page numbers.

Link to publication

\footnotetext{
General rights rights.

- You may freely distribute the URL identifying the publication in the public portal. please follow below link for the End User Agreement:

www.umlib.nl/taverne-license

Take down policy

If you believe that this document breaches copyright please contact us at:

repository@maastrichtuniversity.nl

providing details and we will investigate your claim.
}

Copyright and moral rights for the publications made accessible in the public portal are retained by the authors and/or other copyright owners and it is a condition of accessing publications that users recognise and abide by the legal requirements associated with these

- Users may download and print one copy of any publication from the public portal for the purpose of private study or research.

- You may not further distribute the material or use it for any profit-making activity or commercial gain

If the publication is distributed under the terms of Article $25 \mathrm{fa}$ of the Dutch Copyright Act, indicated by the "Taverne" license above, 


\author{
It has been done elsewhere, \\ it can be done everywhere
}

Impact of smoke-free legislation on smoking

Gera Eveline Nagelhout 


\section{Colophon}

Cover design and lay-out: roosgeeftvorm

Production: Datawyse, Universitaire Pers Maastricht

(C) Gera Nagelhout, 2012

ISBN: 9789461591623

The research presented in this thesis was conducted at the School for Public Health and Primary Care: CAPHRI, Department of Health Promotion, of Maastricht University. CAPHRI participates in the Netherlands School of Primary Care Research CaRe. CAPHRI was classified as 'excellent' by the external evaluation committee of leading international experts that reviewed CAPHRI in December 2010. 


\author{
It has been done elsewhere, \\ it can be done everywhere
}

\title{
Impact of smoke-free legislation on smoking
}

\section{PROEFSCHRIFT}

Ter verkrijging van de graad van doctor

aan de Universiteit Maastricht, op gezag van de Rector Magnificus,

Prof. dr. L. L. G. Soete,

volgens het besluit van het College van Decanen,

in het openbaar te verdedigen

op woensdag 10 oktober 2012 om 16.00 uur

door

Gera Eveline Nagelhout

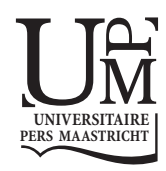




\section{Promotores}

Prof. dr. M. C. Willemsen

Prof. dr. H. de Vries

\section{Beoordelingscommissie}

Prof. dr. N. K. de Vries (voorzitter)

Prof. dr. R. A. Knibbe

Prof. dr. E. H. S. Lechner (Open Universiteit Heerlen)

Prof. dr. C. P. van Schayck

Prof. dr. K. Stronks (Academisch Medisch Centrum Amsterdam)

The research described in this thesis was funded by the Netherlands Organisation for Health Research and Development (ZonMw) 
Dit proefschrift draag ik op aan mijn vader Dries Nagelhout 



\section{Contents}

$\begin{array}{lll}\text { Chapter } 1 & \text { Introduction } & 7\end{array}$

Chapter 2 Methods of the ITC Netherlands Survey 23

Part 1 Population impact of smoke-free legislation on smoking 37

Chapter 3 Smoke-free workplace and hospitality industry legislation 39

Chapter $4 \quad$ Comprehensive and partial smoke-free legislation $\quad 55$

Chapter $5 \quad$ Smoke-free legislation and other effective policies $\quad 69$

Part 2 Individual pathways of change after smoke-free legislation $\quad 89$

$\begin{array}{lll}\text { Chapter } 6 & \text { Increases in support for smoke-free legislation } & 91\end{array}$

$\begin{array}{lll}\text { Chapter } 7 & \text { Newspaper coverage and a media campaign } & 107\end{array}$

$\begin{array}{lll}\text { Chapter } 8 & \text { Policies that reduce the social acceptability of smoking } & 121\end{array}$

$\begin{array}{lll}\text { Chapter } 9 & \text { Smoking in bars after smoke-free legislation } & 137\end{array}$

Chapter 10 Explaining the effect of smoke-free legislation on cessation 159

Part 3 Unintended consequences of smoke-free legislation 175

Chapter 11 Smoke-free legislation and smoking in smokers' homes 177

Chapter 12 Smoke-free legislation and stigmatisation of smokers 197

Chapter 13 Widening socioeconomic inequalities in smoking 207

Chapter $14 \quad$ Inequalities in cessation after three tobacco control policies 221

$\begin{array}{lll}\text { Chapter } 15 \text { Discussion } & 235\end{array}$

References $\quad 255$

$\begin{array}{ll}\text { Summary } & 275\end{array}$

Samenvatting $\quad 283$

Dankwoord 291

$\begin{array}{ll}\text { Curriculum Vitae } & 297\end{array}$ 


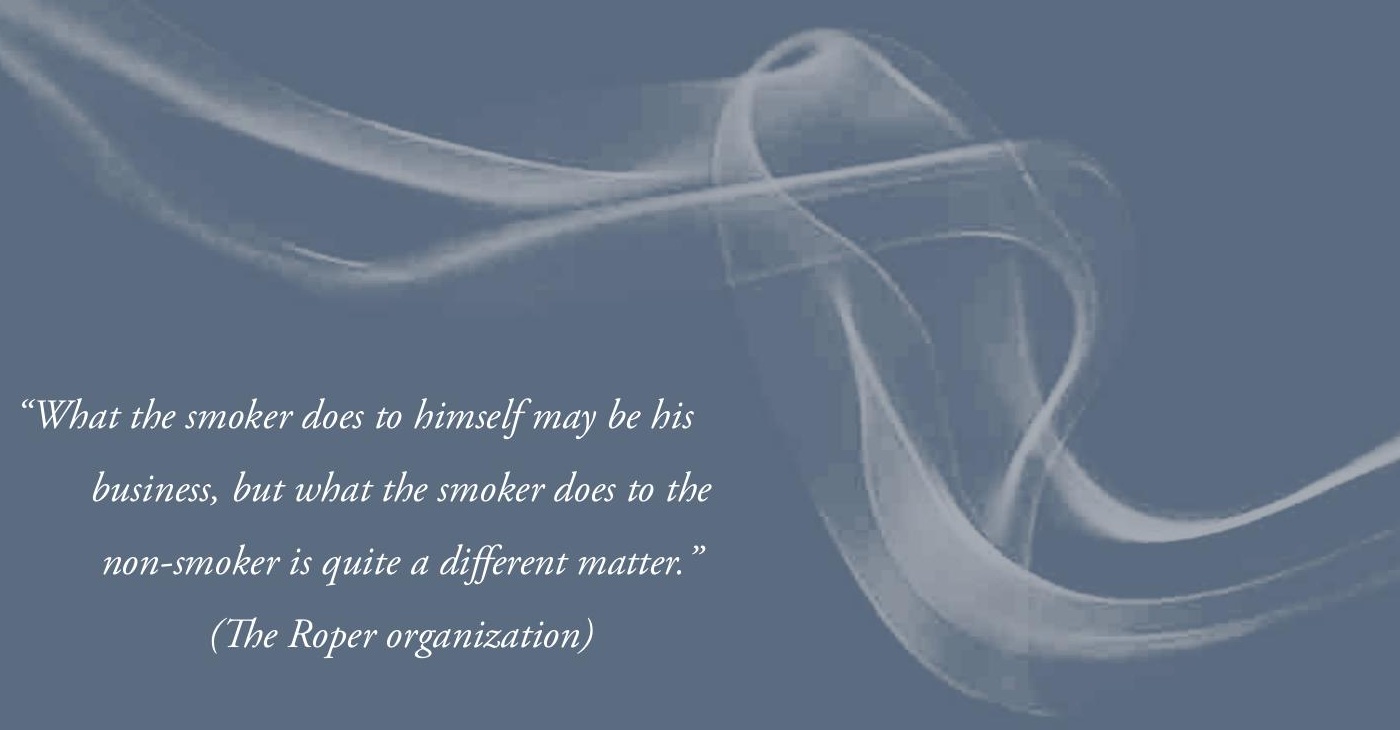


Chapter 1

\section{Introduction}




\section{Going back in time}

Imagine walking into an office building in any developed country fifteen years ago. What do you see? What do you smell? The answer is: tobacco. Although it is now both inappropriate and illegal in most developed countries to light up a cigarette inside an office building, in the twentieth century this was business as usual.

Delegates from countries such as Canada, Ireland, and the United Kingdom who attended the European Conference on Tobacco or Health in 2011 had a similar experience in Amsterdam. When they walked into a small bar to get a drink after a long day of conference presentations, it felt like they had gone back in time. Many were shocked to find that, despite smoking in bars being banned in the Netherlands since 2008, half of the bars in Amsterdam were still filled with tobacco smoke.

The above anecdotes illustrate that smoke-free legislation ${ }^{1}$, the subject of this thesis, differs considerably in time and place. To fully understand these differences, it is necessary to go back further in time, to the beginning of cigarette smoking and tobacco control.

\section{Rise and fall of the cigarette epidemic}

The diffusion of cigarette smoking in populations has been described as an epidemic (Lopez, Collishaw, \& Piha, 1994; U.S. Department of Health and Human Services, 2010; World Health Organization, 2008a). Tobacco has killed 100 million people worldwide in the twentieth century (World Health Organization, 2008a) and in the twenty-first century this number could be closer to one billion. Cigarettes kill one in two persistent users (Peto, Lopez, Boreham, Health, \& Thun, 1992) by causing heart attacks, chronic lung diseases, cancers, and other diseases (U.S. Department of Health and Human Services, 2010). This makes cigarette smoking the single most important cause of premature death in developed countries today, while it is estimated that by 2030 more than 80 per cent of tobacco deaths will be in developing countries (World Health Organization, 2008a).

The Cigarette Epidemic Model (Lopez, Collishaw, \& Piha, 1994) describes the rise and fall of the cigarette epidemic in four stages (Figure1). The first stage marks the beginning of the cigarette epidemic. Along with coffee and chocolate, tobacco was one of the commodities brought back from explorations of the New World (Kluger, 1996). The Indian leaf was thought to have healing powers. In a relatively short period of time, smoking tobacco became socially acceptable among

1 We use the term smoke-free legislation for policies prohibiting smoking in public. The term smoking ban may be a more common term, but has a negative connotation and is therefore not normally used by tobacco control advocates. Some tobacco control activists use the term clean air law. Although this term is more positive, it is also less clear that a policy that bans smoking is intended. Clean air law might just as likely refer to a policy that bans other forms of air pollution. 
men in the Old World and its prevalence began to increase. Smoking-attributable mortality was low at this stage of the epidemic, owing to the time lag between initiating smoking and dying from its effects (Lopez et al., 1994). As a result of low mortality, governments were not likely to take action against smoking at this stage.

Figure 1: Cigarette Epidemic Model (Lopez et al., 1994).

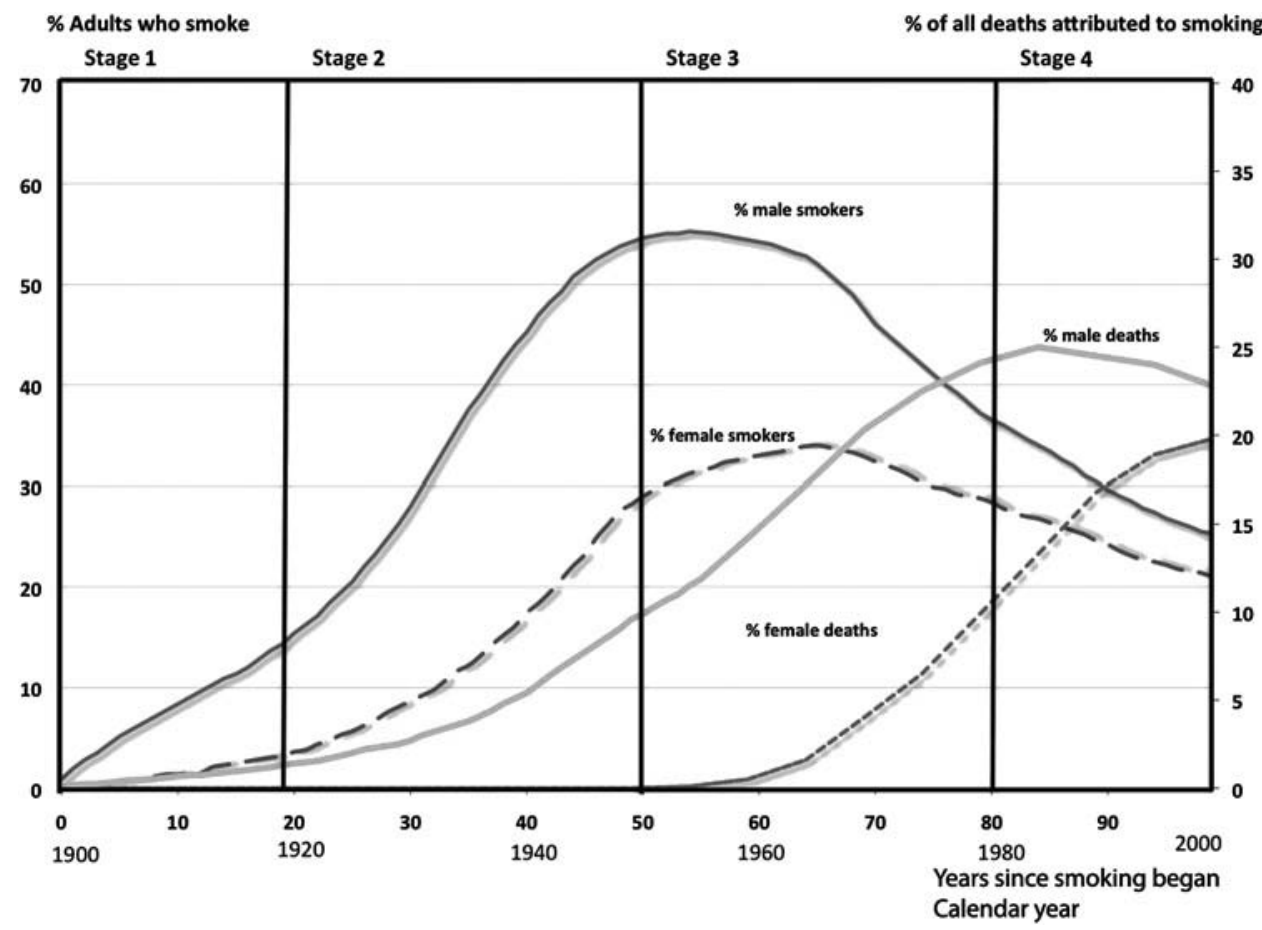

The second stage of the epidemic is characterised by the rapidly increasing prevalence of smoking among men (Lopez et al., 1994). Selling tobacco became a booming business when mechanical cigarette production replaced the handmade process. Tobacco companies started spending large sums of money on marketing (Kluger, 1996). Tobacco was marketed as a healthy product that would make the user appear adventurous, masculine, and glamorous. At the end of the second stage of the epidemic, non-smoking boys and men were the exception rather than the rule and tobacco companies started to focus their marketing and packaging on women as well. At this stage of the epidemic, male deaths from lung cancer were gradually increasing and began to be noticed by doctors and epidemiologists. However, a causal link between smoking and lung cancer could not yet be established. Some medical journals started declining offers of tobacco advertisements, but the general public was unaware of the potential dangers of smoking and governments allowed tobacco marketing to continue unrestricted. 
The third stage of the cigarette epidemic is marked by the beginning of tobacco control. In this stage of the epidemic, smoking prevalence begins to decline among men and levels-off among women. In the developed world, this stage was reached during the 1950s and 60s when the first scientific studies showed that smoking causes lung cancer (Doll \& Hill, 1950; Levin, Goldstein, \& Gerhardt, 1950; U.S. Department of Health Education and Welfare, 1964). Governments realised that they should inform the public about the dangers of smoking and they started to implement educational programmes. Gradually it became clear that the educational approach to tobacco control was not enough to counter the tobacco epidemic. Not all smokers who were aware of the dangers of smoking could quit, because smoking is strongly influenced by the physical and social environment (Christakis \& Fowler, 2008) and is highly addictive (Krasnegor, 1979). Many governments therefore restricted tobacco advertising, implemented health warnings on tobacco products, and increased tobacco taxes. Also, addressing the nuisance for flight attendants, the first smoking restrictions in airplanes were realised (International Agency for Research on Cancer, 2009a).

In the fourth stage of the epidemic, smoking prevalence declines among both men and women and there is a rapid rise in smoking-attributable mortality among women (Lopez et al., 1994). In the developed world, this stage was reached in the 1980s. During this period, it began to be noticed that non-smoking spouses of smokers were dying of lung cancer. Studies revealed that exposure to secondhand smoke $^{2}$ is indeed dangerous for non-smokers (Hirayama, 1981; White \& Froeb, 1980). In 1986, the US Surgeon General concluded that there was strong and consistent evidence that "involuntary smoking causes disease, including lung cancer, in healthy non-smokers" (U.S. Department of Health and Human Services, 1986). The 1986 US Surgeon General's report was a landmark for tobacco control. The tobacco industry could no longer claim that smokers had the right to smoke wherever they wanted. This paved the way for smoke-free legislation to protect non-smokers from the health dangers of second-hand smoking.

2 Second-hand smoke (SHS) is the tobacco smoke that people inhale when they are in the proximity of a smoker. Passive smoking may be a more well-known term, but it does not reflect the fact that exposure to SHS is actively making people sick. Environmental tobacco smoke (ETS) is a term that is often used by the tobacco industry to downplay the detrimental effects of SHS. Currently, some tobacco control researchers are moving away from using SHS and instead use the term tobacco smoke pollution (TSP). SHS is used in the introduction of this thesis because it is a neutral term, while the term TSP emphasises the negative nature of exposure to tobacco smoke. 


\section{Globalisation of tobacco control}

In the early days, tobacco control consisted mainly of an educational approach that aimed to inform the public of the dangers of smoking. This approach was broadened after a 'new public health' approach was proposed, first in the US Surgeon General's Report on Health Promotion and Disease Prevention (Public Health Service, 1979), and later in the Ottawa Charter for Health Promotion that was adopted at the first International Conference on Health Promotion (World Health Organization, Health and Welfare Canada, \& Canadian Public Health Association, 1986). According to this new approach, health promotion should employ an ecological perspective that no longer focused solely on individual behaviour change, but also on the physical, socio-cultural, economical, and political environment (Lechner, Kremers, Meertens, \& Vries, 2007; Swinburn, Egger, \& Raza, 1999). The Ottawa Charter called for building healthy public policy by putting health on the agenda of policy makers. The World Health Organization (WHO) was urged to support countries in setting up strategies and programmes for health promotion.

In 1986, the same year as the publication of the Ottawa Charter, the 39th World Health Assembly (WHA) adopted a resolution encouraging WHO member states to implement comprehensive tobacco control policies. The resolution also called for a global public health approach and international action to combat the tobacco epidemic. The WHO realised that a global tobacco control strategy was necessary, because the tobacco epidemic was an international problem and the tobacco industry increasingly operated globally (Bettcher \& Subramaniam, 2001). The World Bank understood that the economics of tobacco control were critical to the debate on global tobacco control and published the report 'Curbing the epidemic: Governments and the economics of tobacco control' (Jha \& Chaloupka, 1999). This report concluded that tobacco control does not harm economies. Previously confidential internal documents from the tobacco industry obtained through US litigation revealed that the tobacco industry worked hard to discredit this World Bank report (Mamudu, Hammond, \& Glantz, 2008). However, it did not succeed. The World Bank report was released during the 52nd WHA in 1999. Influenced by this authoritative report, the WHA approved the beginning of negotiations for a global tobacco control strategy.

During the 56th WHA in 2003, the WHO Framework Convention on Tobacco Control (FCTC) was adopted (World Health Organization, 2003). The FCTC includes legally binding international rules on topics such as tobacco marketing, pricing policies, and smoke-free legislation. The FCTC is the first international public health treaty. The 40-country threshold required for the treaty to come into force was met within 18 months. To date the FCTC has been ratified in over 170 countries around 
the world. Through this action these countries have legally committed themselves to implementing national legislation that is consistent with the FCTC. To help countries fulfil the FCTC commitments, the WHO defined a policy package of FCTC policies that have been proven to reduce the prevalence of smoking (World Health Organization, 2008a) and are, therefore, the most important to implement. These policies are known under the acronym MPOWER (Figure 2) and are consistent with the policies that the World Bank designated in 2003 as the most cost effective tobacco control measures (World Bank, 2003). MPOWER urges governments to monitor the impact of tobacco control policies on tobacco use and to implement smoke-free legislation, smoking cessation assistance, educational campaigns, health warning labels, advertising bans, and tobacco tax increases.

Figure 2: The MPOWER acronym (World Health Organization, 2008a).

- Monitor tobacco use and prevention policies

- Protect people from tobacco smoke

- Offer help to quit tobacco use

- Warn about the dangers of tobacco

- Enforce bans on tobacco advertising, promotion and sponsorship

- $\quad$ Raise taxes on tobacco

\section{Evaluating the impact of international policies}

The goal of this thesis is to evaluate the impact of FCTC policies. Evaluating the impact of policies is important in order to evaluate existing policies and to inform and support future policies. However, there are considerable methodological challenges. Tobacco control policies cannot be evaluated with randomised controlled trials, because researchers cannot control policy implementation. One of the difficulties with using before-and-after designs is that policies are often implemented simultaneously and may interact with existing policies and social factors. Although studies with interrupted time series designs can separate intervention effects from secular trends, it is not possible to disentangle the effects of interventions that are implemented simultaneously. Evaluating the impact of one policy on smoking behaviour when other policies that have an impact on smoking are simultaneously implemented can be like "unraveling gossamer with boxing gloves" (Chapman, 1993). An elegant solution to this methodological challenge is to use a quasiexperimental design in which jurisdictions (countries, states, or provinces) that have implemented a tobacco control policy are compared to other jurisdictions that have not. Previous evaluation studies of tobacco control policies have mostly compared US states that did and did not implement a certain policy (Farrelly, Pechacek, \& 
Chaloupka, 2003; Hyland, Li et al., 2006; Wakefield \& Chaloupka, 2000). However, owing to the national level of FCTC policies, these policies can best be evaluated by international studies that compare several countries.

Some existing international studies have the potential to evaluate FCTC policies. For example, the WHO, Centres for Disease Control and Prevention, and the Canadian Public Health Association, initiated the Global Tobacco Surveillance System, which includes the Global Youth Tobacco Survey (GYTS) in more than 150 countries and the Global Adult Tobacco Survey (GATS) in 14 countries (Warren et al., 2009). In Europe, the European Commission regularly conducts Eurobarometer surveys on tobacco, and the Tobacco Control Scale surveys tobacco control activity at the national level (Joossens \& Raw, 2011). Some studies have combined national-level information from the Tobacco Control Scale with smoking behaviour information from European surveys to give an indication of the association between tobacco control policies and smoking on an ecological level (Hublet et al., 2009; Martínez-Sánchez et al., 2010; Schaap et al., 2008). However, because these studies employ macro-level data, they cannot identify the individual pathways of change or how the policies affect smoking. Moreover, these existing studies are limited by their cross-sectional design and can, therefore, make no causal inferences about the impact of policies.

The International Tobacco Control Policy Evaluation Project (ITC Project) was specifically designed to evaluate the impact of FCTC policies as they were being implemented in many countries throughout the world (Fong, Cummings, \& Shopland, 2006). The ITC Project was set up prior to the FCTC coming into force in 2003, when the founding researchers realised that the treaty would provide a unique opportunity to evaluate the impact of tobacco control policies. The ITC Project, the first ever international cohort survey of tobacco use, is currently conducted in 20 countries, and is constantly working to persuade additional countries to participate. It uses a quasi-experimental design by which countries that have implemented a particular tobacco control policy are compared to those that have not. Because all ITC Surveys use a longitudinal cohort design by which individual smokers are interviewed in multiple survey waves before and after the implementation of tobacco control policies, it is also possible to examine the effects of exposure to policies within a single country. This design allows for testing hypotheses on the impact of policy measures on tobacco consumption through micro-level changes in smokers' attitudes, beliefs, and cognitions (Fong et al., 2006). 
For this thesis, data from the ITC Project have been used to evaluate the impact of FCTC policies. Most chapters used data from the ITC Netherlands Survey. The ITC Netherlands Survey was initiated in 2008 to evaluate the impact of Dutch FCTC policies. The following FCTC policies were implemented immediately after the first wave of the ITC Netherlands Survey in 2008: smoke-free hospitality industry legislation with an accompanying implementation campaign, a mass media smoking cessation campaign, and a small tax increase. The impacts of these policies are evaluated in this thesis, but the main focus is on the impact of smoke-free hospitality industry legislation. Smoke-free legislation is one of the key FCTC policies and can have an impact on both non-smokers (reduced second-hand smoking) and smokers (reduced active smoking). The largest population health impact may come from effects on smokers. As hypothesised by the Population Model of Tobacco Control (Willemsen, 2011), the impact of tobacco control policies on smokers can set a flywheel in motion that eventually causes tobacco consumption to reduce further and further (Figure 3). Therefore, this thesis focuses on the impact on smokers.

Figure 3: Population Model of Tobacco Control (Willemsen, 2011).

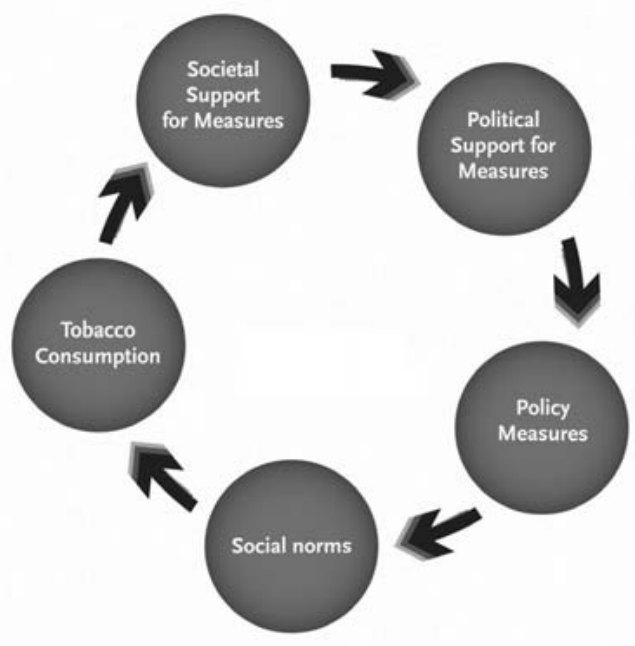

\section{Emergence of smoke-free legislation}

Smoke-free legislation is one of the WHO MPOWER policies and is covered in article 8 of the FCTC. In this article it is stated that "parties recognise that scientific evidence has unequivocally established that exposure to tobacco smoke causes death, disease and disability" (World Health Organization, 2003). Furthermore, article 8 obligates ratifying parties to "adopt and implement in areas of existing 
national jurisdiction (...) effective legislative, executive, administrative and/or other measures, providing for protection from exposure to tobacco smoke in indoor workplaces, public transport, indoor public places and, as appropriate, other public places" (World Health Organization, 2003).

Most countries do not ban smoking immediately in all indoor workplaces, public transport, and indoor public places. The emergence of smoke-free legislation can be divided into four 'waves' (Siegel \& Skeer, 2003). Most countries first implement smoking restrictions in indoor public areas and on public transport (e.g. airplanes, elevators, children's day care facilities, hospitals, and movie theatres). The second wave of smoke-free legislation occurs in workplaces. This often begins with voluntary company policies or local initiatives, and is later followed by national smoke-free workplace legislation. The hospitality industry is often exempted at this stage because its entertainment function means that smoking restrictions enjoy considerably less support in these 'social' settings. Also, the tobacco industry is keen to retain the 'last bastion' of socially acceptable smoking where young adults start or establish their smoking behaviour and therefore fights harder over this particular field (Ling \& Glantz, 2002; Magzamen \& Glantz, 2001). The third wave of smokefree legislation occurs in restaurants. Sometimes restaurants are not required to be smoke-free, but separate seating areas for non-smokers are created. The last wave generally consists of smoking restrictions in bars and casinos. Smoke-free bars send an especially strong message that smoking is no longer socially acceptable (Magzamen \& Glantz, 2001).

Some countries do not implement smoke-free legislation in four 'waves', but implement smoke-free workplace legislation in one legislative action without exceptions for the hospitality industry. For example, Ireland was the first to implement national comprehensive smoke-free legislation in all workplaces, including bars and restaurants, in March 2004. This legislation proved to be an immediate success (Howell, 2004) and the Irish people even chose their smoke-free legislation as Ireland's most positive event of 2004 (Howell \& Allwright, 2005).

The Netherlands is an interesting case study for smoke-free legislation because the emergence of smoke-free hospitality industry legislation was more controversial and problematic than in many other countries. The Netherlands ratified the FCTC in 2005. Prior to this, smoking had already been banned in government buildings and public places (since 1990) and in workplaces (since 2004) with the exception of the hospitality industry. A self-regulation plan was arranged with the hospitality industry that should have resulted in completely smoke-free restaurants and hotels and mostly smoke-free bars and discos. When these results were not achieved, the government decided to implement smoke-free hospitality industry 
legislation in July 2008. From May to September 2008 the Dutch Ministry of Health ran a media campaign in which the date of implementation of the smokefree legislation was communicated but no reference was made to the health consequences of second-hand smoke. The television commercial for this campaign showed a man dressed as a large cigarette being thrown out of hospitality industry venues on to the street. The Dutch expert centre on tobacco control (STIVORO) also ran a media campaign about smoking cessation, but the smoke-free legislation and second-hand smoke were not mentioned.

An organisation 'Red de Kleine Horeca Ondernemer' ('Save the small hospitality industry entrepreneur') was formed by owners of small bars to argue against the legislation. Ties between this organisation and the tobacco industry were confirmed by investigative journalism (Baltesen \& Rosenberg, 2009). The organisation financed court appeals, staged demonstrations, and lobbied for an exemption to the legislation for small bars. The group of bar owners that supported these actions received a disproportionately high level of media attention, which fuelled resistance to the legislation and increased the number of non-complying bars. The legal actions of these bar owners resulted in a temporary suspension of the smoke-free legislation for bars without employees in July 2009. In March 2010, the Dutch Supreme Court ruled that the legislation was not discriminatory to bars without employees, and from that date onwards the legislation was again applied to all bars. However, since July 2011, a new Dutch government has suspended the legislation for bars without employees smaller than 70 square metres and has not fined these venues for allowing smoking since November 2010.

\section{Structure of this thesis}

This introductory chapter is followed by a chapter describing the methods of the ITC Netherlands Survey (chapter 2). The remainder of the thesis is grouped into three parts: 1) population impact of smoke-free legislation on smoking, 2) individual pathways of change after smoke-free legislation, and 3) unintended consequences of smoke-free legislation. These three parts are introduced briefly here.

\section{Population impact of smoke-free legislation on smoking}

Researchers from the tobacco industry were the first to find evidence that smokefree legislation may cause smokers to reduce their cigarette consumption or quit smoking (Cilcote, 1985; Heironimus, 1992). More studies have since been conducted by health promotion scientists on whether banning smoking has an impact on smoking cessation. Reviews of studies on voluntary workplace smoking restrictions found that smoking restrictions were associated with reductions in 
cigarette consumption (Brownson, Eriksen, Davis, \& Warner, 1997; Chapman et al., 1999; Eriksen \& Gottlieb, 1998; Fichtenberg \& Glantz, 2002; Hopkins et al., 2001; Moher, Hey, \& Lancaster, 2005). Evidence of an impact on smoking prevalence and smoking cessation was less consistent. One review examined studies of local and state-level smoke-free legislation in the United States and concluded that smokefree legislation was associated with lower cigarette consumption, lower prevalence rates, and higher cessation rates (Levy \& Friend, 2003). However, the studies that were included in these reviews generally had weak designs (Eriksen \& Gottlieb, 1998; Moher et al., 2005). Control populations were lacking and secular trends were not taken into account (Chapman et al., 1999; Eriksen \& Gottlieb, 1998; Moher et al., 2005). Moreover, the studies did not control for other policies already in place or implemented at the same time (Levy \& Friend, 2003), while voluntary workplace smoking restrictions were almost always accompanied by cessation assistance (Eriksen \& Gottlieb, 1998; Moher et al., 2005).

In 2008, there were still several gaps in the literature on the impact of smoke-free legislation on smoking, including: the impact of national smoke-free legislation on smoking (Hopkins et al., 2001), the impact of smoking restrictions in settings other than the workplace (Chapman et al., 1999), and the differential impact of comprehensive and partial smoking restrictions (Fichtenberg \& Glantz, 2002; Hopkins et al., 2001; Levy \& Friend, 2003). Also, evidence on how the impact of smoking restrictions compared with the impact of other tobacco control policies was lacking (Levy \& Friend, 2003). The studies in the first part of this thesis were conducted to fill these gaps in the literature. We examined the impact of national smoke-free workplace legislation and smoke-free hospitality industry legislation (chapter 3), the impact of comprehensive and partial smoke-free legislation (chapter 4), and the impact of smoke-free legislation compared with the impact of other tobacco control policies (chapter 5). Outcomes studied are: smoking prevalence (chapters 3 and 5), smoking cessation (chapters 3 and 4), and smoking-attributable deaths (chapter 5).

\section{Individual pathways of change after smoke-free legislation}

It is not only important to know whether policies have an impact on tobacco consumption, but also to understand how this process occurs. The ITC Conceptual Model (Fong et al., 2006) describes the individual pathways of change from tobacco control policies to tobacco consumption. According to this model, tobacco control policies influence individuals by first influencing factors that are most proximal to the policy itself, such as increased support for smoke-free legislation (Figure 4). These policy-specific variables in turn influence psychosocial mediators. 
Psychosocial mediators in the ITC Conceptual Model have been taken from various social cognitive models, for example the Theory of Planned Behaviour (Ajzen, 1991), Social Cognitive Theory (Bandura, 1986), and the Health Belief Model (Janz \& Becker, 1984). Concepts from these social cognitive models that have been shown to have a considerable influence on smoking and cessation in previous empirical studies are included in the ITC Surveys. Finally, changes in psychosocial mediators are expected to influence policy-relevant outcomes, which can either be intended (such as smoking cessation) or unintended (such as feelings of stigmatisation).

No studies have been published on a test of the full causal chain, from individual exposure to smoke-free legislation, through policy-specific variables and psychosocial mediators on policy-relevant outcomes. These studies are needed in order to assess exactly how policy measures impact on the individual smoker's behaviour. This is examined in the studies in the second part of this thesis. First, relevant policy-specific variables are determined (chapters 6 and 7). Then, the role of psychosocial mediators is established (chapters 8 and 9). Finally, the entire causal chain, from individual exposure to smoke-free legislation through policy-specific variables and psychosocial mediators on smoking cessation, is tested (chapter 10).

Figure 4: ITC Conceptual Model (Fong et al., 2006).

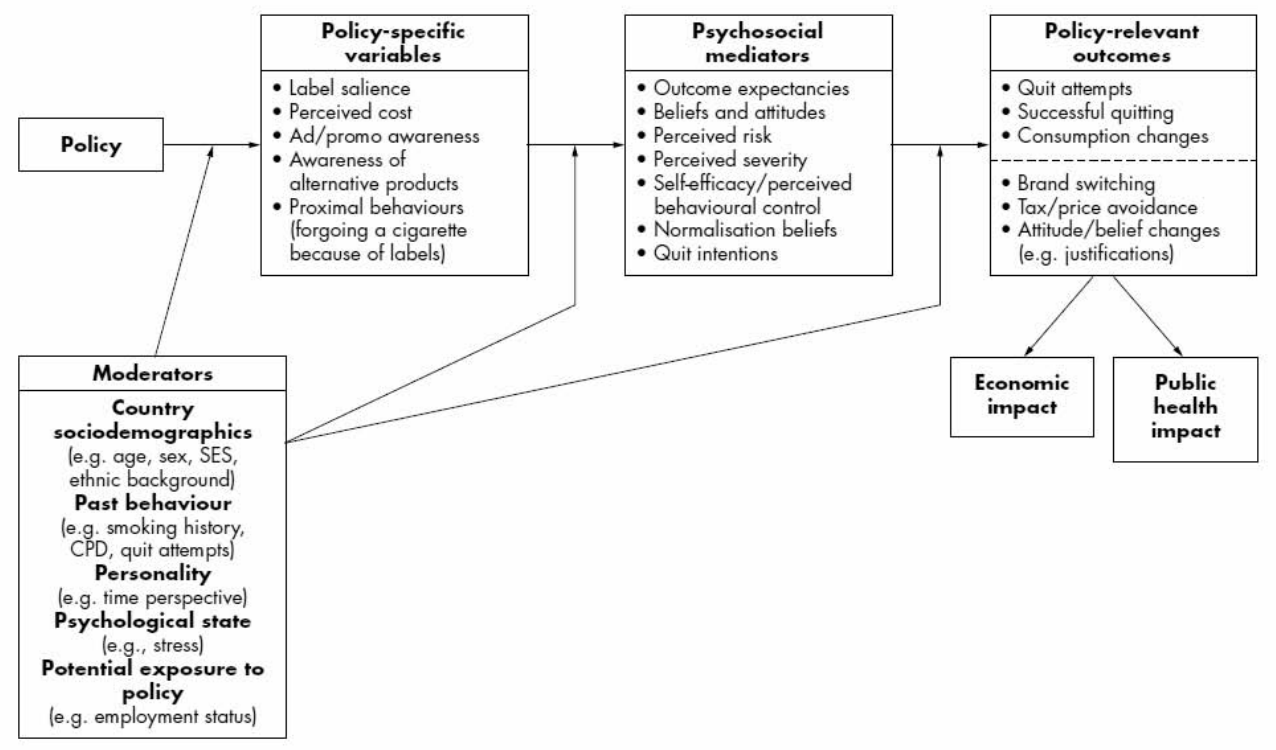

\section{Unintended consequences of smoke-free legislation}

Smoke-free legislation reduces exposure to second-hand smoke and may reduce smoking behaviour. However, smoke-free legislation can also have unintended 
consequences. These are explicitly modeled in the ITC Conceptual Model to provide a more complete picture of the effects of policies. This information can be used for the development of future tobacco control strategies.

An important concern is that smoke-free legislation might lead to a displacement of smoking into private venues (Borland, Yong, Cummings et al., 2006). If this is the case, smoke-free legislation may increase second-hand smoke exposure among children. An alternative hypothesis is that smoke-free legislation inspires smokers to implement voluntary smoking restrictions in private venues (Borland, Yong, Cummings et al., 2006). A study in the third part of this thesis examines changes in voluntary home smoking bans in four countries that implemented smoke-free legislation, and compares this to a country that did not (chapter 11).

Another possible unintended consequence of smoke-free legislation is the increased stigmatisation of smokers. Stigmatisation exists "when elements of labelling, stereotyping, separating, status loss, and discrimination co-occur in a power situation that allows these processes to unfold" (Link \& Phelan, 2001). It is thought that smoke-free legislation may increase feelings of stigmatisation (Gottlieb, Lovato, Weinstein, Green, \& Eriksen, 1992) because it separates smokers from non-smokers by 'forcing' them to smoke outside. Data from before and after the implementation of smoke-free hospitality industry legislation in the Netherlands are used in this thesis to study changes in perceived stigmatisation (chapter 12).

Finally, tobacco control policies sometimes have a greater effect on smokers with higher socioeconomic status (SES) and may therefore increase socioeconomic inequalities (Kunst, Giskes, \& Mackenbach, 2004). Differential effects of smoking restrictions on the smoking behaviour of people from lower and higher SES groups have not been extensively studied (Levy \& Friend, 2003). The few studies that have examined differential effects according to SES reported mixed results (Farrelly, Evans, \& Sfekas, 1999; Moskowitz, Lin, \& Hudes, 2000). Therefore, studies that examine the impact of smoke-free legislation on smoking behaviour should preferably also examine differences in the effects between smokers with lower and higher SES. Most studies in this thesis examine differences in effects of smoke-free legislation between smokers with lower and higher education. One of the studies in the third part of this thesis describes trends in SES differences in smoking prevalence, smoking consumption, smoking initiation, and smoking cessation in the Netherlands (chapter 13). The last study in this thesis focuses specifically on Dutch smoke-free hospitality industry legislation, a tobacco tax increase, and a cessation campaign and the differences in the effects of these three tobacco control interventions on smokers with varying ages and educational levels (chapter 14). 


\section{Research questions in this thesis}

Most chapters in this thesis used data from the ITC Netherlands Survey. Chapter 2 describes a study about the methods of the ITC Netherlands Survey. This chapter is followed by twelve studies on the impact of smoke-free legislation on smoking, grouped in three parts.

\section{Part 1 - Population impact of smoke-free legislation on smoking}

Part 1 focuses on the population impact of smoke-free legislation on smoking. The following research questions are addressed:

1. What is the impact of smoke-free workplace legislation and smoke-free hospitality industry legislation on smoking prevalence and smoking cessation?

2. What is the impact of comprehensive and partial smoke-free legislation on smoking cessation?

3. What is the impact of smoke-free legislation and other effective tobacco control policies on smoking prevalence and smoking-attributable deaths?

Chapter 3 describes the impact on trends in smoking prevalence and smoking cessation in the Netherlands of implementing smoke-free workplace legislation and later extending this legislation to the hospitality industry (research question (RQ) 1). Chapter 4 uses a quasi-experimental analytical approach to examine the impact of both comprehensive and partial smoke-free legislation in Europe on smoking cessation (RQ 2). Chapter 5 presents the results of a simulation model on the impact of smoke-free legislation and other effective tobacco control policies that are part of the MPOWER package, on smoking prevalence and smoking-attributable deaths in the Netherlands (RQ 3).

Part 2 - Individual pathways of change after smoke-free legislation

Part 2 focuses on individual pathways of change after smoke-free legislation. The following research questions are addressed:

4. What is the impact of implementing smoke-free legislation on support for smoke-free legislation among smokers?

5. What is the impact of newspaper coverage on smoke-free legislation and of an implementation campaign on policy-specific variables?

6. Is exposure to smoke-free legislation associated with reduced social acceptability of smoking and is this a predictor of smoking cessation?

7. What are policy-specific and psychosocial predictors of smoking in bars after the implementation of smoke-free legislation?

8. Which policy-specific variables and psychosocial mediators form the causal chain between individual exposure to smoke-free legislation and smoking cessation? 
Chapter 6 uses a quasi-experimental design to examine the impact of implementing smoke-free legislation on support for smoke-free legislation among smokers in Europe (RQ 4). Chapter 7 presents the results of a content analysis of newspaper coverage on smoke-free legislation in the Netherlands and examines the impact of this newspaper coverage and the Dutch implementation campaign on policyspecific variables (RQ 5). Chapter 8 describes the association of exposure to smokefree legislation, warning labels, and anti-tobacco information with reduced social acceptability of smoking, and describes the impact of this on smoking cessation in Europe (RQ 6). Chapter 9 presents the results of an analysis of the policy-specific and psychosocial predictors of smoking in bars after the implementation of smokefree legislation in Europe (RQ 7). Chapter 10 examines the entire causal chain, from individual exposure to smoke-free legislation, through policy-specific variables and psychosocial mediators on smoking cessation in the Netherlands (RQ 8).

\section{Part 3 - Unintended consequences of smoke-free legislation}

Part 3 examines possible unintended consequences of smoke-free legislation. The following research questions are addressed:

9. What is the impact of smoke-free legislation on voluntary home smoking bans?

10. What is the impact of smoke-free legislation and smoking outside on the stigmatisation of smokers?

11. Are there trends in socioeconomic inequalities in smoking prevalence, smoking consumption, smoking initiation, and smoking cessation?

12. Are there age or educational inequalities in exposure to, and effects of, smokefree legislation, a tobacco tax increase, and a campaign on smoking cessation? Chapter 11 uses a quasi-experimental design to examine the impact of smoke-free legislation on voluntary home smoking bans in Europe (RQ 9). Chapter 12 focuses on the impact of smoke-free legislation and smoking outside on the stigmatisation of smokers (RQ 10). Chapter 13 describes trends in socioeconomic inequalities in smoking prevalence, smoking consumption, smoking initiation, and smoking cessation in the Netherlands (RQ 11). Chapter 14 focuses on age and educational inequalities in exposure to, and effects of, smoke-free legislation, a tobacco tax increase, and a cessation campaign on smoking cessation in the Netherlands (RQ 12).

Chapter 15 discusses the results of the studies in this thesis. Important findings from the studies are discussed in relation to other studies that have been conducted since the start of this PhD study. Methodological limitations of the studies in this thesis are discussed, as well as priorities for future research and recommendations for tobacco control policy. 


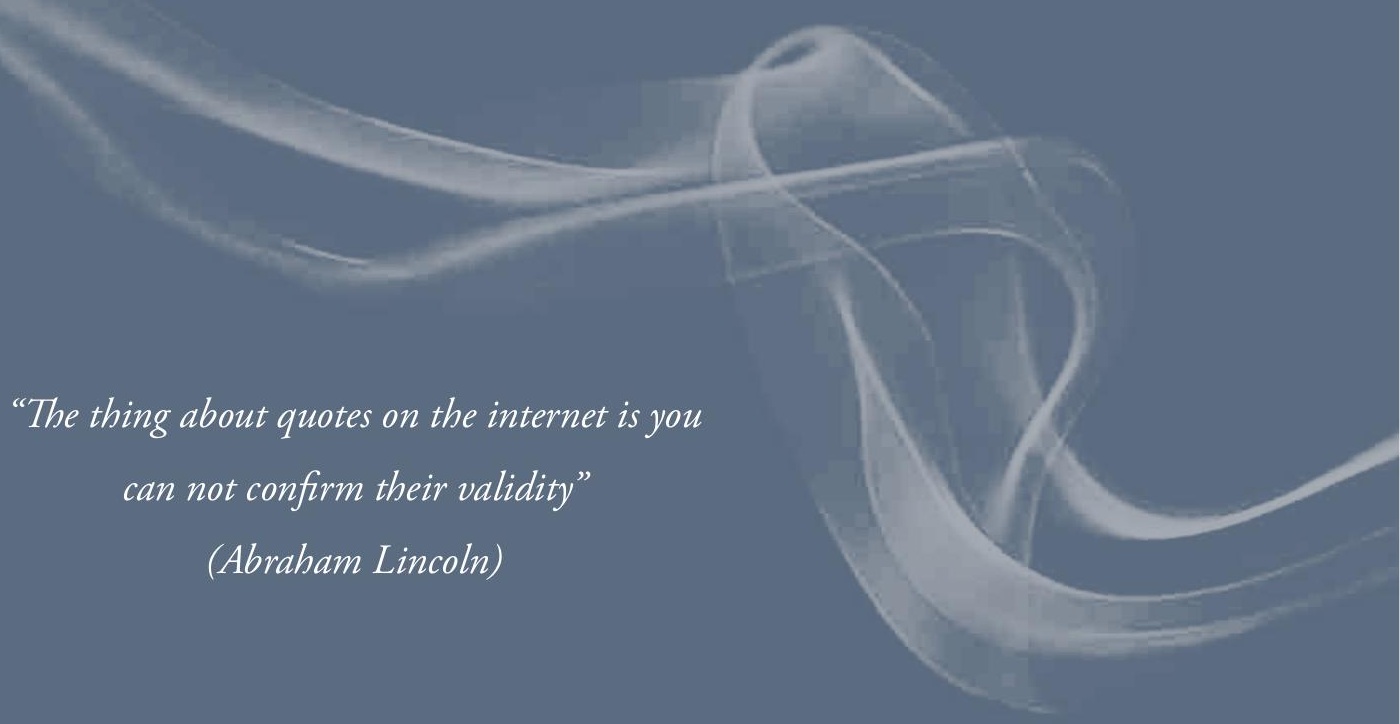
can not confirm their validity"

(Abraham Lincoln) 


\section{Chapter 2}

\section{$\sim \sim \sim$ \\ Methods of the \\ ITC Netherlands Survey}

Parts of this chapter have been published as:

Nagelhout, G. E., Willemsen, M. C., Thompson, M. E., Fong, G. T., Van den Putte, B., \& De Vries, H. (2010). Is web interviewing a good alternative to telephone interviewing? Findings from the International Tobacco Control (ITC) Netherlands Survey. BMC Public Health, 10, 351. 
Web interviewing is becoming increasingly popular worldwide, because it has several advantages over telephone interviewing such as lower costs and shorter fieldwork periods. However, there are also concerns about data quality of web surveys. The aim of this study was to compare the International Tobacco Control (ITC) Netherlands web and telephone samples on demographic and smoking-related variables to assess differences in data quality. Wave 1 of the ITC Netherlands Survey was completed by 1,668 web respondents and 404 telephone respondents of 18 years and older. The two surveys were conducted in parallel among adults who reported smoking at least monthly and had smoked at least 100 cigarettes over their lifetime. Both the web and telephone survey had a cooperation rate of $78 \%$. Web respondents with a fixed line telephone were significantly more often married, had a lower educational level, and were older than web respondents without a fixed line telephone. Telephone respondents with internet access were significantly more often married, had a higher educational level, and were younger than telephone respondents without internet. Web respondents were significantly less often married and lower educated than the Dutch population of smokers. Telephone respondents were significantly less often married and higher educated than the Dutch population of smokers. Web respondents used the 'don't know' options more often than telephone respondents. Telephone respondents were somewhat more negative about smoking, had less intention to quit smoking, and had more self efficacy for quitting. The known association between educational level and self efficacy was present only in the web survey. Differences between the web and telephone sample were present, but the differences were small and not consistently favourable for either web or telephone interviewing. Our study findings suggested sometimes a better data quality in the web than in the telephone survey. Therefore, web interviewing can be a good alternative to telephone interviewing. 


\section{INTRODUCTION}

Most chapters in this thesis used data from the International Tobacco Control (ITC) Netherlands Survey. The ITC Project studies the effects of tobacco control policies on the attitudes and behaviours of smokers in 20 countries. The ITC Netherlands Survey is funded by the Netherlands Organisation for Health Research and Development (ZonMw). In chapters 4, 6, 8, 9, and 11, data from the ITC Netherlands Survey are compared with data from other ITC Europe countries.

Chapters 3 and 13 used data from the Dutch Continuous Survey of Smoking Habits (DCSSH) which aims to monitor smoking habits of the Dutch population. The DCSSH is a unique national population survey, because large samples of respondents are surveyed every week on their smoking behaviour, use of smoking cessation aids, attitudes towards smoking, quitting, and tobacco control policies, and exposure to media campaigns. The DCSSH can be used to examine trends in smoking behaviour on the population level, because the survey is conducted with the same methodology (web interviewing) since 2001. The DCSSH is funded by the Dutch Ministry of Health, Welfare, and Sport.

Chapter 5 used data from the SimSmoke Tobacco Control Policy Simulation Model which aims to develop nation-specific simulation models projecting the effects of tobacco control policies on smoking prevalence and smoking-attributable deaths. The SimSmoke Model is the only simulation model that simultaneously considers the full set of MPOWER policies. The development of the Netherlands SimSmoke Model was part of the PPACTE Project 'Pricing Policies and Control of Tobacco in Europe' and is funded partly by the European Commission.

This chapter reports on a study which aimed to compare the ITC Netherlands web and telephone samples on demographic and smoking-related variables to assess differences in data quality.

\section{METHODS}

\section{Mixed mode design}

Findings of the ITC Project are used to generalise to the population of smokers in different countries. Therefore, using a mode of interviewing that yields representative results is a very important part of the project. The standard ITC survey mode in high-income countries is telephone, by means of random digit dialling. The ITC Netherlands Survey differs from other ITC surveys in that a mixed mode design was used. Some respondents were surveyed using telephone interviewing, but the majority of respondents were surveyed by web interviewing using samples drawn from a large population-based internet panel.

An important objective of tobacco control research in general is studying 
differences between smokers of different socioeconomic status groups. Smokers of lower socioeconomic status groups are less likely to quit smoking (Chandola, Head, \& Bartley, 2004; Lennox, 1992), as is evidenced by lower scores on determinants of smoking cessation (Siahpush, McNeill, Borland, \& Fong, 2006). We will therefore test whether the differences between smokers of different socioeconomic status groups in determinants of smoking cessation are present in both the web and telephone survey.

The web respondents were drawn from TNS NIPObase, a large probabilitybased database with over 140,000 potential Dutch web respondents who have indicated their willingness to participate in research on a regular basis. TNS NIPObase panel members are actively recruited by TNS NIPO. People cannot apply for participation, which results in a low number of professional and inattentive respondents (Willems, Brown, Van Ossenbruggen, \& Vonk, 2006). Web panel members are recruited by phone or mail, but not by internet. A screening procedure selected respondents that met the inclusion criteria for the ITC Netherlands Survey: being a monthly smoker of manufactured or roll-your-own cigarettes and having smoked at least 100 cigarettes in their lifetime. Quotas on gender, geographic region, household size, and education were determined from the 2007 Dutch Continuous Survey of Smoking Habits (DCSSH) to get a sample that was representative of Dutch smokers aged 15 years or older. The DCSSH is a national surveillance survey on smoking with weekly measurements of over 4,000 smoking respondents in 2007 and uses web respondents from TNS NIPObase. An announcement e-mail about the first ITC Netherlands web survey was sent to 2,331 smoking respondents from TNS NIPObase. The announcement e-mail contained information about the subject of the survey, the time needed to fill it in, and the reimbursement that respondents could receive. It also contained a link to the website with conditions from TNS NIPObase. TNS NIPObase panel members had to read and agree to these conditions before becoming a panel member. The regulations state that members' personal information would be protected and that their participation in the surveys was voluntary. The web survey was completed from April 16 to April 25, 2008 by 1,820 respondents of 15 years and older. We analysed the data from 1,668 respondents who were 18 years and older. The respondents received compensation for their participation in the survey by earning points for every answered question, as is standard procedure in the TNS NIPObase web panel. The points could be exchanged into money, which ranged between 5 and 7 Euro for this survey.

The starting point of sampling the telephone respondents was the TNS NIPObase, which contains over 80,000 respondents with fixed line telephone numbers. This database is nationally representative on postal codes and matching 
telephone numbers. A sample was drawn by randomly taking telephone numbers from the database. The last two digits of each randomly drawn number were automatically replaced by two random digits. In total 28,563 numbers were called by the interviewers for the first ITC Netherlands telephone survey. When an interviewer reached an individual on the telephone, the interviewer asked how many people in the household fit the inclusion criteria: those reporting smoking at least monthly and who had smoked at least 100 cigarettes in their lifetime. In households where more than one person fit the criteria, the interviewer asked to speak with the person whose birthday was coming up next. The fieldwork took place from March 12 to April 26, 2008 and resulted in 404 completed interviews. The average telephone interview took 40 minutes. Each telephone respondent received a reimbursement of 10 euro by mail after completing the survey.

\section{Measurements}

The ITC Netherlands web and telephone surveys consisted of 264 questions on demographics, smoking behaviour, and related issues, with extensive sections on tobacco control policies such as health warnings, smoke-free laws, advertising, and prices paid for cigarettes. Fong et al. (2006) provides a description of objectives of the ITC Project Surveys, and Thompson et al. (2006) provides a description of the methods used.

Basic demographic variables that have a known association with smoking cessation (Chandola et al., 2004; Lennox, 1992) were measured: gender, age, marital status, and educational level. Educational level was measured as a proxy of socioeconomic status and was categorised into three groups: low (primary education and lower pre-vocational secondary education), medium (middle pre-vocational secondary education and secondary vocational education), and high (senior general secondary education, (pre-)university education and higher professional education). Respondents who did not want to answer the question about their educational level were recorded separately.

Commonly used measures in smoking cessation research (Hyland, Borland et al., 2006), which were also used in an earlier mode comparison study on smoking (Etter \& Perneger, 2001) were used in this study: (1) number of cigarettes smoked per day, (2) number of previous quit attempts, (3) time (in minutes) before smoking the first cigarette after waking, (4) attitude towards smoking (assessed by asking "What is your overall opinion of smoking?" very positive - positive - neither positive nor negative - negative - very negative - refused - don't know), (5) intention to quit smoking (assessed by asking "Are you planning to quit smoking..." within the next month - within the next 6 months - sometime in the future, beyond 6 months - never 
- refused - don't know; respondents who answered 'don't know' were asked what they would answer if they were forced to choose an answer), and (6) self efficacy for quitting (assessed by asking "If you decided to give up smoking completely in the next 6 months, how sure are you that you would succeed?" not at all sure - slightly sure - moderately sure - very sure - extremely sure - refused - don't know). These questions were the same in wording across modes. Answering categories were read aloud by the telephone interviewers with the exception of the 'refused' and 'don't know' categories. Answering categories were visible on the screen of the web survey with the exception of the 'refused' category. The 'don't know' category was preceded by an extra space and was displayed in a grey font to make it less visible.

\section{Analyses}

Because young smokers were deliberately over sampled in the web survey to address the research question of another study, all analyses were conducted with the data weighted for age. To evaluate coverage in the web sample, telephone respondents who had internet access were compared to telephone respondents without internet access. To evaluate coverage in the telephone sample, web respondents that had a fixed telephone line were compared to web respondents without a fixed line. Since coverage error was expected to affect which part of the population was contacted, respondents were compared with respect to demographic variables. This was done using chi-square tests (gender, marital status, and educational level) and t-tests (age).

To assess differences in the combination of coverage and non-response error, respondents from both samples were compared to the demographic characteristics of smoking respondents of Statistics Netherlands (CBS) from 20062007. The CBS statistics are the official national statistics for the Netherlands, and use the national registry as a sampling frame. The CBS uses computer assisted personal interviewing on a sample of 10,000 persons. Survey interviewing occurs evenly throughout the year. Since non-response error also was expected to affect which part of the initial sample responds to the survey, respondents were compared with respect to demographic variables. The web, telephone, and CBS samples were compared on demographic variables using chi-square tests (gender, marital status, and educational level).

To assess differences which might be attributed in large part to differences in measurement error, web and telephone respondents were compared with each other. Measurement error was expected to arise from reactions to the measurement instrument. The web and telephone samples were therefore compared on smoking 
related questions using chi-square tests and Mann-Whitney U-tests (attitude towards smoking, intention to quit smoking, and self efficacy for quitting) and t-tests and Levene's F-tests (number of cigarettes smoked per day, number of previous quit attempts, and time before smoking the first cigarette after waking). These analyses were employed without respondents who had no fixed telephone or who did not have access to the internet to control for coverage error differences. Furthermore, linear regression analyses were employed that tested the effects of interviewing modes on answers to smoking related questions, controlling for gender, marital status, educational level, and age. Also, interactions between interviewing mode and educational level were tested.

\section{RESULTS}

\section{Response}

Both the web and telephone survey had a cooperation rate of $78.1 \%$, which means that $78.1 \%$ of the eligible respondents who were contacted and capable of doing the interview completed the interview (see Table 1). The response rate for the telephone survey was $4.2 \%$. This means that $4.2 \%$ of all eligible telephone respondents, including non-contacts whose eligibility was estimated, completed the interview. A response rate could not be calculated for the web survey, since the initial sample consisted of only eligible respondents who were all e-mailed. Therefore, there were no non-contacts in the web survey.

\section{Coverage}

As can be seen in Table 2, 1,438 out of 1,668 (86.2\%) web respondents had a fixed line telephone. Web respondents with a fixed line telephone did not differ on gender from web respondents without a fixed line telephone $(p=0.697)$. Web respondents with a fixed line telephone were significantly more often married $(p<0.001)$, had a lower educational level $(p=0.032)$, and were older $(p<0.001)$ than web respondents without a fixed line telephone.

Of the telephone respondents, 359 out of $404(88.9 \%)$ had internet access at home. Telephone respondents with internet access did not differ on gender from telephone respondents without internet access $(p=0.389)$. Telephone respondents with internet access were significantly more often married $(p<0.001)$, had a higher educational level $(p<0.001)$, and were younger $(p<0.001)$ than telephone respondents without internet. 
Table 1: Response information of the web and telephone survey with cooperation and response rates.

\begin{tabular}{lll}
\hline & Web survey & Telephone survey \\
\hline Eligible* & 2,331 & 592 \\
Interviews & 1,820 & 404 \\
Refusals & 511 & 113 \\
Non-contact & - & 52 \\
$\bullet$ adult smoker in household & - & 3 \\
- estimated to be eligible (97,1\%) & - & 49 \\
$\bullet$ unknown if adult smoker in household & - & 11 \\
- estimated to be eligible (22,4\%) & - & 23 \\
Other & - & 11,504 \\
Ineligible* & - & 16,467 \\
Eligibility unknown*** & - & 5,220 \\
Unknown if housing unit & - & 1,169 \\
- estimated to be eligible (22,4\%) & - & 11,247 \\
Housing unit & - & 7,327 \\
$\bullet$ adult smoker in household & - & 7,115 \\
- estimated to be eligible (97,1\%) & - & 3,920 \\
$\bullet$ unknown if adult smoker in household & - & 878 \\
- estimated to be eligible (22,4\%) & 2,331 & 28,563 \\
Total attempted to contact & & $78.1 \%$ \\
Cooperation rate† & - & $4.2 \%$ \\
Response rateł & - & \\
\hline
\end{tabular}

* Eligible cases included cases where an interview was completed, refusal occurred, non-contact at a residential household or where respondents were unable to complete the interview due to language difficulties or disability.

** Ineligible cases included non-residential numbers (such as business or fax lines) and telephone numbers which were invalid. Ineligible cases also included households with no adult monthly smokers of manufactured or roll-your-own cigarettes who have smoked at least 100 cigarettes in their lifetime.

*** Cases where eligibility was unknown were recorded separately.

t Cooperation rate was calculated according to the AAPOR definition COOP4 (The American

Association for Public Opinion Research, 2009). This was the number of interviews (404 for telephone) divided by the number of eligible respondents who were contacted and capable of doing the interview (404 + 113 for telephone).

$\ddagger$ Response rate was calculated according to the AAPOR definition RR4 (The American Association for Public Opinion Research, 2009). This was the number of interviews (404 for telephone) divided by the number of respondents who were eligible or estimated to be eligible $(404+113+3+11+23+$ $1,169+7,115+878$ for telephone). Estimates of eligibility were made using the eligibility rate of the respondents from whom the eligibility was known. The eligibility rate of households with adults smokers was $97,1 \%$ and the eligibility rate of households of which it was unknown if there was an adult smoker was $22,4 \%$. Response rate was not calculated for the web survey, since all respondents from the initial sample were contacted and eligible. 

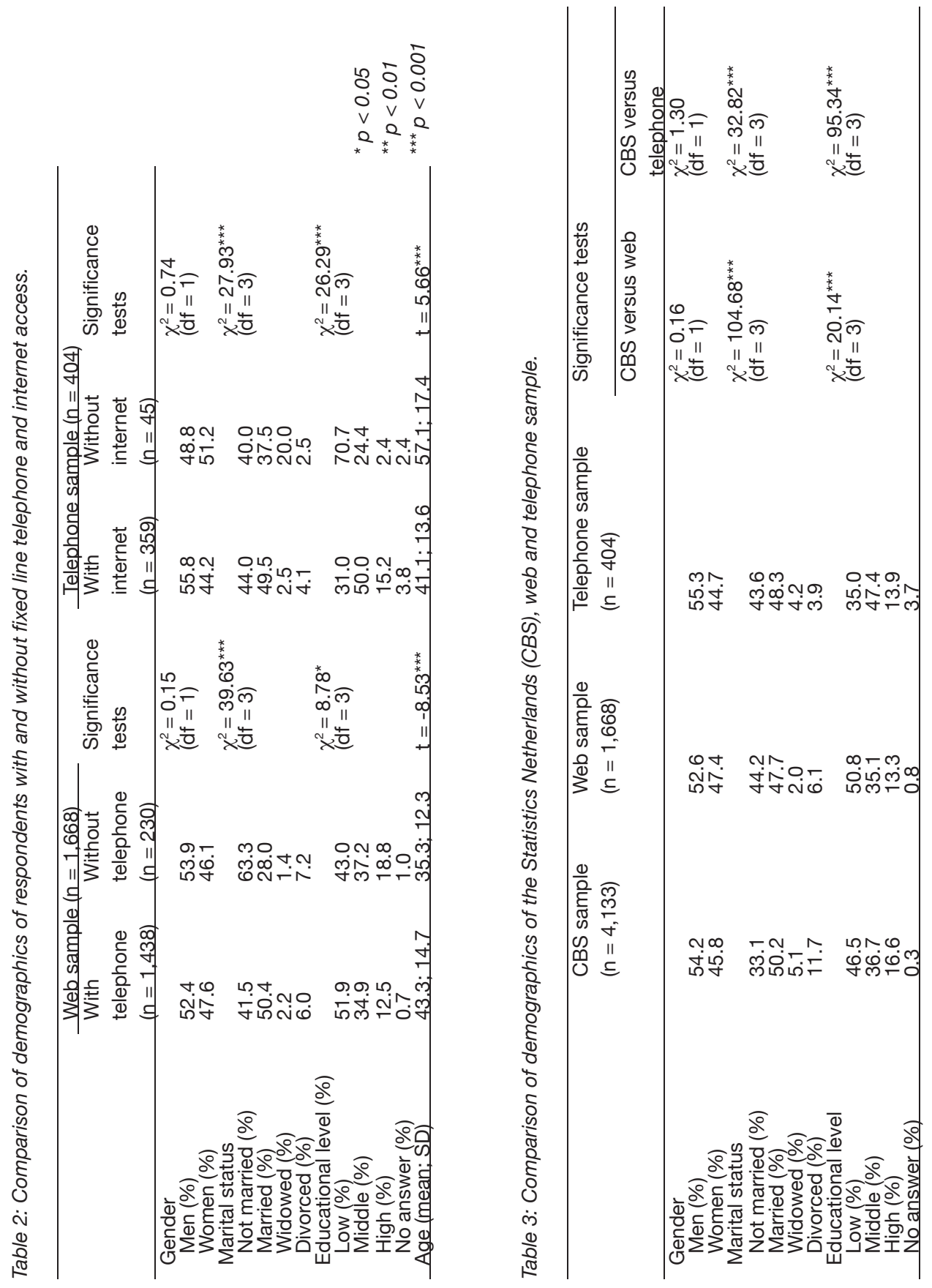


\section{Representativeness}

In Table 3, the demographics of the web and telephone respondents were compared to the demographics of the respondents of Statistics Netherlands (CBS). The CBS, web, and telephone respondents did not significantly differ on gender (CBS with web: $p=0.255$, CBS with telephone: $p=0.689$ ). The web respondents were significantly less often married $(p<0.001)$ and lower educated $(p<0.001)$ than the $\mathrm{CBS}$ respondents. The telephone respondents were significantly less often married $(p<0.001)$ and higher educated $(p<0.001)$ than the CBS respondents.

\section{Smoking-related variables}

Table 4 presents the comparisons of the web and telephone sample on smokingrelated variables. Web and telephone respondents did not differ on mean number of cigarettes smoked per day $(p=0.591)$, mean number of previous quit attempts $(p=$ 0.206 ), and mean number of minutes before smoking the first cigarette after waking $(p=0.492)$. However, there were significant differences between web and telephone respondents in the variances of the number of previous quit attempts $(F=6.11, p$ $=0.014)$ and number of minutes before smoking the first cigarette after waking $(F$ $=4.12, p=0.043)$, but not in the variance of number of cigarettes smoked per day $(F=0.65, p=0.420)$. In the regression analyses we found that, controlling for gender, marital status, educational level, and age, telephone and web respondents did not differ on number of cigarettes smoked per day (Beta $=0.00, p=0.943$ ), number of previous quit attempts (Beta $=0.04, p=0.135$ ), and time before smoking the first cigarette after waking (Beta $=-0.03, p=0.190$ ).

As can be seen in Table 4, web respondents used the 'don't know' options more often than telephone respondents on the categorical variables. Telephone respondents were more negative about smoking $(p<0.001)$, and had less intention to quit smoking $(p<0.001)$, and more self efficacy for quitting, than web respondents $(p<0.001)$. When the 'refused' and 'don't know' answers were recoded to missing values, the central tendency of attitude towards smoking $(U=245,110 ; p<0.001)$, intention to quit smoking $(U=255,932 ; p=0.029)$, and self efficacy for quitting $(U=248,179 ; p=0.004)$ differed significantly between interviewing modes. In the regression analyses we found that, controlling for gender, marital status, educational level, and age, telephone respondents had significantly more negative attitudes towards smoking (Beta $=-0.09, p<0.001$ ), less intention to quit smoking (Beta = $-0.07, p=0.002$ ), and more self efficacy for quitting (Beta $=0.06, p=0.008$ ) than web respondents. 
Table 4: Comparison of smoking-related variables in the web and telephone sample.

\begin{tabular}{|c|c|c|c|}
\hline & $\begin{array}{l}\text { Web sample } \\
(n=1,668)\end{array}$ & $\begin{array}{l}\text { Telephone } \\
\text { sample } \\
(\mathrm{n}=404)\end{array}$ & $\begin{array}{l}\text { Significance } \\
\text { tests }\end{array}$ \\
\hline $\begin{array}{l}\text { Number of cigarettes smoked per day } \\
\text { (mean; SD) }\end{array}$ & $15.3 ; 8.1$ & $15.0 ; 8.5$ & $t=-0.54$ \\
\hline Number of previous quit attempts (mean; SD) & $2.0 ; 2.2$ & $2.2 ; 2.5$ & $t=1.27$ \\
\hline $\begin{array}{l}\text { Time (in minutes) before smoking the first cigarette } \\
\text { (mean; SD) }\end{array}$ & $93.1 ; 189.2$ & $86.5 ; 154.9$ & $t=-0.69$ \\
\hline Attitude towards smoking & & & $\chi^{2}=32.12^{\star \star \star}$ \\
\hline Very positive (\%) & 1.5 & 0.8 & $(d f=6)$ \\
\hline Positive (\%) & 12.7 & 9.2 & \\
\hline Neither positive nor negative (\%) & 64.3 & 60.0 & \\
\hline Negative (\%) & 17.6 & 23.3 & \\
\hline Very negative (\%) & 2.4 & 6.7 & \\
\hline Refused (\%) & 0.0 & 0.0 & \\
\hline Don’t know (\%) & 1.6 & 0.0 & \\
\hline Intention to quit smoking & & & $\chi^{2}=51.25^{\star \star \star}$ \\
\hline Within the next month (\%) & 5.6 & 7.8 & $(\mathrm{df}=5)$ \\
\hline Within the next 6 months (\%) & 19.3 & 20.0 & \\
\hline Sometime in the future, beyond 6 months (\%) & 56.6 & 44.7 & \\
\hline Never (\%) & 14.3 & 26.7 & \\
\hline Refused (\%) & 0.0 & 0.3 & \\
\hline Don't know (\%) & 4.2 & 0.6 & \\
\hline Self efficacy for quitting & & & $\chi^{2}=29.38^{\star \star \star}$ \\
\hline Not at all sure (\%) & 35.4 & 30.6 & $(d f=6)$ \\
\hline Slightly sure (\%) & 35.0 & 29.5 & \\
\hline Moderately sure (\%) & 16.5 & 22.3 & \\
\hline Very sure (\%) & 6.0 & 5.6 & \\
\hline Extremely sure (\%) & 4.5 & 9.7 & \\
\hline Refused (\%) & 0.0 & 0.3 & \\
\hline Don't know (\%) & 2.7 & 1.9 & \\
\hline
\end{tabular}

${ }^{*} p<0.05$

${ }^{* *} p<0.01$

${ }^{* * *} p<0.001$

\section{Educational differences}

When controlling for gender, marital status, educational level, and age, interactions of mode of interviewing with educational level were tested with the smoking-related variables as outcomes. There was a significant interaction effect found of mode of interviewing with educational level on self efficacy for quitting (Beta $=-0.15, p=$ 0.003). Higher educated respondents had more self efficacy for quitting in the web sample (Beta $=0.17, p<0.001$ ), but not in the telephone sample (Beta $=0.05, p=$ 0.314 ). 


\section{Recontacting respondents}

All respondents from the baseline ITC telephone sample were recontacted one year after the first survey, while all respondents from the baseline ITC web survey were recontacted one, two, and three years after the first survey. Also, a smaller sample of the baseline web respondents were recontacted seven months after the first survey to examine short-term effects of a smoking cessation campaign. The samples from the follow-up web surveys were replenished with new samples of smokers to replace the respondents that were lost to follow-up. Figure 1 shows how many respondents participated in each survey wave.

As can be seen in Figure 1, 1,012 of the 1,820 baseline web respondents (56\%) participated in wave 5. Respondents who participated in wave 5 were significantly older (mean age $=39.3, \mathrm{SD}=15.3$ ) than respondents who did not participate in wave $5($ mean age $=33.9, \mathrm{SD}=15.2)(\mathrm{t}=-7.5, \mathrm{p}<0.001)$. Furthermore, respondents who participated in wave 5 were significantly more likely to be male $\left(\chi^{2}\right.$ $=8.8, p=0.003)$, lower educated $\left(x^{2}=9.1, p=0.011\right)$, and more likely to be a heavier smoker $(t=-2.4, p=0.017)$ than respondents who did not participate in wave 5 .

Figure 1: Respondents of the ITC Netherlands Survey wave 1 to 5 by interviewing mode and cohort.

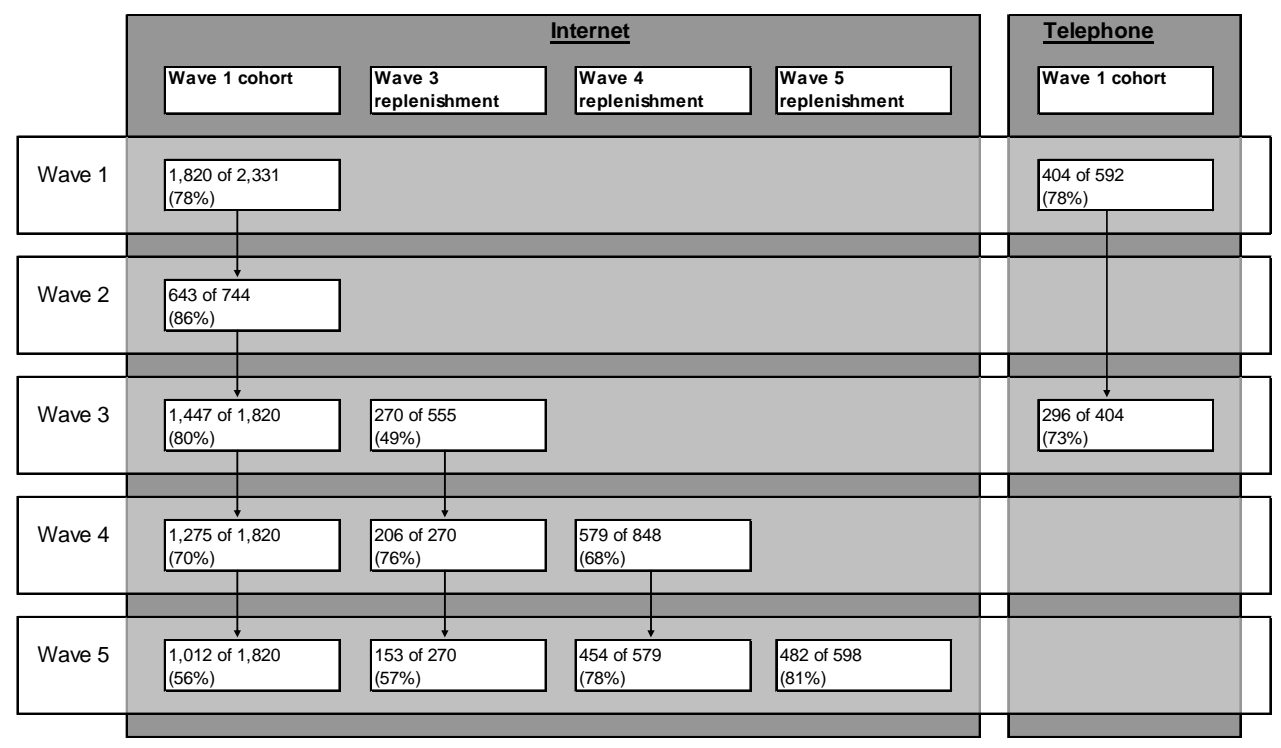




\section{CONCLUSION}

Data quality differences between the ITC Netherlands web and telephone surveys were present, but they were small. Cooperation rates were high for both the web and telephone survey (78\%), which can be explained by the use of a well respected market research company and the use of reimbursements. Web interviewing can be regarded as a good alternative to telephone interviewing in smoking cessation research. This conclusion is based on the facts that both our web and telephone surveys contained coverage and non-response error differences, which were not consistently favourable for either web or telephone interviewing. Differences between the web and telephone surveys on smoking-related variables were small. There were indications of more socially desirable responding with telephone interviewing, suggesting that web surveys may even obtain better data quality than telephone surveys.

Budget constraints can be a powerful motivator to choose web interviewing, since the differences in costs are huge. In our study, the costs were $€ 15$ (US\$22) for fieldwork costs and reimbursements per web respondent and $€ 62$ (US\$90) per telephone respondent. Because of this cost difference and because we established that web interviewing can be regarded a good alternative to telephone interviewing, we decided to go further with web interviewing only. 


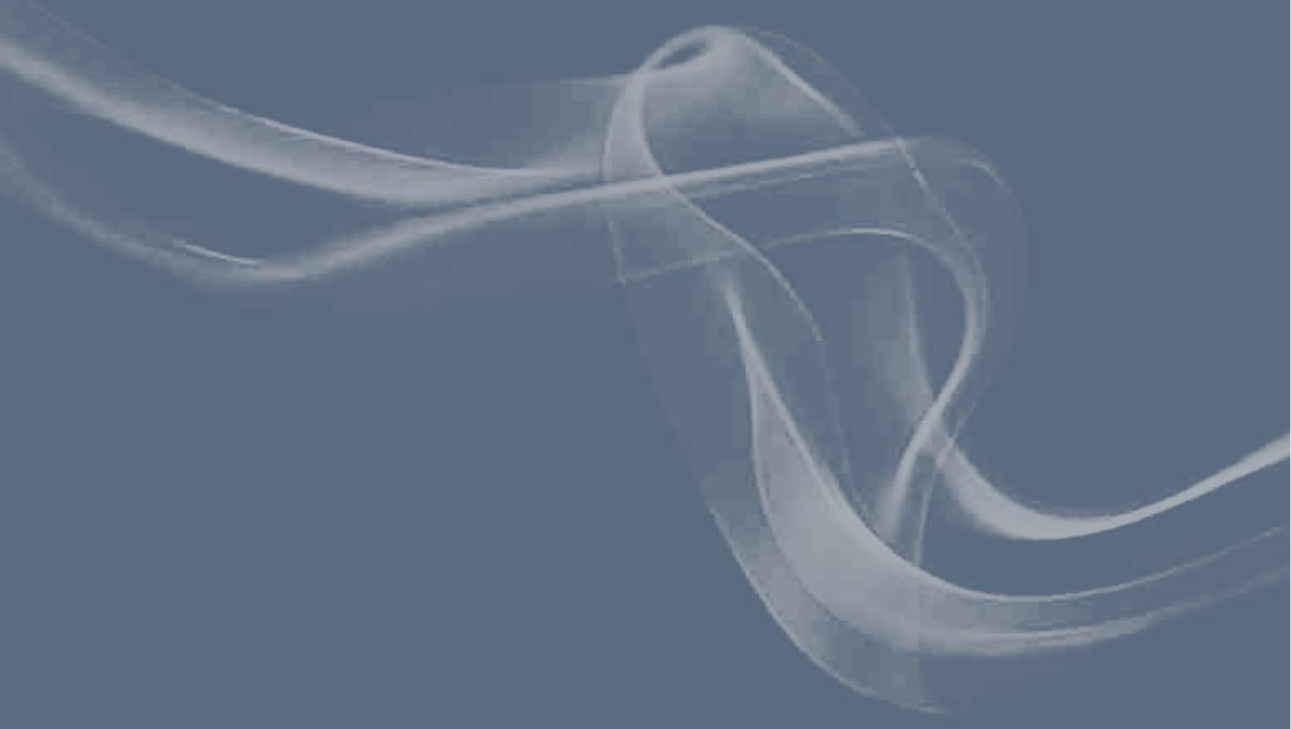

$\mid 36$ | 
Part 1

\section{Population impact of smoke-free legislation on smoking}




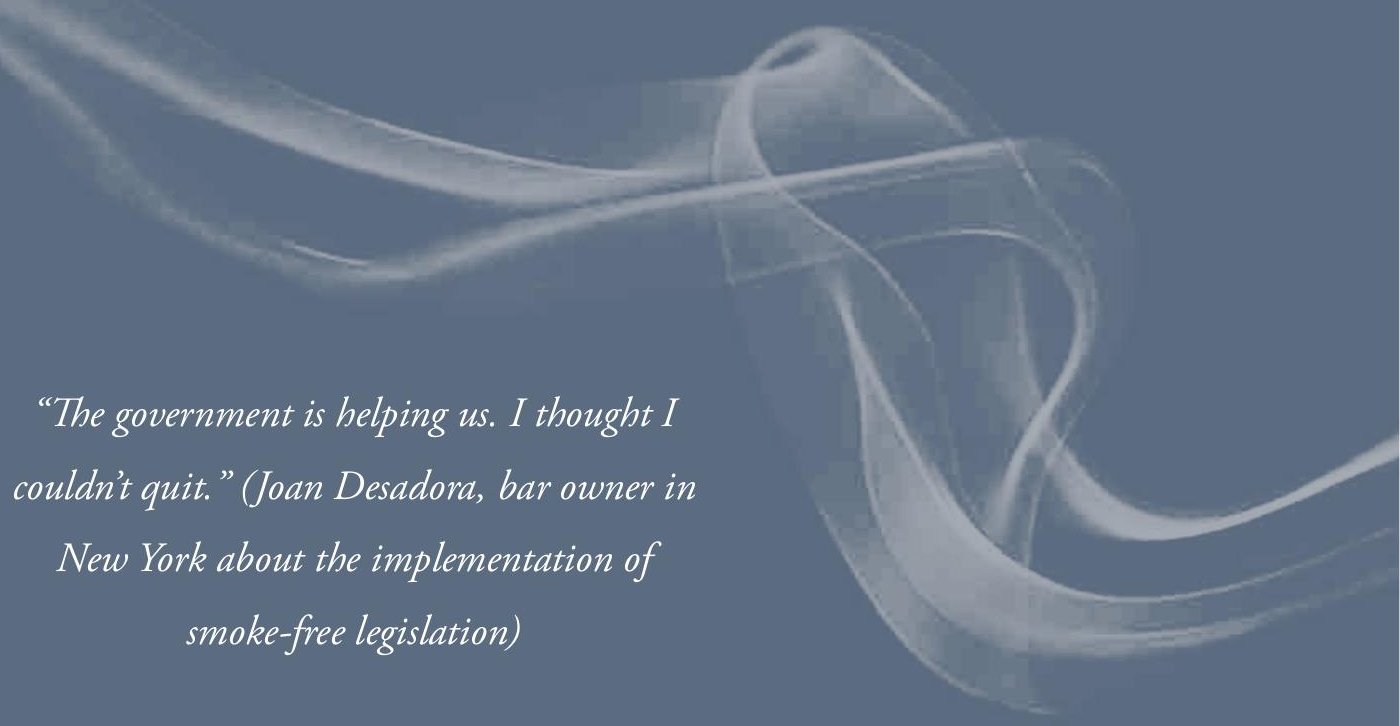

New York about the implementation of smoke-free legislation) 


\section{Chapter 3}

\section{$\sim \sim \sim$ \\ Smoke-free workplace and hospitality industry legislation}

\section{Published as:}

Nagelhout, G. E., Willemsen, M. C., \& De Vries, H. (2011). The population impact of smoke-free workplace and hospitality industry legislation on smoking behaviour. Findings from a national population survey. Addiction, 106, 816-823. 
The aim of this study was to examine the impact of implementing smokefree workplace and hospitality industry legislation on smoking behaviour. A cross-sectional population survey from 2001 to 2008 ( $n \approx 18,000$ per year) was used to assess trends and seasonal patterns in smoking and quitting, and to examine whether changes could be observed after the workplace smoking ban in the Netherlands in 2004 and the hospitality industry ban in 2008. Outcome measures were smoking prevalence, quit attempts, and successful quit attempts. Interactions with educational level (socioeconomic status) and bar visiting (exposure to the hospitality industry ban) were tested. The workplace ban was followed by a decrease in smoking prevalence $(\mathrm{OR}=0.91, \mathrm{p}<0.001)$, but the hospitality industry ban was not $(\mathrm{OR}=0.96, p=0.127)$. Both bans, especially the workplace ban were followed by an increase in quit attempts and successful quit attempts: workplace ban, $\mathrm{OR}=1.31, \mathrm{p}<0.001$; $\mathrm{OR}=1.49, \mathrm{p}<0.001$; hospitality industry ban, $\mathrm{OR}=1.13, \mathrm{p}=0.013$; $\mathrm{OR}=1.44, \mathrm{p}<0.001$. The workplace ban had a larger effect on successful quitting among higher educated $(O R=0.35, p<0.001)$ than on lower educated respondents $(O R=0.74, p=0.052)$. The hospitality industry ban had a larger effect on quit attempts among frequent bar visitors $(O R=1.48, p=0.003)$ than on non bar visitors $(O R=0.71, p=0.014)$. A workplace smoking ban in the Netherlands was followed by more changes in smoking and quitting than a hospitality industry ban. The hospitality industry ban only appeared to have an impact on quit attempts and not on smoking prevalence. 


\section{INTRODUCTION}

The Framework Convention on Tobacco Control (FCTC) was adopted in May 2003 under the auspices of the World Health Organization (WHO) (World Health Organization, 2003). Article 8 of the FCTC states that parties should adopt and implement national laws to protect citizens from exposure to second-hand smoke (SHS) in indoor public places. The Republic of Ireland was the first to implement a national law banning smoking from all enclosed workplaces, with very limited exemptions (Smoke Free Partnership, 2006). Only workplaces that were also private residences - hotel bedrooms, prisons, nursing homes, and psychiatric hospitals - were exempted. Some of the countries that followed Ireland's example temporarily exempted the hospitality industry, because these workplaces also have an entertainment function for the general public and support for hospitality industry smoking bans is generally low; examples were Belgium, France, and the Netherlands (ENSP, 2009). After a period in which the public could get used to smoke-free workplaces and in which the hospitality industry had the opportunity to create voluntary smoking bans, those countries extended the workplace smoking ban to the hospitality industry.

Implementing a workplace smoking ban first and a hospitality industry smoking ban later compromises the health of hospitality industry employees (Smoke Free Partnership, 2006). However, it is thought that this stepwise approach might also stimulate more smokers to quit smoking: first when the workplace ban is implemented and second when it is extended to the hospitality industry. According to the WHO, workplace smoking bans not only protect hospitality employees from exposure to SHS, but also encourages smokers to quit smoking (World Health Organization, 2008a). Several studies found significant decreases in smoking prevalence after the implementation of a workplace ban (Farrelly et al., 1999; Gallus et al., 2007; Hahn et al., 2008; Lemstra, Neudorf, \& Opondo, 2008). Other studies found significant increases in smoking cessation (Farkas, Gilpin, Distefan, \& Pierce, 1999; Fowkes, Stewart, Fowkes, Amos, \& Price, 2008; Hackshaw, McEwen, West, \& Bauld, 2010; Longo, Johnson, Kruse, Brownson, \& Hewett, 2001; Moskowitz et al., 2000). In addition, a rise in the sales of nicotine replacement products (Galeone et al., 2006; Lewis, Haw, \& McNeill, 2008) and increased calls to smoking cessation quitlines (Chan et al., 2009; Edwards et al., 2008; Wilson, Thomson, Grigg, \& Afzal, 2005) were found, suggesting an increase in smoking cessation. However, there were also studies that found no decline in smoking prevalence (Edwards et al., 2008; Elton \& Campbell, 2008; Galán et al., 2007), while other studies found decreases in smoking prevalence too small to reach significance (Haw \& Gruer, 2007; Mullally, Greiner, Allwright, Paul, \& Perry, 2009). 
The above-cited studies evaluated the effects of workplace smoking bans on smoking and quitting. Yet it appears no research has examined the effects of an extension of a workplace ban to the hospitality industry. In this study we will assess the effects of the implementation of a workplace smoking ban in January 2004 in the Netherlands and the extension to the hospitality industry in July 2008.

When studying changes in smoking behaviour after the implementation of a smoking ban, trends in smoking behaviour should be taken into account (Edwards et al., 2008; Fowkes et al., 2008; Lewis et al., 2008). For example, a decline in smoking can only be ascribed to a smoking ban when the decrease is larger than that of previous years. In this study we will relate a seven year trend in smoking and quitting to the changes after the implementation of the workplace and hospitality industry smoking ban. Other policies that were implemented in this time period were tax increases (2001, 2004, and 2008), text warning labels (2002), an advertising ban (2002), and a youth access law (2003). National mass media smoking cessation campaigns ran in 2003,2004 , and 2008 . Our first hypothesis is that there will be fewer smokers and more quitters than normal after the implementation of the workplace and hospitality industry ban in the Netherlands.

Smoking is increasingly a problem for lower socioeconomic status (SES) groups (World Health Organization, 2008a). There is some evidence that smoking bans have more impact on the smoking behaviour of higher SES groups (Farrelly et al., 1999; Fowkes et al., 2008), while other studies did not find differences between SES groups (Hackshaw et al., 2010; Moskowitz et al., 2000). Therefore, our second hypothesis is that we expect to observe more changes in smoking and quitting among people with a higher SES.

Since the Dutch smoking bans were implemented in conjunction with a tax increase and a mass media smoking cessation campaign, we could not simply assume that changes in smoking behaviour were due to the bans only. In other studies this issue was resolved by comparing individuals who were more and less exposed to the ban (Braverman, Aaro, \& Hetland, 2008; Edwards et al., 2008; Verdonk-Kleinjan et al., 2009). In this study we compared individuals who were not exposed to the smoking ban in the hospitality industry (i.e. individuals who never visited bars) with individuals who were somewhat exposed to the ban (i.e. individuals who visited bars yearly), and those who were most exposed (i.e. individuals who visited bars monthly). Our third hypothesis is therefore that we expect to observe more changes in smoking and quitting among individuals who were more exposed to the ban. 


\section{METHODS}

\section{Sample}

The data source of this study was the Dutch Continuous Survey of Smoking Habits (DCSSH). This is a cross-sectional population survey of respondents aged 15 years and older that is used to monitor smoking habits of the Dutch population, using weekly measurements. The DCSSH is conducted by TNS NIPO for the Dutch expert centre on tobacco control (STIVORO) and is supported by grants from the Dutch Ministry of Health. Respondents for the DCSSH were randomly selected from TNS NIPObase, a database with at present over 140,000 potential respondents who participate in internet-based research on a regular basis. TNS NIPObase panel members are actively recruited by TNS NIPO using telephone and mail. Data from the DCSSH from 2001 until 2008 were used for this study. Approximately 18,000 respondents participated in the survey each year $(144,733$ in total from 2001 to 2008), with 18,637 respondents in 2008 of whom 9,572 were surveyed after the implementation of the smoking ban in July 2008. The data were representative for the Dutch population of 15 years and older after applying weights for gender, age, educational level, working hours, geographic region, urbanisation and household size.

\section{Questionnaire}

The questionnaire used assessed background characteristics, smoking behaviour, use of smoking cessation aids, and contained extensive sections on attitudes towards smoking, quitting and tobacco control policies and campaigns. The questionnaire was sent to the respondents by e-mail. Respondents could fill in the questionnaire at their own computer using software from TNS NIPO. For this study, questions about smoking behaviour and background characteristics from 2001 until 2008 were used.

In line with an earlier study (Willemsen, Hoogenveen, \& Van der Lucht, 2002), smoking status at the time of the survey was assessed by asking "Do you (ever) smoke or not at all?". Respondents who answered that they smoke were defined as current smokers. Respondents who answered that they did not smoke were asked "Have you smoked in the past?". Respondents who answered that they had smoked in the past were defined as former smokers and respondents who answered that they had not smoked in the past were defined as never smokers. Smoking prevalence was the percentage of respondents who were current smokers. This was calculated per year (for analyses between years) and per six months (for analyses within years). 
Quit attempts in the last six and twelve months were measured by asking current smokers "How long ago was your most recent attempt to quit smoking?" and by asking former smokers "How long ago did you quit smoking?". In line with earlier studies (Farkas et al., 1999; Hackshaw et al., 2010), these questions were combined to construct dichotomous variables measuring a) whether respondents made a quit attempt in the past year (for analyses between years) and b) whether respondents made a quit attempt in the past six months (for analyses within years).

Successful quit attempts in the last six and twelve months were measured with the same question as quit attempts, but excluding the current smokers (i.e. the unsuccessful quit attempts). This measure was also used in earlier studies (Capannesi, Boshuizen, Willemsen, \& Van Houwelingen, 2009; Willemsen et al., 2002).

Furthermore, age, gender, educational level, employment status, and frequency of bar visiting were assessed. Age was categorised into four groups: 15 to 24 years, 25 to 39 years, 40 to 54 years, and 55 years and older. Educational level was categorised into three groups: low (primary education and lower pre-vocational secondary education), medium (middle pre-vocational secondary education and secondary vocational education), and high (senior general secondary education, (pre-)university education and higher professional education). Employment status was categorised into currently employed and currently not employed for at least two days per week. Frequency of bar visiting was categorised as never, yearly, and monthly visiting.

\section{Analyses}

The first hypothesis implies fewer smokers and more quitters than normal after the implementation of the workplace and hospitality industry smoking ban. To assess how much smoking and quitting was normal, we performed multivariate logistic regression analyses on data from 2001 until 2007. Dependent variables were percentage of smokers, percentage of quitters, and percentage of successful quitters. Independent variables were 'year' for analyses to assess trends and 'period' (first six months and last six months of the year) to assess seasonal patterns. These analyses were repeated for 2003 and 2004 together (to assess trends following the implementation of the workplace smoking ban), 2004 only (to assess seasonal patterns following the workplace ban), 2007 and 2008 together (to assess trends following the hospitality industry ban), and 2008 only (to assess seasonal patterns following the hospitality industry ban). 
The second hypothesis was that we expected to observe more changes in smoking and quitting among people with a higher SES. Educational level and income are common indicators of SES (Huisman, Kunst, \& Mackenbach, 2005b). In this study, we used educational level as indicator of SES, because it contained considerably less missing values $(n=665)$ than income $(n=30,661)$. Additional analyses on the respondents whose income was available resulted in similar conclusions as the analyses with educational level. The analyses for hypothesis 1 were repeated with educational level and the interaction of educational level with year and period added as independent variables.

The third hypothesis states that the changes in smoking and quitting will be more pronounced among individuals who were more exposed to the hospitality industry ban. As a proxy of exposure to the ban we used frequency of bar visiting. The analyses for hypothesis 1 were repeated with frequency of bar visiting and the interaction of frequency of bar visiting with survey year and period added as independent variables.

All analyses were conducted with SPSS version 17.

\section{RESULTS}

\section{Background characteristics}

There were no significant differences in background characteristics between survey years (Table 1). Also, the background characteristics did not differ between the preand post-ban period in 2008. More frequent bar visitors were significantly younger $\left(x^{2}=5,726.48, p<0.001\right)$, more often male $\left(x^{2}=336.69, p<0.001\right)$, higher educated $\left(x^{2}=3,018.78, p<0.001\right)$, and more often employed $\left(x^{2}=2,447.60, p<0.001\right)$. 
Table 1: Background characteristics from 2001 to 2008 (weighted data).

\begin{tabular}{|c|c|c|c|c|c|c|c|c|}
\hline & 2001 & 2002 & 2003 & 2004 & 2005 & 2006 & 2007 & 2008 \\
\hline \multicolumn{9}{|l|}{ Age } \\
\hline $15-24(\%)$ & 14.7 & 14.7 & 14.7 & 14.7 & 14.7 & 14.7 & 14.7 & 14.7 \\
\hline $25-39(\%)$ & 29.9 & 30.3 & 30.3 & 30.6 & 30.3 & 30.3 & 30.7 & 30.8 \\
\hline $40-54(\%)$ & 26.9 & 26.5 & 26.5 & 26.3 & 26.4 & 26.5 & 26.1 & 26.0 \\
\hline 55 and older (\%) & 28.4 & 28.6 & 28.5 & 28.4 & 28.6 & 28.5 & 28.5 & 28.6 \\
\hline \multicolumn{9}{|l|}{ Gender } \\
\hline Men (\%) & 49.1 & 49.1 & 49.1 & 49.2 & 49.1 & 49.1 & 49.1 & 49.0 \\
\hline Women (\%) & 50.9 & 50.9 & 50.9 & 50.8 & 50.9 & 50.9 & 50.9 & 51.0 \\
\hline \multicolumn{9}{|l|}{ Educational level } \\
\hline Low (\%) & 44.4 & 44.5 & 44.4 & 44.5 & 44.4 & 44.5 & 44.5 & 44.5 \\
\hline Medium (\%) & 33.6 & 33.6 & 33.6 & 33.6 & 33.6 & 33.6 & 33.6 & 33.6 \\
\hline High (\%) & 22.0 & 22.0 & 22.0 & 21.9 & 21.9 & 21.9 & 21.9 & 21.9 \\
\hline \multicolumn{9}{|l|}{ Employment* } \\
\hline Yes (\%) & - & - & - & - & 70.6 & 70.4 & 70.9 & 70.8 \\
\hline No $(\%)$ & - & - & - & - & 29.4 & 29.6 & 29.1 & 29.2 \\
\hline \multicolumn{9}{|l|}{$\begin{array}{l}\text { Frequency of bar } \\
\text { visiting }^{*}\end{array}$} \\
\hline Monthly (\%) & - & - & - & - & - & 22.9 & 23.5 & 22.8 \\
\hline Yearly (\%) & - & - & - & - & - & 29.5 & 29.6 & 30.8 \\
\hline Never (\%) & - & - & - & - & - & 47.7 & 46.9 & 46.4 \\
\hline
\end{tabular}

* Data on employment and frequency of bar visiting was collected from 2005 and 2006 respectively.

\section{Differences in smoking and quitting between 2001 and 2008}

Figure 1 shows smoking prevalence, percentage of quit attempts, and percentage of successful quit attempts from 2001 until 2008. Table 2 shows that smoking prevalence significantly decreased in the 2001-2007 period (Odds Ratio (OR) = $0.97, p<0.001)$. This decrease was larger in $2004(\mathrm{OR}=0.91, \mathrm{p}<0.001)$, after the workplace smoking ban had been implemented. Smoking prevalence declined from $29.9 \%$ in 2003 to $27.9 \%$ in 2004 . In 2008 , when the hospitality industry smoking ban was implemented, the observed decrease from $27.5 \%$ to $26.7 \%$ was not significant $(O R=0.96, p=0.127)$. There was no significant seasonal pattern in smoking prevalence in the 2001-2007 period ( $O R=1.00, p=0.726)$. In 2004, there was a significant difference between smoking prevalence in the first and second half of the year. In the second half of 2004 , smoking prevalence was significantly higher than in the first half $(O R=1.08, p=0.023)$. In 2008, smoking prevalence did not significantly differ between the first and second half of the year (OR $=1.05, p=$ 0.147). Therefore, we can conclude that the workplace smoking ban was followed by a decline in smoking prevalence, but the hospitality industry smoking ban was not. 
The analyses in Table 2 show no trends in the percentage of quit attempts in the 2001-2007 period ( $O R=1.00, p=0.759)$. In 2004 there were significantly more quit attempts (33.3\%) than in $2003(27.7 \%)(\mathrm{OR}=1.31, \mathrm{p}<0.001)$. In 2008 there were also significantly more quit attempts (26.3\%) than in 2007 (24.1\%) (OR $=1.13, p=$ 0.013). There was a significant seasonal pattern in the percentage of quit attempts between 2001 and 2007 (OR = 0.90, $p<0.001$ ). In the second half of the years there were fewer quit attempts than in the first half of the years. This pattern was stronger in $2004(\mathrm{OR}=0.75, \mathrm{p}<0.001)$ and absent in $2008(\mathrm{OR}=1.07, \mathrm{p}=0.359)$. This means that the workplace smoking ban especially, but also the hospitality industry ban, was followed by an increase in quit attempts.

From Table 2 it follows that there was no trend in the percentage of successful quit attempts between 2001 and 2007 (OR = 0.99, $p=0.286$ ). However, there was a significant increase from $6.9 \%$ successful quit attempts in 2003 to $10.0 \%$ in 2004 $(\mathrm{OR}=1.49, \mathrm{p}<0.001)$. There was also a significant increase from $5.6 \%$ in 2007 to $8.0 \%$ in 2008 (OR $=1.44, p<0.001)$. There was a seasonal pattern with fewer successful quit attempts in the second half than in the first half of the years (OR = $0.77, p<0.001)$. In 2004 this pattern was stronger $(O R=0.54, p<0.001)$ whereas in 2008 it was absent ( $O R=0.96, p=0.722)$. The conclusion is that the workplace smoking ban in particular, but also the hospitality industry ban, was followed by an increase in successful quit attempts.

Figure 1: Trends in smoking and quitting between 2001 and 2008.

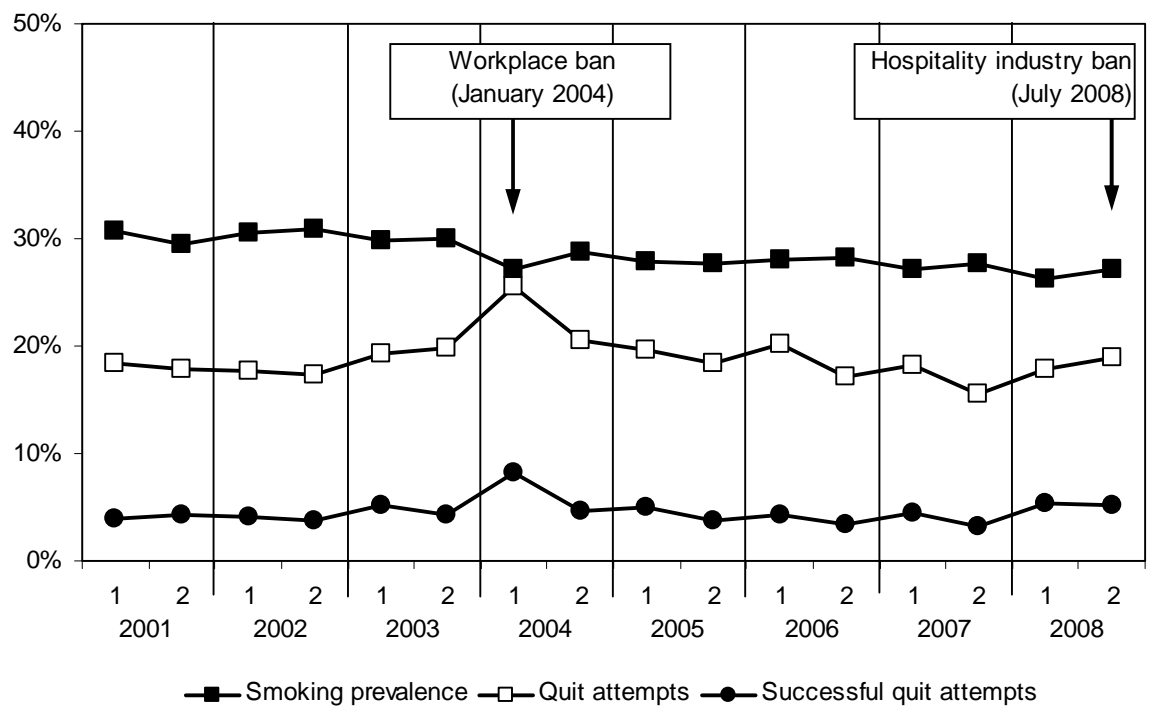



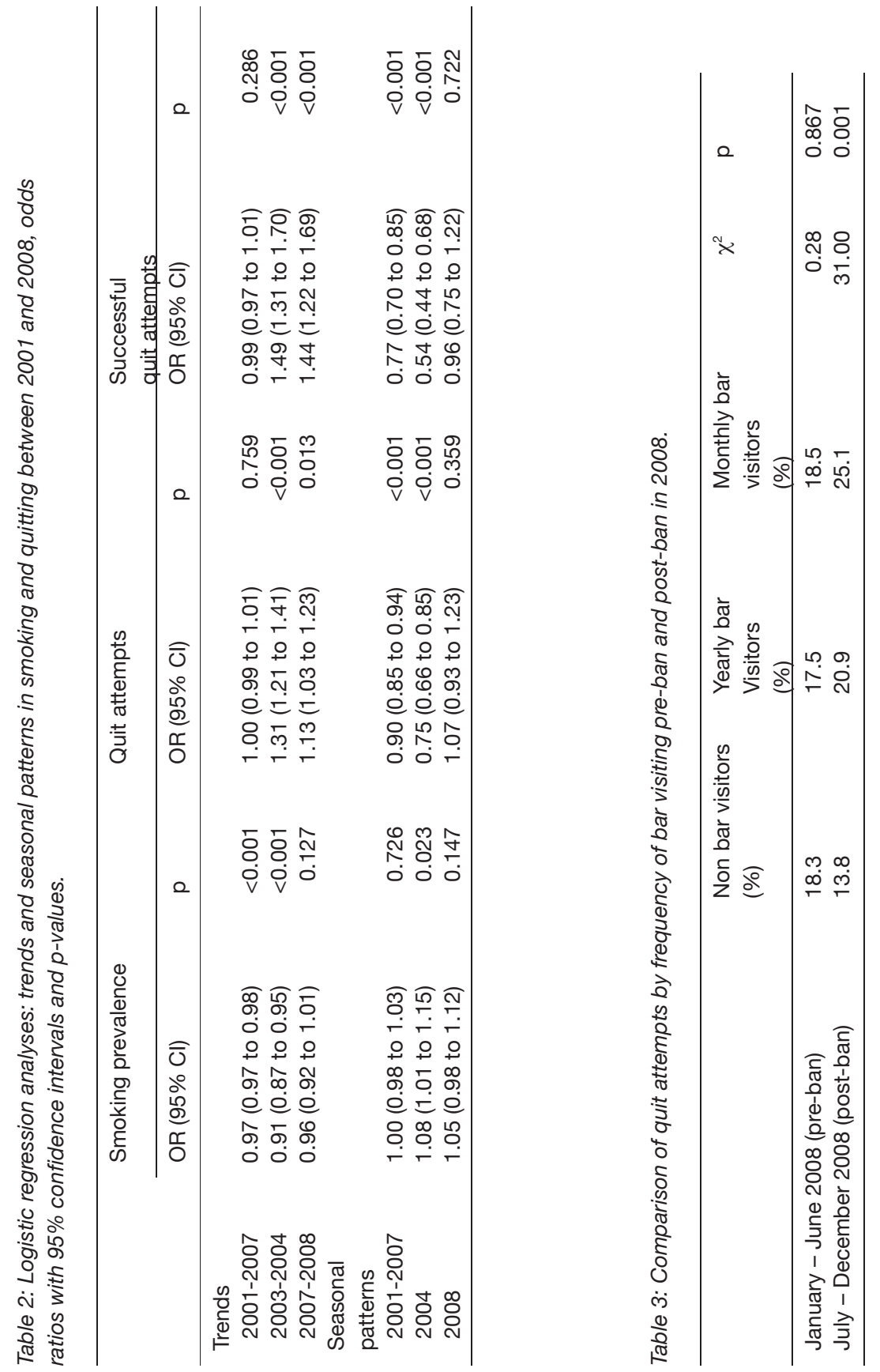


\section{Interaction effects with educational level}

In 2004 a significant interaction with educational level was found in the seasonal pattern of more successful quit attempts in the first half of 2004 compared to the second half $(O R=0.64, p=0.004)$. This pattern was stronger for higher educated $(\mathrm{OR}=0.35, \mathrm{p}<0.001)$, than for medium educated $(\mathrm{OR}=0.41, \mathrm{p}<0.001)$, and lower educated respondents $(\mathrm{OR}=0.74, \mathrm{p}=0.052)$. This difference in seasonal patterns between educational levels was not prevalent between 2001 and 2007. In 2008 there were no significant interactions with educational level in trends or seasonal patterns.

\section{Interaction effects with bar visiting in 2007 and 2008}

There were no significant interactions with bar visiting in trends in smoking and quitting between 2007 and 2008. A significant interaction with bar visiting was found in the seasonal pattern in quit attempts in $2008(O R=1.43, p<0.001)$. Monthly bar visitors were significantly more likely to attempt to quit smoking in the second half of 2008 than in the first half $(\mathrm{OR}=1.48, p=0.003)$; yearly bar visitors were not more or less likely to quit $(\mathrm{OR}=1.25, \mathrm{p}=0.116)$; and non bar visitors were significantly less likely to quit in the second half of $2008(O R=0.71, p=0.014)$. This difference in seasonal pattern between monthly, yearly, and non bar visitors was not prevalent in 2007.

The bivariate analyses in Table 3 reveal that attempting to quit smoking and bar visiting were unrelated before the implementation of the hospitality industry ban in $2008\left(\chi^{2}=0.28, p=0.876\right)$, while they were significantly related after the implementation $\left(x^{2}=31.00, p=0.001\right)$. Monthly bar visitors attempted to quit smoking almost twice as often as non bar visitors ( $25 \%$ and $14 \%$ respectively) postban. When controlling for background variables in a multivariate logistic regression analysis with the 'enter' method, attempting to quit smoking and bar visiting were unrelated pre-ban (Table 4). Post-ban, bar visitors were more likely to attempt to quit smoking. When conducting a multivariate logistic regression analysis with the 'forward' method (not shown), a model was fitted with age as the only predictor of attempting to quit smoking pre-ban and both age and bar visiting as predictors of attempting to quit smoking post-ban. 
Table 4: Logistic regression analysis: factors associated with attempting to quit smoking pre-ban and post-ban in 2008, odds ratios with $95 \%$ confidence intervals and p-values.

\begin{tabular}{|c|c|c|c|c|}
\hline & \multicolumn{2}{|c|}{$\begin{array}{l}\text { January - June } 2008 \text { (pre-ban) } \\
(\mathrm{n}=1,893)\end{array}$} & \multicolumn{2}{|c|}{$\begin{array}{l}\text { July - December } 2008 \text { (post-ban) } \\
(n=1,950)\end{array}$} \\
\hline & OR (95\% Cl) & $p$ & OR $(95 \% \mathrm{Cl})$ & $p$ \\
\hline \multicolumn{5}{|l|}{ Age } \\
\hline $15-24$ & 2.05 (1.26 to 3.31$)$ & 0.004 & 1.89 (1.17 to 3.05$)$ & 0.010 \\
\hline $25-39$ & 1.09 (0.72 to 1.64$)$ & 0.679 & 1.25 (0.85 to 1.85$)$ & 0.256 \\
\hline $40-54$ & 0.81 (0.55 to 1.21$)$ & 0.306 & 0.81 (0.54 to 1.20$)$ & 0.840 \\
\hline 55 and older & $1.0(-)$ & & $1.0(-)$ & \\
\hline \multicolumn{5}{|l|}{ Gender } \\
\hline Men & 0.88 (0.69 to 1.12$)$ & 0.310 & 1.02 (0.82 to 1.29$)$ & 0.840 \\
\hline Women & $1.0(-)$ & & $1.0(-)$ & \\
\hline \multicolumn{5}{|l|}{ Educational } \\
\hline $\begin{array}{l}\text { level } \\
\text { Low }\end{array}$ & 0.77 (0.56 to 1.07$)$ & 0.116 & 0.70 (0.51 to 0.95$)$ & 0.022 \\
\hline Medium & $0.79(0.57(1.08)$ & 0.142 & 0.93 (0.69 to 1.25$)$ & 0.635 \\
\hline High & $1.0(-)$ & & $1.0(-)$ & \\
\hline \multicolumn{5}{|l|}{ Employment } \\
\hline Yes & 0.93 (0.66 to 1.31$)$ & 0.668 & $1.03(0.74$ to 1.44$)$ & 0.852 \\
\hline No & $1.0(-)$ & & $1.0(-)$ & \\
\hline \multicolumn{5}{|l|}{$\begin{array}{l}\text { Frequency of } \\
\text { bar visiting }\end{array}$} \\
\hline Monthly & 0.85 (0.61 to 1.18$)$ & 0.328 & 1.45 (1.07 to 1.97$)$ & 0.018 \\
\hline Yearly & 1.01 (0.75 to 1.37$)$ & 0.955 & 1.41 (1.05 to 1.89$)$ & 0.023 \\
\hline Never & $1.0(-)$ & & $1.0(-)$ & \\
\hline
\end{tabular}

\section{DISCUSSION}

Previous research found that a workplace smoking ban may lead to fewer smokers (Farrelly et al., 1999; Gallus et al., 2007; Hahn et al., 2008; Lemstra et al., 2008) and more quitters (Farkas et al., 1999; Fowkes et al., 2008; Hackshaw et al., 2010; Longo et al., 2001; Moskowitz et al., 2000). However, there were no studies available about the potential added effect of the extension of a workplace smoking ban to the hospitality industry. We hypothesised that there would be fewer smokers and more quitters than normal after the implementation of the smoking bans in the Netherlands. Therefore, we had to assess first which pattern of smoking and quitting was normal. We found that smoking prevalence decreased from 2001 until 2007 and that there were no seasonal variations between the first and second half of the year. The percentage of quit attempts and successful quit attempts was stable from 2001 until 2007, but it was higher in the first than in the second half of most years. This pattern was also found in earlier studies (Chandra \& Chaloupka, 2003; Hackshaw et al., 2010; Momperousse, Delnevo, \& Lewis, 2007) and can probably best be explained by New Year resolutions. 
We found fewer smokers than normal after the implementation of the workplace ban, and increases in quit attempts and successful quit attempts. In contrast, we did not find fewer smokers than normal after the hospitality industry smoking ban, and smaller increases in quit attempts and successful quit attempts. We can therefore conclude that a workplace ban is followed by more changes in smoking and quitting than a hospitality industry ban.

Our second hypothesis was that we expected to observe more changes in smoking and quitting after the implementation of the hospitality industry ban among those with a higher socioeconomic status. We did find more successful quitting among higher educated respondents after the workplace ban, but we did not find this after the hospitality industry ban. It is an encouraging finding that hospitality industry smoking bans have the potential to increase smoking cessation in both higher and lower educational groups.

Our third hypothesis was that we expected to observe more changes in smoking and quitting among individuals who were more exposed to the hospitality industry ban. This hypothesis was supported in that we found fewer quit attempts post-ban than pre-ban for non bar visitors (the normal pattern) and more quit attempts post-ban than pre-ban for frequent bar visitors. Also, we found that respondents who visited bars more frequently more often attempted to quit smoking than non bar visitors post-ban, whereas this pattern could not be observed pre-ban. This implies that the increase in quit attempts after the implementation of the hospitality industry ban is at least partly a consequence of the ban.

Our study does not explain why smoking bans affect smoking behaviour. Workplace bans are often thought to limit smoking behaviour by curtailing smoking opportunities (Levy \& Friend, 2003; Longo et al., 2001). This may not apply to a hospitality industry ban, since people spend less time in bars than in workplaces, and can choose to leave or smoke outside whenever they want. Other explanations for the effects of smoking bans on smoking behaviour are that the ban increases the social stigma attached to smoking (Gallus et al., 2007; Levy \& Friend, 2003), leads to less socially cued smoking (Edwards et al., 2008; Trotter, Wakefield, \& Borland, 2002), and raises awareness of the dangers of smoking (Hahn et al., 2008). It is conceivable that the hospitality industry ban in the Netherlands did not lead to more social stigma regarding smoking and to less socially cued smoking, because of the far less than optimal compliance in bars (ITC Project, 2010b). It is also possible that the ban failed to increase awareness of the dangers of smoking, because the implementation campaign by the Dutch government only focused on the date of implementation and not on the public health reasons for the ban. What remains is that smokers may have been triggered to use the implementation date as their quit 
date (Edwards et al., 2008). There was also a mass media campaign in the period around the implementation of the ban that encouraged attempts to quit smoking. Anecdotal evidence from smoking cessation counsellors suggests that smokers postponed their quit attempts until the date of the introduction of the smoking ban, because they expected that smoke-free bars would help them to stay off tobacco. When numerous bars did not comply with the ban, many were disappointed and gave up on their quit attempt. This might explain why we found that the ban only generated quit attempts and did not cause more lasting effects. These results may therefore not be generalisable to other countries with better compliance. We recommend strong enforcement of smoking bans and combining the introduction of the ban with offering smokers help in staying quit.

A limitation of this study was that the impact of smoking bans could not be separately assessed from the impact of tax increases and mass media campaigns, since these measures were implemented simultaneously. Furthermore, the trend in smoking behaviour from 2001 to 2007 was used to examine whether smoking behaviour in 2008 was different than normal. Another approach would be to compare smoking behaviour between 2008 and 2009. Unfortunately, we could not compare 2008 with 2009, since changes in the sampling strategy of the survey caused considerable differences in the background characteristics of respondents from 2009. In this study we used a large cross-sectional population survey with continuous measures throughout the year with respondents that were representative for the Dutch population. The advantage of this large dataset was that small changes in smoking behaviour could be detected and generalised to the population. A disadvantage is the cross-sectional nature of the data. Consequently, we were not able to draw conclusions about causal relationships. Future research with longitudinal data is therefore recommended. 


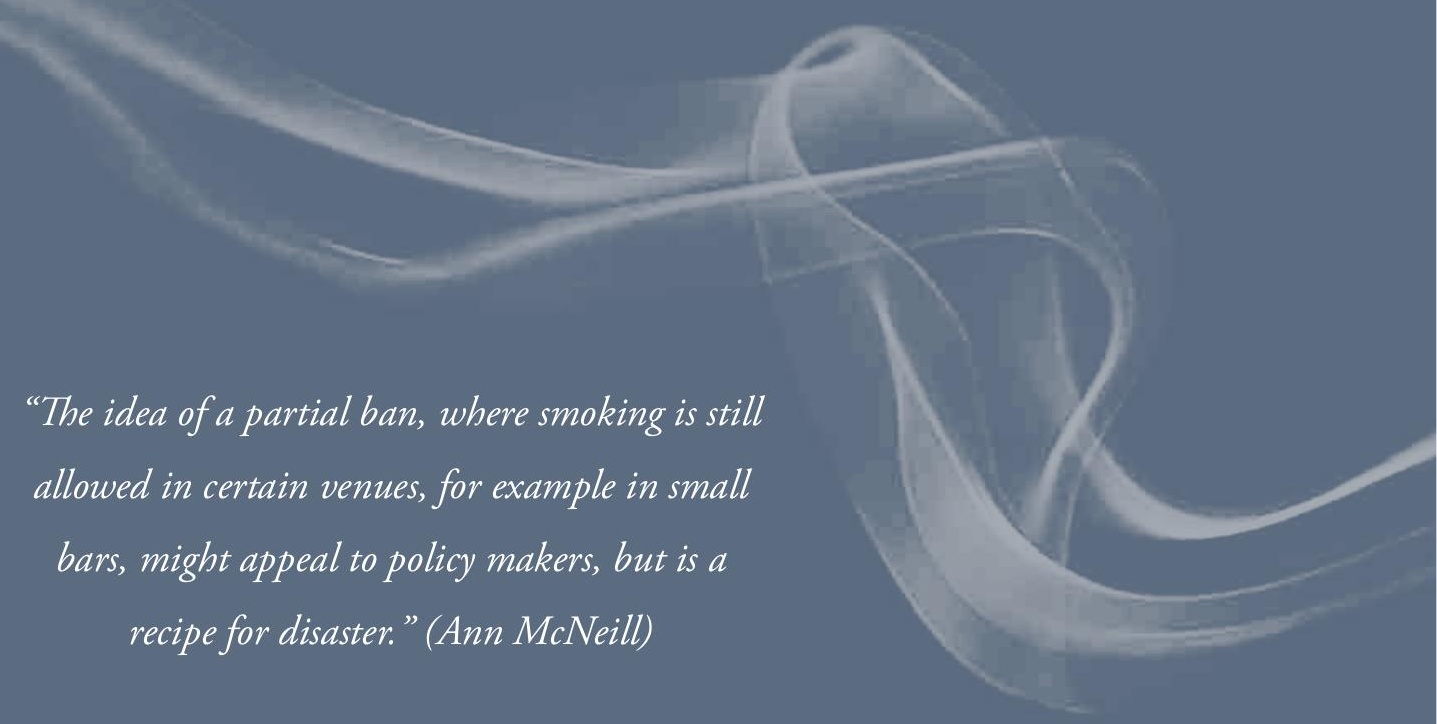




\section{Chapter 4}

\section{Comprehensive and partial smoke-free legislation}

\section{Published as:}

Nagelhout, G. E., De Vries, H., Allwright, S., McNeill, A., Van den Putte, B., Boudreau, C., Fong, G. T., \& Willemsen, M. C. (2012). Comparative impact of smoke-free legislation on smoking cessation in three European countries. European Journal of Public Health, 22(Suppl 1), 4-9. 
Little is known about the differential impact of comprehensive and partial smoke-free legislation on smoking cessation. This study aimed to examine the impact of comprehensive smoke-free workplace legislation in Ireland and England, and partial hospitality industry legislation in the Netherlands on quit attempts and quit success. Nationally representative samples of 2,219 adult smokers were interviewed in three countries as part of the International Tobacco Control (ITC) Europe Surveys. Quit attempts and quit success were compared between period 1 (in which smoke-free legislation was implemented in Ireland and the Netherlands) and period 2 (in which smoke-free legislation was implemented in England). In Ireland, significantly more smokers attempted to quit smoking in period $1(50.5 \%)$ than in period $2(36.4 \%)(p<0.001)$. Percentages of quit attempts and quit success did not change significantly between periods in the Netherlands. English smokers were significantly more often successful in their quit attempt in period $2(47.3 \%)$ than in period $1(26.4 \%)(p=0.011)$. In the first period there were more quit attempts in Ireland than in England and fewer in the Netherlands than in Ireland. Fewer smokers quitted successfully in the second period in both Ireland and the Netherlands than in England. The comprehensive smoke-free legislation in Ireland and England may have had positive effects on quit attempts and quit success respectively. The partial smoke-free legislation in the Netherlands probably had no effect on quit attempts or quit success. Therefore, it is recommended that countries implement comprehensive smoke-free legislation. 


\section{INTRODUCTION}

Smoke-free legislation is one of the policies recommended by the World Health Organization (WHO) in the Framework Convention on Tobacco Control (FCTC) (World Health Organization, 2003). According to the WHO, countries should implement smoke-free legislation that bans smoking in indoor workplaces and other public places to decrease exposure to tobacco smoke pollution (secondhand smoke). Studies have shown that smoke-free legislation can also stimulate smokers to quit smoking (Callinan, Clarke, Doherty, \& Kelleher, 2010; Fichtenberg \& Glantz, 2002). This may happen because smoke-free legislation reduces the social acceptability of smoking (Albers, Siegel, Cheng, Biener, \& Rigotti, 2004; Brown, Moodie, \& Hastings, 2009), increases support for regulating smoking (Brown et al., 2009; Macy, Middlestadt, Seo, Kolbe, \& Jay, 2012), limits smoking opportunities (Levy \& Friend, 2003; Longo et al., 2001), and leads to less socially cued smoking (Edwards et al., 2008; Trotter et al., 2002).

There is evidence that comprehensive smoke-free legislation (i.e. 100\% smoke-free legislation, without exemptions or designated smoking rooms) has larger effects on improving indoor air quality (Gleich, Mons, \& Pötschke-Langer, 2011), reducing exposure to tobacco smoke pollution (López et al., 2011; Naiman, Glazier, \& Moineddin, 2011) and on reducing acute coronary syndrome admissions (Ferrante, Linetzky, Virgolini, Schoj, \& Apelberg, 2011) than partial smoke-free legislation. However, any differences in the effects of comprehensive and partial smoke-free legislation on smoking cessation are not yet studied.

Our study uses data from the International Tobacco Control (ITC) Europe Project to compare the impact of comprehensive smoke-free workplace legislation in Ireland and England with the impact of partial smoke-free hospitality industry legislation in the Netherlands on quit attempts and success.

\section{Ireland}

Ireland implemented comprehensive smoke-free workplace legislation that included the hospitality industry in March 2004. The implementation of the smokefree legislation received extensive national (Fahy, Trench, \& Clancy, 2009) and international (McNabb \& Hearns, 2005) media attention, as Ireland was the first country in the world to implement national comprehensive smoke-free legislation. There was an increase in available smoking cessation support in the period of the implementation of the smoke-free legislation, but it was considered a missed opportunity that cessation support was not emphasised in the mass media campaign (Kosir \& Gutierrez, 2009). 
Data from a repeated cross-sectional national survey showed that smoking prevalence first declined from $29 \%$ to $26 \%$ one year after the implementation, but increased to $28 \%$ another year later (Office of Tobacco Control, 2010). Data from the ITC Project showed that $80 \%$ of smokers who had quit smoking after the ban reported the ban helped them quit and $88 \%$ reported the ban helped them stay quit (Fong, Hyland et al., 2006). However, changes in actual quit rates and success rates after the implementation of the legislation were not studied.

\section{England}

England implemented comprehensive smoke-free workplace legislation that included the hospitality industry in July 2007. At the same time, the $17.5 \%$ rate of value-added tax on nicotine replacement therapy sold over-the-counter was reduced to $5 \%$.

Data from a repeated cross-sectional national survey showed that the introduction of smoke-free legislation was not associated with additional reductions in smoking prevalence above the secular trend (Lee, Glantz, \& Millett, 2011). Data from the longitudinal Smoking Toolkit Study showed a small temporary increase in quit attempts in July and August 2007 compared to July and August 2008, but did not control for longer term quitting activity (Hackshaw et al., 2010). A further study suggested that the smoke-free legislation caused an increase in prescribing of smoking cessation medications, but indicated that there may have only been a temporal displacement of quit attempts (Szatkowski, Coleman, McNeill, \& Lewis, 2011). Changes in quit success after the implementation of the legislation were not studied.

\section{The Netherlands}

The Netherlands implemented smoke-free workplace legislation that excluded the hospitality industry in January 2004 and implemented smoke-free hospitality industry legislation in July 2008. Both the 2004 and 2008 bans were implemented in conjunction with a tobacco tax increase. Tobacco prices increased by $19 \%$ in 2004 and $8 \%$ in 2008. There were also intensive mass media smoking cessation campaigns in both years. Workplaces and hospitality venues were allowed to create designated smoking rooms. Therefore, the Dutch smoke-free legislation is considered partial instead of comprehensive.

Data from a repeated cross-sectional national survey showed that quit attempts and quit success increased after the implementation of the 2004 smokefree workplace legislation, resulting in a decline in smoking prevalence from $30 \%$ in 2003 to 28\% in 2004 (Nagelhout, Willemsen, \& De Vries, 2011). There was a smaller 
increase in quit attempts and success after the implementation of the smokefree hospitality industry legislation, and this resulted in a non-significant decline in smoking prevalence. However, only short-term effects of the 2008 ban were assessed.

\section{This study}

The current study used three consecutive annual surveys from each country. In Ireland and the Netherlands, national smoke-free legislation was implemented between the first and second survey. In England, the smoke-free legislation was implemented between the second and third survey. This allowed for a quasi-experimental design in which the change over time in quit attempts and quit success in Ireland and the Netherlands could be compared with England.

\section{METHODS}

\section{Sample}

The International Tobacco Control (ITC) Europe Project is a longitudinal study in which nationally representative samples of adult smokers are surveyed at regular time intervals (Fong et al., 2006). The current study used three consecutive annual surveys from Ireland, England, and the Netherlands. We refer to the three surveys as wave 1, wave 2, and wave 3. However, for England, wave 1 is actually the fourth wave of ITC United Kingdom. To make the England sample comparable to the wave 1 samples from Ireland and the Netherlands, we have excluded respondents who had quit smoking between the first and fourth survey.

Respondents from Ireland and England were recruited using a stratified random digit dialling (RDD) probability sampling design of fixed line telephone numbers and were surveyed using telephone interviewing. Respondents from the Netherlands were recruited from a large probability-based database with respondents who indicated their willingness to participate in surveys on a regular basis and were surveyed using web interviewing (Nagelhout et al., 2010).

Before the implementation of smoke-free legislation in Ireland, England, and the Netherlands, 3,754 smokers aged 18 years and older were surveyed. Smokers were defined as having smoked at least 100 cigarettes in their lifetime and currently smoked at least once per month. One year later, 2,826 respondents (75.3\%) completed the first follow-up survey. Of those, 2,219 (78.5\%) completed the second follow-up survey. See Figure 1 for a timeline of the survey waves, sample sizes, and smoke-free legislation implementation dates per country. Smokers who were lost to follow-up were younger $(M=39.8, S D=15.2)$ than smokers who were followed-up ( $M=43.6, S D=14.1 ; t=7.77, p<0.001)$ and smokers who were lost to 
follow-up were more often weekly bar visitors $\left(\chi^{2}=30.66, p<0.001\right)$ and more likely to be employed $\left(\chi^{2}=4.46, p=0.035\right)$.

Figure 1: Timeline of the survey waves, sample sizes, and smoke-free legislation implementation dates for Ireland, England, and the Netherlands.

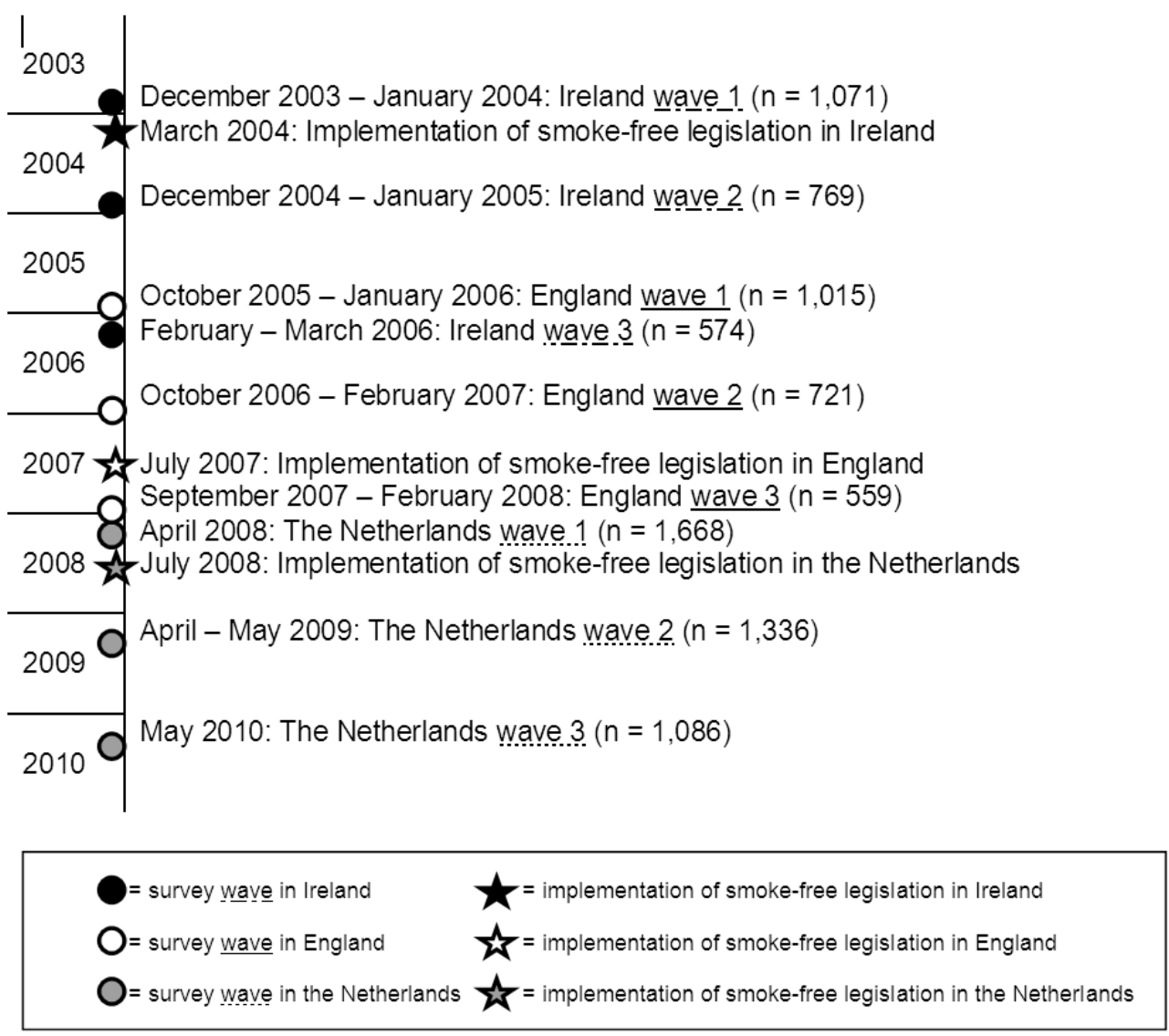

\section{Measurements}

Gender, age, educational level, bar visiting, employment, and heaviness of smoking were assessed in the surveys. Age at recruitment was categorised into four groups: 18 to 24,25 to 39,40 to 54 , and 55 years and older. Education was categorised into three levels (low, moderate, and high) that were only partly comparable across the three countries because of differences in educational systems. Bar visiting was categorised as weekly and non-weekly visiting. The Heaviness of Smoking Index $(\mathrm{HSI})$ was created as the sum of two categorical measures: number of cigarettes smoked per day and time before smoking the first cigarette of the day (Heatherton, Kozlowski, Frecker, Rickert, \& Robinson, 1989). HSI was categorised as low (0 to 1), 
moderate (2 to 4), and high (5 to 6).

Quit attempts were assessed at waves 2 and 3 with the question "Have you made any attempts to stop smoking since the last survey?" Success of quit attempts among respondents who attempted to quit smoking since the last survey was assessed at waves 2 and 3 by asking whether they were back to smoking or still stopped. Respondents who were back to smoking, but reported smoking less than once a month, were defined as quitters (Hyland, Borland et al., 2006).

\section{Analyses}

All analyses were weighted and performed with SAS version 9.2. The sampling weights were calibrated to smoking prevalence by gender-age groups within country, and the weighted data is thus representative of the adult smoker population within each country. Generalised Estimating Equation (GEE) models (Hardin \& Hilbe, 2003; Liang \& Zeger, 1986) were employed to test whether quit attempts and success differed between countries and across time periods. Correlations between observations from individuals who completed multiple waves was handled through the GEE approach, and all confidence intervals and p-values reported in this paper are based on the so-called "sandwich" variance estimator. All GEE models used binomial variations, the logit link, and an exchangeable correlation structure.

Since quit attempts and success were not measured at the baseline surveys, only two time periods were used in the GEE analyses. Quit attempts between waves 1 and 2 (first period) were compared with quit attempts between waves 2 and 3 (second period) and quit success at wave 2 (first period) was compared with quit success at wave 3 (second period). Smoke-free legislation was implemented in the first time period in Ireland and the Netherlands, and in the second time period in England.

Four GEE models were fitted. Dependent variables were quit attempts (Models 1 and 2) and quit success (Models 3 and 4). For Models 1 and 3 the independent variables were period, country, their interaction, gender, and age at recruitment. As mentioned above, sampling weights are calibrated to smoking prevalence by gender-age groups, and these two variables were included in all models, as recommended by survey sampling theory. Of key interest in this study is the period by country interaction, as it allows for formal testing of whether quit attempts and/or success evolved over the two time periods differently in each of the three countries. Models 2 and 4 were also adjusted for educational level at recruitment, and bar visiting, employment, and heaviness of smoking at prior wave (i.e. bar visiting, employment, and heaviness of smoking at wave 1 were used to model quitting in the first time period, and bar visiting, employment, and heaviness 
of smoking at wave 2 were used to model quitting in the second time period). Contrast statements were added to the four models to examine whether differences in quit attempts and quit success between periods were statistically significant in each of the three countries.

\section{RESULTS}

\section{Characteristics}

Baseline characteristics of respondents are shown in Table 1. There were significant differences between countries on all baseline characteristics, except for gender. Differences between countries were large for educational level and bar visiting. Smokers from Ireland had the lowest educational level and visited bars most often. Smokers from the Netherlands had the highest educational level and visited bars least often. Note that educational levels were only partly comparable across the three countries because of differences in educational systems. To account for differences in characteristics between countries, GEE models 2 and 4 are adjusted for all covariates.

Table 1: Baseline characteristics of respondents by country (\%).

\begin{tabular}{|c|c|c|c|c|}
\hline & $\begin{array}{l}\text { Ireland } \\
(n=574)\end{array}$ & $\begin{array}{l}\text { England } \\
(\mathrm{n}=559)\end{array}$ & $\begin{array}{l}\text { The Netherlands } \\
(n=1,086)\end{array}$ & $\begin{array}{l}\text { Between country } \\
\text { differences }\end{array}$ \\
\hline \multicolumn{5}{|l|}{ Gender } \\
\hline Male & 500 & 522 & 529 & \multirow{2}{*}{$\begin{array}{l}\chi^{2}(2)=1.32 \\
p=0.518\end{array}$} \\
\hline Female & 50.0 & 47.8 & 47.1 & \\
\hline \multicolumn{5}{|l|}{ Age group } \\
\hline 18-24 years old & 14.6 & 11.6 & 86 & \multirow{4}{*}{$\begin{array}{l}\chi^{2}(6)=21.30 \\
p=0.002\end{array}$} \\
\hline 25-39 years old & 30.6 & 29.7 & $\begin{array}{l}0.0 \\
27.0\end{array}$ & \\
\hline $40-54$ years old & 32.7 & 34.9 & 38.3 & \\
\hline $\begin{array}{l}55 \text { years and older } \\
\text { Educational level }\end{array}$ & 22.1 & 23.7 & 26.2 & \\
\hline Low & & & & \multirow{4}{*}{$\begin{array}{l}\chi^{2}(4)=113.17 \\
p<0.001\end{array}$} \\
\hline Moderate & 65.8 & 55.9 & 39.7 & \\
\hline High & 22.0 & 27.7 & 41.4 & \\
\hline \multicolumn{4}{|l|}{ Bar visiting } & \\
\hline Weekly & 610 & 0 & 180 & \multirow{3}{*}{$\begin{array}{l}\chi^{2}(2)=303.08 \\
p<0.001\end{array}$} \\
\hline Non-weekly & 390 & 69.0 & 811 & \\
\hline \multicolumn{4}{|l|}{ Employment } & \\
\hline Yes & 64.6 & 71.7 & 58.5 & \multirow{3}{*}{$\begin{array}{l}\chi^{2}(2)=28.48 \\
p<0.001\end{array}$} \\
\hline No & 35.4 & 28.3 & 41.5 & \\
\hline \multicolumn{4}{|l|}{ Heaviness of smoking } & \\
\hline 0 to 1 & 30.8 & 24.4 & 26.6 & \multirow{3}{*}{$\begin{array}{l}\chi^{2}(4)=15.04 \\
p=0.005\end{array}$} \\
\hline 2 to 4 & 58.5 & 67.7 & 66.2 & \\
\hline 5 to 6 & 10.7 & 79 & 7.1 & \\
\hline
\end{tabular}




\section{Quit attempts}

Figure 2 shows that more Irish smokers attempted to quit smoking in the first period (when the smoke-free legislation was implemented) (50.5\%) than in the second period (36.4\%). In England and the Netherlands, the percentage of quit attempts remained at the same level. Within-country GEE contrasts (not shown in table) confirmed that the difference in quit attempts between periods was only significant for Ireland $(p<0.001)$. This difference remained highly significant after controlling for all covariates $(p=0.003)$.

The between-country GEE analyses shown in Table 2 (Models 1 and 2) revealed that there were significant differences in quit attempts between countries and periods, as indicated by the significant $\mathrm{p}$-values for the overall tests for country by period interactions. GEE Model 1 showed that in the first period there were more quit attempts in Ireland than in England $(O R=1.77, p<0.001)$ and fewer quit attempts in the Netherlands than in Ireland $(O R=0.54, p<0.001)$. These differences remained statistically significant in Model 2 that controlled for all covariates (OR Ireland versus England $=1.76, p=0.001$; OR the Netherlands versus Ireland $=0.55$, $p<0.001$ ). Significant covariates were age and employment. Smokers aged 40 to 54 years were less likely to attempt to quit smoking than smokers aged 18 to 24 (OR $=0.60, p=0.003)$. Employed smokers were more likely to attempt to quit smoking than unemployed smokers $(\mathrm{OR}=1.32, \mathrm{p}=0.003)$.

\section{Quit success}

As can be seen in Figure 2, English smokers who attempted to quit smoking were more successful in the second period (when the smoke-free legislation was implemented) (47.3\%) than in the first period (26.4\%). In Ireland and the Netherlands, the level of quit success did not change between periods. Within-country GEE contrasts (not shown in table) confirmed that the differences in quit success between periods was only significant for England ( $p=0.011)$. This difference remained significant after controlling for all covariates $(p=0.006)$.

The between-country GEE analyses (Models 3 and 4 in Table 2) showed that there were significant differences in quit success between countries and periods, as indicated by the significant $p$-values for the overall tests for country by period interactions. Model 3 showed that fewer smokers successfully quitted in the second period in both Ireland $(O R=0.55, p=0.044)$ and the Netherlands $(O R=0.45, p$ $=0.003)$ than in England. The differences between the Netherlands and England remained statistically significant in Model 4 that controlled for all covariates $(\mathrm{OR}=$ $0.47, p=0.004)$, while the difference between Ireland and England was borderline significant in Model $4(O R=0.56, p=0.076)$. Significant covariates were gender and 
heaviness of smoking. Men were less successful in their quit attempts than women $(\mathrm{OR}=0.68, p=0.008)$. Moderate heavy smokers (HSI: 3 to 4$)$ were less successful in their quit attempt than not heavy smokers (HSI: 0 to 2$)(O R=0.70, p=0.024)$.

Figure 2: Percentage of quit attempts and quit success in two periodst in Ireland, England, and the Netherlands.
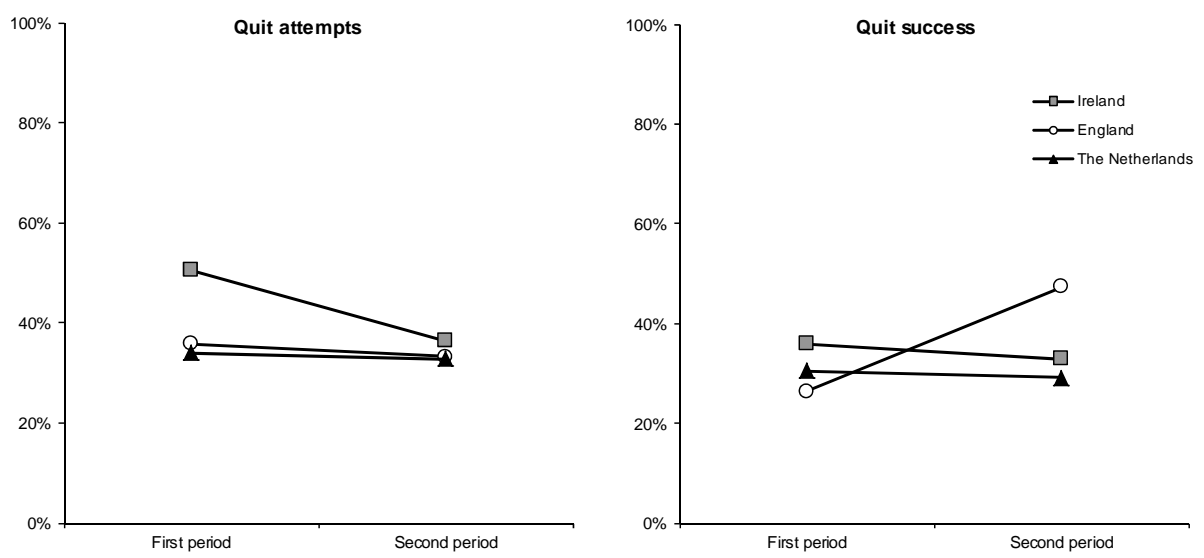

† National smoke-free legislation was implemented in the first period in Ireland and the Netherlands, and in the second period in England.

Table 2: GEE analyses of country and period predicting quit attempts and quit success (Odds Ratios with $95 \%$ confidence interval).

\begin{tabular}{|c|c|c|c|c|}
\hline & $\begin{array}{l}\text { Model 1† Quit } \\
\text { attempts }\end{array}$ & $\begin{array}{l}\text { Model } 2 \text { Quit } \\
\text { attempts }\end{array}$ & $\begin{array}{l}\text { Model } 3 \text { Quit } \\
\text { success }\end{array}$ & $\begin{array}{l}\text { Model } 4 \text { Quit } \\
\text { success }\end{array}$ \\
\hline First period: & 1.77 (1.28 to & 1.76 (1.26 to & $1.55(0.92$ to & $1.52(0.91$ to \\
\hline $\begin{array}{l}\text { Ireland versus England } \\
\text { First period: }\end{array}$ & $\frac{2.46)^{\star \star \star}}{0.95(0.72 \text { to }}$ & $\frac{2.47)^{\star \star}}{0.97(0.74 \text { to }}$ & $\frac{2.59)}{1.22(0.76 \text { to }}$ & $\frac{2.53)}{1.27(0.77 \text { to }}$ \\
\hline $\begin{array}{l}\text { The Netherlands versus } \\
\text { England }\end{array}$ & 1.26) & 1.29) & 1.96) & 2.11) \\
\hline First period: & 0.54 (0.42 to & 0.55 (0.42 to & 0.79 (0.53 to & 0.84 (0.55 to \\
\hline $\begin{array}{l}\text { The Netherlands versus } \\
\text { Ireland }\end{array}$ & $0.69)^{\star \star \star}$ & $0.73)^{\star \star \star}$ & 1.16) & $1.28)$ \\
\hline $\begin{array}{l}\text { Second period: } \\
\text { Ireland versus England }\end{array}$ & $\begin{array}{l}1.11(0.79 \text { to } \\
1.56)\end{array}$ & $\begin{array}{l}1.19(0.83 \text { to } \\
1.72)\end{array}$ & $\begin{array}{l}0.55(0.31 \text { to } \\
0.98)^{*}\end{array}$ & $\begin{array}{l}0.56(0.30 \text { to } \\
1.06)\end{array}$ \\
\hline Second period: & 1.00 (0.76 to & 1.07 (0.80 to & $0.45(0.27$ to & 0.47 (0.28 to \\
\hline $\begin{array}{l}\text { The Netherlands versus } \\
\text { England }\end{array}$ & 1.33) & 1.42) & $0.76)^{\star \star}$ & $0.78)^{\star \star}$ \\
\hline Second period: & 0.90 (0.70 to & 0.89 (0.66 to & 0.83 (0.52 to & $0.83(0.49$ to \\
\hline $\begin{array}{l}\text { The Netherlands versus } \\
\text { Ireland }\end{array}$ & 1.17) & 1.21) & 1.31) & 1.41) \\
\hline & $\begin{array}{l}<0.001^{\mathrm{a}} ; 0.490^{\mathrm{b}} \\
0.012^{\mathrm{c}}\end{array}$ & $\begin{array}{l}<0.001^{\mathrm{a}} ; 0.434^{\mathrm{b}} \\
0.046^{\mathrm{c}}\end{array}$ & $\begin{array}{l}0.226^{\mathrm{a}} ; 0.003^{\mathrm{b}} ; \\
0.021^{\mathrm{c}}\end{array}$ & $\begin{array}{l}0.280^{\mathrm{a}} ; 0.002^{\mathrm{b}} ; \\
0.021^{\mathrm{c}}\end{array}$ \\
\hline
\end{tabular}

† Model 1 and 3: Adjusted for gender and age. Model 2 and 4: Adjusted for gender, age, educational level, bar visiting, employment, and heaviness of smoking.

${ }^{*} p<0.05,{ }^{* *} p<0.01,{ }^{* * *} p<0.001$

a $p$-value for overall 2 df test for country

$b p$-value for overall $1 d f$ test for period

$c p$-value for overall $2 d f$ test for country by period interaction 


\section{DISCUSSION}

In this study, we found that Irish smokers made more quit attempts in the period in which comprehensive smoke-free workplace legislation was implemented than in the period after the implementation. This suggests that if the smoke-free legislation has increased quit attempts in Ireland, the effect was not sustained. This finding is in line with the Irish national survey showing a large temporary decline in smoking prevalence after the implementation of smoke-free legislation (Office of Tobacco Control, 2010).

In England, we found more quit success in the period in which comprehensive smoke-free workplace legislation was implemented than in the period before. This suggests that the smoke-free legislation increased quit success. Previous research from England found a small temporary increase in quit attempts after the smokefree legislation (Hackshaw et al., 2010) and no effects on smoking prevalence (Lee et al., 2011). We did not find an increase in quit attempts in our study, which can be explained by the fact that the increase that was found in the earlier study was small and their study sample was three times larger. Also, the English legislation may not have had an effect on quit attempts because many English workplaces were already smoke-free when the national legislation was implemented (Bauld, 2011; Lee et al., 2011). The reduction in value-added tax on nicotine replacement therapy in England may have helped smokers who attempted to quit smoking to be more successful. More research is needed on the synergistic effects of smoke-free legislation with other tobacco control interventions before strong conclusions can be made (Levy \& Friend, 2003).

We found no changes in quit attempts or quit success between the period in which partial smoke-free hospitality industry legislation was implemented in the Netherlands and the period after the implementation. This suggests that the smoke-free legislation in the Netherlands either did not have an impact on smoking cessation or that there was a sustained impact. Since the percentage of quit attempts $(33 \%)$ and quit success $(30 \%)$ in the Netherlands was in both periods comparable to the percentage of quit attempts (36\%) and quit success $(30 \%)$ in the other countries in the periods in which no legislation was implemented, we believe it is more likely that the smoke-free legislation in the Netherlands had no impact on smoking cessation. This may be explained by the limited scope of the legislation (the hospitality industry) and the fact that only $19 \%$ of Dutch smokers visited bars weekly. Previous research found small short-term increases in quit attempts and success after the implementation of smoke-free hospitality industry legislation in the Netherlands (Nagelhout, Willemsen et al., 2011). The fact that we did not find these small short-term increases could be explained by the smaller sample size in our study. 
Smoking cessation can be an important effect of smoke-free legislation (Callinan et al., 2010). However, smoke-free legislation is implemented primarily to protect non-smokers from exposure to tobacco smoke pollution. In the Netherlands, the implementation of smoke-free legislation was not accompanied by a campaign about tobacco smoke pollution. This may have resulted in low levels of support for the legislation and high levels of non-compliance among bars (Gonzalez \& Glantz, 2011; Nagelhout, Mons et al., 2011). Although an intensive smoking cessation campaign ran during the implementation of the Dutch legislation, there was no measurable impact on smoking prevalence (Nagelhout, Willemsen et al., 2011). In Ireland, it was considered a missed opportunity that cessation support was not emphasised in the mass media campaign (Kosir \& Gutierrez, 2009). Campaign evaluations should assess whether mentioning cessation support in mass media campaigns about smoke-free legislation can stimulate smoking cessation without diluting the message that the legislation is implemented for the protection of nonsmokers.

In most quasi-experimental studies, a control country is used in which no legislation is implemented and in which cessation behaviour is stable. Unfortunately, there were no data available from an ITC Europe country with three annual waves during which no legislation was implemented and cessation behaviour was thus stable. The lack of data on smoking cessation before the implementation of smoke-free legislation in Ireland and the Netherlands precluded conclusions about before-and-after differences in smoking cessation in these countries. Also, stronger conclusions could have been drawn about the comparative impact of comprehensive and partial smoke-free legislation when data from more countries was available. Furthermore, we have not controlled for intention to quit smoking in our GEE models. This could be seen as a limitation, because intention to quit smoking is an important causal predictor of smoking cessation (Hyland, Borland et al., 2006). However, including intention to quit in the models would overcorrect the models, because smoke-free legislation makes smokers more likely to quit (Hackshaw et al., 2010). Finally, more than $40 \%$ of baseline respondents were lost to follow-up by the third survey. These respondents were younger, were more often weekly bar visitors, and more likely to be employed. Therefore, our results may not be fully generalisable to the smoker population in the three countries.

We found an increase in quit success after the implementation of comprehensive smoke-free legislation in England. Also, there were indications that there might have been a temporary increase in quit attempts after the implementation of comprehensive smoke-free legislation in Ireland. The most likely explanation for the unchanged percentage of quit attempts and quit success after 
the implementation of partial smoke-free legislation in the Netherlands is that the legislation had no impact on smoking cessation. It would appear, therefore, that as well as offering greater protection from tobacco smoke pollution for all employees, comprehensive smoke-free legislation might also maximise quitting behaviour. Therefore, we recommend that countries implement comprehensive smoke-free legislation. 


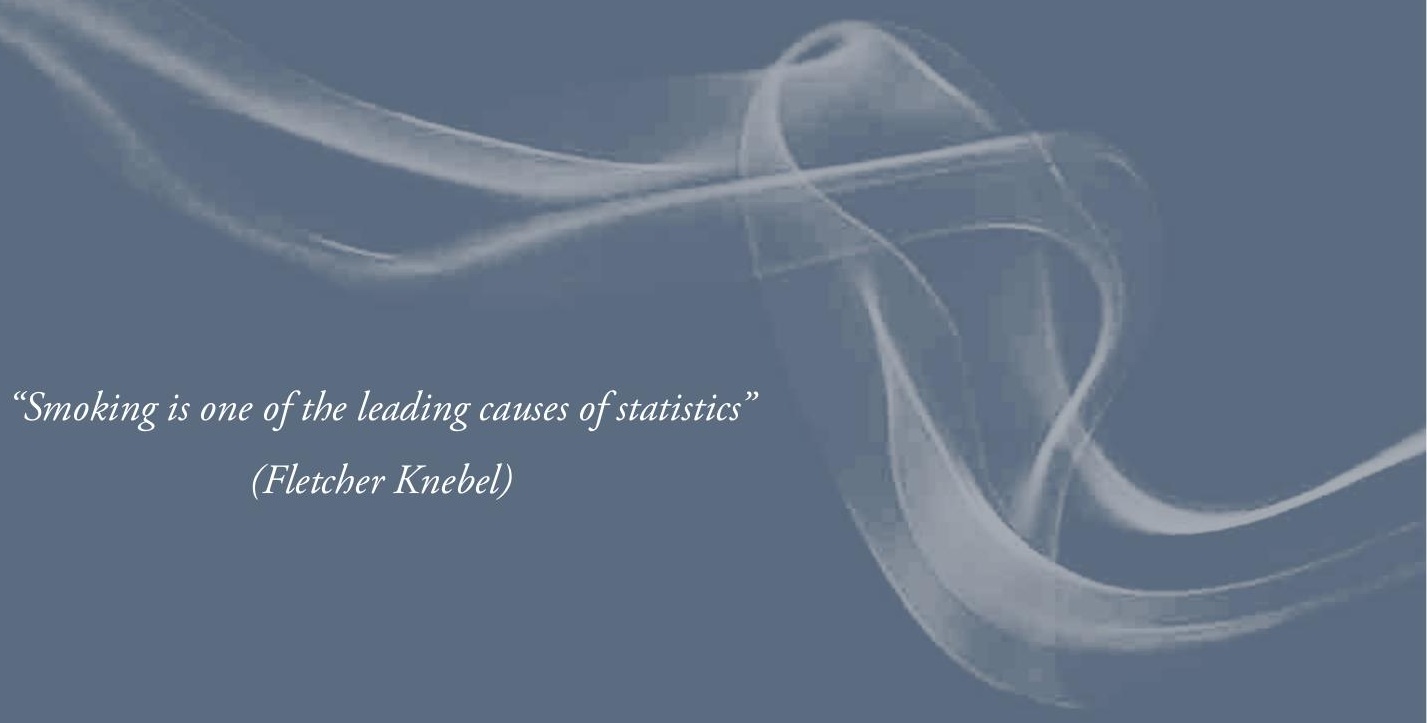




\section{Chapter 5}

\section{$\sim \sim \sim$ \\ Smoke-free legislation and other effective policies}

\section{Published as:}

Nagelhout, G. E., Levy, D. T., Blackman, K., Currie, L., Clancy, L., \& Willemsen, M. C. (2012). The effect of tobacco control policies on smoking prevalence and smoking-attributable deaths. Findings from the Netherlands SimSmoke Tobacco Control Policy Simulation Model. Addiction, 107, 407-416. 
The aim of this study was to develop a simulation model projecting the effect of tobacco control policies in the Netherlands on smoking prevalence and smoking-attributable deaths. Netherlands SimSmoke - an adapted version of the SimSmoke simulation model of tobacco control policy uses population, smoking rates and tobacco control policy data for the Netherlands to predict the effect of seven types of policies: taxes, smokefree legislation, mass media, advertising bans, health warnings, cessation treatment, and youth access policies. Outcome measures were smoking prevalence and smoking-attributable deaths. With a comprehensive set of policies, as recommended by MPOWER, smoking prevalence can be decreased by as much as $21 \%$ in the first year, increasing to a $35 \%$ reduction in the next twenty years and almost $40 \%$ by 30 years. By 2040 , 7,706 deaths can be averted in that year alone with the stronger set of policies. Without effective tobacco control policies, a million lives will be lost to tobacco-related diseases between 2011 and 2040. Of those, 145,000 can be saved with a comprehensive tobacco control package. Smoking prevalence and smoking-attributable deaths in the Netherlands can be substantially reduced through tax increases, smoke-free legislation, high intensity media campaigns, stronger advertising bans and health warnings, comprehensive cessation treatment, and youth access laws. The implementation of these FCTC/MPOWER recommended policies could be expected to show similar or even larger relative reductions in smoking prevalence in other countries which currently have weak policies. 


\section{INTRODUCTION}

Globally, it is estimated that 5 million premature deaths each year are attributable to smoking, with trends driving a rise to 10 million deaths per year by the 2030s (Ezzati \& Lopez, 2003). Substantial evidence indicates that higher cigarette taxes, smokefree legislation, advertising bans, and well funded media campaigns can appreciably reduce adult smoking rates, especially when combined as a comprehensive strategy (Hopkins et al., 2001; Levy, Chaloupka, \& Gitchell, 2004). Evidence is mounting for health warnings (Hammond, 2011) and cessation treatment coverage (Reda, Kaper, Fikretler, Severens, \& Schayck, 2009).

The World Health Organization has set out the Framework Convention on Tobacco Control (FCTC). The MPOWER Report (World Health Organization, 2008a) has defined a set of policies that are consistent with the FCTC. MPOWER suggests that each nation impose taxes on cigarettes that constitute at least $70 \%$ of the retail price, require large, bold and graphic health warnings, provide broad access to cessation treatments, conduct a well-funded mass media campaign, and implement and enforce comprehensive smoke-free legislation and advertising restrictions.

The Netherlands ratified the FCTC in January 2005. Since 2000, the Netherlands has increased taxes on cigarettes, strengthened advertising restrictions and health warnings on cigarette packs, implemented smoke-free legislation and mass media campaigns, and offered a quitline. Although considerable progress has been made, Dutch tobacco control policies are not compliant with WHO guidelines. For example, taxes on cigarettes are $57 \%$ of the retail price in the Netherlands (World Health Organization, 2008a) rather than the 70\% recommended by MPOWER guidelines. Also, the Dutch smoke-free legislation does not apply to all bars and allows for designated smoking rooms in all workplaces. This study uses a simulation model to examine the effect of Dutch policies implemented since 1996 and to predict the effect of implementing stricter policies fully consistent with WHO guidelines.

Most statistical studies of tobacco control policies have examined the effect of only one or, at most, two policies (e. g. Hu, Sung, \& Keeler, 1995a, b) because the ability to untangle the effects of tobacco control policies on smoking rates is often limited by a lack of data or models that cannot statistically distinguish the effects. Simulation models combine information from different sources to provide a useful tool for examining how the effects of public policies unfold over time in complex social systems (Homer \& Hirsch, 2006). Simulation models examining the effect of tobacco control policies have been developed by Mendez and Warner (Mendez \& Warner, 2004; Mendez, Warner, \& Courant, 1998), Tengs et al. (Tengs, Osgood, \& Chen, 2001), Ahmad (Ahmad, 2005; Ahmad \& Billimek, 2005) and Levy et al (Levy, 
Bauer, \& Lee, 2006; Levy, Nikolayev, \& Mumford, 2005). In the Netherlands, the Chronic Disease Model has been used to examine the impact of tobacco control policies on smoking rates and health risks, but has not modeled the full set of MPOWER interventions (Hoogenveen, Van Baal, Boshuizen, \& Feenstra, 2008; Van Genugten et al., 2003). The SimSmoke model of Levy et al. simultaneously considers a broader array of public policies than other models (Levy, Chaloupka, Gitchell, Mendez, \& Warner, 2002) and has been validated in several countries (Levy, Benjakul, Ross, \& Ritthiphakdee, 2008; Levy et al., 2010) and states (Levy, Bauer, Ross, \& Powell, 2007; Levy, Hyland, Higbee, Remer, \& Compton, 2007; Levy, Tworek, Hahn, \& Davis, 2008).

In order to examine past trends in smoking rates and the potential effect of tobacco control policies on future smoking rates, a modified version of SimSmoke has been developed for the Netherlands. The Netherlands is an interesting case, since Dutch tobacco control policy has seen a marked improvement between 2000 and 2004 , followed by a long period of stagnation. This provides a good setting to demonstrate the ability of the SimSmoke model to do two things: to calculate the impact of real policy changes and to examine what could potentially be accomplished with full implementation of MPOWER policies. The Netherlands has strong tobacco control policies relative to many of the other high income countries (Joossens \& Raw, 2011).

Using data from the Netherlands on population, birth rates, death rates, and smoking rates, the model predicts future smoking rates. Using data on relative mortality risks, the model also estimates the number of smoking-attributable deaths (SADs). Netherlands SimSmoke shows the effect of policies implemented since 1996. The model also assesses the effect of MPOWER interventions and youth access restrictions. The following research questions are examined in this study:

1. What would have been the smoking prevalence and SADs in 2010 if tobacco control policies had remained unchanged from their 1996 levels?

2. What were the effects of tobacco control policies implemented between 1996 and 2010 on smoking prevalence and SADs in 2010?

3. What will be the smoking prevalence and SADs in 2040 if tobacco control policies remain unchanged from their 2010 levels?

4. What would be the effects of MPOWER policies implemented in 2011 on smoking prevalence and SADs in 2040? 


\section{METHODS}

\section{Basic model}

SimSmoke includes a population model, a smoking model, a smoking-attributable death model, and policy modules (Levy et al., 2006; Levy et al., 2005). The model begins in a baseline year with the population divided into smokers, never smokers, and previous smokers by age and gender. The baseline year for the Netherlands model was chosen as 1996 because a large survey was conducted and major policy changes had not yet been implemented.

A discrete time, first-order Markov process is employed to project future population growth through fertility and deaths, and to project smoking rates. Individuals are classified as never smokers from birth until they initiate smoking or die. They may evolve from current to former smoker through cessation or may return to smoker through relapse. The extent of relapse depends on the number of years since quitting. Smoking rates, and thereby smoking-attributable deaths, change over time in response to changes in tobacco control policies.

\section{Population model}

Population (1996), mortality (1999), and fertility (2008) data by age and gender were obtained from Statistics Netherlands (CBS). Population projections from the model for the year 2010 were close to 2010 estimates.

\section{Smoking model}

The 1996 data from the Dutch Continuous Survey of Smoking Habits (DCSSH) was used to obtain smoking prevalence and cessation rates. This is a cross-sectional population survey of respondents aged 15 years and older that is used to monitor smoking habits of the Dutch population, using weekly measurements (Willemsen et al., 2002). The DCSSH is conducted by TNS NIPO for the Dutch expert centre on tobacco control (STIVORO). Data on smoking prevalence from the DCSSH were available for each year from 1988 to 2010 by gender and age group. The interviewing method changed in 2001 from face-to-face to web surveying and the sampling method changed in 2009 from household to person-based sampling.

Net initiation rates at each age through age 30 were measured as the difference between the smoking rate at that age year and the rate at the previous age year. Cessation rates were measured after age 30 as the number of ex-smokers who quit in the last year divided by the number of those smoking one year ago (current smokers plus those quitting in the last year). U.S. relapse rates were used, because data were not available for the Netherlands, but the rates were calibrated to the model. 


\section{Smoking-attributable death model}

Smoking-attributable deaths (SADs) by age, gender and smoking status were calculated from death rates, smoking rates, and relative risks. The number of current and former smokers at each age was multiplied by their respective excess risk and summed to obtain total SADs.

Large scale studies of the relative risk of smoking were not available for the Netherlands. However, because the Netherlands has a similar smoking history to the U.S. and is a high income country, we used relative risk estimates from the U.S. Cancer Prevention Study II (Thun et al., 1997) and other high income countries (Doll, Peto, Boreham, \& Sutherland, 2004).

\section{Policy modules}

Policy effect sizes are in terms of percentage reductions applied to smoking prevalence in the year when a policy is implemented and, unless otherwise specified, applied to initiation and cessation rates in future years. The effect sizes are shown relative to the absence of any policy. They are based on literature reviews, advice of an expert panel and previous model validation. As a high income country, the effects for the Netherlands were determined primarily from studies for that country and other high income countries. Policies and potential effect sizes in the Netherlands are summarised in Table 1. 
Table 1: Policies, description and effect sizes of the SimSmoke model and policies in the Netherlands.

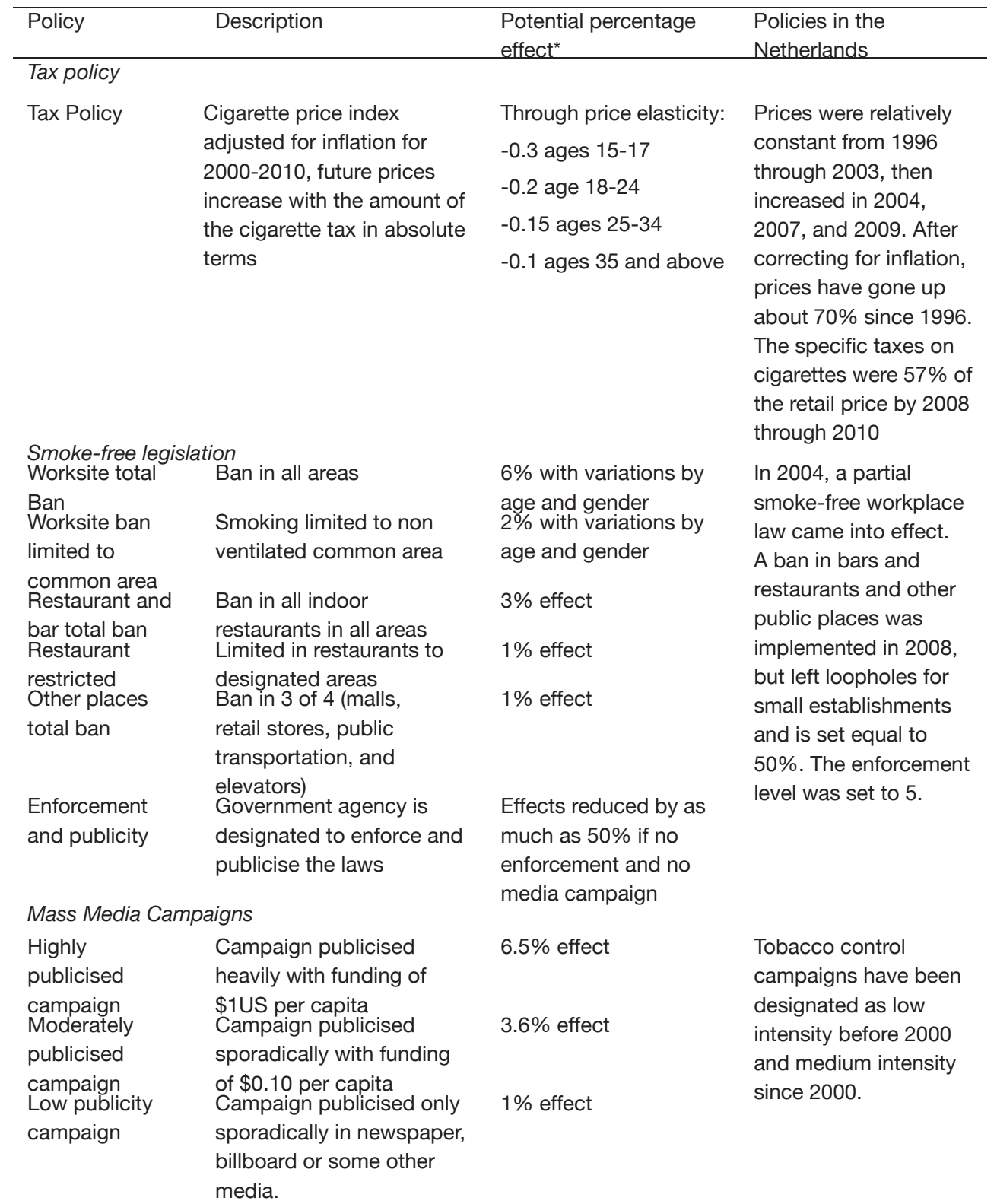


Table 1 (continued)

Marketing Bans

\begin{tabular}{|c|c|c|c|}
\hline & $\begin{array}{l}\text { Ban is applied to } \\
\text { television, radio, print, } \\
\text { billboard, in-store displays, } \\
\text { sponsorships and free } \\
\text { samples }\end{array}$ & $\begin{array}{l}5 \% \text { reduction in } \\
\text { prevalence, } 6 \% \text { reduction } \\
\text { in initiation, } 3 \% \text { increase } \\
\text { in cessation rates }\end{array}$ & $\begin{array}{l}\text { Marketing is } \\
\text { considered a weak } \\
\text { ban from } 1996 \\
\text { increasing to } 50 \% \\
\text { of a moderate }\end{array}$ \\
\hline $\begin{array}{l}\text { Moderate } \\
\text { Marketing Ban }\end{array}$ & $\begin{array}{l}\text { Ban is applied to all media } \\
\text { television, radio, print, } \\
\text { billboard }\end{array}$ & $\begin{array}{l}3 \% \text { reduction in } \\
\text { prevalence, } 4 \% \text { reduction } \\
\text { in initiation, } \\
2 \% \text { increase in cessation }\end{array}$ & $\begin{array}{l}\text { ban in } 2003 \text { and a } \\
100 \% \text { moderate } \\
\text { ban in 2008. The } \\
\text { enforcement level }\end{array}$ \\
\hline $\begin{array}{l}\text { Weak marketing } \\
\text { ban }\end{array}$ & $\begin{array}{l}\text { Ban is applied to some } \\
\text { of television, radio, print, } \\
\text { billboard }\end{array}$ & $\begin{array}{l}\text { rates } \\
1 \% \text { reduction in } \\
\text { prevalence and initiation } \\
\text { only }\end{array}$ & was set to 5 . \\
\hline $\begin{array}{l}\text { Enforcement } \\
\text { and publicity }\end{array}$ & $\begin{array}{l}\text { Government agency is } \\
\text { designated to enforce the } \\
\text { laws }\end{array}$ & $\begin{array}{l}\text { Effects reduced by as } \\
\text { much as } 50 \% \text { if no } \\
\text { enforcement }\end{array}$ & \\
\hline \multicolumn{4}{|l|}{ Health warnings } \\
\hline Strong & $\begin{array}{l}\text { Labels are large, bold and } \\
\text { graphic }\end{array}$ & $\begin{array}{l}2 \% \text { reduction in } \\
\text { prevalence, } 1 \% \text { reduction } \\
\text { in initiation, } 4 \% \text { increase }\end{array}$ & $\begin{array}{l}\text { Health warnings } \\
\text { are considered to } \\
\text { increase from low }\end{array}$ \\
\hline Moderate & $\begin{array}{l}\text { Warning covers at least } \\
1 / 3 \text { of both sides of } \\
\text { package, not bold or } \\
\text { graphic }\end{array}$ & $\begin{array}{l}\text { in cessation rate } \\
1 \% \text { reduction in } \\
\text { prevalence, } 0.5 \% \\
\text { reduction in initiation, } \\
2.5 \% \text { increase in } \\
\text { cessation }\end{array}$ & $\begin{array}{l}\text { through } 2001 \text { to } \\
\text { moderate in } 2002 \\
\text { and remaining at } \\
\text { that level. }\end{array}$ \\
\hline Weak & $\begin{array}{l}\text { Warning covers less than } \\
1 / 3 \text { of package, not bold or } \\
\text { graphic }\end{array}$ & $\begin{array}{l}1 \% \text { reduction in } \\
\text { prevalence and initiation } \\
\text { rates, } 1 \% \text { increase in }\end{array}$ & \\
\hline Publicity & $\begin{array}{l}\text { Health information is well } \\
\text { publicised }\end{array}$ & $\begin{array}{l}1 \% \text { additional effect on } \\
\text { prevalence and initiation } \\
\text { rate }\end{array}$ & \\
\hline \multicolumn{4}{|c|}{ Cessation Treatment Policy } \\
\hline $\begin{array}{l}\text { Cessation } \\
\text { Treatment Policy }\end{array}$ & $\begin{array}{l}\text { Complete availability } \\
\text { and reimbursement } \\
\text { of pharmaco- and } \\
\text { behavioural treatments, } \\
\text { quitlines, and brief } \\
\text { interventions }\end{array}$ & $\begin{array}{l}4.75 \% \text { reduction in } \\
\text { prevalence, } 39 \% \text { increase } \\
\text { in cessation rate }\end{array}$ & $\begin{array}{l}\text { The Netherlands has } \\
\text { had NRT available } \\
\text { in pharmacies and } \\
\text { Buproprion by } \\
\text { prescription since } \\
2001 \text {, a quitline since } \\
2000 \text {, and cessation } \\
\text { treatment from some } \\
\text { health care providers } \\
\text { since } 1996 \text {. }\end{array}$ \\
\hline
\end{tabular}


Youth Access Restrictions

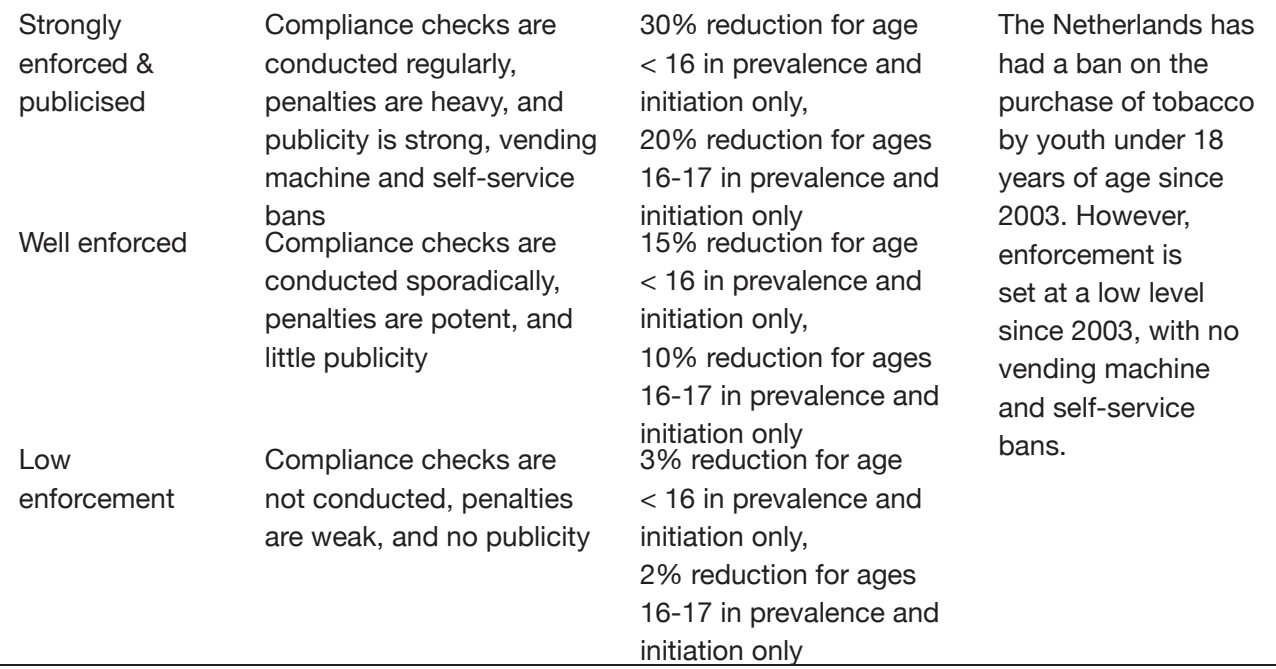

* Unless otherwise specified, the same percentage effect is applied as a percentage reduction in the prevalence and initiation rate and a percentage increase in the cessation rate, and is applied to all ages and both genders. The effect sizes are shown relative to the absence of any policy. 


\section{Analyses}

The model estimates the effects over time for two primary outcomes: smoking prevalence and SADs. The model estimates these outcomes for the tracking period, from 1996 to 2010, and projects future outcomes for 2011 through 2040.

Based on comparing the actual to the predicted smoking prevalence rates from 1996 to 2000 , we calibrated the model by adjusting the first year cessation rates downward, increasing the relapse rate of first year cessation from $50 \%$ to $65 \%$ for males and females, and also modifying the rates to $40 \%$ at ages above 65 . To validate the model, we compared the predicted smoking rates overall and by gender and age to annual smoking rates by age and gender from the yearly DCSSH. More information about the model validation can be found in the full Netherlands SimSmoke report (Levy, Blackman, Currie, Clancy, \& Willemsen, 2011).

The effect of past policies from 1996 to 2010 was examined relative to a counterfactual scenario, where no tobacco control policies are implemented. In the model, we set policies through 2010 to their levels in 1996. The difference between the smoking rate and SADs with policies held constant at their 1996 levels and with the actual policies in place yields the net effect of policies implemented since 1996. For the role of single policies, we compared the scenario with only that policy implemented (in the year in which it was implemented) to the no policy scenario.

Furthermore, the effect of implementing MPOWER policies in 2011 was examined relative to the status quo scenario, where tobacco control policies were maintained at their 2010 level. For SADs, we calculated deaths averted as the difference between the number of deaths under the new policy and the number of deaths under the status quo.

\section{RESULTS}

\section{Smoking prevalence from 1996 to 2010}

Between 1996 and 2010, the model predicts that male smoking rates decrease from $38.4 \%$ to $29.0 \%$ (a $24.5 \%$ decrease in relative terms) and that female smoking decrease from $29.6 \%$ to $24.5 \%$ (a $17.2 \%$ relative decline). The male and female models generally tracked well with annual data on smoking prevalence (see for more details Levy et al., 2011). The model slightly under-predicts the actual reduction in smoking prevalence, which is a relative decline of $26.9 \%$ for males and $17.7 \%$ for females. The model is most accurate in the 25-64 year age range.

\section{Past policy tracking from 1996 to 2010}

When tobacco control policies were held constant at their 1996 levels, smoking prevalence decreased from $34.5 \%$ in 1996 , to $33.9 \%$ in 2000 , and to $32.1 \%$ in 2010 
(Table 2). Compared to the level with policies ( $27.0 \%$ by 2010$)$, smoking prevalence has been reduced by $16 \%$. SADs increased from 30,193 in 1996 to 33,502 in 2010 and would have been 465,031 in total over all years from 1996 to 2010. Compared to the status quo 1996 scenario, 7,078 deaths were averted from 1996 to 2010.

We considered the effects of individual policies at the levels at which they were implemented in the Netherlands between 1996 and 2010. The Dutch tax policy had the largest effect on smoking prevalence by 2010 (reducing prevalence by $9 \%$ ), followed by smoke-free legislation (reducing prevalence by $2 \%$ ) (Table 2 ). However, mass media campaigns had the largest effect on smoking prevalence by 2000. If only the tax policy had been implemented, SADs would have increased to 29,925 in 2000 and to 32,736 in 2010 and would have totaled 461,933 between 1996 and 2010. Therefore, 3,098 deaths were averted due to the tax policy. Due to the mass media campaigns, 1,217 deaths were averted, and due to the cessation treatment policy 1,113 deaths. The other policies averted between 0 (youth access restrictions) and 652 (smoke-free legislation) deaths between 1996 and 2010.

Table 2: Tracking the effect of past policies using SimSmoke on smoking prevalence for ages 18 and above and total smoking-attributable deaths, Netherlands, 1996-2010.

\begin{tabular}{lllll}
\hline & 1996 & 2000 & 2010 & Cumulative \\
\hline Smoking prevalence & & & & \\
Status quo 1996 & $34.5 \%$ & $33.9 \%$ & $32.1 \%$ & \\
Tax policy & $34.5 \%$ & $33.6 \%$ & $29.2 \%$ & \\
Smoke-free legislation & $34.5 \%$ & $33.9 \%$ & $31.4 \%$ & \\
Advertising ban & $34.5 \%$ & $33.9 \%$ & $31.8 \%$ & \\
Mass media campaigns & $34.5 \%$ & $33.5 \%$ & $31.6 \%$ & \\
Health warnings & $34.5 \%$ & $33.9 \%$ & $31.8 \%$ & \\
Youth access restrictions & $34.5 \%$ & $33.9 \%$ & $32.1 \%$ & \\
Cessation treatment policy & $34.5 \%$ & $33.9 \%$ & $31.6 \%$ & \\
All above policies combined & $34.5 \%$ & $33.2 \%$ & $27.0 \%$ & \\
Smoking-attributable deaths & & & & \\
Status quo 1996 & 30,193 & 29,948 & 33,502 & 465,031 \\
Tax policy & 30,193 & 29,925 & 32,736 & 461,933 \\
Smoke-free legislation & 30,193 & 29,948 & 33,273 & 464,379 \\
Advertising ban & 30,193 & 29,948 & 33,397 & 464,619 \\
Mass media campaigns & 30,193 & 29,948 & 33,319 & 463,814 \\
Health warnings & 30,193 & 29,948 & 33,387 & 464,493 \\
Youth access restrictions & 30,193 & 29,948 & 33,502 & 465,031 \\
Cessation treatment policy & 30,193 & 29,948 & 33,284 & 463,918 \\
All above policies combined & 30,193 & 29,925 & 31,888 & 457,953 \\
\hline
\end{tabular}




\section{Future policy projections from 2010 to 2040}

If tobacco control policies remain unchanged from their 2010 levels, as in the status quo scenario, male adult smoking is projected to decrease from $29.6 \%$ to $26.7 \%$ from 2010 to 2020 , to $24.6 \%$ by 2030 , and to $23.1 \%$ by 2040 (Table 3 ). In the status quo scenario, female adult smoking prevalence is projected to decrease from $24.9 \%$ in 2010 to $23.5 \%$ by 2020 , and to $20.9 \%$ by 2040 (Table 4). As is seen in Table 5, the estimated number of SADs in 2010 is 31,888 (21,990 for males and 9,898 for females). Male SADs are projected to reach their highest point in 2024 and female SADs reach their highest point in 2034. The total number of SADs is projected to rise to 33,013 by 2040 . From 2010 to 2040 , the cumulative SADs are projected to be $1,042,836$ in the status quo scenario.

When taxes are increased to $70 \%$ of the retail price, smoking rates are projected to decrease to $19.8 \%$ for males (Table 3) and $18.0 \%$ for females (Table 4) by 2040. Summing over years from 2011 through 2040, 40,839 deaths are averted by increased taxes by 2040 (Table 5). Increasing taxes to $70 \%$ of the retail price has the largest effect on smoking prevalence and SADs of all MPOWER policies.

Complete bans on smoking in worksites, bars, restaurant and other public places, along with strong enforcement, is predicted to decrease smoking prevalence to $21.8 \%$ for males and $19.7 \%$ for females by 2040 . In total, 27,278 deaths are averted by 2040 .

A comprehensive marketing ban, directed at all promotions as well as media advertising and having strong enforcement, will decrease smoking to $22.1 \%$ for males and $19.9 \%$ for females by 2040 . By $2040,21,104$ deaths are averted with a comprehensive marketing ban.

We considered a well-funded tobacco control campaign directed at all smokers relative to the current policy of a medium intensity campaign. The model predicts a decrease in smoking prevalence to $22.0 \%$ in males and $19.9 \%$ in females by 2040 , with 23,293 deaths averted by 2040 .

Implementing graphic health warnings consistent with MPOWER recommendations is projected to have the smallest impact on smoking prevalence. Smoking prevalence is projected to decrease to $22.9 \%$ for males and $20.6 \%$ for females by 2040, and 4,051 deaths are averted.

With the enforcement of youth access laws, the model predicts a decrease in smoking prevalence to $21.2 \%$ for males and $19.2 \%$ for females by 2040 . Youth access laws have the lowest impact on SADs. From 2010 to 2040, 603 deaths are projected to be averted.

The MPOWER combination of ready availability of nicotine replacement therapy and buproprion, the provision of quitlines, and the provision of cessation 
treatment is projected to reduce smoking prevalence to $21.6 \%$ in males and $19.4 \%$ in females by 2040 . Smoking cessation treatment policies can avert 37,566 SADs from 2010 to 2040 .

The final scenario projects the effect of implementing all MPOWER policies in 2011. By 2040, smoking prevalence is projected to decrease to $14.0 \%$ in males and $12.7 \%$ in females. If the number of lives saved is added up for all years between 2011 and 2040 , then 89,736 male and 55,033 female deaths are averted by 2040 , or a total of 144,769 deaths.

Table 3: SimSmoke Projections: male Smoking Prevalence for ages 18 and above, Netherlands, 20102040.

\begin{tabular}{|c|c|c|c|c|c|}
\hline & 2010 & 2011 & 2020 & 2030 & 2040 \\
\hline Status quo policies & $29.6 \%$ & $29.3 \%$ & $26.7 \%$ & $24.6 \%$ & $23.1 \%$ \\
\hline \multicolumn{6}{|l|}{ Independent policy effects } \\
\hline Tax at $70 \%$ of retail price & $29.6 \%$ & $26.9 \%$ & $24.0 \%$ & $21.5 \%$ & $19.8 \%$ \\
\hline Complete smoke-free air law & $29.6 \%$ & $28.0 \%$ & $25.5 \%$ & $23.4 \%$ & $21.8 \%$ \\
\hline Comprehensive marketing ban & $29.6 \%$ & $28.3 \%$ & $25.7 \%$ & $23.6 \%$ & $22.1 \%$ \\
\hline High-intensity tobacco control campaign & $29.6 \%$ & $28.3 \%$ & $25.7 \%$ & $23.5 \%$ & $22.0 \%$ \\
\hline Strong health warnings & $29.6 \%$ & $29.2 \%$ & $26.6 \%$ & $24.4 \%$ & $22.9 \%$ \\
\hline Strong youth access enforcement & $29.6 \%$ & $29.3 \%$ & $26.0 \%$ & $23.2 \%$ & $21.2 \%$ \\
\hline Cessation treatment policies & $29.6 \%$ & $28.5 \%$ & $25.4 \%$ & $23.1 \%$ & $21.6 \%$ \\
\hline \multicolumn{6}{|l|}{ Combined policy effects } \\
\hline All above policies combined & $29.6 \%$ & $23.2 \%$ & $19.0 \%$ & $16.0 \%$ & $14.0 \%$ \\
\hline \multicolumn{6}{|l|}{$\begin{array}{l}\% \text { Change in smoking prevalence from } \\
\text { status quo }\end{array}$} \\
\hline \multicolumn{6}{|l|}{ Independent Policy Effects } \\
\hline Tax at $70 \%$ of retail price & & $-8.3 \%$ & $-10.3 \%$ & $-12.5 \%$ & $-14.5 \%$ \\
\hline Complete smoke-free air law & & $-4.3 \%$ & $-4.7 \%$ & $-5.1 \%$ & $-5.5 \%$ \\
\hline Comprehensive marketing ban & & $-3.5 \%$ & $-3.8 \%$ & $-4.2 \%$ & $-4.5 \%$ \\
\hline High-intensity tobacco control campaign & & $-3.5 \%$ & $-4.0 \%$ & $-4.4 \%$ & $-4.8 \%$ \\
\hline Strong health warnings & & $-0.2 \%$ & $-0.6 \%$ & $-0.9 \%$ & $-1.0 \%$ \\
\hline Strong youth access enforcement & & $0.0 \%$ & $-2.7 \%$ & $-5.6 \%$ & $-8.2 \%$ \\
\hline Cessation treatment policies & & $-2.6 \%$ & $-5.2 \%$ & $-6.2 \%$ & $-6.6 \%$ \\
\hline \multicolumn{6}{|l|}{ Combined policy effects } \\
\hline All above policies combined & & $-20.8 \%$ & $-28.8 \%$ & $-35.0 \%$ & $-39.5 \%$ \\
\hline
\end{tabular}


Table 4: SimSmoke Projections: female smoking prevalence for ages 18 and above, Netherlands, 20102040.

\begin{tabular}{|c|c|c|c|c|c|}
\hline & 2010 & 2011 & 2020 & 2030 & 2040 \\
\hline Status quo policies & $24.9 \%$ & $24.8 \%$ & $23.5 \%$ & $22.1 \%$ & $20.9 \%$ \\
\hline \multicolumn{6}{|l|}{ Independent policy effects } \\
\hline Tax at $70 \%$ of retail price & $24.9 \%$ & $22.8 \%$ & $21.1 \%$ & $19.5 \%$ & $18.0 \%$ \\
\hline Complete smoke-free air law & $24.9 \%$ & $23.7 \%$ & $22.4 \%$ & $21.0 \%$ & $19.7 \%$ \\
\hline Comprehensive marketing ban & $24.9 \%$ & $23.9 \%$ & $22.6 \%$ & $21.2 \%$ & $19.9 \%$ \\
\hline High-intensity tobacco control campaign & $24.9 \%$ & $23.9 \%$ & $22.5 \%$ & $21.1 \%$ & $19.9 \%$ \\
\hline Strong health warnings & $24.9 \%$ & $24.7 \%$ & $23.3 \%$ & $21.9 \%$ & $20.6 \%$ \\
\hline Strong youth access enforcement & $24.9 \%$ & $24.8 \%$ & $22.9 \%$ & $20.9 \%$ & $19.2 \%$ \\
\hline Cessation treatment policies & $24.9 \%$ & $24.1 \%$ & $22.2 \%$ & $20.6 \%$ & $19.4 \%$ \\
\hline \multicolumn{6}{|l|}{ Combined policy effects } \\
\hline All above policies combined & $24.9 \%$ & $19.6 \%$ & $16.7 \%$ & $14.4 \%$ & $12.7 \%$ \\
\hline \multicolumn{6}{|c|}{$\%$ Change in smoking prevalence from status quo } \\
\hline \multicolumn{6}{|l|}{ Independent policy effects } \\
\hline Tax at $70 \%$ of retail price & & $-8.2 \%$ & $-10.1 \%$ & $-12.0 \%$ & $-13.7 \%$ \\
\hline Complete smoke-free air law & & $-4.3 \%$ & $-4.7 \%$ & $-5.2 \%$ & $-5.5 \%$ \\
\hline Comprehensive marketing ban & & $-3.5 \%$ & $-3.8 \%$ & $-4.2 \%$ & $-4.5 \%$ \\
\hline High-intensity tobacco control campaign & & $-3.5 \%$ & $-4.1 \%$ & $-4.5 \%$ & $-4.8 \%$ \\
\hline Strong health warnings & & $-0.2 \%$ & $-0.7 \%$ & $-0.9 \%$ & $-1.1 \%$ \\
\hline Strong youth access enforcement & & $0.0 \%$ & $-2.7 \%$ & $-5.5 \%$ & $-7.9 \%$ \\
\hline Cessation treatment policies & & $-2.6 \%$ & $-5.4 \%$ & $-6.7 \%$ & $-7.2 \%$ \\
\hline \multicolumn{6}{|l|}{ Combined policy effects } \\
\hline All above policies combined & & $-20.7 \%$ & $-28.9 \%$ & $-35.0 \%$ & $-39.3 \%$ \\
\hline
\end{tabular}


Table 5: Total smoking-attributable deaths, SimSmoke Netherlands, 2010-2040.

\begin{tabular}{llllll}
\hline & 2010 & 2020 & 2030 & 2040 & Cumulative \\
\hline $\begin{array}{llll}\text { Status quo policies } \\
\text { Independent policy effects }\end{array}$ & 31,888 & 34,572 & 36,227 & 33,013 & $1,042,836$ \\
$\quad$ Tax at 70\% of retail price & 31,888 & 33,742 & 34,266 & 30,864 & $1,001,997$ \\
$\quad$ Complete smoke-free air law & 31,888 & 33,992 & 34,901 & 31,691 & $1,015,557$ \\
$\quad$ Comprehensive marketing ban & 31,888 & 34,114 & 35,202 & 32,015 & $1,021,731$ \\
High-intensity tobacco control campaign & 31,888 & 34,095 & 35,095 & 31,841 & $1,019,543$ \\
Strong health warnings & 31,888 & 34,506 & 36,031 & 32,755 & $1,038,784$ \\
Strong youth access enforcement & 31,888 & 34,572 & 36,217 & 32,901 & $1,042,233$ \\
Cessation treatment policies & 31,888 & 33,933 & 34,399 & 30,722 & $1,005,269$ \\
Combined policy effects & & & & & \\
All above policies combined & 31,888 & 31,715 & 29,212 & 25,307 & 898,067 \\
& & & & & \\
Absolute change in attributable deaths from status quo & & & & \\
Independent policy effects & & & & & \\
$\quad$ Tax at 70\% of retail price & & 830 & 1,960 & 2,149 & 40,839 \\
Complete smoke-free air law & & 580 & 1,325 & 1,322 & 27,278 \\
Comprehensive marketing ban & & 458 & 1,025 & 998 & 21,104 \\
High-intensity tobacco control campaign & & 477 & 1,132 & 1,172 & 23,293 \\
Strong health warnings & & 66 & 196 & 259 & 4,051 \\
Strong youth access enforcement & & 0 & 10 & 112 & 603 \\
Cessation treatment policies & & 639 & 1,828 & 2,291 & 37,566 \\
Combined policy effects & & 2,857 & 7,015 & 7,706 & 144,769 \\
All above policies combined & & & & & \\
\hline
\end{tabular}




\section{DISCUSSION}

Using the SimSmoke model, we have presented a short and long-term projection of the role of various tobacco control policies in reducing smoking prevalence and the number of smoking-attributable deaths. Due to the policies that were implemented in the Netherlands between 1996 and 2010, smoking prevalence was reduced by $16 \%$ and 7,078 deaths were averted by the year 2010 . Almost half of these deaths $(3,098)$ were averted by the Dutch tax policy. Mass media campaigns $(1,217$ deaths averted) and the cessation treatment policy (1,113 deaths averted) also contributed. The low level of enforcement meant that the tobacco purchase ban for youth implemented in 2003 had negligible effects by 2010 . However, the number of deaths averted by youth access as well as the other policies implemented between 1996 and 2010 continues to grow into the future. By 2040, 148,000 deaths are averted as a result of the policies already implemented.

While the Netherlands has implemented some tobacco control policies, there is still ample scope to strengthen tobacco control policies consistent with the FCTC. Smoking prevalence can be decreased by as much as $21 \%$ in the first year, with a $35 \%$ reduction in the next twenty years and almost $40 \%$ by 30 years. Because of the natural history of tobacco-related illnesses, reductions in smoking prevalence have a relatively small impact on the number of smoking-attributable deaths in the short-term. By 2040, however, 7,706 deaths can be averted in that year alone with the stronger set of policies. Without effective tobacco control policies, a million lives will be lost to tobacco-related diseases between 2011 and 2040, of which 145,000 can be saved with a comprehensive tobacco control package.

\section{Study limitations and strengths}

The smoking prevalence results depend first on estimates of the rates of smoking in 1996, and initiation, cessation and relapse rates. Reliable data were not available for relapse rates in the Netherlands and are, therefore, based on U.S. rates. The estimated relative mortality risks for smokers are also based on studies from the U.S. (Thun et al., 1997) and other high income countries (Doll et al., 2004), but the rates may differ in the Netherlands. We did not consider differences by socioeconomic status, which may be expected to play an increasing role, nor did we consider the effect of immigration. Notably, the projections also do not include the additional deaths averted due to reductions in second-hand smoke exposure.

The policy modules depend on underlying assumptions, estimated parameters of the predicted effect on initiation and cessation, and assumptions about the interdependence of policies. While we have not conducted sensitivity analysis for the current model, we have estimated confidence intervals in previous 
work (Levy et al., 2004; Levy, Hyland et al., 2007). For example, many studies, with relatively consistent results, have been conducted on the effects of tax policies, and we gauge that the effect sizes can vary by as much as $25 \%$ above or below our current estimate. There are also many studies of smoke-free legislation, with results somewhat less consistent than those of prices, but still falling into similar ranges. Studies on media campaigns and advertising bans provide a broad range of estimates, and effect sizes might be expected to vary by about $50 \%$ around the current model estimates. Studies on the overall effect of health warnings and cessation treatment policies on smoking prevalence are generally lacking, such that bounds are $100 \%$ (from zero to twice) the current estimates. Studies need to be conducted not only to gauge the initial effect of policies, but also to understand how those policies unfold over time and depend on other policies in effect. Evidence indicates that public policies may be synergistic through their cumulative impact on social norms and their reinforcing effects on smokers' motivation to quit (Levy, Hyland et al., 2007). We have made the conservative assumption that the effects of each policy are a constant proportion of the smoking rate independent of other policies. However, the effects of health warnings, smoke-free legislation, and cessation treatment policies are magnified in the model by the publicity of a wellfunded media campaign. In turn, the effects of these other policies on the effect of a tobacco control campaign are intensified by the publicity that they generate.

Although the Netherlands has more extensive data than most EU nations, it will be important to continue to collect detailed information on smoking prevalence by age and gender. In particular, smoking rates at early ages are needed, as well as information on the prevalence of former smokers, so that cessation rates can be estimated and quitting can be tracked. In addition, it would be useful to monitor quit attempt behaviours, the use of pharmacotherapies and quitlines, the involvement of physicians in advising patients to quit, cigarette prices of the prominent brands and the amount of smuggled cigarettes, and compliance with marketing restrictions and smoke-free legislation. As this information is collected and monitored, the model can be adapted to more accurately reflect trends in smoking rates over time. Most important, improved data can be used to better monitor and evaluate policies, so that policies can be modified and adapted in reaction to successes and failures.

\section{Conclusion}

The SimSmoke results highlight the relative contribution of numerous policies to reducing the tobacco health burden. We have shown that policies have already had an important impact in the Netherlands, but there is room for improvement. In complying with MPOWER FCTC recommendations (i.e., increasing the tax to 
$70 \%$ of price, strengthening health warnings, media campaigns and the provision of cessation treatment, as well as the complete prohibition and enforcement of smoking in public and workplaces, industry marketing, and sales of tobacco to youth) the smoking rate is projected to fall by $40 \%$ in relative terms with 145,000 deaths averted by 2040. A large increase in taxes alone, or in the provision of cessation treatments, would substantially reduce the number of lives lost to smoking.

Implementation of the FCTC/MPOWER recommended policies could be expected to show similar or larger relative reductions in smoking prevalence in other countries which currently have weak policies. Substantial number of deaths can thereby be averted, especially in those countries which have a large smoking population. 


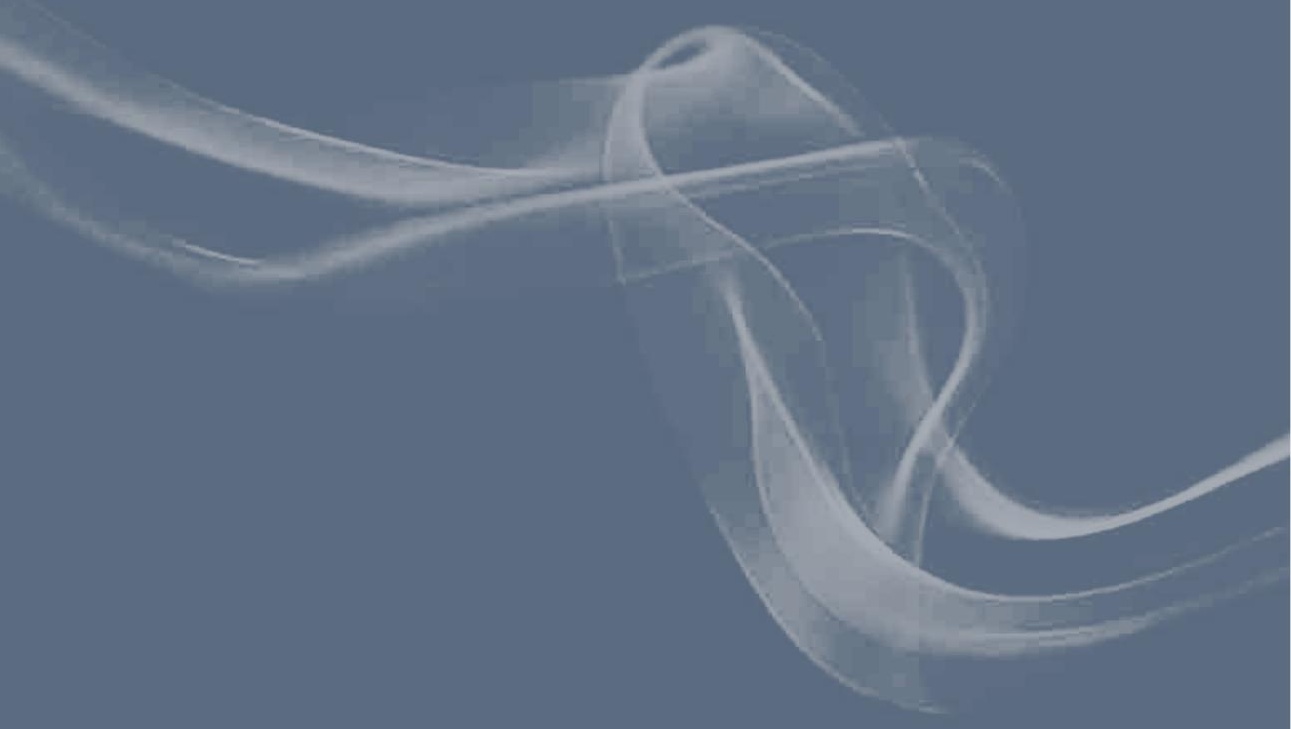


Part 2

\section{Individual pathways of change after smoke-free legislation}


"Like surfers, legislators and corporate officials who wish to change everyday social norms must wait for signs of a rising wave of cultural support, catching it at just the right time. Legislate too soon and they will be swamped by the swells of public resistance. Legislate too late and they will be irrelevant. Legislate at the right moment and an emerging cultural norm still tentatively struggling for authority . . . acquires much greater social force.

$$
\text { (Robert Kagan) }
$$




\section{Chapter 6}

\section{$\sim \sim \sim$ \\ Increases in support for smoke-free legislation}

\section{Published as:}

Mons, U., Nagelhout, G. E., Guignard, R., McNeill, A., Van den Putte, B., Willemsen, M. C., Brenner, H., Pötschke-Langer, M., \& Breitling, L. P. (2012). Comprehensive smoke-free policies attract more support from smokers in Europe than partial policies. European Journal of Public Health, 22(Suppl 1), 10-16. 
Support for smoke-free policies increases over time and particularly after implementation of the policy. In this study we examined whether the comprehensiveness of such policies moderates the effect on support among smokers. We analysed two waves (pre- and post-smoke-free legislation) of the International Tobacco Control (ITC) surveys in France, Germany, and the Netherlands, and two pre-legislation waves of the ITC surveys in UK as control. Of 6,903 baseline smokers, 4,945 (71.6\%) could be followed up and were included in the analyses. Generalised Estimating Equations (GEE) were used to compare changes in support from pre- to post-legislation to the secular trend in the control country. Multiple logistic regression models were employed to identify predictors of individual change in support. In France, the comprehensive smoking ban was associated with sharp increases in support for a total smoking ban in drinking establishments and restaurants that were above secular trends. In Germany and the Netherlands, where smoke-free policies and compliance are especially deficient in drinking establishments, only support for a total smoking ban in restaurants increased above the secular trend. Notable prospective predictors of becoming supportive of smoking bans in these countries were higher awareness of cigarette smoke being dangerous to others and weekly visiting of restaurants. Our findings suggest that smoke-free policies have the potential to improve support once the policy is in place. This effect seems to be most pronounced with comprehensive smoking bans, which thus might be the most valid option for policy-makers despite their potential for creating controversy and resistance in the beginning. 


\section{INTRODUCTION}

Despite tobacco smoke pollution (TSP) being a confirmed risk factor for several severe chronic diseases and acute symptoms (International Agency for Research on Cancer, 2004; U.S. Department of Health and Human Services, 2006), and a large body of evidence supporting the effectiveness of smoke-free policies in protecting non-smokers from TSP (Callinan et al., 2010), the implementation of smoking bans in the hospitality sector has been the subject of substantial public controversy in various countries in the past few years.

Public attitudes towards smoke-free policies are considered to be a key variable in the process of their adoption and with regards to compliance with the regulations (International Agency for Research on Cancer, 2009a). Before the enactment of smoke-free policies, supportive public attitudes are helpful in the process of passing the legislation. After implementation, increasing support might reflect changes in smoking-related norms. It is assumed that policies banning smoking reduce the visibility and perceived social acceptability of smoking (Albers et al., 2004; Alesci, Forster, \& Blaine, 2003; Brown et al., 2009), and that once people experience them, public support increases (Hyland et al., 2009). Most importantly, smokers being supportive of smoke-free policies are more likely to comply with the regulations (Nagelhout, Mons et al., 2011).

Previous cross-sectional and longitudinal studies have shown that among non-smokers and smokers, support for smoking bans generally follows a rising trend (Brooks \& Mucci, 2001; Hyland, Higbee et al., 2009; International Agency for Research on Cancer, 2009a; Osypuk \& Acevedo-Garcia, 2010), and increases particularly sharply after implementation of smoke-free policies, even if these are comprehensive and rigid and pre-legislation policy support had been low (Braverman, Aaro, Bontempo, \& Hetland, 2010; Cooper, Borland, Yong, \& Hyland, 2010; Edwards et al., 2008; Fong, Hyland et al., 2006; Hyland, Hassan et al., 2009; Larsson, Boethius, Axelsson, \& Montgomery, 2008; Lund, 2006; Palmersheim, Remington, \& Gundersen, 2006; Pursell et al., 2007; Rayens et al., 2007; Tang et al., 2003; Tang, Cowling, Stevens, \& Lloyd, 2004).

Some of these studies also investigated country differences in patterns of change in policy support: these multiple-country studies either employed a quasiexperimental design comparing countries with national smoke-free legislation with countries without such legislation (Brown et al., 2009; Fong, Hyland et al., 2006; Hyland, Hassan et al., 2009), or used respondents' self-reported information about local public smoking bans (Hyland et al., 2009). The quasi-experimental studies support a positive causal effect of comprehensive smoke-free legislation on policy support (Brown et al., 2009; Fong, Hyland et al., 2006; Hyland, Hassan et al., 2009). 
The findings of a study on the effect of self-reported local smoking restrictions implied a 'dose-response relationship', with smokers reporting smoking bans at several locations and/or for several years being more likely to support smoking bans than smokers who reported no or only few smoking restrictions (Hyland et al., 2009). These findings suggest that comprehensiveness of smoke-free policies is a relevant factor, but an alternative explanation could be that people supporting such policies are just more aware of the existence of smoking restrictions. To examine the question of causality, this study explored the impact of smoke-free legislation on policy support among smokers in three European countries with differential comprehensiveness of smoke-free legislation, using longitudinal pre- and postlegislation data from the prospective International Tobacco Control Policy Evaluation Project (ITC Project) Europe Surveys. The examined countries were France, Germany, and the Netherlands. While the French bar and restaurant smoking ban is nearly comprehensive, the Netherlands and Germany allow for several exemptions. In France, smoking is allowed in smoking rooms, but the technical requirements for smoking rooms are so strict that they are actually a rarity. In the Netherlands and Germany, at the time of the post-legislation survey, smoking was allowed in smoking rooms in drinking establishments and restaurants. In Germany, smoking was furthermore allowed in designated smoking venues, i.e. drinking establishments of a size less than $75 \mathrm{~m}^{2}$, which chose to operate as smoking venue. More information about the different legislations can be found elsewhere (Nagelhout, Mons et al., 2011).

Consequently, the difference in comprehensiveness of the regulations is reflected in the frequency of smoking in hospitality venues. While smoking in bars was almost eliminated post-legislation in France (proportion of smokers who noticed smoking at their last visit: $4 \%$ ), it was still rather common in the Netherlands (36\%) and Germany (50\%). For restaurants, the policies were more effective: the proportion of smokers noticing smoking was slightly higher in the Netherlands (5\%) than in France (2\%), but considerably higher in Germany (29\%) (ITC Project, 2010a). These implications are also supported by other studies using different indicators (Gleich et al., 2011; Nagelhout, Mons et al., 2011).

In addition to examining the impact of smoke-free legislation on policy support among smokers in these three countries, the multi-country approach was combined with a quasi-experimental design, using data from two pre-legislation ITC survey waves from the UK serving as control. As public support for smoking bans tends to increase even when no bans are in place, using a control allowed us to disentangle the contribution of secular trends and of the smoke-free legislation to changes in public support in the countries where such legislation was implemented. 


\section{DATA AND METHODS}

\section{Study and sampling design}

The prospective ITC Surveys are part of the ITC Project (www.itcproject.org), which is committed to evaluating the psychosocial and behavioural effects of national tobacco control policies. The surveys are based on the same conceptual framework and methods, and use standardised survey questionnaires (Thompson et al., 2006).

The surveys covered probability samples of current smokers aged 18 years and older, with smokers being defined as having smoked at least 100 cigarettes in their lifetime and currently smoking at least monthly. In France, Germany and UK, respondents were recruited and interviewed using random digit dialling (RDD) and computer-assisted telephone interviews (CATI). In the Netherlands, the sample consisted of a small RDD CATI sample and a larger computer-assisted web interview sample (CAWI), which was drawn from a large probability-based internet panel. Whereas the two Dutch samples showed small differences in socio-demographics and smoking behaviour (Nagelhout et al., 2010), there were no significant differences with regard to pre-legislation support for a total smoking ban in bars (crude OR CAWI vs. CATI $=1.48,95 \% \mathrm{Cl}=0.92-2.39)$ or restaurants $(0.77,0.57-1.05)$. The samples were thus pooled for the analyses.

For all countries but the UK, respondents were first interviewed before implementation of the national smoke-free legislation and re-interviewed after implementation. As UK was used as control country, data were drawn from two pre-legislation waves. In order to have a pre-legislation observation period as close as possible to the pre- to post-legislation period in the other countries, we used waves 4 and 5 of the ITC UK survey. Because Scotland had implemented smokefree legislation between these two waves, we excluded respondents from Scotland from all analyses. The timing of the surveys and the different regulations of the smoke-free policies are summarised in Table 1.

The analyses presented here were based on the longitudinal samples, i.e. respondents who had been surveyed both at baseline and follow-up. Of 6,903 baseline smokers, 4,945 (71.6\%) could be followed up (Table 1). 


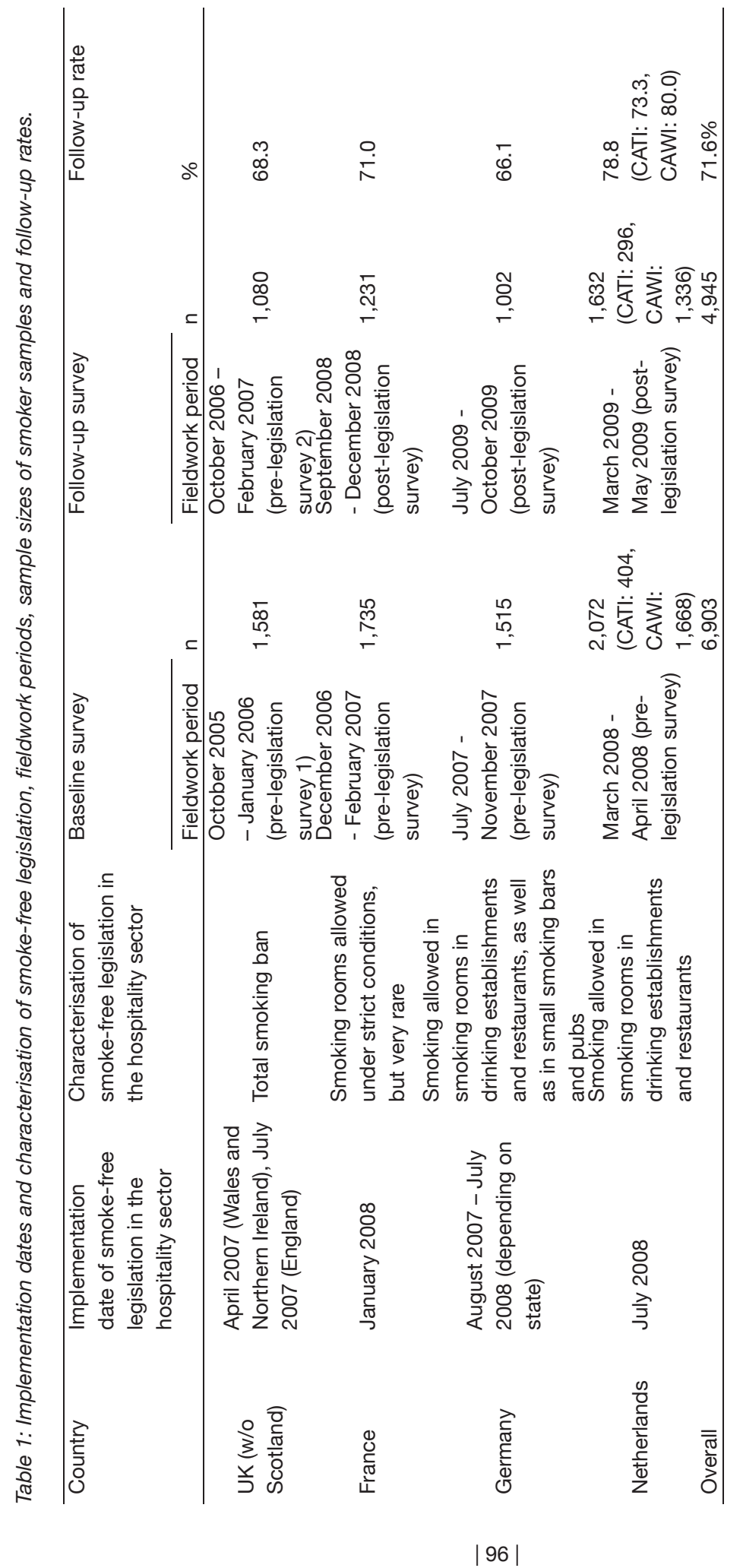




\section{Measures and outcomes}

The pre- and post-legislation questionnaires included relevant socio-demographic variables, such as gender, age, and education. Smoking-related questions of particular relevance to the present analyses were the Heaviness of Smoking Index (Heatherton et al., 1989) and intention to quit smoking. Awareness of the harm of TSP, a potential confounder, was measured by reported agreement with the statement "Cigarette smoke is dangerous to non-smokers". The frequency of bar and restaurant visits was used to assess to what extent respondents would be exposed to the smoking restrictions in hospitality venues.

Support for smoke-free policies was assessed by asking whether "smoking should be allowed in all indoor areas, in some indoor areas, or not allowed indoors at all", separately for restaurants and drinking establishments: bars and pubs. For each of these two venues, those who stated that smoking should not be allowed indoors at all were categorised as supporting a total smoking ban, those who stated that smoking should be allowed in some indoor areas were categorised as supporting a partial smoking ban, and those who stated that smoking should be allowed in all indoor areas were categorised as supporting no smoking restrictions. Both variables were dichotomised for the multivariate analyses in the form of: supporting a total smoking ban versus not supporting a total smoking ban.

\section{Statistical analyses}

For the descriptive analyses, percentages for country-specific estimates of support for smoke-free policies were reported.

To evaluate changes in support for smoking bans, separate Generalised Estimating Equations (GEE) models (Hanley, Negassa, Edwardes, \& Forrester, 2003; Zeger \& Liang, 1986) were computed for Germany, France, and the Netherlands, with UK as control in each of these models. Separate models were computed with supporting a total smoking ban in drinking establishments, and supporting a total smoking ban in restaurants as dependent variables (binomial distribution, logit link, exchangeable correlation structure). Estimates were adjusted for timeinvariant covariates reported at baseline (country, age, gender, education) as well as for time-varying covariates reported at each survey (wave, frequency of visiting the respective hospitality venue, TSP harm awareness). Country $\mathrm{x}$ wave-interaction terms were included to account for the pattern of change in the outcome variables over time and to test for differences from UK as control country.

In order to identify prospective predictors of individual change in policy support (i.e. transition from not supporting a total smoking ban to supporting a total smoking ban) in the countries where smoke-free legislation was implemented, 
multiple logistic regression models were computed, separately for support for smoking bans in drinking establishments and in restaurants. These models included socio-demographic and smoking-related variables, frequency of visiting hospitality venues and TSP harm awareness as independent covariates measured at baseline, and used pooled data. In additional models, we tested for country differences in prospective predictors of change in policy support by adding by-countryinteraction terms for each of the covariates (Jaccard, 2001). These models included UK as control country, which was chosen as reference category for all by-countryinteractions. That way we could examine for each covariate, whether predictors of change in policy support in the countries that implemented smoke-free legislation between baseline and follow-up were different to the control country UK, which did not have smoke-free legislation at any measurement.

The statistical package SAS 9.2 was used for all analyses.

\section{RESULTS}

\section{Pre- and post-legislation levels of support for a total smoking ban}

In all four countries examined and at both measurements, a substantially higher proportion of smokers supported a total smoking ban in restaurants than in drinking establishments (Table 2). Nevertheless, for both types of venues support for a total smoking ban increased from baseline to follow-up measurement. For support for a total smoking ban in drinking establishments, the relative increase was sharpest in France (+183.1\%), and ranged from $66.2 \%$ to $69.5 \%$ in the other three countries. The proportion of smokers supporting no smoking restrictions in drinking establishments decreased in all countries except the Netherlands.

For support for a total smoking ban in restaurants, the greatest relative increase was found in the Netherlands $(+122.8 \%)$, where baseline support had been lowest, and the smallest in UK (+35.7\%), where baseline support had been highest. In France and Germany, support increased by $70.0 \%$ and $82.7 \%$, respectively. 
Table 2: Baseline and follow-up levels of support for smoking bans in drinking establishments and restaurants by country.

\begin{tabular}{|c|c|c|c|c|c|c|c|c|c|}
\hline \multirow[b]{2}{*}{ Measure } & \multirow[b]{2}{*}{ Categories } & \multicolumn{2}{|l|}{ UK } & \multicolumn{2}{|c|}{ France } & \multicolumn{2}{|c|}{ Germany } & \multicolumn{2}{|c|}{ Netherlands } \\
\hline & & $\begin{array}{l}\text { Pre- } \\
\text { ban } \\
1\end{array}$ & $\begin{array}{l}\text { Pre- } \\
\text { ban } \\
2 \\
\end{array}$ & $\begin{array}{l}\text { Pre- } \\
\text { ban }\end{array}$ & $\begin{array}{l}\text { Post- } \\
\text { ban }\end{array}$ & $\begin{array}{l}\text { Pre- } \\
\text { ban }\end{array}$ & $\begin{array}{l}\text { Post- } \\
\text { ban }\end{array}$ & $\begin{array}{l}\text { Pre- } \\
\text { ban }\end{array}$ & $\begin{array}{l}\text { Post- } \\
\text { ban }\end{array}$ \\
\hline \multirow{3}{*}{$\begin{array}{l}\text { Support for a } \\
\text { smoking ban } \\
\text { in drinking } \\
\text { establishments }\end{array}$} & $\begin{array}{l}\mathrm{n} \\
\% \text { total smoking ban } \\
\% \text { partial smoking }\end{array}$ & $\begin{array}{l}1,063 \\
11.6\end{array}$ & 20.9 & $\begin{array}{l}1,224 \\
15.4\end{array}$ & 43.6 & $\begin{array}{l}985 \\
7.1\end{array}$ & 11.8 & $\begin{array}{l}1,566 \\
9.5\end{array}$ & 16.1 \\
\hline & ban & 73.1 & 65.4 & 62.2 & 48.6 & 52.1 & 63.4 & 60.6 & 54.7 \\
\hline & $\begin{array}{l}\% \text { no smoking } \\
\text { restrictions }\end{array}$ & 15.3 & 13.7 & 22.5 & 7.8 & 40.8 & 24.9 & 29.9 & 29.3 \\
\hline \multirow{4}{*}{$\begin{array}{l}\text { Support for a } \\
\text { smoking ban in } \\
\text { restaurants }\end{array}$} & $\begin{array}{l}\mathrm{n} \\
\% \text { total smoking }\end{array}$ & 1,064 & & 1,231 & & 994 & & 1,587 & \\
\hline & $\begin{array}{l}\text { ban } \\
\% \text { partial smoking }\end{array}$ & 46.7 & 55.3 & 41.3 & 70.2 & 30.7 & 56.1 & 19.3 & 43.0 \\
\hline & ban & 49.9 & 41.5 & 56.6 & 29.0 & 62.3 & 42.2 & 72.8 & 54.0 \\
\hline & restrictions & 3.4 & 3.3 & 2.1 & 0.8 & 7.0 & 1.7 & 7.8 & 3.0 \\
\hline
\end{tabular}

\section{Changes in support for total smoking bans after implementation of smoke-free legislation}

In both the countries with a smoke-free legislation and in the control country, there was a statistically significant increase in support for smoking bans in drinking establishments from baseline to follow-up (Table 3). Only in France, the country $\mathrm{x}$ wave-interaction proved to be statistically significant, indicating that smokers in France were more likely to become supporters of a total smoking ban in drinking establishments after implementation of a smoke-free legislation than smokers from UK in a period without such legislation. The increase in support in Germany and the Netherlands was not statistically different from that in the UK, indicating that support did not increase above the secular trend.

For support for smoking bans in restaurants, there also was a significant increase in all countries examined. Additionally, all country $x$ wave-interactions were statistically significant. This implies that in all three countries that implemented smoke-free legislation, support increased to a greater extent than in the control country. 
Table 3: Results of pair-wise GEE models for support for a total smoking ban in drinking establishments and in restaurants.

\begin{tabular}{|c|c|c|c|}
\hline & & $\begin{array}{l}\text { Support for a } \\
\text { total smoking } \\
\text { ban in drinking } \\
\text { establishments }\end{array}$ & $\begin{array}{l}\text { Support for a total } \\
\text { smoking ban } \\
\text { in restaurants }{ }^{\mathrm{a}}\end{array}$ \\
\hline \multirow[t]{2}{*}{ Model } & Pattern of change & OR (95\% Cl) & OR (95\% Cl) \\
\hline & follow-up vs. baseline & & \\
\hline \multirow{3}{*}{$\begin{array}{l}\text { Germany vs. } \\
\text { UK }\end{array}$} & Germany & $1.78(1.37-2.30)$ & $3.03(2.59-3.54)$ \\
\hline & UK & $2.17(1.76-2.68)$ & $1.42(1.23-1.62)$ \\
\hline & $\begin{array}{l}\text { Germany } x \text { wave-interaction } \\
\text { follow-up vs. baseline }\end{array}$ & $0.82(0.58-1.14)$ & $2.14(1.74-2.63)$ \\
\hline \multirow{3}{*}{$\begin{array}{l}\text { Netherlands } \\
\text { vs. UK }\end{array}$} & Netherlands & $1.77(1.46-2.15)$ & $3.29(2.86-3.78)$ \\
\hline & UK & $2.16(1.75-2.67)$ & $1.41(1.23-1.62)$ \\
\hline & $\begin{array}{l}\text { Netherlands } x \text { wave-interaction } \\
\text { follow-up vs. baseline }\end{array}$ & $0.82(0.62-1.09)$ & $2.33(1.91-2.84)$ \\
\hline \multirow{3}{*}{$\begin{array}{l}\text { France } \\
\text { vs. UK }\end{array}$} & France & $4.58(3.85-5.44)$ & $3.54(3.09-4.06)$ \\
\hline & UK & $2.18(1.77-2.69)$ & $1.41(1.23-1.62)$ \\
\hline & France $x$ wave-interaction & $2.10(1.61-2.75)$ & $2.51(2.06-3.04)$ \\
\hline
\end{tabular}

a Models were adjusted for time-invariant covariates reported at baseline (country, gender, age, education) and time-varying covariates (wave, frequency of visiting the respective venue, TSP harm awareness) and included country $x$ wave-interaction terms. The odds ratios reported for each country estimate the change in odds of supporting a smoking ban between the two waves. The interaction odds ratios are the ratios of these estimates and were used to assess if the change in the respective country with a smoke-free legislation was statistically significantly different from the change in the no-legislation control country (UK). In this table, an interaction $O R>1$ indicates that the change was greater in the country where a smoke-free legislation was implemented compared to the control country, an $O R<1$ indicates that it was smaller.

\section{Prospective predictors of change in policy support: supporting total smoking bans after implementation of smoke-free legislation}

Of smokers who did not support a total smoking ban in drinking establishments prelegislation, those being older, less educated, those being less heavy smokers, those having baseline quit intentions, and those with higher TSP harm awareness, were more likely to support a total smoking ban post-legislation (Table 4). Smokers from Germany and the Netherlands were less likely to become supporters of a smoking ban in drinking establishments than smokers from France, with German smokers having the lowest odds.

In comparison, prospective predictors of transition to support for a total smoking ban in restaurants post-legislation were generally similar. Notable differences were that higher age and lower education did not predict support, and that there was a borderline significant $(p=0.054)$ positive association with visiting restaurants at least weekly. 
Table 4: Prospective predictors of supporting a total smoking ban at follow-up in countries which implemented smoke-free legislation between baseline and follow-up (restricted to respondents who did not support a total smoking ban at baseline), results of multiple logistic regression models.

\begin{tabular}{|c|c|c|}
\hline & $\begin{array}{l}\text { Support for a total } \\
\text { smoking ban in drinking } \\
\text { establishments }{ }^{\text {a }} \\
\text { France, Germany and the } \\
\text { Netherlands pooled }\end{array}$ & $\begin{array}{l}\text { Support for a total smoking } \\
\text { ban in restaurants a } \\
\text { France, Germany and the } \\
\text { Netherlands pooled }\end{array}$ \\
\hline Predictor variable ${ }^{a}$ & $\frac{n=3.282 ; \text { events }=636}{\text { OR }(95 \% \mathrm{Cl})}$ & $\begin{array}{l}n=2.566 ; \text { events }=1,127 \\
\text { OR }(95 \% \mathrm{Cl})\end{array}$ \\
\hline $\begin{array}{l}\text { Gender } \\
\quad \text { male (vs. female) }\end{array}$ & $1.19(0.99-1.44)$ & $1.18(1.00-1.39)$ \\
\hline Age (in years) & $1.02(1.02-1.03)$ & $1.01(0.99-1.01)$ \\
\hline $\begin{array}{l}\text { Education } \\
\text { low (vs. high) } \\
\text { moderate (vs. high) } \\
\text { Heaviness of Smoking Index (HSI) }{ }^{\text {b }}\end{array}$ & $\begin{array}{l}1.29(0.99-1.66) \\
1.29(1.01-1.65) \\
0.86(0.81-0.92)\end{array}$ & $\begin{array}{l}1.02(0.82-1.28) \\
1.15(0.94-1.41) \\
0.82(0.78-0.87)\end{array}$ \\
\hline $\begin{array}{l}\text { Intention to quit } \\
\text { within next } 6 \text { months (vs. no } \\
\text { intention) }\end{array}$ & $1.27(1.04-1.55)$ & $1.45(1.20-1.76)$ \\
\hline $\begin{array}{l}\text { Frequency of visiting the respective } \\
\text { hospitality venue } \\
\text { visiting at least weekly (vs. less than } \\
\text { weekly) }\end{array}$ & $0.97(0.79-1.20)$ & $1.24(0.99-1.55)$ \\
\hline $\begin{array}{l}\text { Agreement with statement "Cigarette } \\
\text { smoke is dangerous to others" (TSP } \\
\text { harm awareness) c } \\
\text { Country }\end{array}$ & $1.40(1.23-1.60)$ & $1.31(1.18-1.44)$ \\
\hline Germany (vs. France) & $0.17(0.13-0.23)$ & $0.78(0.62-0.99)$ \\
\hline
\end{tabular}

\section{Prospective predictors of change in policy support: country differences}

With regards to prospective predictors of becoming a supporter of a total smoking ban in drinking establishments and in restaurants, respectively, several country differences were observed (Table 5). Notable country differences to the UK sample were the significant negative association of heaviness of smoking with supporting a smoking ban in drinking establishments in the Dutch sample and the positive associations of lower education in the Dutch and the German sample. Furthermore, there were interesting significant country differences regarding the associations of frequently visiting hospitality venues with supporting a total smoking ban in restaurants: while weekly restaurant visitors in the UK were less likely to support a smoking ban in restaurants at follow-up compared to non-weekly restaurant 


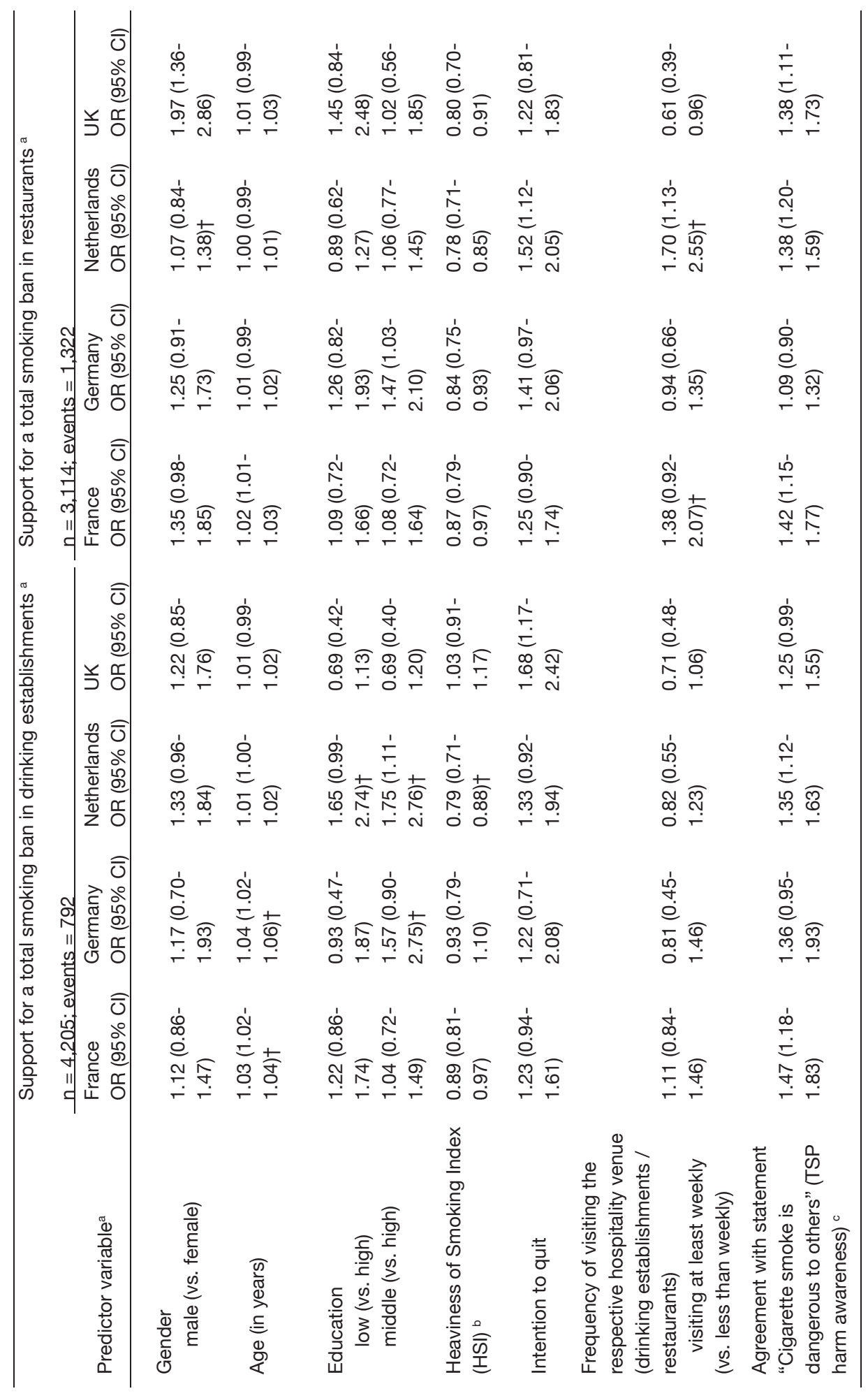


$\leftarrow$ Table 5: Country-specific prospective predictors of supporting a total smoking ban at follow-up (restricted to those who did not support a total smoking ban at baseline), results of multiple logistic regression by-country interaction models.

a Covariates refer to baseline. The basic model used UK as reference and included all variables in the table together and additional by-country interaction terms for each of the predictor variables. Estimates presented are the main effects of the predictor of interest for each country, which were derived by redefining the reference group and rerunning the model for each of the countries where a smoke-free legislation was implemented. To keep the table simple and non-redundant, the main effects of country and all by-country interaction effects were not reported, but significant interaction effects in the basic model (with UK as reference) were marked with a $\dagger$.

${ }^{\mathrm{b}}$ The index ranges from 0 to 6 , with higher values indicating higher addiction/heavier smoking.

${ }^{\mathrm{c}}$ Five-point scale ranging from strongly disagree (1) to strongly agree (5).

$\dagger$ Statistically significant $(p<0.05)$ interaction effect between the predictor of interest and country, indicating significant country differences to UK.

visitors, the effect was of opposite direction in the Netherlands and France, where visiting restaurants weekly predicted support for a restaurant smoking ban after the implementation of smoke-free legislation.

\section{DISCUSSION}

To our knowledge, this is the first longitudinal multiple-country study to compare patterns of change in policy support among smokers in countries with differential comprehensiveness of national smoke-free legislation. We examined data from the ITC Surveys in France, Germany, and the Netherlands. These countries vary substantially with regards to the comprehensiveness of their smoke-free policy in the hospitality sector: While France has the most comprehensive policy; the Netherlands and Germany have partial policies that are especially weak in the case of drinking establishments and also experience problems with enforcement. We found that the comprehensive legislation in France was associated with a marked increase in support for total smoking bans in drinking establishments and in restaurants, which was found to be above the secular trend. In the Netherlands and Germany, we also observed increasing support for total smoking bans, but only for a smoking ban in restaurants was the increase in support above the secular trend.

Thus, our findings are in line with previous studies showing a positive impact of smoke-free legislation on smokers' support for smoking bans (Braverman et al., 2010; Cooper et al., 2010; Edwards et al., 2008; Fong, Hyland et al., 2006; Hyland, Hassan et al., 2009; Larsson et al., 2008; Lund, 2006; Palmersheim et al., 2006; Pursell et al., 2007; Rayens et al., 2007; Tang et al., 2003; Tang et al., 2004). In addition, our findings suggest that comprehensive smoking bans have a stronger effect on policy support than partial smoking bans. This might be unexpected given the high level of opposition among smokers and the low support that many 
countries have experienced in the process of debating and implementing smokefree policies. But, as others have also suggested (Hyland et al., 2009), smokefree legislation seems to have the potential to change attitudes, and acceptance increases once smokers experience the legislation and its benefits. In contrast, we assume that in countries with only partial smoking restrictions, initial concerns among smokers persist, possibly due to ongoing debates about proportionality and fairness of the regulations. This is reflected in our findings of low pre-legislation support levels and the only slight increase in support levels for smoking bans in drinking establishments in Germany and the Netherlands, where the partial smoking bans are especially deficient in bars and pubs due to exemptions and problems with compliance (Gleich et al., 2011; Nagelhout, Mons et al., 2011). Germany's smokefree policy is even less effective than that of the Netherlands (Gleich et al., 2011; Nagelhout, Mons et al., 2011), which might explain why German smokers had even lower odds of becoming supporters of a smoking ban in drinking establishments than Dutch smokers. Opposition among smokers generally seems to be more prevalent in the case of smoking bans in drinking establishments, which had the lowest pre-legislation support levels. This was also found in other studies (Cooper et al., 2010; Hyland, Hassan et al., 2009). Possible explanations could be a stronger association of bars and pubs with (social) smoking compared to other types of hospitality venues, and tobacco industry efforts to preserve the "last bastion of socially acceptable smoking" (Magzamen \& Glantz, 2001).

An alternative interpretation of the observed changes in support following the smoking bans would be that these changes were induced by campaigns and media reports related to the smoking bans. While campaigns were run prior to the implementation of the legislation in France and the Netherlands, there were no campaigns in Germany. However, the finding that frequency of visiting restaurants - and thus the frequency of being directly exposed to and affected by the smoking ban - seems to play a significant role in the transition to supporting smoking bans suggests that at least part of the effect is caused by the policy itself. A relevant mediator might be TSP harm awareness, which was a significant predictor of postlegislation support. As TSP-related health knowledge can be reinforced by media reports and social marketing campaigns (Nagelhout et al., 2012; Thrasher et al., 2011), this could indeed be an important driving factor in the process of normative changes that occur after implementation of the legislation. However, we could not further examine the role of campaigns and media reports as detailed information about exposure among respondents was lacking.

Limitations of this study include differences in the timing of the surveys and the loss of nearly $30 \%$ of respondents to follow-up. Because the smoke-free 
legislation was implemented at different dates in the examined countries, the preand post-legislation surveys were conducted at different times, and also the followup time and time between implementation of the legislation and post-legislation varied. As secular trends influence the level of policy support, the differences in timing of the survey might explain pre-legislation country-differences in levels of support, but the patterns of change should be largely unaffected by survey timing. In order to assess secular changes we used the UK (without Scotland) as a control country. Comparable baseline support rates implied that UK was an appropriate choice for this purpose. However, it is possible that with associated publicity around the enactment of the smoke-free legislation in Scotland, the secular increase in the rest of UK might have been an overestimate. This would make our estimate of the secular trend more conservative.

Loss to follow-up is a common problem in longitudinal studies and can lead to attrition bias. Non-responder analyses showed that smokers of younger age $(\mathrm{OR}=0.99,95 \% \mathrm{Cl}=0.98-0.99)$, those with a pre-legislation intention to quit $(1.15,1.03-1.29)$, and weekly visitors of drinking establishments $(1.13,1.01-1.27)$ or restaurants $(1.27,1.11-1.46)$ were somewhat more likely to be lost to follow-up. However, these odds ratios suggest only limited potential for bias in the results reported in Table 2.

The relevance of the interviewing modes in the Dutch surveys was explored in sensitivity analyses running the GEE and the logistic regression models separately for CAWI- and CATI-respondents, which yielded consistent results (details not shown).

Finally, our findings were consistent with results from ITC studies from Ireland, UK, USA, Canada, and Australia (Brown et al., 2009; Fong, Hyland et al., 2006; Hyland, Hassan et al., 2009), which is in line with a broad generalisability of our findings for Western industrial nations.

Our study of smokers from four EU-countries demonstrates that smoking bans have the potential to create and improve support once the policy is in place. This effect is stronger the more comprehensive the policy, but might not be valid for partial smoking bans with many exemptions, as these could be cause for ongoing debates about fairness and proportionality of the regulations. The findings imply that compliance problems that often occur with partial smoking bans might lessen with more comprehensive regulations and increasing support. Most importantly, policy-makers should not waver from implementing comprehensive smokefree legislation because of low public acceptance rates, as it seems that despite potential controversy and resistance in the beginning, comprehensive regulations attract support from smokers once implemented. 


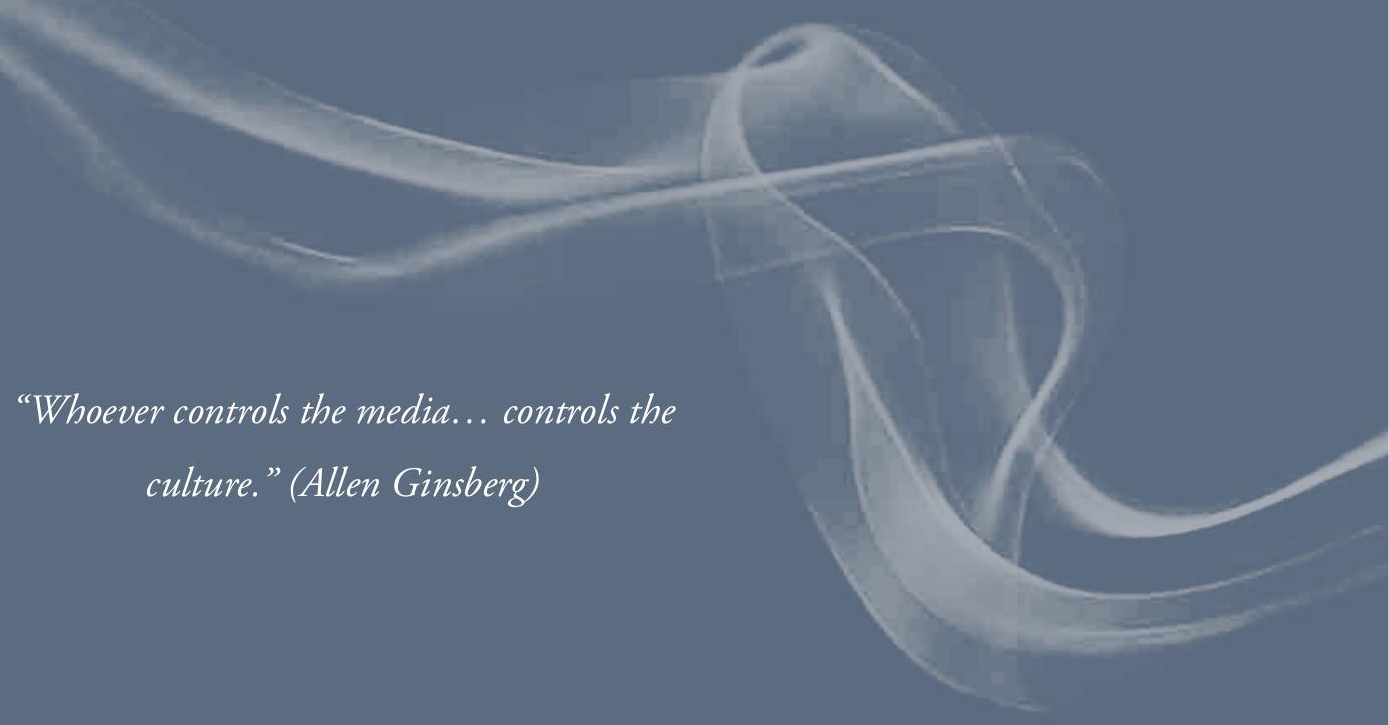




\section{Chapter 7}

\section{$\sim \sim \sim$ \\ Newspaper coverage and a media campaign}

\section{Published as:}

Nagelhout, G. E., Van den Putte, B., De Vries, H., Crone, M., Fong, G. T., \& Willemsen, M. C. (2012). The influence of newspaper coverage and a media campaign on smokers' support for smoke-free bars and restaurants and on second-hand smoke harm awareness. Findings from the International Tobacco Control (ITC) Netherlands Survey. Tobacco Control, 21, 24-29. 
The objective of this study was to assess the influence of newspaper coverage and a media campaign about Dutch smoke-free legislation on smokers' support for smoke-free bars and restaurants and on secondhand smoke (SHS) harm awareness. A content analysis was conducted of 1,041 newspaper articles on the smoke-free legislation published in six Dutch newspapers from March 2008 until April 2009. Smokers who were regular readers of at least one of these newspapers $(n=677)$ were selected from the pre- and post-ban waves of the International Tobacco Control (ITC) Netherlands Survey. Exposure to newspaper coverage and to the implementation campaign were correlated with changes in smokers' support for smoke-free bars and restaurants and SHS harm awareness. Most newspaper coverage was found to be negative towards the smoking ban $(57 \%)$ and focused on economic aspects $(59 \%)$ rather than health aspects $(22 \%)$. Exposure to this coverage had a small but significantly negative effect on support for smoke-free bars and restaurants (Beta = $-0.09, p=0.013$ ). Among higher educated smokers, exposure to positive newspaper coverage had a more positive effect on support for smokefree bars and restaurants. In addition, exposure to the implementation campaign had a small but significantly positive effect on SHS harm awareness (Beta $=0.11, p=0.001$ ). Media attention about smoke-free legislation can influence smokers' support for the legislation and SHS harm awareness. Tobacco control advocates should aim to establish positive media attention that puts forward the health arguments for the legislation. 


\section{INTRODUCTION}

In many countries around the world, smoke-free legislation is being implemented to protect non-smokers from the health dangers of second-hand smoke (SHS) (World Health Organization, 2008a). Optimal protection is achieved when compliance with smoking bans is high. Several studies have shown that compliance is positively related to higher levels of support for the legislation and to greater SHS harm awareness (Borland, Yong, Siahpush et al., 2006; Li et al., 2010; Thrasher, Besley, \& González, 2010). Both can possibly be influenced by means of well-designed media campaigns and advocacy. In this study, we assess the influence of newspaper coverage and a campaign about smoke-free legislation on changes in smokers' support for the legislation and SHS harm awareness.

Both opponents and proponents of tobacco control believe that media attention can influence public support for tobacco control policies. This is evidenced by the fact that influencing media attention about smoking is a known strategy of tobacco control advocates (American Cancer Society, 2003; National Cancer Institute, 2008) and the tobacco industry (National Cancer Institute, 2006; World Health Organization, 2008b) alike. However, research on media attention about tobacco has mainly focused on describing media coverage, and few studies have linked this with individual outcomes (National Cancer Institute, 2008). Two recent studies from the United States found an association between media coverage of tobacco control policy in a region and support for the policy in that region (CleggSmith et al., 2008; Harris, Shelton, Moreland-Russell, \& Luke, 2010). Another recent US study found no association between self reported media coverage and support for tobacco control policies (Blake, Viswanath, Blendon, \& Vallone, 2010). These studies provided no conclusive evidence on the matter, as their cross-sectional design made it difficult to reach firm conclusions about causal relationships. Furthermore, these studies did not report on differential effects of media coverage between people from higher and lower educational levels. This is important, because smoking is increasingly a problem for lower educated groups (World Health Organization, 2008a). The available research suggests that media campaigns are more effective among higher educated groups (Niederdeppe, Kuang, Crock, \& Skelton, 2008) and that these groups learn more from the media than lower educated groups (Tichenor, Donohue, \& Olien, 1970).

The theoretical concept of framing explains how media attention can influence attitudes. Frames give context to an issue, which influences how the issue is perceived and understood (Goffman, 1974). For example, smoke-free legislation is often framed by tobacco control advocates as a measure to protect the health of non-smokers but by the tobacco industry as a measure that causes economic 
losses to the hospitality industry (Fahy et al., 2009; Magzamen, Charlesworth, \& Glantz, 2001). A study on the effects of newspaper coverage about a tobacco tax increase found that coverage of economic aspects was associated with less support for the tax increase, while coverage of health aspects was associated with more support (Harris et al., 2010).

The case that we present in this study is that of the implementation of the smoke-free hospitality industry legislation in the Netherlands in July 2008. The implementation of this legislation did not proceed as planned. A small minority of bars failed to comply with the smoking ban at first (VWA, 2010), but this small group received a disproportionate high amount of media attention. This may have fuelled resistance to the legislation and increased the number of non-complying bars. While support for legislation typically increases considerably after its implementation (Fong, Hyland et al., 2006; Hyland, Hassan et al., 2009; Wakefield, Roberts, \& Owen, 1996), support for the Dutch legislation was low before and stayed low after its implementation (ITC Project, 2010b). In fact, of all European countries, the Netherlands had the lowest support for smoke-free bars: only 44 percent of the population (European Commission, 2009). The Dutch government ran a mass media implementation campaign for the smoke-free legislation on television (849 GRPs3), radio (1,636 GRPs), and posters (144 GRPs) from May to September 2008. Although the World Health Organization guidelines recommend an emphasis on the public health arguments for implementing smoke-free legislation (World Health Organization, 1998), the Dutch implementation campaign only communicated the date of implementation. The television commercial showed a man dressed as a large cigarette being thrown out of hospitality industry venues onto the street.

The present study examined the effects of the implementation campaign and newspaper coverage about the smoke-free legislation on support for smokefree bars and restaurants and on SHS harm awareness. The following hypotheses were tested: 1) positive newspaper coverage has a more positive effect on support and harm awareness than negative coverage; 2) newspaper coverage of health aspects has a more positive effect on support and harm awareness than coverage of economic aspects; 3) the implementation campaign has no effect on support or harm awareness; 4) there are more positive effects from media attention among smokers with higher than lower educational levels. To study this, we used longitudinal data from the International Tobacco Control (ITC) Netherlands Survey and a content analysis of newspaper coverage about the smoke-free legislation.

3 GRP stands for Gross Rating Point, which is the percentage of the target audience that is reached by the campaign times the frequency of exposure. Normally, government campaigns in the Netherlands have 300 GRPs on television and 640 GRPs on radio. 


\section{METHODS}

\section{ITC Netherlands Survey}

In this study we used the pre-ban (April 2008) and post-ban (April-May 2009) internet survey of the ITC Netherlands Survey. All respondents were aged 15 years or older at the pre-ban survey, smoked manufactured or roll-your-own cigarettes at least monthly, and had smoked at least 100 cigarettes in their lifetime. The pre-ban survey was sent to 2,331 smoking panel members of the TNS NIPObase and was returned by 1,820 respondents $(78 \%)$. Of the 1,820 pre-ban respondents, 1,447 participated again in the post-ban survey (80\%). Additional details about the methods of the ITC Netherlands Survey can be found on the ITC Project website (ITC Project, 2009b).

The first aspect of media attention about the smoke-free legislation that we assessed in this study is newspaper coverage. All post-ban respondents were presented with a list of 38 newspapers, with a request to indicate which newspapers they read and how often. This method of asking respondents of a population survey about their newspaper reading behaviour to assess the population effects of newspaper coverage was also recently used by Dunlop and Romer (2010). Because this method requires a content analysis of every included newspaper, we did not include readers of all 38 newspapers, but only respondents who read at least one of the six largest newspapers ( $n=677$ newspaper readers). A smaller number of the post-ban respondents read one of the other 32 newspapers $(n=351)$, read no newspaper at all $(n=415)$, or did not answer the question $(n=4)$. Table 1 shows the number of respondents per newspaper.

The second aspect of media attention about the smoke-free legislation was the implementation campaign. Recall of exposure to this campaign was assessed at the post-ban survey by showing post-ban respondents pictures and texts of the three different parts of the campaign: posters, television, and radio commercials. Of each part of the campaign we asked how often they had seen or heard something about this. Response categories were "Never", "Once or twice", "Sometimes", "Often", and "Very often". One exposure variable was created by computing a mean score of exposure to the three different parts of the campaign for every respondent, ranging from 0 to $4(M=1.12, S D=0.83)$.

Support for smoke-free bars and restaurants was assessed at the preand post-ban survey using the question "Do you support or oppose a complete Dutch smoking ban in drinking establishments: cafés, bars, and pubs?" and "Do you support or oppose a complete Dutch smoking ban in restaurants?" Response categories were "Strongly support", "Support", "Oppose", and "Strongly oppose". The mean of these two variables was used as indicator of support for smoke-free bars and restaurants. 
SHS harm awareness was assessed at the pre- and post-ban survey using the question "In the last month, how often, if at all, did you think about the harm your smoking might be doing to other people?" Response categories were "Never", "Rarely", "Sometimes", "Often", and "Very often".

Furthermore, age, gender, and educational level of respondents were assessed at the pre-ban survey. Education was categorised in three levels: low (primary education and lower pre-vocational secondary education), moderate (middle pre-vocational secondary education and secondary vocational education), and high (senior general secondary education, (pre-)university education and higher professional education).

Table 1: Number of respondents and articles per newspaper.

\begin{tabular}{|c|c|c|c|c|c|c|c|}
\hline & Metro & Telegraaf & Sp!ts & $\begin{array}{l}\text { Volks- } \\
\text { krant }\end{array}$ & $\begin{array}{l}\text { AD } \\
\text { Rotterdam }\end{array}$ & $\begin{array}{l}\text { Gelder- } \\
\text { lander }\end{array}$ & Total \\
\hline $\begin{array}{l}\text { Number of } \\
\text { respondents } \\
\text { Number of } \\
\text { articles } \\
\text { Smoke-free }\end{array}$ & 327 & 310 & 302 & 85 & 60 & 54 & 677 \\
\hline $\begin{array}{l}\text { legislation } \\
\text { Economic }\end{array}$ & 145 & 183 & 94 & 142 & 118 & 359 & 1,041 \\
\hline $\begin{array}{l}\text { aspects } \\
\text { Health }\end{array}$ & 76 & 114 & 58 & 81 & 60 & 229 & 618 \\
\hline aspects & 33 & 42 & 20 & 51 & 21 & 59 & 226 \\
\hline
\end{tabular}

\section{Content analysis}

A content analysis was performed on the six Dutch newspapers that were most often read by smoking respondents of the ITC Netherlands Survey. Two of the newspapers were the largest regular national newspapers in the Netherlands (De Telegraaf and De Volkskrant), two were the largest free national newspapers (Metro and Sp!ts), and two were large regular regional newspapers (AD Rotterdams Dagblad and De Gelderlander).

Articles that appeared in one of these six newspapers from March 2008 until April 2009 were selected from the digital database LexisNexis $₫$, which contains all articles that appear in these newspapers. A search with words related to smoking (e.g. smoking, smoker, and cigarette) and words related to the smokefree hospitality industry legislation (e.g. hospitality industry, bar, smoking ban, and smoke-free) resulted in a selection of articles with a high probability of being about the smoke-free hospitality industry legislation. Of the selected articles, only the 1,086 articles that were about the smoke-free hospitality industry legislation and had a tobacco focus (i.e. the article had smoking or tobacco in the heading, or at least more than half of one paragraph of the article dealt with smoking or tobacco) 
were included in the study.

All 1,086 included articles were coded on reference to health and economic aspects and on slant towards the smoking ban (positive, negative, mixed, or neutral). The coding on slant was done from the perspective of tobacco control according to the method of Clegg-Smith et al. (Clegg-Smith et al., 2008). The coding was done by two coders and had a high level of correspondence with respect to health aspects (Cohen's kappa $=0.85$ ) and economic aspects (Cohen's kappa $=0.85$ ) and a satisfactory level of correspondence with respect to slant (Cohen's kappa $=0.62$ ). A third coder coded the articles on which there was no agreement between the first two coders and made the decision about the coding. If the third coder disagreed with each of the first two coders (only possible for codings on slant), that article was excluded $(n=45)$, which left 1,041 articles for the analyses.

\section{Analyses}

Individual exposure to articles about the smoke-free legislation was estimated by combining the content analysis of newspaper coverage with information about the newspaper reading behaviour of the ITC respondents. This method was also used by Dunlop and Romer (2010), with the difference that the current study does not use newspaper reading frequency in general but per newspaper. For example, a respondent who read the newspaper De Telegraaf three times a week and the newspaper Metro every day could be exposed to half of the 49 articles that were positive about the smoking ban in De Telegraaf (49 / 2 = 24.5) and all 52 articles that were positive about the smoking ban in Metro. Maximum exposure of this respondent to positive articles on the smoking ban would then be estimated to be $24.5+52=76.5$ articles. We do not assume that this respondent did read all 76.5 articles, but we assume that the relative difference in maximum exposure between respondents indicated the relative differences in actual exposure.

Pearson correlation coefficients were reported between exposure to the implementation campaign and newspaper coverage and support for smoke-free bars and restaurants and SHS harm awareness. Linear regression analysis was used to determine the effect of exposure to the implementation campaign and newspaper coverage on support for smoke-free bars and restaurants and on harm awareness. The dependent variables were post-ban support for smoke-free bars and restaurants and post-ban SHS harm awareness. The predictor variables were gender, age, educational level, recall of exposure to the implementation campaign, estimation of exposure to newspaper coverage about the smoke-free legislation, and the value of the dependent variable on the pre-ban survey. Estimation of exposure to newspaper coverage consisted of four predictors in the regression analyses: (1) 
estimated total number of articles a smoker was exposed to; (2) ratio of coverage about health aspects and coverage about economic aspects, with higher ratios meaning relatively more coverage about health aspects than economic aspects; (3) estimated percentage of articles that were positive towards the smoking ban; and (4) estimated percentage of articles that were mixed or neutral. The percentage of articles that were negative towards the ban had a strong negative correlation with the percentage of positive articles and was therefore not included in the analyses. When, in additional analyses, the percentage of positive articles was replaced by the percentage of negative articles, the regression coefficients of negative newspaper coverage were nearly the same as those of positive newspaper coverage, with the difference that the coefficients were of different signs. The regression analyses were repeated with the interaction between educational level and recall of exposure to the implementation campaign and the interaction between educational level and estimation of exposure to newspaper coverage.

\section{RESULTS}

\section{Characteristics of smoking newspaper readers}

Smokers in the ITC Netherlands Survey who were newspaper readers had a mean age of 39.6 years $(S D=15.5)$, most of the respondents were male $(54 \%)$, and had a moderate educational level (low $30 \%$, moderate $46 \%$, high $23 \%$ ). Readers of the six newspapers differed from each other on age and educational level, but not on gender. For example, readers of De Telegraaf were older (mean age 42.4, SD = 15.3) and had a lower educational level (low $32 \%$, moderate $50 \%$, high $18 \%$ ).

\section{Newspaper coverage of smoke-free legislation}

As can be seen in Table 1, economic aspects of the legislation were mentioned in $618(59 \%)$ of the articles and health aspects in $226(22 \%)$ of the articles. Both economic and health aspects were mentioned in 688 of the articles. Articles that were not about economic or health aspects $(n=353)$ mostly dealt with resistance against the ban, with rules about smoking rooms in bars, and with smoking in coffee shops. There were differences in coverage between newspapers. The total number of articles per newspaper ranged from 94 to 359 articles.

Most articles were negative towards the smoking ban (57\%), while less than a third were positive (29\%), and only a few articles were mixed (5\%) or neutral $(9 \%)$ (Table 2). This was also true for articles in which the economic aspects of the legislation were mentioned (62\% was negative). However, articles in which health aspects were mentioned were about equally positive about the smoking ban (42\%) as negative (43\%). Differences were found in the newspaper coverage over time (Figure 1). There was 
an increase in the number of articles in July 2008, when the smoke-free legislation was implemented. This was followed by a larger increase in the number of articles in the autumn of 2008. These articles were mostly negative about the smoking ban and mainly concerned with economic aspects.

Table 2: Percentage of newspaper coverage that was positive, negative, mixed, and neutral.

\begin{tabular}{llll}
\hline & $\begin{array}{l}\text { Smoke-free } \\
\text { legislation }\end{array}$ & $\begin{array}{l}\text { Economic } \\
\text { aspects }\end{array}$ & Health aspects \\
\hline Positive (\%) & 28.8 & 29.4 & 42.0 \\
Negative (\%) & 57.4 & 61.8 & 42.9 \\
Mixed (\%) & 4.5 & 5.5 & 8.8 \\
Neutral (\%) & 9.2 & 3.2 & 6.2 \\
\hline
\end{tabular}

Figure 1: Newspaper coverage of the smoke-free legislation from March 2008 until April 2009.

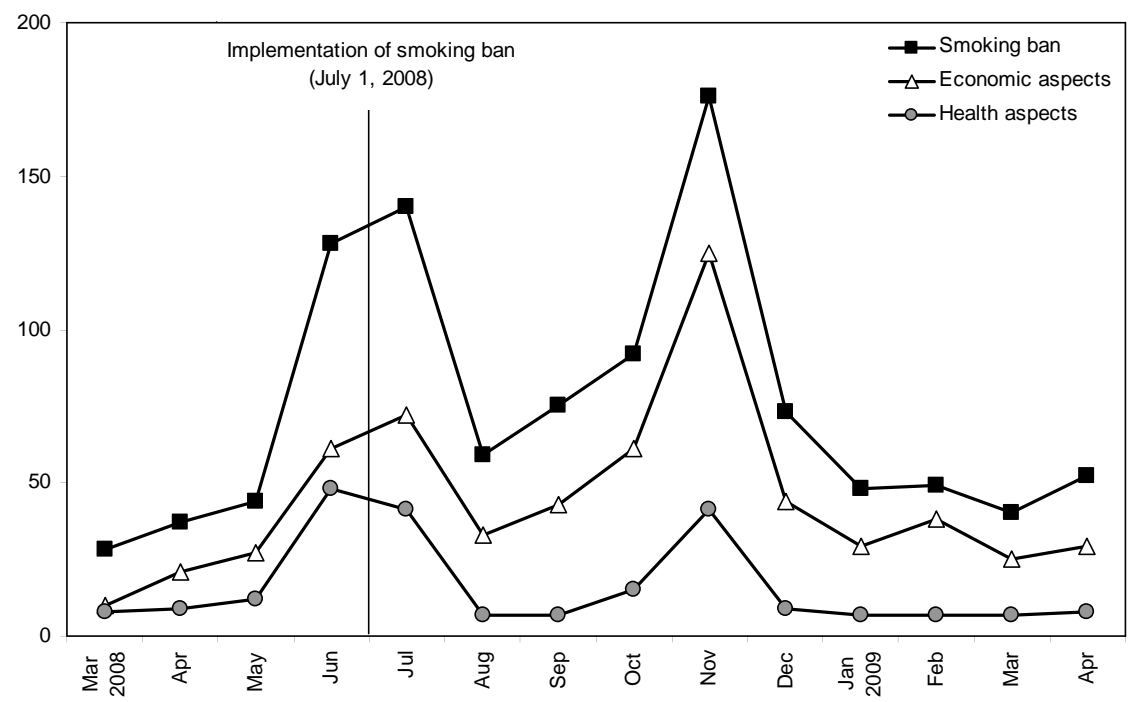




\section{Effects of exposure to media attention}

The correlations between exposure to newspaper coverage and the implementation campaign and support for smoke-free bars and restaurants and SHS harm awareness were generally low (Table 3). There was a negative correlation between exposure to newspaper coverage and support for smoke-free bars and restaurants. There was a positive correlation between the ratio of coverage about health aspects and economic aspects and support for smoke-free bars and restaurants. There was a positive correlation between exposure to mixed or neutral newspaper coverage and support for smoke-free bars and restaurants. In addition, there was a positive correlation between exposure to the implementation campaign and SHS harm awareness.

Table 3: Associations between media attention (implementation campaign and newspaper coverage) and post-ban support for smoke-free bars and restaurants and post-ban SHS harm awareness (correlation coefficients).

\begin{tabular}{lcc}
\hline & $\begin{array}{c}\text { Support smoke-free bars } \\
\text { and restaurants }\end{array}$ & SHS harm awareness \\
\hline Exposure to implementation campaign & 0.00 & $0.12^{\star \star}$ \\
$\begin{array}{l}\text { Exposure to newspaper coverage about } \\
\text { the ban }\end{array}$ & $-0.09^{*}$ & 0.01 \\
$\begin{array}{c}\text { Ratio of coverage about health aspects } \\
\text { and economic aspects }\end{array}$ & $0.11^{* *}$ & 0.03 \\
$\begin{array}{c}\text { Positive newspaper coverage about } \\
\text { the ban }\end{array}$ & -0.07 & -0.02 \\
$\begin{array}{l}\text { Negative newspaper coverage about } \\
\text { the ban }\end{array}$ & 0.02 & 0.00 \\
$\begin{array}{l}\text { Mixed or neutral newspaper coverage } \\
\text { about the ban }\end{array}$ & $0.09^{*}$ & 0.04 \\
\hline
\end{tabular}

$\ddagger A$ higher ratio means relatively more coverage about health aspects than economic aspects

${ }^{*} p<0.05$

${ }^{* *} p<0.01$

The regression analyses showed that exposure to newspaper coverage of the smoke-free legislation had a small negative effect on support for smoke-free bars and restaurants (Table 4). Exposure to the implementation campaign had a small positive effect on SHS harm awareness. There were no significant effects of theme and slant of newspaper coverage.

The regression analyses from Table 4 were repeated with interactions with educational level. The only significant interaction was between educational level and positive newspaper coverage on support for smoke-free bars and restaurants (Beta $=0.10, p=0.012$ ). Among higher educated smokers, exposure to positive newspaper coverage had a more positive effect on support for smoke-free bars and restaurants than among lower educated smokers. 
Table 4: Influence of media attention (implementation campaign and newspaper coverage) on post-ban support for smoke-free bars and restaurants and on post-ban SHS harm awareness (linear regression analyses).

\begin{tabular}{lll}
\hline & $\begin{array}{l}\text { Support smoke-free bars } \\
\text { and restaurants } \\
n=646\end{array}$ & $\begin{array}{l}\text { SHS harm awareness } \\
n=668\end{array}$ \\
\cline { 2 - 3 } & Beta $(95 \% \mathrm{Cl})$ & Beta $(95 \% \mathrm{Cl})$ \\
\hline Pre-ban value of dependent variable & $0.59(0.52 \text { to } 0.65)^{\star *}$ & $0.43(0.36 \text { to } 0.50)^{\star *}$ \\
Gender (men vs. women) & $0.04(-0.02$ to 0.11$)$ & $-0.12(-0.19 \text { to }-0.05)^{\star \star}$ \\
Age & $0.02(-0.04$ to 0.09$)$ & $0.03(-0.05$ to 0.10$)$ \\
Low versus high educational level & $-0.10(-0.19 \text { to }-0.02)^{\star}$ & $0.07(-0.02$ to 0.18$)$ \\
Moderate versus high educational level & $-0.08(-0.16$ to 0.01$)$ & $0.10(0.01 \text { to } 0.19)^{\star}$ \\
Exposure to implementation campaign & $0.02(-0.04$ to 0.08$)$ & $0.11(0.04 \text { to } 0.18)^{\star *}$ \\
$\begin{array}{c}\text { Exposure to newspaper coverage about } \\
\text { the ban }\end{array}$ & $-0.09(-0.14 \text { to }-0.02)^{\star}$ & $0.04(-0.03$ to 0.11$)$ \\
$\begin{array}{c}\text { Ratio of coverage about health aspects } \\
\text { and economic aspectsł }\end{array}$ & $-0.02(-0.10$ to 0.07$)$ & $0.04(-0.05$ to 0.13$)$ \\
$\begin{array}{c}\text { Positive newspaper coverage about } \\
\text { the ban }\end{array}$ & $-0.03(-0.10$ to 0.03$)$ & $-0.02(-0.09$ to 0.06$)$ \\
$\begin{array}{c}\text { Mixed or neutral newspaper coverage } \\
\text { about the ban }\end{array}$ & $0.03(-0.05$ to 0.11$)$ & $0.04(-0.05$ to 0.12$)$ \\
Adjusted $R^{2}$ & 0.37 & 0.23 \\
\hline
\end{tabular}

$¥ A$ higher ratio means relatively more coverage about health aspects than economic aspects

${ }^{*} p<0.05$

${ }^{* *} p<0.01$ 


\section{DISCUSSION}

Our first hypothesis was that exposure to positive newspaper coverage has a more positive effect on support for smoke-free bars and restaurants and on SHS harm awareness than exposure to negative newspaper coverage. However, no effects were found of positive or negative slant of newspaper coverage. We did find that smokers who were exposed to a larger amount of newspaper coverage about the smoke-free legislation were somewhat less likely to support smoke-free bars and restaurants. This might be explained by the fact that newspaper coverage was twice as often negative than positive about the ban.

Our second hypothesis was that exposure to newspaper coverage of health aspects of the smoke-free legislation has a more positive effect on support and harm awareness than coverage of economic aspects. We did indeed find a small positive correlation with support for smoke-free bars and restaurants, but no significant effect in the multivariate analysis. There was, however, very little newspaper coverage about the health aspects of the smoke-free legislation. Newspaper coverage contained almost three times more references to economic aspects than health aspects of the legislation.

Because the implementation campaign of the smoke-free legislation only communicated the date of implementation, our third hypothesis was that the campaign has no effect on support and harm awareness. We found no effects on support for smoke-free bars and restaurants, but we did find a small positive effect on SHS harm awareness. A possible explanation for this unexpected finding is that the campaign stimulated thinking about the reason for the smoking ban and smokers concluded that it was implemented to protect people from the harm of second-hand smoke. However, the fact that support for smoke-free bars and restaurants was not positively influenced by the campaign is a missed opportunity. A clear campaign in which the government explained the health arguments for the smoke-free legislation could have positively influenced smokers' support for the smoke-free legislation. This may also have prevented many of the problems involving compliance with the ban.

Our last hypothesis was that there are more positive effects from media attention among smokers with a higher than lower educational level. We indeed found that newspaper coverage that was positive about the ban had a more positive effect on support for smoke-free bars and restaurants among higher educated smokers than among lower educated smokers. Because more support for smokefree legislation can increase intentions to quit smoking (Brown et al., 2009) this could contribute to a widening of health inequalities. 
Studies about newspaper coverage of the smoke-free legislation in California (Magzamen et al., 2001) and Ireland (Fahy et al., 2009) show that there was a lot of newspaper coverage about the legislation around the implementation date. Our study shows that this is also true for the Netherlands. However, while newspaper coverage of the smoke-free legislation decreased immediately after implementation in California and Ireland, this did not happen in the Netherlands. A few months after the implementation of the Dutch smoke-free legislation, there was a large increase in articles about the legislation. This newspaper coverage was mostly about the resistance of small bars to the legislation, that was organised by a newly formed organisation of small bar owners. Investigative journalism revealed that there were ties between this organisation and the tobacco industry (Baltesen \& Rosenberg, 2009). This suggests that the tobacco industry influenced public opinion about the Dutch smoke-free legislation through media attention.

A limitation of this study is that we estimated the exposure to articles on smoking by combining individual data on the general amount of newspaper reading per newspaper with a content analysis of articles that appeared in each newspaper. We cannot be sure that all readers of a newspaper with many articles on smoking also read these particular articles. Therefore, although we used a longitudinal design, causal relationships could not be established with absolute certainty. Causal effects of exposure to individual articles can be more reliably established in an experimental design, but this severely limits the time period that can be studied (most often, one experimental session) and reduces the ecological validity of the study. A second limitation is that we only looked at coverage of smoking in newspapers and not in other media. This may not be a problem, since the content of newspapers is highly associated with the content of other media (National Cancer Institute, 2008).

A year after the implementation of the smoke-free hospitality industry legislation in the Netherlands, Greece implemented similar legislation. As in the Netherlands, compliance with the ban was less than optimal. It is suggested that the unsupportive and pessimistic newspaper coverage in Greece had an important role in this (Andreou, Gourgoulianis, \& Galantomos, 2010). In contrast to Greece and the Netherlands, the smoke-free legislation in Ireland is known for its immediate success (Smoke Free Partnership, 2006). A qualitative study suggests that this success is the result of the efforts of tobacco control advocates who consistently repeated the health arguments for the legislation in the media and who prevented anti-ban advocates from shifting the debate to the economic arguments against the legislation (Fahy et al., 2009). This suggests that media attention about the health aspects of smoke-free legislation can have an important influence on the success of the legislation. 



\section{Chapter 8}

\section{$\sim \sim \sim$ \\ Policies that reduce the social acceptability of smoking}

Submitted as:

Rennen, E., Nagelhout, G. E., Van den Putte, B., Janssen, E., Mons, U., Guignard, R., Beck, F., De Vries, H., Thrasher, J. F., \& Willemsen, M. C. The effects of tobacco control policy awareness on smoking cessation by reducing the social acceptability of smoking. Findings from the International Tobacco Control (ITC) Europe Surveys. 
This study examined whether awareness of tobacco control policies had an effect on social unacceptability of smoking and whether social unacceptability had an effect on smoking cessation. Also, the possible moderating effects of education and country were investigated. Representative samples ( $n=3,865)$ of adult smokers in France, the Netherlands, and Germany were used from two survey waves of the longitudinal International Tobacco Control (ITC) Europe Surveys. Regression analyses were used to determine effects of tobacco policy awareness (i.e. warning labels, anti-tobacco information, smoking restrictions at work) on aspects of social unacceptability of smoking (i.e. feeling uncomfortable, subjective norm, societal disapproval) and effects of aspects of social unacceptability on quit attempt and quit success. Awareness of antitobacco information and awareness of smoking restrictions at work were related to feeling uncomfortable and to perceived societal disapproval of smoking, while awareness of warning labels was related to the perceived subjective norm about smoking. The subjective norm predicted whether smokers attempted to quit, while feeling uncomfortable and societal disapproval did not. Interactions with education suggested that societal disapproval can have a positive impact on cessation among high educated smokers and may have a negative impact among low educated smokers. We found associations of tobacco control policy awareness with aspects of the social unacceptability of smoking, although these were small. A long-term strategy with ongoing comprehensive tobacco control programs accompanied by mass media campaigns might be needed to substantially change the social acceptability of smoking and reduce tobacco consumption. 


\section{INTRODUCTION}

The social acceptability of smoking is declining. Indicators of a decreased social acceptability of smoking are a negative image of smokers, smoke-free homes, and negative perceptions of the tobacco industry (Chapman \& Freeman, 2008). Denormalisation strategies can be used to reduce the social acceptability of smoking. These strategies are described as "all the programs and actions undertaken to reinforce the fact that tobacco use is not a mainstream or normal activity in our society" (Lavack, 1999). Denormalisation strategies within tobacco control programs have been used in California (California Department of Health Services, 1998) and Canada (Steering Committee of the National Strategy to Reduce Tobacco Use in Canada, 1999) to reduce the social acceptability of smoking as a mechanism to reduce tobacco consumption.

Different tobacco control policies can be used as part of a larger denormalisation strategy. Smoke-free legislation limits the places where smoking is allowed and thus may decrease the social acceptability of smoking (Hamilton, Biener, \& Brennan, 2008; Hammond, Fong, Zanna, Thrasher, \& Borland, 2006; Thrasher, Boado, Sebrié, \& Bianco, 2009; Thrasher, Pérez-Hernández, Swayampakala, Arillo-Santillán, \& Bottai, 2010). Other policies that may have an effect on the social acceptability of smoking are warning labels on tobacco products and media campaigns against smoking (Hammond et al., 2006; Lavack, 1999; Thrasher et al., 2011). Most studies about the effects of policies on social acceptability of smoking focused on one specific policy measure, mainly smoke-free legislation. However, multiple tobacco control policies are often in place or even implemented at the same time. For that reason, this study compares awareness of three tobacco control policies to disentangle which policy measures are most effective in reducing the social acceptability of smoking. One previous study examined this, showing that noticing anti-tobacco information and noticing smoking restrictions were associated with negative perceptions of the social acceptability of smoking, although the associations were weak (Hammond et al., 2006). It is important to investigate whether the effects of these policies on the social acceptability of smoking can be generalised to other countries as well, because this can help policy makers in deciding which policies they should implement in their country as part of a larger denormalisation strategy to reduce tobacco consumption.

In many countries and cultural contexts, the decreased social acceptability of smoking has been shown to reduce tobacco use, through reducing cigarette consumption (Alamar \& Glantz, 2006), increasing quit intentions (Brown et al., 2009; Hammond et al., 2006; Hosking et al., 2009; Van den Putte, Yzer, \& Brunsting, 2005; Zhang, Cowling, \& Tang, 2010), and by increasing smoking cessation (Hammond 
et al., 2006; Hosking et al., 2009; Thrasher, Pérez-Hernández et al., 2010; Zhang et al., 2010). However, different aspects of social acceptability of smoking have been examined in different studies making comparisons difficult. Whereas several studies examined whether smokers feel uncomfortable about smoking (Brown et al., 2009; Hammond et al., 2006; Thrasher et al., 2009), other studies examined the perceived subjective norm about the disapproval of smoking among people who are important to them (Brown et al., 2009; Hammond et al., 2006; Thrasher et al., 2009; Thrasher, Pérez-Hernández et al., 2010), or the perceived societal disapproval of smoking (Brown et al., 2009; Hammond et al., 2006; Nagelhout, Mons et al., 2011; Thrasher et al., 2009; Thrasher, Pérez-Hernández et al., 2010). In the current study, we will therefore examine all these aspects of social acceptability of smoking separately and establish their relations with awareness of tobacco control policies and smoking cessation.

In our study, surveys of the International Tobacco Control Policy Evaluation Project (ITC Project) from France, the Netherlands, and Germany were used, while focusing on awareness of three tobacco control policies: warning labels, smoking restrictions at work, and anti-tobacco information. All three countries required text warning labels on tobacco products at the time of the surveys according to the EU Tobacco Products Directive (2001/37/EC). However, the labels were found to have a greater self-reported impact on smoking behaviour in France than in the Netherlands and Germany (Hitchman et al., 2011). Since 2004, smoke-free workplaces have been in place in Germany and the Netherlands. France implemented smoke-free legislation for workplaces in 2007. In-between the two ITC survey waves that were used in this study, all three countries extended their smoke-free legislation to include the hospitality industry (Nagelhout, Mons et al., 2011). Anti-tobacco information was more extensive in France and the Netherlands than in Germany, evidenced by higher public information campaign spending in these countries (Joossens \& Raw, 2007).

The effects of tobacco control policy awareness on social unacceptability of smoking and smoking cessation are examined in this study by using the Conceptual Model of the ITC Project (Fong, Cummings, Borland et al., 2006). The model hypothesises a causal chain from policy (e.g. smoking restrictions at work) to policy-relevant outcomes (e.g. quit attempt), through policy-specific variables (e.g. awareness of smoking restrictions at work) and psychosocial mediators (e.g. social acceptability of smoking). According to this model, the impact of tobacco control policies on individuals can be understood only by examining experiences from the individual with these policies, which are conceptualised in this study as smokers' awareness of tobacco control policies. In a previous study, we applied the 
ITC Conceptual Model to smoke-free legislation and found a mediated effect from individual awareness of smoke-free legislation on smoking cessation via policyspecific variables and psychosocial mediators (Nagelhout, De Vries, Fong et al., 2012).

Education is included as a possible moderating factor in the ITC Conceptual Model (Fong, Cummings, Borland et al., 2006). Smoking is more prevalent among people with a lower education, and they are less likely to quit (Schaap et al., 2008), both of which may be explained by differences in social norms across educational groups. For example, one study found that smokers with higher education experienced more social unacceptability of smoking than smokers with lower education (Hammond et al., 2006), and another study showed that social unacceptability of smoking has more impact on smoking patterns of higher educated smokers compared to lower educated smokers (Stuber, Galea, \& Link, 2008). Studying educational differences is important because denormalisation strategies could increase differences in smoking behaviour between educational groups which could result in a widening of health inequalities.

This study aimed at examining relationships between tobacco control policies, the social unacceptability of smoking, and smoking cessation. The following research questions were formulated: 1) which policy awareness factors (warning labels, anti-tobacco information and smoking restrictions at work) are associated with aspects of social unacceptability of smoking? and 2) which aspects of social unacceptability of smoking predict smoking cessation? In addition, the possible moderating effects of education and country were explored for both research questions.

\section{METHODS}

\section{Sample}

The ITC Project is a prospective cohort study among adult smokers that aims at evaluating the effect of national-level tobacco control policies on psychosocial factors and smoking behaviour (Fong, Cummings, Borland et al., 2006). More information about ITC survey methods can be found elsewhere (Thompson et al., 2006). In this study, two survey waves of ITC France, the Netherlands, and Germany were used. Participants in the survey were smokers aged 18 years and older, who have smoked more than 100 cigarettes in their life, and smoked at least monthly at baseline.

A random digit dialing (RDD) telephone design was used to yield a representative sample of smokers within each country. Respondents were interviewed with computer assisted telephone interviewing (CATI). In the Netherlands, a web- 
based sample from the TNS NIPObase was also used, surveyed with computer assisted web interviewing (CAWI) (Nagelhout et al., 2010). Because results from the ITC Netherlands Survey revealed significant differences between telephone and web interviewing for one of the aspects of social unacceptability of smoking (feeling uncomfortable: $\mathrm{t}=3.23, \mathrm{p}=0.001$ ), mode of interviewing was added as predictor variable in all multivariate analyses in order to control for this difference.

In total, 5,322 smokers were surveyed at baseline and 3,865 smokers also completed the follow-up survey (72.6\%). Respondents who were followed-up and who were not followed-up did not differ on most baseline measures that were used in this study. However, respondents lost to follow-up were significantly younger (t $=-8.44, p<0.001)$, had more intention to quit $\left(\chi^{2}=6.98, p=0.008\right)$, were slightly more aware of warning labels $(t=2.04, p=0.041)$, and slightly more often agreed that there are fewer and fewer places where they feel comfortable smoking $(t=$ $-2.50, p=0.013)$. The time interval between the two surveys was about one year in the Netherlands and two years in France and Germany. See Table 1 for exact data collection periods, sample sizes, and follow-up rates per country.

Table 1: Fieldwork periods, sample sizes and retention rates for France, the Netherlands and Germany

\begin{tabular}{|c|c|c|c|c|c|}
\hline Country & $\begin{array}{l}\text { Baseline survey } \\
\text { Data collection period }\end{array}$ & $\begin{array}{l}\text { No. of } \\
\text { smokers }\end{array}$ & $\begin{array}{l}\text { Follow-up survey } \\
\text { Fieldwork period }\end{array}$ & $\begin{array}{l}\text { No. of } \\
\text { smokers }\end{array}$ & $\begin{array}{l}\text { Follow-up } \\
\text { rate (\%) }\end{array}$ \\
\hline France & December 2006 - & 1,735 & September 2008 - & 1,231 & 71.0 \\
\hline The Netherlands & $\begin{array}{l}\text { February } 2007 \\
\text { March } 2008 \text { - April }\end{array}$ & 2,072 & $\begin{array}{l}\text { December } 2008 \\
\text { March } 2009 \text { - May }\end{array}$ & $1,632^{\mathrm{a}}$ & 78.8 \\
\hline Germany & 2008 July 2007 - & 1,515 & $\begin{array}{l}2009 \\
\text { July } 2009 \text { - October }\end{array}$ & 1,002 & 66.1 \\
\hline Total & November 2007 & 5,322 & & 3,865 & 72.6 \\
\hline
\end{tabular}

a Dutch smokers per interviewing mode: $C A T I n=266$, CAWI $n=1,366$.

\section{Measures}

Survey questions in the ITC Surveys were standardised across countries. Control variables were age, gender, education, heaviness of smoking, intention to quit, quit attempt in the last year, country, and interviewing mode, all collected at baseline. Age was categorised into four groups: 18 to 24,25 to 39,40 to 54 , and 55 years and older. Education was categorised into three levels (low, moderate, and high) that were roughly comparable across the three countries because of differences in educational systems. Heaviness of smoking was assessed with the Heaviness of Smoking Index (HSI) which was created as the sum of two categorised measures: number of cigarettes per day and time before smoking the first cigarette of the day (Heatherton et al., 1989). HSI values range from 0 to 6 and have been shown to be 
positively associated with nicotine dependence. Intention to quit was categorised into having plans to quit within six months (1) and having no plans to quit within six months (0). People who attempted to quit in the last year (1) were distinguished from people who did not attempt to quit in the last year (0).

The levels of awareness of three different policies were included (Hammond et al., 2006). Awareness of warning labels was measured with the question: "In the last month, how often have you noticed the warning labels on cigarette packages or on roll-your-own packs?" Awareness of anti-tobacco information was measured by asking: "In the last 6 months, how often have you noticed advertising or information that talks about the dangers of smoking, or encourages quitting?" Response options for these two questions were on a 5-point scale from never (1) to very often (5). To measure smoking restrictions at work, respondents were asked: "Which of the following best describes the smoking policy where you work?" with the categories no restrictions (0), some restrictions (1), and completely restricted (2). Respondents without a job or with an outdoor job were placed in the category 'no restrictions' (Thrasher et al., 2009).

Each of the three aspects of social unacceptability of smoking was measured with one statement. Feeling uncomfortable about smoking was measured with the statement "There are fewer and fewer places where I feel comfortable about smoking" (Brown et al., 2009; Hammond et al., 2006; Thrasher et al., 2009). Perceived subjective norm about smoking from people who are important was measured with the statement "People who are important to me believe that I should not smoke" (Hammond et al., 2006; Thrasher et al., 2009; Thrasher et al., 2011; Thrasher, PérezHernández et al., 2010; Van den Putte, Yzer, \& Brunsting, 2005). Perceived societal disapproval was measured with the statement "Society disapproves of smoking" (Brown et al., 2009; Hammond et al., 2006; Nagelhout, Mons et al., 2011; Thrasher et al., 2009). Answers on the three statements were given on a 5-point Likert scale, ranging from strongly disagree (1) to strongly agree (5).

Quit attempt (0: no quit attempt; 1: quit attempt) was measured by asking respondents at the second survey whether they had made any attempts to quit smoking since the first survey. Quit success (0: no quit success 1: quit success) was assessed by asking respondents who had attempted to quit whether they were back to smoking or still stopped. Respondents who were still stopped, or who were back to smoking but reporting smoking less than once a month, were defined as successful quitters. Respondents who were back to smoking more than once a month, were defined as smokers (Hyland, Borland et al., 2006). 


\section{Data analysis}

All analyses were conducted with SPSS version 19.0 and adjusted for sampling weights by age and gender, to make the results representative of the adult smoking population in each country. The analyses were restricted to respondents who completed both the baseline and the follow-up survey. Differences between countries and educational levels at baseline were tested with chi-square tests.

Bivariate and multivariate linear regression analyses were performed to determine correlates of the aspects of social unacceptability of smoking at baseline. Separate models were run for each aspect of social unacceptability (feeling uncomfortable, subjective norm, societal disapproval), with the three policy awareness variables included as independent variables. Multivariate analyses were controlled for gender, age, education, interviewing mode, heaviness of smoking, quit attempt in the last year, intention to quit, and country. To test the possible moderating effects of country and education, policy awareness $x$ country interaction variables and policy awareness $x$ education interaction variables were included in separate regression analyses. High education was used as reference category for interaction analyses with education. France was used as reference country for interaction analyses with country.

To examine whether aspects of social unacceptability of smoking at baseline predicted attempting to quit and having quit successfully at follow-up, bivariate and multivariate logistic regression analyses were used. Quit attempt and quit success at wave 2 were used as dependent variables in separate models, with the three aspects of social unacceptability of smoking at wave 1 as independent variables. Multivariate analyses were controlled for gender, age, education, interviewing mode, heaviness of smoking, quit attempt in the last year, intention to quit, and country. Between-country differences were assessed by including unacceptability aspect $x$ country interaction variables. To assess whether educational level acts as a moderator, unacceptability aspect $x$ education interaction variables were entered in separate analyses.

\section{RESULTS}

\section{Sample characteristics by country}

Demographics, smoking behaviour, policy awareness, and aspects of social unacceptability by country are shown in Table 2 . Significant differences were found between the countries on all variables except for gender.

Large significant differences between countries were found for the awareness of warning labels and the awareness of anti-tobacco information: awareness was higher in France than in Germany and the Netherlands. Country 
differences in the awareness of smoking restrictions at work were considerably smaller. Overall, $21.2 \%$ of the respondents noticed warning labels very often, $5.2 \%$ noticed anti-tobacco information very often and $32.5 \%$ reported that smoking was completely restricted at work.

Table 2: Differences between countries on demographics, smoking behaviour, policy awareness, and aspects of social unacceptability at wave 1 (\%).

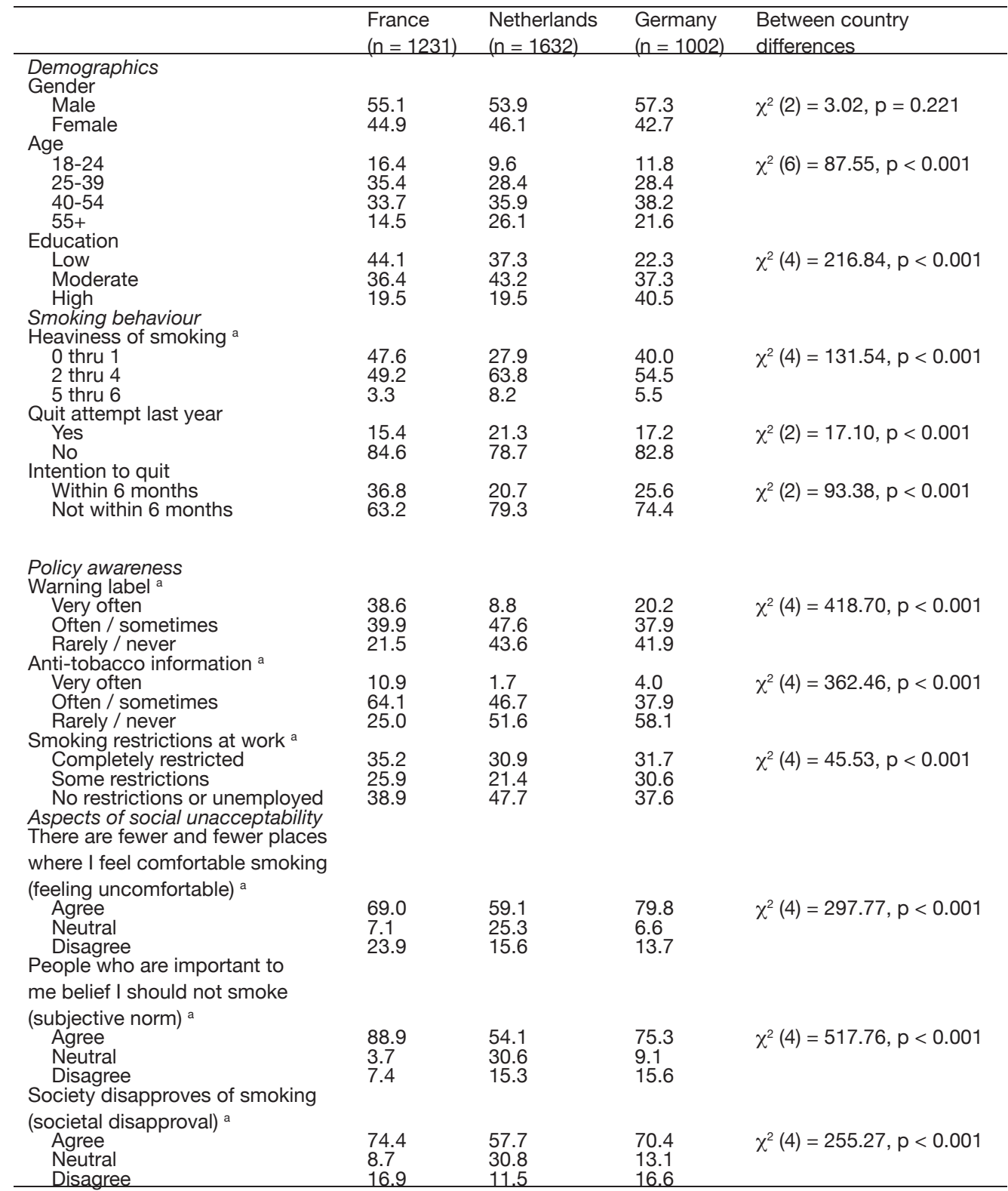

a Heaviness of smoking, policy awareness variables, and social unacceptability aspects are used as continuous variables in regression analyses. 
In France, smokers had a stronger perception that people who are important to them believe they should not smoke and that society disapproves of smoking compared with Germany and the Netherlands. In Germany, smokers stronger reported that there are fewer and fewer places where they felt comfortable smoking. The perception of social unacceptability of smoking was lowest among Dutch smokers. Dutch smokers scored more often neutral on the three aspects of social unacceptability compared with smokers from the other countries. Overall, $67.6 \%$ of the respondents agreed that there are fewer and fewer places where they feel comfortable smoking, $70.7 \%$ agreed that people important to them think they should not smoke and $66.3 \%$ agreed that society disapproves of smoking.

\section{Aspects of social unacceptability by educational level}

Significant differences between educational levels were found for whether smokers feel uncomfortable about smoking $\left(\chi^{2}=13.40, p=0.009\right)$. Higher educated smokers $(72.1 \%)$ reported more often than moderately $(67.2 \%)$ and lower educated smokers $(65.3 \%)$ that there are fewer and fewer places where they feel comfortable smoking. No significant differences were found for subjective norm and societal disapproval between smokers from different educational levels.

\section{Correlates of social unacceptability}

To examine which policy awareness factors were associated with the social unacceptability of smoking, we first performed bivariate linear regression analyses (not shown in table). Smokers who were more aware of warning labels significantly more often thought that others believe they should not smoke $(\beta=0.15, p<0.001)$. Higher awareness of anti-tobacco information was significantly associated with all aspects of the social unacceptability of smoking (feeling uncomfortable $\beta=0.08, p<$ 0.001 , subjective norm $\beta=0.14, p<0.001$, societal disapproval $\beta=0.09, p<0.001$ ). Higher awareness of smoking restrictions at work was significantly associated with thinking that others believe they should not smoke $(\beta=0.04, p=0.017)$ and thinking that society disapproves of smoking $(\beta=0.08, p<0.001)$.

We also performed multivariate linear regression analyses (Table 3 ). After adjustment for demographic and smoking-related variables, smokers who were more aware of warning labels more often thought that others believe they should not smoke $(\beta=0.04, p=0.022)$. Smokers who were more aware of antitobacco information believed more often that there are fewer and fewer places where they feel comfortable smoking $(\beta=0.08, p<0.001)$ and felt stronger that society disapproves of smoking ( $\beta=0.05, p=0.005$ ). More awareness of smoking restrictions at work was also associated with feeling uncomfortable about smoking 
$(\beta=0.04, p=0.033)$ and with a stronger belief that society disapproves of smoking $(\beta=0.05, p=0.002)$. All relationships between policy awareness factors and factors of social unacceptability of smoking were small.

In additional interaction analyses (not shown in table), one significant interaction ( $\beta=0.09, p=0.034)$ between restrictions at work and educational level on subjective norm was found. The interaction suggest that there may be a small negative effect of restrictions at work on subjective norm among low educated smokers, however the main effects were not significant (low education $\beta=-0.03$, $p=0.216$; moderate education $\beta=0.03, p=0.172$; high education $\beta=0.01, p=$ $0.717)$.

No significant policy awareness by country interactions were found.

Table 3: Multivariate linear regression analyses of aspects of social unacceptability of smoking at wave 1.

\begin{tabular}{|c|c|c|c|}
\hline & Feeling uncomfortable & Subjective norm & Societal disapproval \\
\hline Variable & Beta $(95 \% \mathrm{Cl})$ & Beta $(95 \% \mathrm{Cl})$ & Beta $(95 \% \mathrm{Cl})$ \\
\hline \multicolumn{4}{|l|}{ Demographics } \\
\hline Gender & & & \\
\hline $\begin{array}{l}\text { Female } \\
\text { Male }\end{array}$ & $\begin{array}{l}0.08(0.05 \text { to } 0.11)^{\star \star \star} \\
0.00\end{array}$ & $\begin{array}{l}0.04(0.01 \text { to } 0.07)^{\star \star} \\
0.00\end{array}$ & $\begin{array}{l}0.08(0.05 \text { to } 0.11)^{\star \star \star} \\
0.00\end{array}$ \\
\hline \multicolumn{4}{|l|}{ Age } \\
\hline $\begin{array}{l}18-24 \\
25-39 \\
40-54 \\
55+\end{array}$ & $\begin{array}{l}-0.25(-0.30 \text { to }-0.22)^{\star \star \star *} \\
-0.16(-0.21 \text { to }-0.12)^{\star \star \star} \\
-0.07(-0.12 \text { to }-0.03)^{\star \star \star} \\
0.00\end{array}$ & $\begin{array}{l}-0.06(-0.10 \text { to }-0.03)^{\star \star \star} \\
-0.04(-0.08 \text { to } 0.00) \\
0.00(-0.04 \text { to } 0.04) \\
0.00\end{array}$ & $\begin{array}{l}-0.09(-0.13 \text { to }-0.05)^{\star \star *} \\
-0.01(-0.05 \text { to } 0.04) \\
0.06(0.01 \text { to } 0.10)^{*} \\
0.00\end{array}$ \\
\hline \multicolumn{4}{|l|}{ Education } \\
\hline $\begin{array}{l}\text { Low } \\
\text { Moderate } \\
\text { High }\end{array}$ & $\begin{array}{l}-0.03(-0.07 \text { to } 0.01) \\
-0.01(-0.05 \text { to } 0.03) \\
0.00\end{array}$ & $\begin{array}{l}0.00(-0.04 \text { to } 0.04) \\
0.02(-0.01 \text { to } 0.06) \\
0.00\end{array}$ & $\begin{array}{l}0.02(-0.03 \text { to } 0.05) \\
0.02(-0.02 \text { to } 0.06) \\
0.00\end{array}$ \\
\hline \multicolumn{4}{|l|}{ Interview mode } \\
\hline $\begin{array}{l}\text { CAWI } \\
\text { CATI }\end{array}$ & $\begin{array}{l}-0.07(-0.14 \text { to }-0.01)^{\star} \\
0.00\end{array}$ & $\begin{array}{l}0.01(-0.05 \text { to } 0.07) \\
0.00\end{array}$ & $\begin{array}{l}0.03(-0.03 \text { to } 0.10) \\
0.00\end{array}$ \\
\hline \multicolumn{4}{|l|}{ Country } \\
\hline $\begin{array}{l}\text { Netherlands } \\
\text { Germany } \\
\text { France }\end{array}$ & $\begin{array}{l}-0.03(-0.10 \text { to }-0.03) \\
0.06(0.02 \text { to } 0.09)^{\star \star} \\
0.00\end{array}$ & $\begin{array}{l}-0.37(-0.44 \text { to }-0.31)^{\star \star \star} \\
-0.19(-0.23 \text { to }-0.16)^{\star \star \star} \\
0.00\end{array}$ & $\begin{array}{l}-0.18(-0.24 \text { to }-0.11)^{\star \star \star} \\
-0.07(-0.11 \text { to }-0.03)^{\star \star \star} \\
0.00\end{array}$ \\
\hline \multicolumn{4}{|l|}{ Smoking behaviour } \\
\hline $\begin{array}{l}\text { Heaviness of smoking } \\
\text { Quit attempt last year }\end{array}$ & $\begin{array}{l}0.02(-0.01 \text { to } 0.05) \\
0.00\end{array}$ & $\begin{array}{c}-0.03(-0.06 \text { to } 0.00) \\
0.01(-0.02 \text { to } 0.04)\end{array}$ & $\begin{array}{r}-0.01(-0.05 \text { to } 0.02) \\
0.01(-0.02 \text { to } 0.05)\end{array}$ \\
\hline $\begin{array}{l}\text { Intention to quit } \\
\text { Policy awareness }\end{array}$ & $0.04(0.01 \text { to } 0.07)^{\star}$ & $0.17(0.14 \text { to } 0.20)^{\star \star \star}$ & $0.09(0.05 \text { to } 0.12)^{\star \star \star}$ \\
\hline $\begin{array}{l}\text { Warning label } \\
\text { Anti-tobacco } \\
\text { information }\end{array}$ & $\begin{array}{r}-0.02(-0.05 \text { to } 0.01) \\
0.08(0.04 \text { to } 0.11)^{\star \star \star}\end{array}$ & $\begin{array}{l}0.04(0.01 \text { to } 0.07)^{\star} \\
0.02(-0.02 \text { to } 0.05)\end{array}$ & $\begin{array}{l}-0.03(-0.06 \text { to } 0.00) \\
0.05(0.02 \text { to } 0.08)^{\star \star}\end{array}$ \\
\hline $\begin{array}{l}\text { Smoking restrictions } \\
\text { at work }\end{array}$ & $0.04(0.00 \text { to } 0.07)^{*}$ & $0.01(-0.02$ to 0.04$)$ & $0.05(0.02 \text { to } 0.08)^{\star \star}$ \\
\hline
\end{tabular}

${ }^{*} p<0.05$

** $p<0.01$

${ }^{* * *} p<0.001$

\section{Predictors of smoking cessation}

In total, $35.8 \%$ of respondents attempted to quit between baseline and follow-up, while $34.9 \%$ of those attempting to quit did not smoke at the time of follow-up. There were no significant differences between the three countries on quit attempts $\left(\chi^{2}=4.19, p=0.123\right)$ and quit success $\left(\chi^{2}=1.54, p=0.463\right)$. 
To examine which aspects of social unacceptability of smoking predicted quit attempts and quit success, we first performed bivariate logistic regression analyses (not shown in table). Smokers who perceived a stronger subjective norm about smoking were more likely to attempt to quit smoking at follow-up (Odds Ratio $(\mathrm{OR})=$ $1.27, p<0.001)$. Also, smokers who perceived that society disapproves of smoking were more likely to attempt to quit $(O R=1.09, p=0.007$ ). Feeling uncomfortable was not predictive of attempting to quit smoking. None of the social unacceptability aspects predicted whether a quit attempt was successful.

We also performed multivariate logistic regression analyses (Table 4). Smokers who perceived a stronger subjective norm about smoking were more likely to attempt to quit smoking at follow-up $(O R=1.16, p<0.001)$. Feeling uncomfortable and perceived societal disapproval did not predict whether a smoker attempted to quit. In the multivariate analyses we also found that none of the social unacceptability aspects predicted whether a quit attempt was successful.

Two significant interactions between aspects of social unacceptability and education were found on attempting to quit smoking in additional interaction analyses (not shown in table). There was a significant interaction between feeling uncomfortable and education ( $O R=0.91, p=0.021$ ). It seemed that high educated smokers less often attempted to quit smoking when they felt that there are fewer and fewer places where it is comfortable to smoke, but the main effects were not significant (low education $\mathrm{OR}=1.03, \mathrm{p}=0.649$; moderate education $\mathrm{OR}=0.95, \mathrm{p}=$ 0.347 ; high education $\mathrm{OR}=0.87, \mathrm{p}=0.062$ ). There was also a significant interaction between societal disapproval and education $(O R=1.13, p=0.009)$. This interaction suggested that high educated smokers who perceived societal disapproval of smoking had higher odds of attempting to quit smoking. With this interaction, the main effects stratified by educational level were also not significant (low education $\mathrm{OR}=0.94, \mathrm{p}=0.326$; moderate education $\mathrm{OR}=1.01, \mathrm{p}=0.830$; high education $\mathrm{OR}$ $=1.16, p=0.060$ ).

Interaction analyses for quit success showed that the interaction between subjective norm and education was significant $(O R=0.85, p=0.049)$. A higher subjective norm seemed to predict more quit success among low educated smokers, but the main effects were not significant (low education $O R=1.19, p$ $=0.163$; moderate education $\mathrm{OR}=1.03, \mathrm{p}=0.798$; high education $\mathrm{OR}=0.89$, $\mathrm{p}=0.332$ ). Also, the interaction between societal disapproval and education was significant $(O R=0.72, p=0.029)$. This interaction suggested that more societal disapproval may predict more quit success among high educated smokers and less quit success among low educated smokers. The main effects for each education group were, however, not significant (low education $\mathrm{OR}=0.87, \mathrm{p}=0.163$; moderate 
education $\mathrm{OR}=1.02, \mathrm{p}=0.847$; high education $\mathrm{OR}=1.21, \mathrm{p}=0.112$ ).

No significant country by social unacceptability interactions were found for both quit attempt and quit success.

Table 4: Multivariate logistic regression analyses with aspects of social acceptability at baseline as predictors of quit attempt and quit success at follow-up.

\begin{tabular}{|c|c|c|}
\hline & Quit attempt & Quit success \\
\hline Variable & Odds Ratio $(95 \% \mathrm{Cl})$ & Odds Ratio $(95 \% \mathrm{Cl})$ \\
\hline \multicolumn{3}{|l|}{ Demographics } \\
\hline \multicolumn{3}{|l|}{ Gender } \\
\hline $\begin{array}{l}\text { Female } \\
\text { Male }\end{array}$ & $\begin{array}{l}1.01(0.88-1.17) \\
1.00\end{array}$ & $\begin{array}{l}0.85(0.67-1.07) \\
1.00\end{array}$ \\
\hline \multicolumn{3}{|l|}{ Age } \\
\hline $18-24$ & $0.91(0.71-1.18)$ & $0.57(0.37-0.87)^{\star \star}$ \\
\hline $25-39$ & $1.06(0.81-1.31)$ & $0.91(0.66-1.26)$ \\
\hline $40-54$ & $0.84(0.69-1.03)$ & $0.82(0.59-1.13)$ \\
\hline $55+$ & 1.00 & 1.00 \\
\hline \multicolumn{3}{|l|}{ Education } \\
\hline Low & $0.99(0.81-1.20)$ & $0.77(0.57-1.04)$ \\
\hline $\begin{array}{l}\text { Moderate } \\
\text { High }\end{array}$ & $0.86(0.71-1.03)$ & $0.76(0.57-1.01)$ \\
\hline \multicolumn{3}{|l|}{ Interview mode } \\
\hline CAWI & $0.88(0.66-1.18)$ & $0.75(0.47-1.19)$ \\
\hline \multicolumn{3}{|l|}{ Smoking behaviour } \\
\hline Heaviness of smoking & $0.90(0.86-0.95)^{\star \star \star}$ & $0.84(0.77-0.90)^{\star \star \star}$ \\
\hline Quit attempt last year & $2.18(1.82-2.60)^{\star \star \star}$ & $0.66(0.50-0.86)^{\star \star}$ \\
\hline Intention to quit & $3.24(2.76-3.80)^{\star \star \star}$ & $0.80(0.63-1.03)$ \\
\hline \multicolumn{3}{|l|}{ Country } \\
\hline Netherlands & $1.33(0.98-1.80)$ & $1.39(0.87-2.23)$ \\
\hline Germany & $1.15(0.95-1.41)$ & $1.09(0.80-1.48)$ \\
\hline \\
\hline $\begin{array}{l}\text { Aspects of soclal unacceptability } \\
\text { Feeling uncomfortable }\end{array}$ & $0.96(0.90-1.03)$ & $1.08(0.97-1.20)$ \\
\hline Subjective norm & $1.16(1.07-1.24)^{\star \star \star}$ & $1.05(0.93-1.19)$ \\
\hline Societal disapproval & $1.02(0.95-1.09)$ & $1.00(0.89-1.12)$ \\
\hline
\end{tabular}

${ }^{*} p<0.05$

${ }^{* *} p<0.01$

${ }^{* * *} p<0.001$

\section{DISCUSSION}

Awareness of anti-tobacco information and smoking restrictions were found to be positively associated with both feeling uncomfortable about smoking and perceived societal disapproval of smoking. Awareness of warning labels was associated with a higher subjective norm. These results are comparable with earlier findings from the United States, Canada, the United Kingdom, and Australia showing that especially exposure to anti-tobacco information and smoking restrictions were associated with reduced social acceptability of smoking (Hammond et al., 2006). What this earlier study did not show, was that only subjective norms were predictive of quit attempts. These results imply that tobacco control policies should focus more on changing subjective norms than on stimulating societal disapproval, especially because the latter could also lead to the stigmatisation of smokers (Bell, McCullough, Salmon, \& Bell, 2010). Warning labels and anti-smoking campaigns have the potential to change 
subjective norms by stimulating social support and interpersonal communication with friends and family. We did not find strong associations between awareness of these policies and subjective norms in this study, possible because France, the Netherlands, and Germany did not have strong warning labels and anti-smoking campaigns at the time of the ITC surveys.

The observed relationships between policy awareness, social acceptability of smoking, and quit attempt and quit success were similar between France, the Netherlands, and Germany. Actions to reduce the social acceptability of smoking may be most needed in the Netherlands, as only $58 \%$ of Dutch smokers agreed that society disapproves of smoking, compared to about $70 \%$ in France and Germany and about $80 \%$ in the United Kingdom, United States, Canada, and Australia (Hammond et al., 2006).

Smoking restrictions, anti-smoking campaigns, and graphic warning labels could contribute to reduce the social acceptability of smoking, but further research is needed to understand their effects across socioeconomic groups. We found several interactions with educational level, but because the main associations were weak the effects stratified by educational level were not significant. For both quit attempts and quit success, the interactions with educational level suggested that more societal disapproval can have a positive impact on cessation among high educated smokers, while it may have a negative impact on cessation among low educated smokers. This finding is in line with previous research (Stuber et al., 2008).

The most important strength of this study is the use of large representative samples of smokers from three countries. However, there were also some limitations. Differences between the three countries in time of data collection and time interval between the waves can influence comparisons of the three countries. However, this may not have had a large influence, because we did not find any significant country interactions. A common problem with longitudinal studies is the loss of respondents to follow-up, which could have affected our results. Finally, the measurement of social unacceptability of smoking was somewhat limited. It would be an asset for future studies to use more items to be able to measure each aspect of social acceptability more thoroughly. Also, it is possible that there are other aspects of social acceptability of smoking that were not examined in this study, such as descriptive norms (Van den Putte, Yzer, \& Brunsting, 2005). We would therefore recommend future research in this field to establish the various dimensions of social acceptability of smoking and to develop and validate measurements for individual constructs.

Our study has important implications for tobacco control programs that aim at influencing tobacco consumption through reducing the social acceptability of 
smoking. We found associations of tobacco control policy awareness with aspects of the social unacceptability of smoking, although these were small. This suggests that reducing tobacco consumption by substantially changing the social acceptability of smoking through tobacco control policies might indeed be a long-term process that requires strong comprehensive policies. The study period of our study of one to two years might be too short to find substantial effects on the social acceptability of smoking. It has been shown in California that a long-term comprehensive tobacco control program with a social-norm change paradigm can stimulate quit attempts and reduce tobacco consumption (Zhang et al., 2010). Changing the social acceptability of smoking might thus need ongoing comprehensive tobacco control programs accompanied by mass media campaigns to ultimately influence smoking behaviour in the population. 


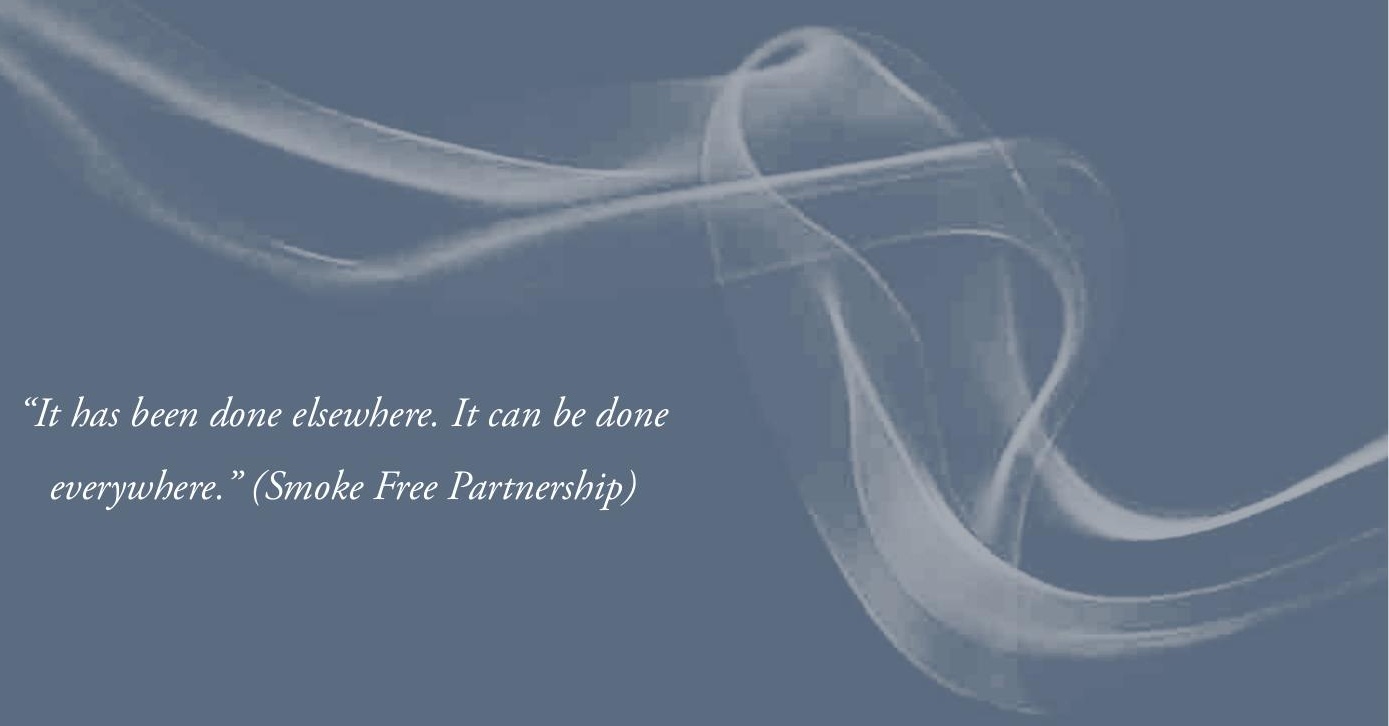




\section{Chapter 9}

\section{Smoking in bars after smoke-free legislation}

\section{Published as:}

Nagelhout, G. E., Mons, U., Allwright, S., Guignard, R., Beck, F., Fong, G. T., De Vries, H., \& Willemsen, M. C. (2011). Prevalence and predictors of smoking in "smoke-free" bars. Findings from the International Tobacco Control (ITC) Europe Surveys. Social Science \& Medicine, 72, 1643-1651. 
National-level smoke-free legislation is implemented to protect the public from exposure to second-hand tobacco smoke (SHS). The first aim of this study was to investigate how successful the smoke-free hospitality industry legislation in Ireland (March 2004), France (January 2008), the Netherlands (July 2008), and Germany (between August 2007 and July 2008) was in reducing smoking in bars. The second aim was to assess individual smokers' predictors of smoking in bars post-ban. The third aim was to examine country differences in predictors and the fourth aim to examine differences between educational levels (as an indicator of socioeconomic status). This study used nationally representative samples of 3,147 adult smokers from the International Tobacco Control (ITC) Europe Surveys who were surveyed pre- and post-ban. The results reveal that while the partial smoke-free legislation in the Netherlands and Germany was effective in reducing smoking in bars (from $88 \%$ to $34 \%$ and from $87 \%$ to $44 \%$ respectively), the effectiveness was much lower than the comprehensive legislation in Ireland and France which almost completely eliminated smoking in bars (from $97 \%$ to $3 \%$ and from $84 \%$ to $3 \%$ respectively). Smokers who were more supportive of the ban, were more aware of the harm of SHS, and who had negative opinions of smoking were less likely to smoke in bars post-ban. Support for the ban was a stronger predictor in Germany. SHS harm awareness was a stronger predictor among less educated smokers in the Netherlands and Germany. The results indicate the need for strong comprehensive smoke-free legislation without exceptions. This should be accompanied by educational campaigns in which the public health rationale for the legislation is clearly explained. 


\section{INTRODUCTION}

National-level smoke-free legislation is implemented to protect the public from exposure to second-hand tobacco smoke (SHS) (World Health Organization, 2003). It is a key policy under the World Health Organization (WHO) Framework Convention on Tobacco Control (FCTC), which has, as of September 2010 been ratified by over 170 countries. Smoke-free legislation is being implemented in various settings and is more successful in reducing SHS in some settings than in others. Smokefree bars are often less successful in reducing SHS than smoke-free restaurants or workplaces (Borland, Yong, Siahpush et al., 2006; Thrasher, Pérez-Hernández et al., 2010). Many consider bars as the "last bastion" of socially acceptable smoking (Magzamen \& Glantz, 2001). Therefore, the tobacco industry fights harder to keep bars from becoming smoke-free than in any other setting (Ling \& Glantz, 2002). This has resulted in lower rates of compliance with smoking bans in bars and designated smoking rooms in bars being permitted in a considerable number of countries (Magzamen \& Glantz, 2001; Smoke Free Partnership, 2006).

Studies have shown that comprehensive smoke-free legislation leads to more reductions in exposure to SHS and improvements in health than legislation with designated smoking rooms or other exceptions (Fernández et al., 2009; World Health Organization, 2007b). This implies that the comprehensiveness of the legislation affects the level of smoking that may remain in bars after the implementation. However, individual smokers' characteristics may also affect whether smokers choose to smoke in bars post-ban. Identifying these characteristics may help to deal with the issue of continued smoking in bars after the implementation of smokefree legislation.

In this study we used data from the International Tobacco Control (ITC) Europe Surveys, in which nationally representative probability samples of adult smokers were surveyed before and after the implementation of national-level smoke-free legislation. According to the International Tobacco Control's Conceptual Model, support for the ban and SHS harm awareness are policy-specific variables that are immediately affected by the implementation of smoke-free legislation (Fong, Cummings et al., 2006). Psychosocial variables that are possible mediators of the relationship between these policy-specific variables and smoking in bars post-ban are smokers' attitudes towards smoking (Sheldon, 2010) and perceived societal approval of smoking (Brown et al., 2009). Findings from baseline ITC Project surveys showed that support for the ban (Borland, Yong, Siahpush et al., 2006; Li et al., 2010; Yong et al., 2010) and SHS harm awareness, smokers' attitudes towards smoking, and perceived societal approval of smoking (Li et al., 2010) were associated with smoking in the hospitality industry. However, these findings were cross-sectional, 
and the studied countries did not have national-level smoke-free hospitality industry legislation in place at the time of the survey. In the current study, we tested whether pre-ban support for the ban, SHS harm awareness, smokers' attitudes towards smoking, and perceived societal approval of smoking were predictors of smoking in bars after implementation of national-level smoke-free legislation.

The benefits of smoke-free bars are likely to be higher among people from lower socioeconomic status (SES) groups because they are more likely to smoke and to be employed in bars (European Commission, 2007). However, compliance with the ban may be lower among low SES groups (Eadie et al., 2008). In the current study, we examine differences between SES groups in predictors of smoking in bars post-ban. Identifying these differences may help in designing interventions that are effective in decreasing smoking in bars post-ban among low SES groups. The prevalence and predictors of smoking in bars post-ban can be different between countries, due to cultural differences or the comprehensiveness of the smoke-free legislation. In the current study, we compared prevalence and predictors of smoking in bars after the comprehensive smoke-free bar legislation in Ireland and France and the partial smoke-free bar legislation in the Netherlands and Germany. First, we describe how the battle over smoke-free bars was fought in these four countries (see Table 1).

\section{Ireland}

Ireland was the first European country to implement nationwide smoke-free workplace legislation. With support from both government and opposition parties, smoking was banned from all indoor workplaces from March 2004 (Howell, 2004; McNicholas, 2004). Violations of the legislation carry a fine of up to $€ 3,000$ for the smoker and the owner.

Prior to the implementation of the legislation, a health alliance was formed between government departments, the Minister for Health, health authorities, nongovernmental organisations, health care professional organisations, the newly formed Office of Tobacco Control and the trade union movement, to argue in favour of the legislation using consistent messaging (Fahy et al., 2009; Howell \& Allwright, 2005). They all positioned the legislation as a civil society public health initiative with the primary objective of protecting workers from the harmful effects of SHS. The Office of Tobacco Control created a television and radio campaign in which the health effects of SHS were explained and the date of implementation of the legislation was communicated (Allwright, 2004). An alliance of vested interests came together under the banner of the 'Irish Hospitality Industry Alliance' (IHIA) to co-ordinate a campaign of opposition. This Alliance released a report on predicted 
economic consequences of the legislation and argued that the legislation could not be enforced due to the country's pub culture. Ties between the Alliance and the tobacco industry were suspected but not confirmed (McNicholas, 2004). Pro-ban and anti-ban advocates received a similar amount of media attention (Fahy et al., 2009).

An extensive evaluation of the Irish smoke-free legislation (Fong, Hyland et al., 2006) found dramatic declines in reported smoking in all venues post-ban. Furthermore, there was significantly stronger support for the smoke-free legislation post-ban among smokers and non-smokers compared to England, which did not have smoke-free legislation at that time. In addition, the legislation was accompanied by an increase in smoke-free homes, contrary to the fears of some that smoke-free public places could result in more smoking at home.

Although many feared that the Irish pub culture would prevent the legislation from succeeding, the legislation proved to be an immediate success (Howell, 2004; McNicholas, 2004; Office of Tobacco Control, 2004). The Irish people chose the smoke-free legislation as the most positive event that happened in Ireland in 2004 (Howell \& Allwright, 2005). An EU-wide survey in December 2008 revealed that 80 percent of the Irish population supported the smoke-free bar legislation, which was considerably higher than the European average of 65 percent (European Commission, 2009).

\section{France}

France implemented nationwide smoke-free legislation in all enclosed public areas, workplaces, hospitals, schools and transport from February 2007, but made an exception for the hospitality industry until January 2008. Since the smoke-free hospitality industry legislation permits enclosed smoking rooms under very strict conditions - areas separated from the rest of the clientèle, maximum $35 \mathrm{~m}^{2}$ and 20 percent of the establishment, appropriate ventilation, and no service in the room they are not common. Smokers receive a $€ 68$ fine for violations and venue owners $a € 135$ fine when the conditions for smoking rooms are not met or when there are no no-smoking signs. When venue owners actively incite violations of the law, the public prosecutor decides on the fine.

Several associations actively argued for the legislation: among others the national association against tobacco smoking (Comité National Contre le Tabagisme, CNCT), the non-smokers' rights association (Droit des Non-Fumeurs, DNF), and the national institute for prevention and health education (Institut National de Prévention et d'Éducation pour la Santé, INPES). The Institut National started campaigning against exposure to SHS in 2004 with television and radio commercials, and 
posters. The government ran a television, radio, print, and internet campaign at the beginning of 2007 in which the date of implementation of the legislation was communicated and the health effects of SHS were explained. The Comité National ran three television commercials in January 2008. One of them showed restaurant employees working, with a voice-over asking "do you know what risks a restaurant employee has to take?" Opposition to the legislation came mainly from bar owners and tobacconists. Their main argument against the legislation was fear of economic losses, since they already faced a 35 percent decrease in the number of cigarettes sold in 2004 compared to 2002, because of price increases in 2003 and 2004.

At the end of 2008, 67 percent of the French population supported the smoke-free bar legislation, which was slightly higher than the European average (European Commission, 2009).

\section{The Netherlands}

The Dutch smoke-free workplace legislation was implemented in January 2004, but excluded the hospitality industry. A self-regulation plan was arranged with the hospitality industry that should have resulted in completely smoke-free restaurants and hotels and mostly smoke-free bars and discos by the end of 2008 . These results were not achieved, which caused the government to decide to implement smoke-free hospitality industry legislation from July 2008. Enclosed smoking rooms in the hospitality industry were permitted, but serving was not allowed in these rooms. After a period of three months in which venue owners only got a warning for violations, venue owners were fined $€ 300$ for the first violation and up to $€ 2,400$ for the fourth violation within five years. Although the legislation was intended to protect employees from exposure to SHS, venues without employees were also obliged to ban smoking. This was considered discriminatory by two Dutch courts, with the consequence that the legislation was temporarily suspended for bars without employees from July 2009. In March 2010 the Dutch Supreme Court ruled that the legislation was not discriminatory, and from that date, the legislation applied to all bars again. However, the new Dutch government is currently considering permanently suspending the legislation for bars smaller than 70 square meters without employees and since November 2010 has not fined these venues for allowing smoking.

The Ministry of Health ran a television, radio, print and internet campaign from May to September 2008 in which only the date of implementation of the smokefree bar legislation was communicated and no reference to health consequences of SHS was made. The television commercial of this campaign showed a man dressed as a large cigarette being thrown out of hospitality industry venues onto the street. 
The Dutch expert centre on tobacco control (STIVORO) ran a television, radio, print, and internet smoking cessation campaign, but the smoke-free legislation and SHS were not mentioned in this campaign. An organisation "Red de Kleine Horeca Ondernemer" ("Save the small hospitality industry entrepreneur") was formed by small bars to argue against the legislation. Ties between this organisation and the tobacco industry were confirmed by investigative journalism (Baltesen \& Rosenberg, 2009). The organisation financed court appeals, organised demonstrations, and lobbied for an exemption to the legislation for small bars. Newspaper coverage on the smoke-free legislation was mostly negative towards the legislation, with the economic aspects of the legislation dominating the coverage.

At the end of 2008, six months after the implementation of the legislation, only 44 percent of the Dutch population supported the smoke-free bar legislation, which was the lowest amongst all European countries (European Commission, 2009).

\section{Germany}

The German workplace regulation from 2004 required employers to effectively protect employees from SHS, but workplaces with public access, such as the hospitality industry, were excluded from this obligation. An agreement between the German Ministry of Health and the DEHOGA, the German hotel and restaurant association, was formed to improve the protection of non-smokers in hospitality venues. This self-regulation was declared a failure by the Ministry of Health in February 2007. Following an extensive public debate, a national law banning smoking in federal buildings and public transport was implemented in September 2007. Between August 2007 and July 2008, each of Germany's 16 states enacted smoke-free legislation, banning smoking in educational, recreational, health and state institutions and in bars and restaurants.

Regarding the smoke-free hospitality industry legislation, implementation dates, fines, and rules for smoking rooms varied between the federal states. Only one state had total smoke-free legislation at first (Bavaria), and most states allowed smoking in designated smoking rooms, but prohibited smoking in one-room bars and pubs. These exceptional rules caused constitutional complaints by venue owners who feared economic disadvantages. In July 2008 the Federal Constitutional Court ruled that the state laws were unconstitutional on the ground that they gave undue advantage to owners of venues with two or more rooms. The court gave the state legislators until 31 December 2009 to either remove all exceptions or to extend them to all hospitality owners. So although the court declared that a total smoking ban would have been constitutional, they suggested permitting smoking 
in drinking establishments without food service, which are smaller than 75 square metres, do not have a separate smoking room, and do not allow persons under 18 years to enter (German Constitutional Court, 2008). All federal states followed this suggestion at first, so that at the International Tobacco Control follow-up survey, all states allowed smoking rooms in restaurants and in bars and pubs, and all states allowed smoking in small one-room-drinking establishments. The fines for violations of the smoke-free legislation vary from state to state. While Baden-Württemberg does not require fines for non-compliant venue owners, the fines in the other states vary from $€ 50-€ 500$ in Hamburg and Thüringen to up to $€ 10,000$ in MecklenburgVorpommern. Fines for non-compliant smokers vary from $€ 5-€ 100$ in Brandenburg to up to $€ 5000$ in Saxony. When the decision of the German Constitutional Court was pending, there was no enforcement of penalties. There was no national media campaign preceding the smoke-free laws.

At the end of 2008, 45 percent of the German population supported the smoke-free bar legislation, which was similar to the low level of support in the Netherlands (European Commission, 2009).

\section{Research questions}

This study focused on smokers reporting that they themselves have smoked in bars after the implementation of national smoke-free hospitality industry legislation. We refer to this behaviour as "smoking in bars post-ban". In Ireland, smoking in bars post-ban equates to non-compliance with the ban, as smoking is completely prohibited in bars in Ireland. In France, Germany, and the Netherlands, smoking in bars post-ban is either non-compliance or reflects smoking in smoking rooms or (in Germany) smoking in bars where smoking is allowed.

The present study aims to answer the following research questions: (1) what is the prevalence of smoking in bars pre- and post-ban in Ireland, France, the Netherlands, and Germany? (2) are support for the ban, SHS harm awareness, smokers' attitudes towards smoking, and perceived societal approval of smoking predictors of smoking in bars post-ban? (3) Are there differences between countries in the predictors of smoking in bars post-ban? (4) Are there differences between SES groups in the predictors of smoking in bars post-ban? 
Table 1: Differences between smoke-free bar legislation in Ireland, France, the Netherlands, and Germany.

\begin{tabular}{|c|c|c|c|c|}
\hline & Ireland & France & The Netherlands & Germany \\
\hline $\begin{array}{l}\text { Period of } \\
\text { allowing } \\
\text { smoking in bars } \\
\text { but not in other } \\
\text { workplaces }\end{array}$ & No & Yes, one year & Yes, four years & Yes, four years \\
\hline $\begin{array}{l}\text { Ban preceded } \\
\text { by a self- } \\
\text { regulation period }\end{array}$ & No & No & Yes & Yes \\
\hline $\begin{array}{l}\text { Implementation } \\
\text { date bar } \\
\text { smoking ban }\end{array}$ & March 2004 & January 2008 & July 2008 & $\begin{array}{l}\text { Varying between } \\
\text { states from August } \\
2007 \text { to July } 2008\end{array}$ \\
\hline $\begin{array}{l}\text { Smoking rooms } \\
\text { in bars allowed }\end{array}$ & Not allowed & $\begin{array}{l}\text { Allowed when } \\
\text { it is separated, } \\
\text { maximum } 35 \mathrm{~m}^{2} \\
\text { and } 20 \% \text { of the } \\
\text { bar, appropriate } \\
\text { ventilation, and } \\
\text { no serving in } \\
\text { the room }\end{array}$ & $\begin{array}{l}\text { Allowed when there } \\
\text { is no serving in the } \\
\text { room }\end{array}$ & Allowed \\
\hline $\begin{array}{l}\text { Smoking bars } \\
\text { allowed }\end{array}$ & Not allowed & Not allowed & $\begin{array}{l}\text { July 2009-March } \\
\text { 2010: allowed } \\
\text { for bars without } \\
\text { employees. From } \\
\text { November 2010: } \\
\text { allowed for small } \\
\text { bars without } \\
\text { employees. }\end{array}$ & $\begin{array}{l}\text { After constitutional } \\
\text { complaints: } \\
\text { allowed for small } \\
\text { one-room-drinking } \\
\text { establishments }\end{array}$ \\
\hline $\begin{array}{l}\text { Fines for } \\
\text { violations of bar } \\
\text { smoking ban }\end{array}$ & $\begin{array}{l}€ 3,000 \text { for } \\
\text { smoker and } \\
\text { owner }\end{array}$ & $\begin{array}{l}€ 68 \text { for smoker } \\
\text { and } € 135 \text { for } \\
\text { owner }\end{array}$ & $\begin{array}{l}\text { First } 3 \text { months } \\
\text { warning, later } € 300 \\
\text { to up to } € 2400 \text { for } \\
\text { owner, no fine for } \\
\text { smoker }\end{array}$ & $\begin{array}{l}\text { For smoker } € 5 \text { to } \\
\text { up to } € 5,000 \text {, for } \\
\text { owner } € 0 \text { to up to } \\
€ 10,000 \text {; no fines } \\
\text { when constitutional } \\
\text { complaints were } \\
\text { pending }\end{array}$ \\
\hline $\begin{array}{l}\text { Pro-ban } \\
\text { advocacy }\end{array}$ & $\begin{array}{l}\text { Campaign with } \\
\text { implementation } \\
\text { date and health } \\
\text { rationale }\end{array}$ & $\begin{array}{l}\text { Campaign with } \\
\text { implementation } \\
\text { date and health } \\
\text { rationale }\end{array}$ & $\begin{array}{l}\text { Campaign with } \\
\text { implementation } \\
\text { date }\end{array}$ & $\begin{array}{l}\text { No national } \\
\text { campaign }\end{array}$ \\
\hline $\begin{array}{l}\text { Anti-ban } \\
\text { advocacy }\end{array}$ & $\begin{array}{l}\text { Media reports } \\
\text { on economic } \\
\text { losses }\end{array}$ & $\begin{array}{l}\text { Media reports } \\
\text { on economic } \\
\text { losses }\end{array}$ & $\begin{array}{l}\text { Media reports on } \\
\text { economic losses, } \\
\text { court appeals, } \\
\text { demonstrations, } \\
\text { and lobby against } \\
\text { ban in small bars }\end{array}$ & $\begin{array}{l}\text { Media reports on } \\
\text { economic losses, } \\
\text { constitutional } \\
\text { complaints against } \\
\text { the ban in small } \\
\text { bars, lobby against } \\
\text { ban in small bars }\end{array}$ \\
\hline $\begin{array}{l}\text { Population } \\
\text { support for bar } \\
\text { smoking ban in } \\
\text { December } 2008 \\
\text { according to } \\
\text { Eurobarometer } \\
\# 253\end{array}$ & 80 percent & 67 percent & 44 percent & 45 percent \\
\hline
\end{tabular}




\section{METHODS}

\section{Sample}

Before the implementation of the smoke-free bar legislation in Ireland, France, the Netherlands, and Germany, 6,393 smokers aged 18 years and older were surveyed. Smokers were defined as having smoked at least 100 cigarettes in their lifetime and currently smoke at least once per month. Post-ban 4,634 baseline smokers were followed up (72.5\% follow-up). See Table 2 for fieldwork periods and sample sizes for each country.

Smokers who were followed up and who were lost to follow-up did not differ by gender, educational level, number of cigarettes per day, and time before smoking the first cigarette of the day. However, smokers who were lost to follow-up were younger $(M=38.3, S D=14.4)$ than smokers who were followed up $(M=42.3$, $\mathrm{SD}=14.3 ; \mathrm{t}=-9.88, \mathrm{p}<0.001)$.

Respondents were recruited using probability sampling methods with fixed line telephone numbers selected at random from the population of each country. The Netherlands sample differed in that most respondents were surveyed using web interviewing ( $n=1,668$ of baseline sample of 2,072) instead of telephone interviewing (Nagelhout et al., 2010). The Dutch web sample was drawn from a large probabilitybased database with respondents who had indicated their willingness to participate in research on a regular basis. Dutch telephone and web respondents did not differ by age, gender, and number of cigarettes per day. However, web respondents were less educated $\left(\chi^{2}=23.74, p<0.001\right)$, and smoked their first cigarette of the day later than telephone respondents $(t=-3.75, p<0.001)$. Therefore, univariate analyses were carried out separately for the Dutch telephone and web respondents and interviewing mode was added as predictor variable in multivariate analyses. Follow-up rates were considerably higher for the Netherlands web survey $(80.1 \%)$ than the Netherlands telephone survey (73.7\%) and the telephone surveys in the other countries (Ireland 71.8\%, France 71.0\%, Germany 66.1\%). 
Table 2: Fieldwork periods and sample sizes for each country, International Tobacco Control (ITC) Europe Surveys.

\begin{tabular}{|c|c|c|c|c|}
\hline & Pre-ban survey wave & \multirow[b]{2}{*}{$\begin{array}{l}\text { No. of } \\
\text { smokers }\end{array}$} & Post-ban survey wave & \multirow[b]{2}{*}{$\begin{array}{l}\text { No. of } \\
\text { smokers }\end{array}$} \\
\hline & Fieldwork period & & Fieldwork period & \\
\hline Ireland & $\begin{array}{l}\text { December } 2003 \text { - } \\
\text { January } 2004\end{array}$ & 1,071 & $\begin{array}{l}\text { December } 2004 \text { - } \\
\text { January } 2005\end{array}$ & 769 \\
\hline France & $\begin{array}{l}\text { December } 2006 \text { - } \\
\text { February } 2007\end{array}$ & 1,735 & $\begin{array}{l}\text { September } 2008 \text { - } \\
\text { December } 2008\end{array}$ & 1,231 \\
\hline The Netherlands & $\begin{array}{l}\text { March } 2008 \text { - April } \\
2008\end{array}$ & $2,072^{*}$ & $\begin{array}{l}\text { March } 2009 \text { - May } \\
2009\end{array}$ & 1,632 \\
\hline Germany & $\begin{array}{l}\text { July } 2007 \text { - November } \\
2007\end{array}$ & 1,515 & $\begin{array}{l}\text { July } 2009 \text { - October } \\
2009\end{array}$ & 1,002 \\
\hline Total & & 6,393 & & 4,634 \\
\hline
\end{tabular}

${ }^{*}$ The ITC Netherlands Survey consisted of 2,224 smokers aged 15 years and older of whom 1,743 were followed up. Smokers aged 15 to 17 years were excluded from this study as the other countries only surveyed smokers aged 18 years and older.

Since the focus of this study is smoking in bars after the implementation of national smoke-free bar legislation, respondents who did not visit bars after the implementation $(n=985)$ were excluded from the analyses. Also, respondents who had quit smoking $(n=606)$ were excluded. In total 1,487 of 4,634 respondents were excluded leaving 3,147 respondents for the analyses (Ireland $n=573$, France $n=$ 820 , the Netherlands $n=1,034$ (telephone $n=185$, web $n=849$ ), Germany $n=720$ ).

\section{Measurements}

The questions used for the International Tobacco Control Europe surveys were all adapted from the conceptual model and questionnaire of the Four Country survey (Fong, Cummings, Borland et al., 2006). All surveys were cleared for ethics by the Research Ethics Board of the University of Waterloo and when necessary also by the ethics boards in individual countries.

\section{Control variables}

The multivariate analyses controlled for country, interviewing mode, gender, age, educational level, heaviness of smoking, smoking in bar on last visit pre-ban, and bar visiting in last six months. These variables were assessed at the pre-ban surveys. Age was categorised into four groups: 18 to 24,25 to 39,40 to 54 , and 55 years and older. Education was categorised into three levels (low, moderate, and high) that were roughly comparable across the four countries because of differences in educational systems. The Heaviness of Smoking Index (HSI) was created as the sum of two categorical measures: number of cigarettes per day and time before smoking the first cigarette of the day. Smoking index values ranged from 0 to 6 and 
are positively associated with nicotine dependence (Heatherton et al., 1989). Bar visiting was assessed using the question "In the last 6 months, how often have you visited a drinking establishment such as a bar or pub?"

Policy-specific variables

Support for a bar smoking ban was assessed at the pre-ban surveys using the question "Do you think smoking should be allowed in all indoor areas, allowed in some indoor areas, or not allowed indoors at all at drinking establishments (bars and pubs)?". This question was used as indicator of support for smoke-free legislation in several other studies (Borland, Yong, Siahpush et al., 2006; Fong, Hyland et al., 2006; Li et al., 2010; Yong et al., 2010). SHS harm awareness was assessed at the pre-ban surveys using the question "In the last month, how often, if at all, did you think about the harm your smoking might be doing to other people?" This question was also used in previous studies (Borland, Yong, Siahpush et al., 2006; Yong et al., 2010).

Psychosocial mediators

Smokers' attitudes towards smoking were assessed at the pre-ban surveys using the question "What is your overall opinion of smoking?" This question was used in previous research as predictor of smoking cessation (Hyland, Borland et al., 2006). In line with previous research (Brown et al., 2009; Hammond et al., 2006), perceived societal approval of smoking was assessed at the pre-ban surveys using the statement "Society disapproves of smoking".

\section{Outcome variable}

Smoking in bars was assessed at the pre- and post-ban surveys using the question "Did you smoke at all at the pub or bar during your last visit, either inside or outside?" Respondents who answered "yes" were asked whether they smoked inside the bar, outside or both. Respondents who answered that they smoked inside or both inside and outside were categorised as "smoked inside the bar on last visit".

\section{Analyses}

To examine the prevalence of smoking in bars pre- and post-ban (research question 1), proportions of smokers reporting smoking in bars pre- and post-ban were presented for each country separately. Chi-square tests were conducted to assess differences in country proportions and to assess difference from pre- to post-ban. All analyses have been weighted by age and gender to be representative of the adult smoker population within each country. More details on the weighting procedure can be found in Thompson et al. (2006).

Predictors of smoking in bars post-ban (research question 2) were assessed using multivariate regression mediation analyses using SPSS macros and 
guidelines developed by Preacher \& Hayes (2004), that were adjusted to allow for a binary outcome (Preacher \& Hayes, 2010). Sobel tests were calculated to estimate the strength and significance of mediation effects. In addition, multivariate logistic regression analysis was employed with smoking in bars post-ban as dependent variable. Independent variables were the above mentioned control variables, policyspecific variables, and psychosocial mediators.

Differences between countries (research question 3) in predictors of smoking in bars post-ban were assessed by adding country interactions to the multivariate logistic regression analysis predicting smoking in bars post-ban. As Germany was the country with the highest level of smoking in bars post-ban, this country was chosen as reference for comparison with Ireland, France, and the Netherlands. Added interactions were country by: support for a bar smoking ban, SHS harm awareness, smokers' attitudes towards smoking, and perceived societal approval of smoking.

Differences between SES groups (research question 4) were assessed by adding educational level interactions to the multivariate logistic regression analysis predicting smoking in bars post-ban. These analyses were done separately for each country. Added interactions were educational level by: support for a bar smoking ban, SHS harm awareness, smokers' attitudes towards smoking, and perceived societal approval of smoking. Educational level was used as indicator of SES, because it contained considerably fewer missing values $(n=14)$ than income $(n=$ 363).

\section{RESULTS}

\section{Prevalence of smoking in bars}

As can be seen in Table 3, the prevalence of smoking in bars was around 90 percent in all countries pre-ban. Smoking in bars decreased significantly from pre-ban to post-ban in each country (Ireland $\chi^{2}=954.91, p<0.001$; France $\chi^{2}=1,039.10, p<$ 0.001; Netherlands $\chi^{2}=606.55, p<0.001$; Germany $\left.\chi^{2}=299.85, p<0.001\right)$. The post-ban percentage of smoking in bars significantly differed between countries $\left(\chi^{2}=566.49, p<0.001\right)$ and was lowest in France $(2.7 \%)$, followed by Ireland (3.3\%), the Netherlands (34.0\%; telephone survey $44.8 \%$, web survey $31.6 \%$ ), and Germany (43.6\%).

\section{Predictors of smoking in bars}

There were significant between-country differences in the predictor variables, except for gender of respondents (Table 3). Smokers from Ireland and France were younger and less educated than smokers from the Netherlands and Germany. Smokers in 
France were the least heavy smokers and smokers in Ireland were the heaviest smokers. Smokers from Ireland were the most frequent bar visitors and smokers from the Netherlands the least frequent. Smokers from Ireland and France more often supported smoke-free bars, more often thought about the harm of smoking to others, more often thought negative of smoking, and more often thought that society disapproves of smoking than smokers in Germany and the Netherlands.

The multiple regression mediation analyses showed that both the policyspecific variables and the psychosocial mediators significantly predicted smoking in bars post-ban (Figure 1). Sobel tests showed that the inclusion of smokers' attitudes towards smoking as mediator significantly decreased the influence of support for the ban $(z=2.29, p=0.022)$ and SHS harm awareness $(z=2.53, p$ $=0.012$ ) on smoking in bars post-ban. Also, the inclusion of perceived societal approval of smoking as mediator significantly decreased the influence of support for the ban $(z=2.61, p=0.009)$ and SHS harm awareness $(z=3.68, p<0.001)$ on smoking in bars post-ban. Since the influence of the policy-specific variables on smoking in bars post-ban was still significant after controlling for the psychosocial mediators, we can conclude that there is partial mediation. Mediation analyses by country did not show significant mediation effects, indicating that the mediation effects are small.

A multivariate logistic regression analysis showed that country was the most important predictor of prevalence of smoking in bars post-ban. Smokers from the Netherlands and Germany were more likely to smoke in bars post-ban than smokers from Ireland and France (OR Ireland $=0.03,95 \% \mathrm{Cl}=0.02-0.05$; OR France $=0.03,95 \% \mathrm{Cl}=0.02-0.05$; OR the Netherlands $=0.96,95 \% \mathrm{Cl}=0.65-$ 1.43; Germany is the reference category). Furthermore, there was more smoking in bars post-ban by telephone respondents (versus web respondents from the Netherlands), male smokers, younger smokers, less educated smokers, heavier smokers, smokers who smoked in bars pre-ban, and smokers who visited bars more often (data not shown). More support for the ban and very often thinking about the harm of smoking to others was negatively associated with smoking in bars post-ban (Table 4). Moreover, a negative opinion of smoking was significantly associated with a smaller likelihood of smoking in bars post-ban. 
Table 3: Differences between Ireland, France, the Netherlands, and Germany in predictor variables of smoking in bars post-ban (\%).

\begin{tabular}{|c|c|c|c|c|c|}
\hline & $\begin{array}{l}\text { Ireland } \\
(\mathrm{n}=573)\end{array}$ & $\begin{array}{l}\text { France } \\
(\mathrm{n}=820)\end{array}$ & $\begin{array}{l}\text { The } \\
\text { Netherlands } \\
(n=1,034)\end{array}$ & $\begin{array}{l}\text { Germany } \\
(\mathrm{n}=720)\end{array}$ & $\begin{array}{l}\text { Between country } \\
\text { differences }\end{array}$ \\
\hline \multicolumn{6}{|l|}{ Control variables } \\
\hline $\begin{array}{l}\text { Gender } \\
\text { Male } \\
\text { Female }\end{array}$ & $\begin{array}{l}53.9 \\
46.1\end{array}$ & $\begin{array}{l}55.5 \\
44.5\end{array}$ & $\begin{array}{l}54.4 \\
45.6\end{array}$ & $\begin{array}{l}57.5 \\
42.5\end{array}$ & $\chi^{2}(3)=2.16, p=0.540$ \\
\hline $\begin{array}{l}\text { Age } \\
18-24 \\
25-39 \\
40-54 \\
55+\end{array}$ & $\begin{array}{l}19.6 \\
30.8 \\
32.2 \\
17.5\end{array}$ & $\begin{array}{l}19.9 \\
36.2 \\
32.1 \\
11.8\end{array}$ & $\begin{array}{l}13.1 \\
30.5 \\
35.0 \\
21.5\end{array}$ & $\begin{array}{l}14.4 \\
29.7 \\
37.5 \\
18.3\end{array}$ & $\chi^{2}(9)=54.03, p<0.001$ \\
\hline $\begin{array}{l}\text { Educational level } \\
\text { Low } \\
\text { Moderate } \\
\text { High } \\
\text { Heaviness of }\end{array}$ & $\begin{array}{l}66.4 \\
21.3 \\
12.2\end{array}$ & $\begin{array}{l}39.9 \\
39.0 \\
21.1\end{array}$ & $\begin{array}{l}33.8 \\
44.0 \\
22.2\end{array}$ & $\begin{array}{l}20.1 \\
38.3 \\
41.6\end{array}$ & $\chi^{2}(6)=366.43, p<0.001$ \\
\hline $\begin{array}{l}\text { Smoking } \\
0 \text { thru } 1 \\
2 \text { thru } 4 \\
5 \text { thru } 6 \\
\text { Smoking in bar on } \\
\text { last visit pre-ban }\end{array}$ & $\begin{array}{l}27.9 \\
59.2 \\
12.9\end{array}$ & $\begin{array}{l}48.8 \\
48.2 \\
3.1\end{array}$ & $\begin{array}{l}29.3 \\
63.3 \\
7.4\end{array}$ & $\begin{array}{l}39.2 \\
55.4 \\
5.4\end{array}$ & $\chi^{2}(6)=130.51, p<0.001$ \\
\hline $\begin{array}{l}\text { Yes } \\
\text { No } \\
\text { Bar visiting in last } \\
\text { six months }\end{array}$ & $\begin{array}{l}96.7 \\
3.3\end{array}$ & $\begin{array}{l}83.6 \\
16.4\end{array}$ & $\begin{array}{l}87.8 \\
12.2\end{array}$ & $\begin{array}{l}86.9 \\
13.1\end{array}$ & $\chi^{2}(3)=53.60, p<0.001$ \\
\hline $\begin{array}{l}\text { Weekly / monthly } \\
\text { Yearly / never } \\
\text { Policy-specific } \\
\text { variables } \\
\text { Support for bar } \\
\text { smoking ban }\end{array}$ & $\begin{array}{l}86.9 \\
13.1\end{array}$ & $\begin{array}{l}70.0 \\
30.0\end{array}$ & $\begin{array}{l}58.3 \\
41.7\end{array}$ & $\begin{array}{l}68.2 \\
31.8\end{array}$ & $\chi^{2}(3)=141.56, p<0.001$ \\
\hline $\begin{array}{l}\text { Total ban } \\
\text { Partial ban } \\
\text { No ban } \\
\text { Think about harm } \\
\text { of smoking to } \\
\text { others }\end{array}$ & $\begin{array}{l}12.5 \\
56.5 \\
31.1\end{array}$ & $\begin{array}{l}13.2 \\
60.8 \\
25.9\end{array}$ & $\begin{array}{l}8.1 \\
61.3 \\
30.6\end{array}$ & $\begin{array}{l}6.3 \\
51.2 \\
42.5\end{array}$ & $\chi^{2}(6)=69.34, p<0.001$ \\
\hline $\begin{array}{l}\text { Very often } \\
\text { Often / sometimes } \\
\text { Rarely / never }\end{array}$ & $\begin{array}{l}19.3 \\
43.8 \\
37.0\end{array}$ & $\begin{array}{l}16.7 \\
50.2 \\
33.1\end{array}$ & $\begin{array}{l}2.0 \\
43.5 \\
54.5\end{array}$ & $\begin{array}{l}7.5 \\
39.9 \\
52.6\end{array}$ & \multirow[t]{2}{*}{$\chi^{2}(6)=225.23, p<0.001$} \\
\hline $\begin{array}{l}\text { Psychosocial } \\
\text { mediators } \\
\text { Overall opinion of } \\
\text { smoking }\end{array}$ & & & 54.5 & & \\
\hline $\begin{array}{l}\text { Positive } \\
\text { Negative } \\
\text { Neutral } \\
\text { Society } \\
\text { disapproves of } \\
\text { smoking }\end{array}$ & $\begin{array}{l}12.4 \\
62.9 \\
24.7\end{array}$ & $\begin{array}{l}9.4 \\
63.4 \\
27.2\end{array}$ & $\begin{array}{l}12.6 \\
21.7 \\
65.7\end{array}$ & $\begin{array}{l}20.8 \\
25.1 \\
54.2\end{array}$ & $\chi^{2}(6)=561.50, p<0.001$ \\
\hline $\begin{array}{l}\text { Agree } \\
\text { Disagree }\end{array}$ & $\begin{array}{l}79.9 \\
13.6\end{array}$ & $\begin{array}{l}73.8 \\
16.2\end{array}$ & $\begin{array}{l}60.3 \\
10.6\end{array}$ & $\begin{array}{l}69.0 \\
17.5\end{array}$ & \multirow[t]{2}{*}{$\chi^{2}(6)=199.99, p<0.001$} \\
\hline Neutral & 6.5 & 10.0 & 29.0 & 13.5 & \\
\hline
\end{tabular}

t Heaviness of smoking is used as continuous variable in the regression analysis 


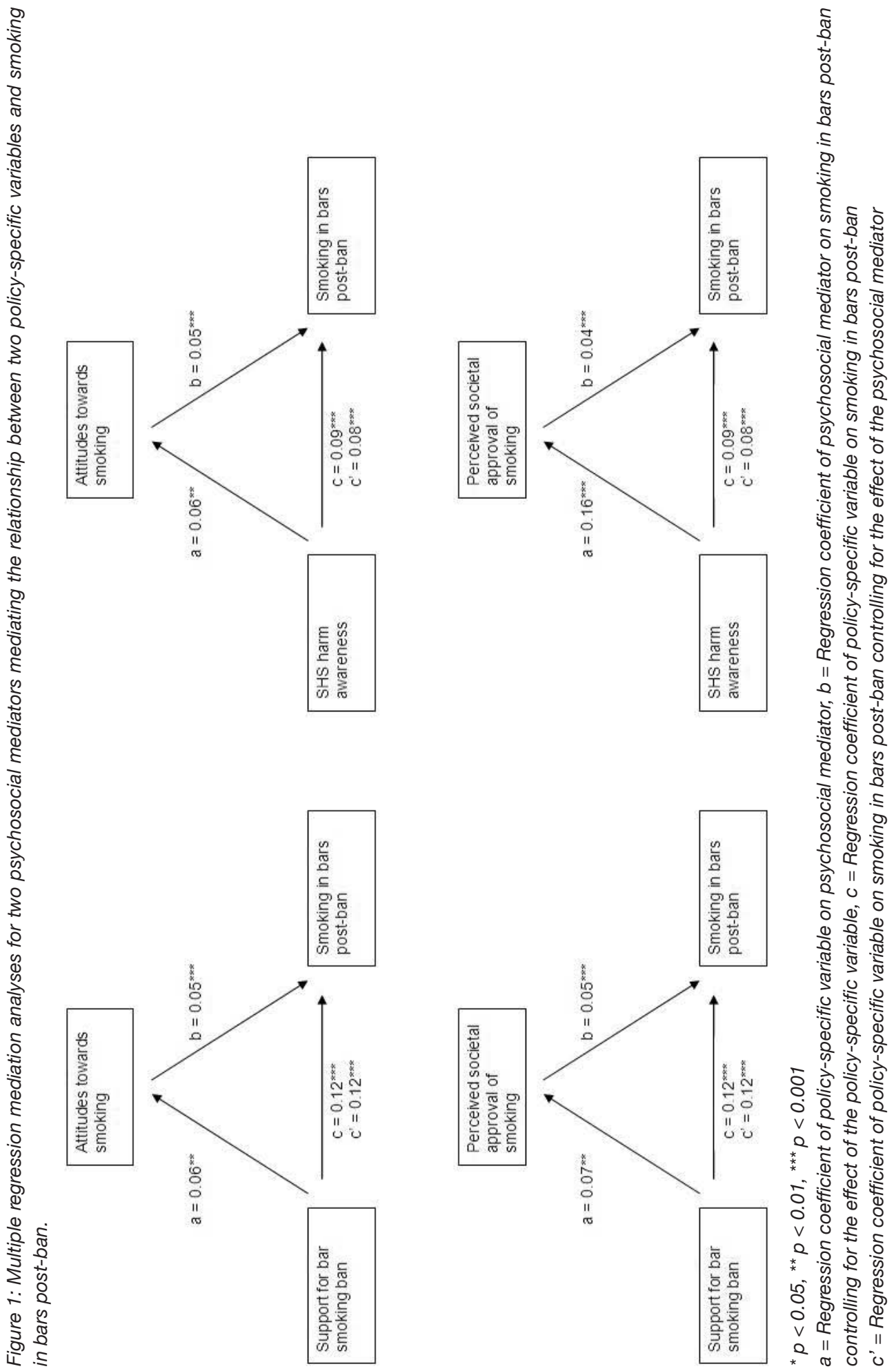




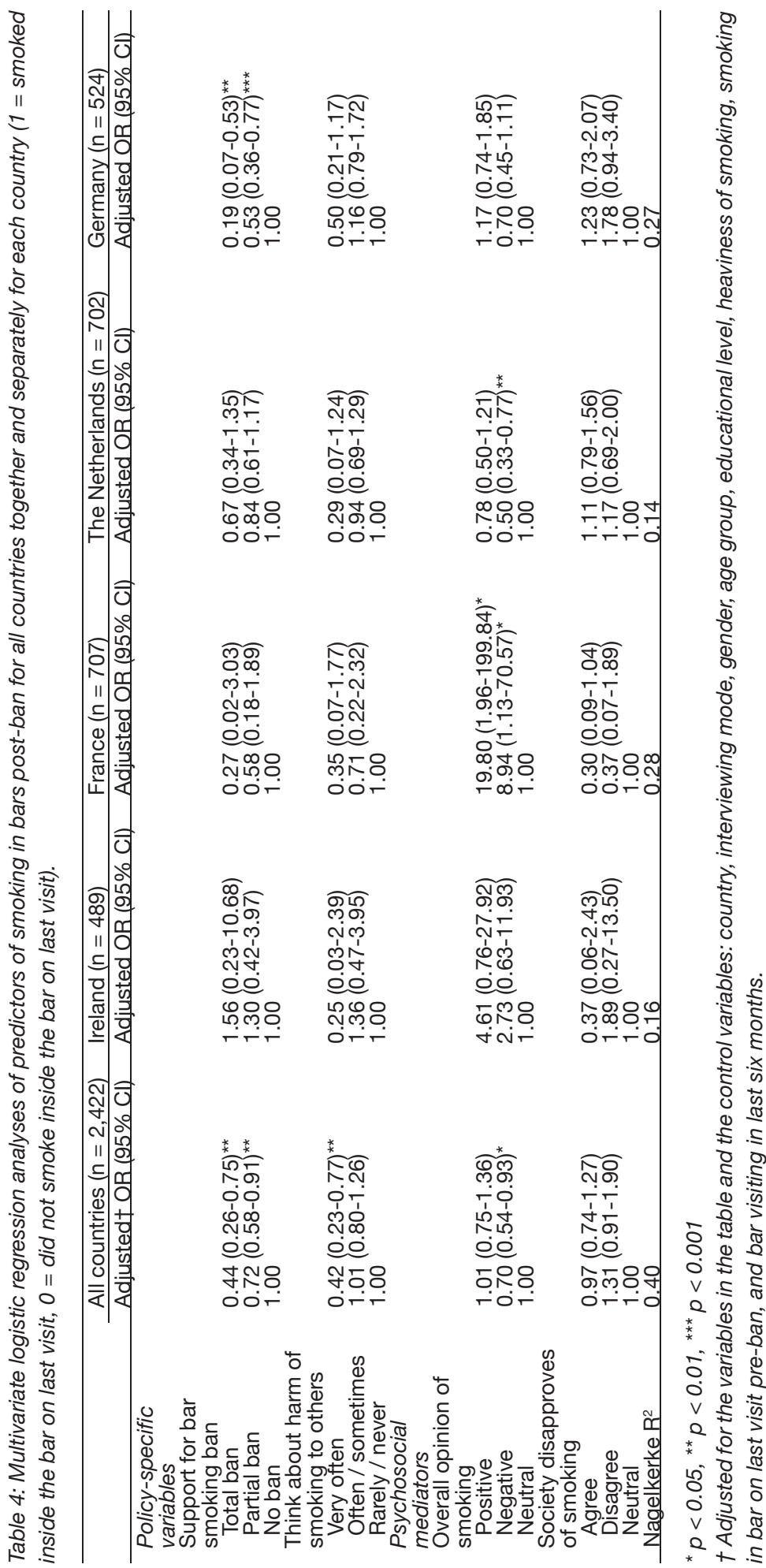




\section{Differences between countries}

Table 4 shows the multivariate logistic regression analysis for all countries together and the analyses separately for each country. Country interaction analyses with Germany as reference showed that support for the ban was a stronger predictor in Germany than in Ireland and the Netherlands (the interaction with France was not significant). There were also interactions found between attitudes towards smoking and perceived societal approval of smoking in France compared to Germany. However, probably due to few French smokers smoking in bars post-ban, the main effects were either not significant or had a very large confidence interval, suggesting that these results may not be reliable.

\section{Differences between SES groups}

There were significant interactions between educational level and the extent to which the policy-specific variables and the psychosocial mediators predicted smoking in bars post-ban in the Netherlands and Germany. Highly educated smokers from the Netherlands who were supportive of a partial ban were less likely to smoke in bars post-ban (OR highly educated $=0.53,95 \% \mathrm{Cl}=0.26-1.08$ ). Moderately educated smokers from the Netherlands who often or sometimes thought about the harm of smoking to others were less likely to smoke in bars (OR moderately educated = $0.54,95 \% \mathrm{Cl}=0.34-0.88$ ). Societal approval of smoking was a stronger predictor of smoking in bars among highly educated smokers (OR highly educated $=2.87$, $95 \% \mathrm{Cl}=1.01-8.18)$. Low and moderately educated smokers from Germany who very often thought about the harm of smoking to others were borderline significantly less likely to smoke in bars (OR low educated $=0.14,95 \% \mathrm{Cl}=0.02-1.15$; OR moderately educated $=0.23,95 \% \mathrm{Cl}=0.05-1.11$ ).

\section{DISCUSSION}

Smoking was highly prevalent in bars in Ireland, France, the Netherlands and Germany before these countries implemented national-level smoke-free bar legislation. While the partial legislation in the Netherlands and Germany was effective in reducing smoking in bars, the level of effectiveness was much lower than that achieved in Ireland and France. Many bar workers and patrons in the Netherlands and Germany are still exposed to SHS, whereas the comprehensive legislation in Ireland and France almost completely eliminated smoking in bars. Since there is no risk-free minimal level of exposure to SHS (U.S. Department of Health and Human Services, 2006; World Health Organization, 2007b), no countries should settle with less than eliminating smoking in all indoor public places. The Netherlands and Germany should, therefore, aim to further reduce smoking in bars. 
This study showed that 'country' was the most important predictor of prevalence of smoking in bars post-ban, with smokers from the Netherlands and Germany more likely to smoke in bars post-ban than smokers from Ireland and France. The weaker smoke-free bar legislation in the Netherlands and Germany compared to Ireland and France (see Table 1) is the most plausible explanation of this finding. The Netherlands and Germany both allowed smoking in bars but not in other workplaces for a period of four years. In this period, the hospitality industry was expected to reduce smoking by means of self-regulation. Both countries eventually banned smoking in bars, but allowed smoking in designated smoking rooms and in small bars. In the Netherlands and some German states, violations of the legislation were not fined in the first months after the implementation of the legislation. Since the exceptions and the moderate level of enforcement probably causes the higher levels of smoking in bars post-ban, we recommend countries to implement smoke-free legislation without exceptions and to enforce the legislation heavily. This corresponds with guidelines and recommendations of the World Health Organization (World Health Organization, 2007a, b) and the European Commission (European Commission, 2007).

In this study, we identified individual smokers' predictors of smoking in bars post-ban. Smokers who were more supportive of the ban, were more aware of the harm of SHS, and who had negative opinions of smoking were less likely to smoke in bars post-ban. There was more support for the ban, SHS harm awareness, negative opinions of smoking, and societal disapproval of smoking in Ireland and France than in the Netherlands and Germany. These predictors can possibly be positively influenced by educational campaigns that clearly explain that the smokefree legislation is implemented to protect people against harm from exposure to SHS (European Commission, 2007; Smoke Free Partnership, 2006; World Health Organization, 2007a, b). In Ireland and France several health organisations argued in favour of the legislation in the media, and educational campaigns highlighted the fact that the legislation was intended to protect people against SHS exposure. In the Netherlands and Germany there was less media advocacy from health organisations, and the educational campaign in the Netherlands only communicated the date of the implementation of the legislation and did not explain the health rationale for the legislation. In Germany, there was no national implementation campaign at all. However, since we did not directly study exposure to educational campaigns, we cannot be certain that campaigns would have increased SHS harm awareness and support for the ban. More research is needed to study this further.

According to the ITC Conceptual Model, each tobacco control policy ultimately has an influence on behaviour by influencing policy-specific variables, which in turn influence psychosocial mediators, which influence policy-relevant 
outcome behaviours (Fong, Cummings, Borland et al., 2006). Our study showed that smokers' attitudes towards smoking and perceived societal approval of smoking were partial mediators of the relationship between support for the ban and SHS harm awareness on smoking in bars post-ban. Support for the ban and SHS harm awareness also had a direct influence on smoking in bars post-ban. This suggests that increasing support for the ban and SHS harm awareness can lead to less smoking in bars post-ban, even when attitudes and norms about smoking are not affected.

There were some differences between countries in the predictors of smoking in bars post-ban. Greater support for the ban was a stronger predictor in Germany. As the German smoke-free law allows smoking rooms as well as smoking in small bars, smokers from Germany have more options regarding bars than smokers from Ireland, France, and the Netherlands. German smokers can either go to a smokefree bar, to a bar with a smoking room or to a smoking bar, and this decision would likely influence their smoking behaviour during the time spent at the bar. Assuming that support for the ban reflects preferences regarding smoke-free bar legislation, German smokers supporting smoke-free bars would be more likely to go to smokefree bars and thus be less likely to smoke in bars.

Smokers with a low educational level were more likely than smokers with a high educational level to smoke in bars post-ban. The predictors of smoking in bars post-ban were also different between smokers from different educational levels. In Germany and the Netherlands, SHS harm awareness was a stronger predictor among less educated smokers. This suggests that smoking in bars postban can be decreased among lower SES smokers by communicating about the harm of smoking to others. This is especially urgent for the Netherlands, where only 1 percent of low educated smokers thinks very often about the harm of their smoking to others (compared to $19 \%$ of Irish, $17 \%$ of French, and $9 \%$ of German low educated smokers).

\section{Limitations}

The primary strength of the ITC Project is that findings in one country can be compared with findings in another country (Fong, Cummings, Borland et al., 2006). In a perfect world, the ITC Europe surveys used in this study would have been conducted in parallel, while using exactly the same questions and methods. Unfortunately, practical issues prevented us from doing so. The survey months and years and the time intervals between waves and between the ban and post-ban waves were different between countries, there were demographic differences between countries and the interviewing methods were different for the ITC Netherlands survey. 
Although we recommend standardisation of the methods between countries for future research, we expect the influence of these inconsistencies on the pattern of results of the study to be only minor.

Another issue is that it might be perceived as socially undesirable to smoke in bars when there is legislation that bans smoking. Therefore, the point estimates of smoking in bars post-ban presented in this study could be an underestimation of the actual figures. Fortunately, we not only asked about whether smokers have smoked themselves in a bar post-ban, but also about whether they have seen other people smoking. These figures are indeed slightly higher, but show a corresponding pattern: Ireland self $=3 \%$, others $=5 \%$, France self $=3 \%$, others $=4 \%$, Netherlands self $=34 \%$, others $=36 \%$, Germany self $=44 \%$, others $=50 \%$.

Furthermore, younger smokers had lower follow-up rates. Since younger smokers were more likely to smoke in bars post-ban, this could have led to an underestimation of the point estimates of smoking in bars post-ban.

\section{Conclusion}

In Ireland and France, comprehensive smoke-free legislation almost completely eliminated smoking in bars post-ban. In contrast, the partial legislation in the Netherlands and Germany was much less successful, although this legislation did reduce smoking in bars. Smokers who were more supportive of the ban, were more aware of the harm of SHS, and who had negative opinions of smoking were less likely to smoke in bars post-ban. The results indicate the need for strong comprehensive smoke-free legislation without exceptions. This should be accompanied by educational campaigns in which the public health rationale for the legislation is clearly explained. 


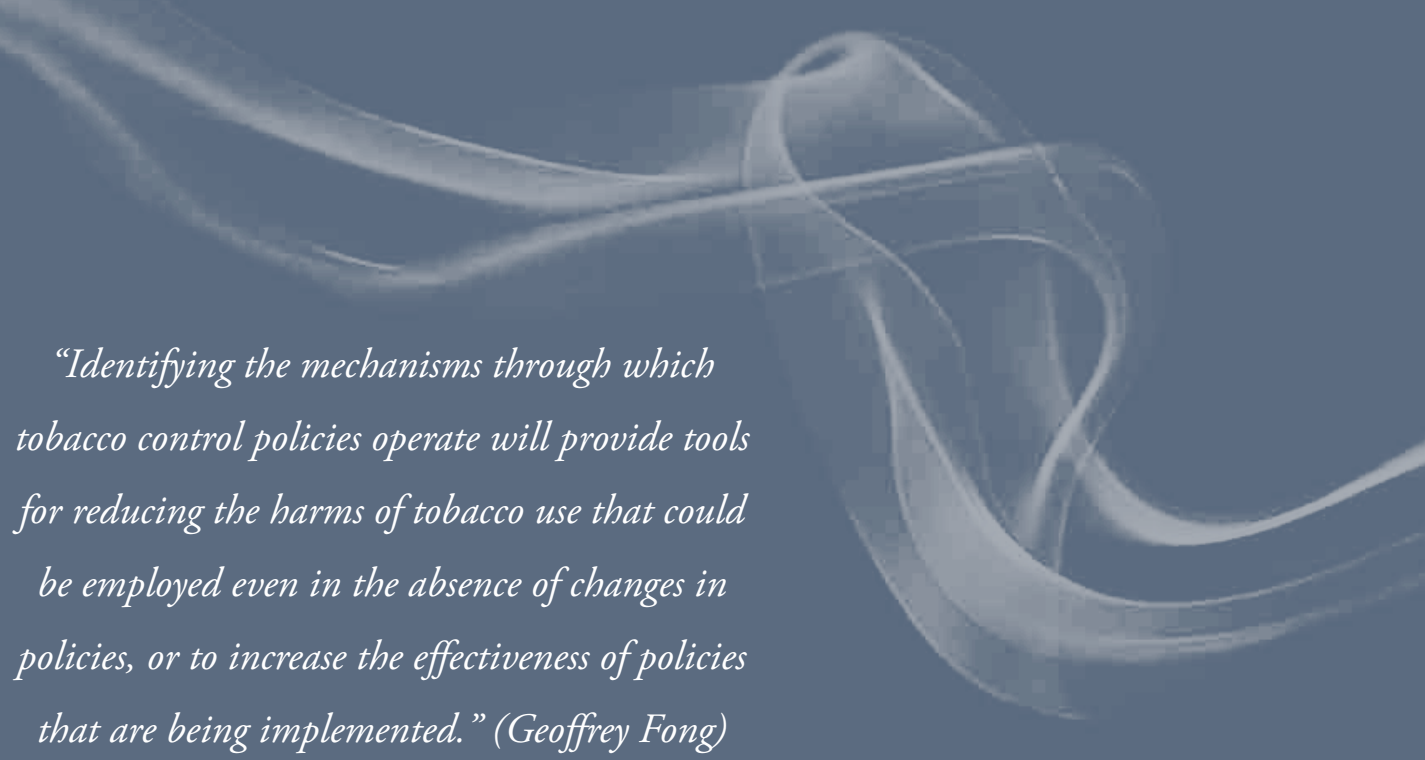
that are being implemented." (Geoffrey Fong) 


\section{Chapter 10}

\section{$\sim \sim \sim$ \\ Explaining the effect of smoke-free legislation on cessation}

\section{Published as:}

Nagelhout, G. E., De Vries, H., Fong, G. T., Candel, M. J. J. M., Thrasher, J. F., Van den Putte, B., Thompson, M. E., Cummings, K. M., \& Willemsen, M. C. Pathways of change explaining the effect of smokefree legislation on smoking cessation in the Netherlands. An application of the International Tobacco Control (ITC) Conceptual Model. Nicotine \& Tobacco Research. Published Online First: 5 April 2012. 
This study aims to test the pathways of change from individual exposure to smoke-free legislation on smoking cessation, as hypothesised in the International Tobacco Control (ITC) Conceptual Model. A nationally representative sample of Dutch smokers aged 15 years and older was surveyed during four consecutive annual surveys. Of the 1,820 baseline smokers, 1,012 participated in the fourth survey. Structural Equation Modelling was employed to test a model of the effects of individual exposure to smoke-free legislation through policy-specific variables (support for smoke-free legislation and awareness of the harm of (secondhand) smoking) and psychosocial mediators (attitudes, subjective norm, self-efficacy, and intention to quit) on quit attempts and quit success. The effect of individual exposure to smoke-free legislation on smoking cessation was mediated by one pathway via support for smoke-free legislation, attitudes about quitting, and intention to quit smoking. Exposure to smoke-free legislation also influenced awareness of the harm of (second-hand) smoking, which in turn influenced the subjective norm about quitting. However, only attitudes about quitting were significantly associated with intention to quit smoking, whereas subjective norm and self-efficacy for quitting were not. Intention to quit predicted quit attempts and quit success, and self-efficacy for quitting predicted quit success. Our findings support the ITC Conceptual Model which hypothesised that policies influence smoking cessation through policy-specific variables and psychosocial mediators. Smoke-free legislation may increase smoking cessation provided that it succeeds in influencing support for the legislation. 


\section{INTRODUCTION}

Tobacco smoke pollution (TSP or second-hand smoke) can cause death, disease, and disabilities in non-smokers (World Health Organization, 2003). TSP accounts for about 600,000 deaths a year among non-smokers (Öberg, Jaakkola, Woodward, Peruga, \& Prüss-Ustün, 2011). To protect non-smokers from this risk, many countries have implemented smoke-free legislation that bans smoking in indoor workplaces and public places. A review on smoke-free legislation reported that some studies found a positive effect on smoking cessation, whereas other studies did not find this effect (Callinan et al., 2010). A recent study using data from 21 jurisdictions (countries, states, and provinces) that implemented smoke-free legislation in public places found evidence of a decrease in smoking prevalence in eight jurisdictions but no change in the other 13 (Bajoga, Lewis, McNeill, \& Szatkowski, 2011). Knowledge about the pathways of change explaining the effect of smoke-free legislation on smoking cessation may help in understanding why smoke-free legislation increases smoking cessation in some circumstances and not in others.

The International Tobacco Control (ITC) Conceptual Model is a model that explicitly describes the pathways of change from tobacco control policies to smoking cessation (Fong, Cummings, Borland et al., 2006). According to the ITC Conceptual Model, tobacco control policies influence individuals by first influencing factors that are most proximal (conceptually closest) or most specifically related to the policy itself. These factors are called policy-specific variables and include variables like warning label salience, perceived costs of cigarettes, and support for smoke-free legislation. Policy-specific variables in turn influence psychosocial mediators. Psychosocial mediators in the ITC Conceptual Model have been taken from various social cognitive models. These models assume that behaviour is the result of intentions and intentions in turn, are the result of three main types of factors: attitudes, subjective norms, and self-efficacy (e.g. Ajzen, 1991; De Vries \& Mudde, 1998). Finally, changes in psychosocial mediators are expected to influence policy-relevant outcomes, such as quit attempts and quit success.

To date, no published studies have reported on a test of the full causal chain explaining the effect of individual exposure to smoke-free legislation on smoking cessation (see Figure 1). Most studies have focused on the effects of implementing smoke-free legislation on support for smoke-free legislation and awareness of the harm of (second-hand) smoking (policy-specific variables). These studies mainly found that exposure to smoke-free legislation increases support for smoke-free legislation without examining how such support translates into changes in smoking behaviour (Borland, Yong, Siahpush et al., 2006; Brown et al., 2009; Fong, Hyland et al., 2006; Hyland, Higbee et al., 2009; Mons et al., 2012; Thrasher et al., 2009; 
Thrasher, Pérez-Hernández et al., 2010; Thrasher, Swayampakala et al., 2010). Some studies have also found associations of exposure to smoke-free legislation with awareness of the harm of smoking and second-hand smoking (Hyland, Higbee et al., 2009; Thrasher, Pérez-Hernández et al., 2010), while other studies have shown that support for smoke-free legislation is associated with awareness of the harm of second-hand smoking (Borland, Yong, Siahpush et al., 2006; Mons et al., 2012). Some studies have examined the effects of support for smoke-free legislation on attitudes, subjective norms, and self-efficacy (psychosocial mediators). It was found that support for smoke-free legislation was associated with attitudes (Macy et al., 2012; Nagelhout, Mons et al., 2011; Thrasher, Besley, \& González, 2010) and subjective norms (Brown et al., 2009; Macy et al., 2012; Nagelhout, Mons et al., 2011; Thrasher et al., 2009) about smoking and quitting. These in turn increased intentions to quit smoking (Brown et al., 2009; Macy et al., 2012), but effects on smoking cessation were not studied.

For the current study, a nationally representative sample of smokers participating in the ITC Netherlands Survey was surveyed at four consecutive years before and after the implementation of smoke-free hospitality industry legislation in July 2008. Although the implementation of smoke-free legislation went relatively well in restaurants, there were considerable problems with the implementation in bars (Mons et al., 2012; Nagelhout, Mons et al., 2011). High levels of non-compliance and low levels of societal and political support eventually led to a partial reversal of the smoke-free legislation in small, owner-run bars at the end of 2010. Possibly due to the problems with bars, the smoke-free hospitality industry legislation had only a small impact on smoking cessation, without significantly reducing smoking prevalence (Nagelhout, Willemsen et al., 2011).

The aim of the current study was to apply the ITC Conceptual Model on pathways of change explaining the effect of individual exposure to smoke-free legislation on smoking cessation. Based on the ITC Conceptual Model and previous literature, we hypothesise that smoke-free legislation influences smoking cessation by first increasing support and harm awareness (policy-specific variables) and in turn increasing attitudes, subjective norms, and self-efficacy for quitting (psychosocial mediators). 
Figure 1: Hypothesised model of the pathways of change between exposure to smoke-free legislation and smoking cessation; adapted from the ITC Conceptual Model (Fong, Cummings, Borland et al., 2006).

\begin{tabular}{|c|c|c|c|}
\hline Policy & $\begin{array}{l}\text { Policy-specific } \\
\text { variables }\end{array}$ & Psychosocial mediators & $\begin{array}{l}\text { Policy-relevant } \\
\text { outcomes }\end{array}$ \\
\hline $\begin{array}{l}\text { Exposure to } \\
\text { smoke-free } \\
\text { legislation }\end{array}$ & $\begin{array}{l}\text { Support for } \\
\text { smoke-free } \\
\text { legislation } \\
\text { Awareness of } \\
\text { harm of } \\
\text { (second-hand) } \\
\text { smoking }\end{array}$ & 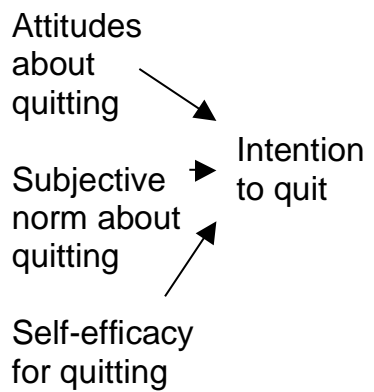 & $\begin{array}{l}\text { Quit attempt } \\
\text { Quit success }\end{array}$ \\
\hline
\end{tabular}

\section{METHODS}

\section{Design}

We used longitudinal data from four consecutive annual surveys of the ITC Netherlands Survey. The baseline survey was performed about two months before the implementation of the smoke-free legislation in 2008. The follow-up surveys were performed after the implementation, respectively one, two, and three years later in 2009, 2010, and 2011. Policy-specific variables, psychosocial mediators, and smoking cessation were modeled at consecutive survey waves, while controlling for policy-specific variables and psychosocial mediators at baseline, to allow for more confident inferences about the causality of the tested pathways of change.

\section{Sample}

Dutch smokers aged 15 years and older were recruited from TNS NIPObase, a large probability-based web database (Nagelhout et al., 2010). Quotas on gender, geographic region, household size, and education were determined from the Dutch Continuous Survey of Smoking Habits (DCSSH) to get a sample that was representative of Dutch smokers. Potential respondents were identified as smokers (having smoked at least 100 cigarettes in their lifetime and currently smoking at least once per month) by means of a short screening survey in March 2008. In April 2008, 2,331 smokers were invited to participate in a web survey. Of these, 1,820 participated in the 2008 survey (78.1\%). In April and May 2009, all 1,820 baseline smokers were invited to participate in the 2009 survey and 1,447 took part (79.5\%). In May 2010, all baseline respondents were invited and 1,275 respondents participated in the 2010 survey (70.1\%). In May and June 2011, all baseline 
respondents were invited and 1,012 respondents participated in the 2011 survey (55.6\%). The respondents received compensation for their participation in each survey by earning points for every answered question, as is standard procedure in the TNS NIPObase web panel. The points could be exchanged for money, which ranged between 5 and 7 Euros for each survey.

\section{Measurements}

Control variables (2008)

Control variables were gender, age group, educational level, heaviness of smoking, smoking status, and attempts to quit smoking in the last year. These variables were assessed at the 2008 survey. Age was categorised as 15 to 24, 25 to 39, 40 to 54, and 55 years and older. Education was categorised in three levels: low (primary education and lower pre-vocational secondary education), moderate (middle pre-vocational secondary education and secondary vocational education), and high (senior general secondary education, (pre-)university education and higher professional education). The Heaviness of Smoking Index (HSI) was created as the sum of two categorised measures: number of cigarettes per day and time before smoking the first cigarette of the day (Heatherton et al., 1989). HSI values ranged from 0 to 6 and were positively associated with nicotine dependence. Smoking status was categorised as daily smoker versus occasional smoker. Attempts to quit smoking were categorised as attempted to quit in the last year versus did not attempt to quit in the last year.

Individual exposure (2009)

Not all individuals were exposed to the smoke-free legislation, because not all hospitality industry venues complied with the legislation and not all individuals visited hospitality industry venues. Individual exposure to smoke-free legislation was assessed using the questions "Which of the following best describes the rules about smoking in bars where you live?" and "Which of the following best describes the rules about smoking in restaurants where you live?" Response categories were "No rules or restriction" (0), "Smoking is allowed only in some indoor areas" (1), and "Smoking is not allowed in any indoor area" (2). Respondents who had not visited bars or restaurants or did not know the rules about smoking were placed in the category "no rules or restrictions". The two questions were also used in previous research to assess exposure to smoking restrictions (Hammond et al., 2006).

Policy-specific variables $(2008,2009)$

Consistent with previous research (Nagelhout, Van den Putte et al., 2012), support for smoke-free legislation was assessed using the questions "Do you support or oppose a complete Dutch smoking ban in bars?" and "Do you support or oppose a 
complete Dutch smoking ban in restaurants?" Response categories were "Strongly oppose" (1), "Oppose" (2), "Support" (3), and "Strongly support" (4). Cronbach's Alpha was 0.72 .

Awareness of the harm of (second-hand) smoking was measured with two questions "In the last month, how often, if at all, did you think about the harm your smoking might be doing to you?" and "In the last month, how often, if at all, did you think about the harm your smoking might be doing to other people?" (Nagelhout, Van den Putte et al., 2012). Response categories were "Never" (1), "Rarely" (2), "Sometimes" (3), "Often" (4), and "Very often" (5). Cronbach's Alpha was 0.67. Psychosocial mediators (2008, 2010)

Attitudes about quitting were assessed using the question "If you quit smoking within the next 6 months, this would be..." Respondents could answer on three 5-point scales whether they thought this would be wise or unwise, pleasant or unpleasant, and positive or negative (Van den Putte, Yzer, Brunsting, \& Willemsen, 2005). Cronbach's Alpha was 0.87 .

Subjective norm about quitting was measured with the question "How do you think that most of the people who are important to you would feel about your quitting smoking within the next 6 months?" (Van den Putte, Yzer, \& Brunsting, 2005). Response categories were "Strongly disapprove" (1), "Disapprove" (2), "Neutral" (3), "Approve" (4), "Strongly approve" (5).

Self-efficacy for quitting was measured using the questions "Suppose you want to quit smoking within the next 6 months, will you be able to resist smoking when: ..you just woke up?”, "..you have experienced something annoying?”, "..you are having a cup of coffee or tea?", "..you are drinking alcohol?", "..you are offered a cigarette?" (Hoving, Mudde, \& De Vries, 2006). Response categories were "I will certainly not be able" (1), "I will probably not be able" (2), "Maybe I will be able, maybe not" (3), "I will probably be able" (4), and "I will certainly be able" (5). Cronbach's Alpha was 0.88 .

Intention to quit was assessed with a single question: "Are you planning to quit smoking: ..within the next month?" (4), "..within the next 6 months?" (3), "..sometime in the future, beyond 6 months" (2), "..or are you not planning to quit?" (1) (De Vries, Mudde, Dijkstra, \& Willemsen, 1998).

Policy-relevant outcomes (2011)

Whether respondents had attempted to quit smoking was measured with the question: "Have you made any attempts to stop smoking since the last survey?" (Hyland, Borland et al., 2006).

Quit success was assessed by asking respondents who had attempted to quit whether they were back to smoking or still stopped. Respondents who where 
still stopped, or who were back to smoking, but reporting smoking less than once a month, were defined as successful quitters. Respondents who did not attempt to quit, or who were back to smoking more than once a month, were defined as smokers (Hyland, Borland et al., 2006).

\section{Ethics}

The ITC Netherlands surveys received ethics clearance from the Research Ethics Board of the University of Waterloo and the Central Committee on Research Involving Human Subjects in the Netherlands.

\section{Analyses}

Attrition analyses, sample characteristics, and correlation analyses were performed with SPSS version 17.0. For the correlation analyses, all variables were treated as continuous variables.

Structural Equation Modelling was performed using Mplus version 5.21 (Muthén \& Muthén, 2007), while employing weighted least square parameter estimates. Model fit was assessed using the Comparative Fit Index (CFI), the TuckerLewis-Index (TLI), and the Root-Mean-Square Error of Approximation (RMSEA). For a satisfactory model fit, the CFI and TLI should be above 0.90, and the RMSEA should be under 0.05 (Hox \& Bechger, 1998). All respondents who participated in the 2008 and 2011 survey $(n=1,012)$ were included in the analyses. Respondents who had quit smoking successfully before the 2011 survey were not asked the questions about psychosocial mediators at the 2010 survey and smoking cessation at the 2011 survey. These respondents could be included in the model because Mplus can use all available information from all observed (including incomplete) cases. ${ }^{4}$ All analyses were weighted by age and gender to be representative of the smoker population in the Netherlands.

We tested a model of the effects of individual exposure to smoke-free legislation in 2009 on quit attempts and quit success in 2011 through policyspecific variables in 2009 and psychosocial mediators in 2010 . We controlled for the above mentioned control variables in 2008 and the policy-specific variables and psychosocial mediators, all as measured in 2008. Exposure to smoke-free legislation, support for smoke-free legislation, harm awareness, attitudes about quitting, and self-efficacy for quitting were entered as latent constructs and measured by the indicators as defined in the measurements section. Subjective

$4 \quad$ Additional analyses with only complete cases who responded to all four surveys and did not quit successfully before the 2011 survey $(n=766)$ resulted in a similar model in which all paths that were significant in the reported model remained significant. 
norm about quitting, intention to quit, quit attempt, quit success, and the control variables were measured with single items and were thus observed variables. Support for smoke-free legislation, intention to quit, quit attempt, and quit success were treated as categorical variables, because they had non-normal distributions. All other variables had approximately normal distributions and were treated as continuous variables.

Within the above described model, we tested the significance of the indirect paths of exposure to smoke-free legislation via all policy-specific variables and psychosocial mediators to quit attempts and quit success. In a separate model, we added direct paths from exposure to smoke-free legislation on quit attempts and quit success to test for full mediation.

\section{RESULTS}

\section{Attrition analyses}

Of the 1,820 baseline respondents, 1,012 (55.6\%) participated in the 2011 survey. Respondents who participated in the 2011 survey were significantly older (mean age $=39.3, \mathrm{SD}=15.3$ ) than respondents who did not participate in the 2011 survey (mean age $=33.9, S D=15.2)(t=-7.5, p<0.001)$. Furthermore, respondents who participated in the 2011 survey were significantly more likely to be male $\left(\chi^{2}=8.8, p=\right.$ $0.003)$, lower educated $\left(\chi^{2}=9.1, p=0.011\right)$, and more likely to be a heavier smoker $(\mathrm{t}=-2.4, \mathrm{p}=0.017)$ than respondents who did not participate in the 2011 survey. Respondents who participated in the 2011 survey and who did not participate in the 2011 survey did not differ on support for smoke-free legislation, harm awareness, attitudes about quitting, subjective norm about quitting, and intention to quit smoking in 2008. Respondents who participated in the 2011 survey did have slightly less self-efficacy for quitting $(t=2.3, p=0.023)$.

\section{Sample characteristics}

Sample characteristics are shown in Table 1. Most respondents were daily smoker at baseline. About $23 \%$ of respondents reported at the 2008 survey to have attempted to quit smoking in the previous year. Respondents were mostly not supportive of smoke-free legislation and not much aware of the harm of (second-hand) smoking. Most respondents intended to quit smoking sometime in the future. More than onethird of respondents reported at the 2011 survey to have attempted to quit smoking in the previous year and almost one fifth quit smoking successfully. 


\section{Correlations}

Table 2 shows correlations between individual exposure, policy-specific variables, psychosocial mediators, and policy-relevant outcomes. Individual exposure to smoke-free legislation was weakly correlated with support for smoke-free legislation. Support for smoke-free legislation and harm awareness had a positive correlation. Both support and harm awareness correlated stronger with attitudes about quitting than with the subjective norm about quitting and self-efficacy. Attitudes about quitting correlated strongest with subjective norm about quitting and intention to quit. Attempting to quit correlated most with intention to quit. Quit success correlated most with self-efficacy for quitting and quit attempts.

Table 1: Sample characteristics in 2008, 2009, 2010, and $2011(n=1,012)$.

\begin{tabular}{|c|c|c|c|c|}
\hline & 2008 & 2009 & 2010 & 2011 \\
\hline \multicolumn{5}{|l|}{ Control variables } \\
\hline \multicolumn{5}{|l|}{ Gender } \\
\hline Male (\%) & 48.9 & - & - & - \\
\hline Female (\%) & 51.1 & - & - & - \\
\hline \multicolumn{5}{|l|}{ Age group } \\
\hline $15-24$ years $(\%)$ & 19.5 & - & - & - \\
\hline $25-39$ years $(\%)$ & 25.6 & - & - & - \\
\hline 40-54 year (\%) & 30.2 & - & - & - \\
\hline 55 years and older (\%) & 24.7 & - & - & - \\
\hline \multicolumn{5}{|l|}{ Educational level } \\
\hline Low (\%) & 40.8 & - & - & - \\
\hline Moderate (\%) & 41.0 & - & - & - \\
\hline High (\%) & 18.2 & - & - & - \\
\hline \multicolumn{5}{|l|}{ Smoking status } \\
\hline Daily smoker (\%) & 92.3 & - & - & - \\
\hline Occasional smoker (\%) & 7.7 & - & - & - \\
\hline \multicolumn{5}{|l|}{ Attempts to quit in the last year } \\
\hline Yes $(\%)$ & 23.4 & - & - & - \\
\hline No $(\%)$ & 76.6 & - & - & - \\
\hline \multicolumn{5}{|l|}{$\begin{array}{l}\text { Heaviness of SmoKIng (mean, SD) } \\
\text { Individual exposure }\end{array}$} \\
\hline Exposure to smoke-free legislation** (mean, SD) & - & $1.4(0.6)$ & - & - \\
\hline $\begin{array}{l}\text { Sollcy-specric Varlables } \\
\text { Support for smoke-free legislation† (mean, SD) }\end{array}$ & $2.1(0.8)$ & $2.3(0.8)$ & - & - \\
\hline \multicolumn{5}{|l|}{ 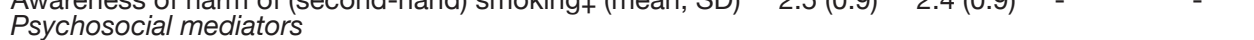 } \\
\hline Attitudes about quitting $\ddagger$ (mean, SD) & $3.9(0.7)$ & - & $4.0(0.8)$ & - \\
\hline Subjective norm about quitting $\ddagger$ (mean, SD) & $4.2(0.8)$ & - & $4.2(0.8)$ & - \\
\hline \multirow{2}{*}{\multicolumn{5}{|c|}{ Intention to quit }} \\
\hline & & & & \\
\hline Within the next month (\%) & 4.5 & - & 2.8 & - \\
\hline Within the next 6 months (\%) & 17.5 & - & 15.9 & - \\
\hline Sometime in the future, beyond 6 months (\%) & 58.2 & - & 53.5 & - \\
\hline Not planning to quit (\%) & 19.8 & - & 27.8 & - \\
\hline \multicolumn{5}{|l|}{ Policy-relevant outcomes } \\
\hline \multicolumn{5}{|l|}{ Quit attempt } \\
\hline Yes (\%) & - & - & - & 35.2 \\
\hline No $(\%)$ & - & - & - & 64.8 \\
\hline \multicolumn{5}{|l|}{ Quit success } \\
\hline $\begin{array}{l}\text { Yes }(\%) \\
\text { No }(\%)\end{array}$ & - & - & - & $\begin{array}{l}19.4 \\
80.6\end{array}$ \\
\hline
\end{tabular}

* on a scale from 0 to $6,{ }^{* *}$ on a scale from 0 to 2 , † on a scale from 1 to 4 , $\neq$ on a scale from 1 to 5 . 
Table 2: Pearson correlations between individual exposure (2009), policy-specific variables (2009), psychosocial mediators (2010), and policy-relevant outcomes (2011).

\begin{tabular}{|c|c|c|c|c|c|c|c|c|c|}
\hline & 1 & 2 & 3 & 4 & 5 & 6 & 7 & 8 & 9 \\
\hline $\begin{array}{l}\text { 1. Exposure to smoke- } \\
\text { free legislation (2009) } \\
\text { 2. Support for smoke- }\end{array}$ & 1.00 & & & & & & & & \\
\hline $\begin{array}{l}\text { free legislation (2009) } \\
\text { 3. Awareness of harm } \\
\text { of (second-hand) }\end{array}$ & $0.11^{\star \star \star}$ & 1.00 & & & & & & & \\
\hline $\begin{array}{l}\text { smoking (2009) } \\
\text { 4. Attitudes about }\end{array}$ & 0.06 & $0.20^{\star \star \star}$ & 1.00 & & & & & & \\
\hline $\begin{array}{l}\text { quitting (2010) } \\
5 \text {. Subjective norm }\end{array}$ & $0.08^{*}$ & $0.27^{\star \star \star}$ & $0.28^{\star \star \star}$ & 1.00 & & & & & \\
\hline $\begin{array}{l}\text { about quitting (2010) } \\
6 \text {. Self-efficacy for }\end{array}$ & 0.04 & $0.16^{\star \star \star}$ & $0.17^{\star \star \star}$ & $0.57^{\star * *}$ & 1.00 & & & & \\
\hline $\begin{array}{l}\text { quitting (2010) } \\
\text { 7. Intention to quit }\end{array}$ & 0.02 & $0.20^{\star \star \star}$ & 0.03 & $0.27^{\star \star \star}$ & $0.09^{\star \star}$ & 1.00 & & & \\
\hline (2010) & $0.12^{\star \star \star}$ & $0.18^{\star \star \star}$ & $0.27^{\star \star \star}$ & $0.44^{\star \star \star}$ & $0.22^{\star \star \star}$ & $0.22^{\star \star \star}$ & 1.00 & & \\
\hline 8. Quit attempt (2011) & 0.05 & $0.11^{\star \star}$ & $0.11^{\star *}$ & $0.23^{\star * \star}$ & $0.16^{\star \star \star}$ & $0.13^{\star \star \star}$ & $0.36^{\star \star \star}$ & 1.00 & \\
\hline 9. Quit success (2011) & 0.01 & $0.14^{\star \star \star}$ & 0.03 & $0.24^{\star \star \star}$ & $0.17^{* \star *}$ & $0.39^{\star \star *}$ & $0.13^{\star \star \star}$ & $0.31^{\star * *}$ & 1.00 \\
\hline
\end{tabular}

${ }^{*} p<0.05,{ }^{* *} p<0.01,{ }^{* * *} p<0.001$

Figure 2: Structural Equation Model with standardised regression coefficients $†$ assessing the pathways of change between exposure to smoke-free legislation and quit attempts and quit success.

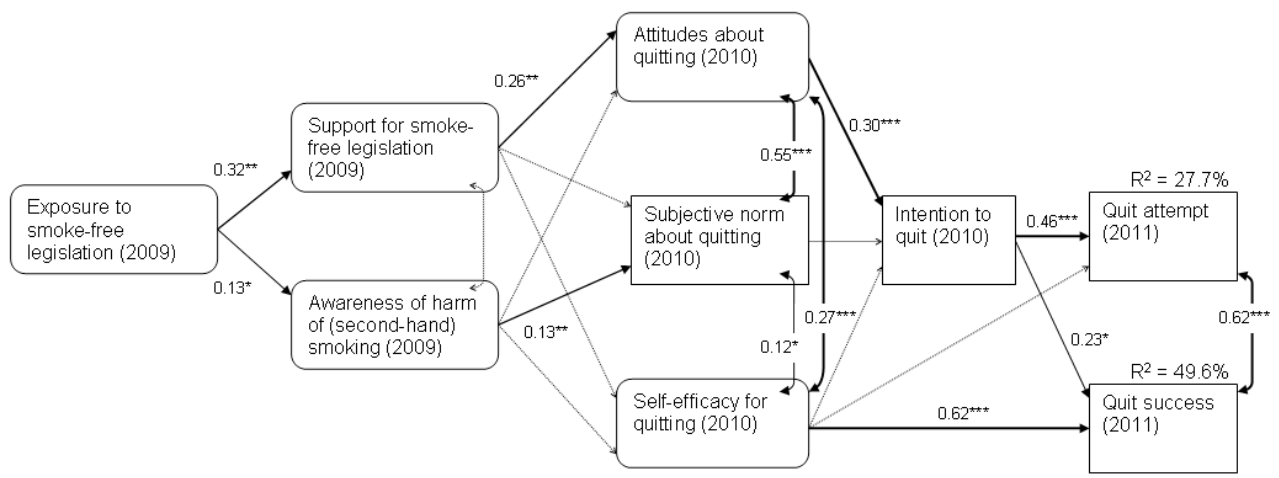

† To simplify the presentation, control variables, factor loadings, residual values and regression coefficients of non-significant paths (dotted lines) were omitted from the figure.

${ }^{*} p<0.05,{ }^{* *} p<0.01,{ }^{* * *} p<0.001$

\section{Structural Equation Model}

The results of the Structural Equation Model are displayed in Figure 2. The model fitted the data reasonably well $(\mathrm{CFI}=0.899, \mathrm{TLI}=0.933, \mathrm{RMSEA}=0.037)$ and explained $27.7 \%$ of the variance in quit attempts and $49.6 \%$ of the variance in quit success. All factor loadings in the final model were significant, with values between 0.51 and 0.91 . 
As can be seen in Figure 2, exposure to smoke-free legislation was associated with more support for smoke-free legislation $(\beta=0.32, p=0.007)$ and more harm awareness $(\beta=0.13, p=0.034)$. More support for smoke-free legislation predicted positive attitudes about quitting $(\beta=0.26, p=0.004)$, while more harm awareness predicted a stronger subjective norm about quitting $(\beta=0.13, \mathrm{p}=0.023)$. Positive attitudes about quitting were associated with more intention to quit smoking $(\beta=$ $0.30, p<0.001)$, while subjective norm about quitting $(\beta=0.03, p=0.572)$ and self-efficacy for quitting ( $\beta=0.05, p=0.347$ ) were not significantly associated with intention to quit after controlling for the other predictors in the model. Intention to quit predicted quit attempts $(\beta=0.46, p<0.001)$ and quit success $(\beta=0.23, p=$ $0.023)$ and self-efficacy for quitting predicted quit success $(\beta=0.62, p<0.001)$.

\section{Tests of indirect and direct paths}

Within the model in Figure 2, we tested the significance of the indirect paths of exposure to smoke-free legislation via all policy-specific variables and psychosocial mediators to quit attempts and quit success. There was a borderline significant indirect path from exposure to smoke-free legislation on quit attempts via support, attitudes, and intention ( $\beta=0.01, p=0.059)$.

In a separate model (not shown), we tested for full mediation by adding direct paths from exposure to smoke-free legislation on quit attempts and quit success. Direct paths from exposure to smoke-free legislation to quit attempts ( $\beta$ $=-0.05, p=0.495)$ and quit success $(\beta=0.06, p=0.447)$ were non-significant, suggesting full mediation.

\section{DISCUSSION}

The analyses presented in this paper, involving longitudinal data from four survey waves across three years, represent the most extensive test so far of the mediational pathways between policy and behaviour that are presented in the ITC Conceptual Model (Fong, Cummings, Borland et al., 2006). We found support for the ITC Conceptual Model which hypothesised that policies influence smoking cessation through policy-specific variables and psychosocial mediators. The effect of smoke-free legislation on smoking cessation was mediated by one pathway via support for smoke-free legislation, attitudes about quitting, and intention to quit smoking. Smoke-free legislation also influenced the subjective norm about quitting by creating more awareness of the harm of (second-hand) smoking. Our findings are largely in line with earlier studies that have tested parts of the causal chain from exposure to smoke-free legislation on smoking cessation. Consistent with earlier studies, we found that support for smoke-free legislation and attitudes about 
quitting were crucial factors in increasing intention to quit smoking (Brown et al., 2009; Macy et al., 2012).

In our model, only attitudes about smoking were significantly associated with intention to quit smoking, whereas subjective norm and self-efficacy for quitting were not after controlling for the other predictors in the model. This is not in line with predictions of social cognitive models (Ajzen, 1991; De Vries \& Mudde, 1998), although a meta-analysis (Armitage \& Conner, 2001) did find that subjective norms were a weaker predictor of intentions than attitudes and selfefficacy. This meta-analysis also showed that multiple-item measures of subjective norms were a stronger predictor of intentions than single-item measures, which may explain our results. Although this was also found in an earlier study (Bledsoe, 2006), it is unclear why self-efficacy was not significantly associated with intention after controlling for the other predictors in the model. A meta-analysis showed that attitudes, subjective norms, self-efficacy, and intention explain $27 \%$ of the variance in behaviour (Armitage \& Conner, 2001). Our explained variance was similar for quit attempts $(28 \%)$, but much higher for quit success $(50 \%)$. This may be caused by the strong direct effect from self-efficacy on quit success, which is consistent with predictions of social cognitive models. Consistent with earlier studies (Borland et al., 2010; Hyland, Borland et al., 2006; Zhou et al., 2009), intention to quit was a stronger predictor of quit attempts than of quit success.

Earlier studies that examined the direct effects of smoke-free legislation on smoking behaviour found positive effects in some jurisdictions and not in others (Bajoga et al., 2011; Callinan et al., 2010). Earlier ITC studies have also found inconsistent evidence of an effect of smoke-free legislation on smoking cessation (Cooper et al., 2010; Fong, Hyland et al., 2006; Hyland, Hassan et al., 2009; Nagelhout, De Vries, Boudreau et al., 2012). The current study sheds some light on psychosocial factors that mediate the effects of smoke-free legislation on smoking cessation, that is, if the legislation is not supported by smokers and smokers do not change their attitudes about quitting no effects on cessation are to be expected. However, behavioural factors like implementing voluntary smoking bans in homes and cars and complying with smoke-free legislation might also explain why smoke-free legislation stimulates smoking cessation in some individuals and not in others. Moreover, implementation characteristics of the smoke-free legislation may influence whether smoke-free legislation increases smoking cessation. It is, for example, reported that support for smoke-free legislation increases more after the implementation of comprehensive than after the implementation of partial smoke-free legislation (Mons et al., 2012; Thrasher, Swayampakala et al., 2010). Comprehensive smoke-free legislation may therefore lead to more smoking 
cessation than partial legislation. Also, smoke-free legislation that is implemented with accompanying media attention may lead to more support and harm awareness (Thrasher et al., 2011; Villalobos et al., 2010). The Dutch smoke-free hospitality industry legislation was not comprehensive and was accompanied by unsupportive media attention and an implementation campaign that did not emphasise the harm of (second-hand) smoking (Nagelhout, Van den Putte et al., 2012). More research is needed on the relations between psychosocial factors, behavioural factors, and implementation characteristics, and how they account for smoke-free legislation effects on smoking cessation.

This study has some important strengths. It is the first study to examine the full causal chain explaining the effect of individual exposure to smoke-free legislation on smoking cessation. The longitudinal nature of the study with four survey waves and a relatively large sample of smokers allows for more confident inferences about the causality of the tested pathways of change. However, there are several limitations that deserve to be acknowledged. First, we were only able to retain half of the baseline respondents over four survey waves which could introduce selection bias into the inferences from this study. Respondents lost to follow-up were more likely to be younger, female, higher educated, less heavy smokers, and had slightly more self-efficacy for quitting. Therefore, our results may not be fully generalisable to the broader population of Dutch smokers. Furthermore, because we used self-reported measures we could not objectively determine exposure to smoke-free legislation and smoking cessation. People may have been exposed to smoke-free legislation without remembering this at the time of the survey. Also, exposure may take place without actually visiting the hospitality industry, for example by media attention. The main aim of our modelling strategy, using four waves, was to infer causality of the hypothesised relationships in the ITC Conceptual Model. This has the drawback of being unable to account for short-term effects of smoke-free legislation on smoking cessation. Because modeled effects on policy-specific variables, psychosocial mediators, and smoking cessation are spread over the course of several years, the found total effect may be smaller than the actual total effect, which suggests that our results are conservative.

Our results may not be fully generalisable to other countries because of differences in smoke-free legislation. Because the smoke-free legislation in Germany is comparable to the Netherlands (Nagelhout, Mons et al., 2011), we expect that the results are generalisable to Germany. However, the results may not be generalisable to countries where smoke-free legislation is more comprehensive, which may lead to stronger effects than found in our study. For example, in Ireland and England stronger effects on smoking cessation were found after implementation of a more 
comprehensive ban (Nagelhout, De Vries, Boudreau et al., 2012).

Our findings have important implications for smoke-free policy implementation and development of accompanying media campaigns. Our study shows that support for smoke-free legislation and attitudes about quitting are crucial factors in increasing intention to quit smoking after the implementation of smokefree legislation. This suggests that the countries where smoke-free legislation had a positive effect on smoking cessation are the countries where support for the legislation and attitudes about quitting increased the most. Although more (ecological) research is needed to examine this hypothesis, anecdotal evidence from Ireland (Currie \& Clancy, 2010) and Greece (Tamvakas \& Amos, 2010) has already pointed out that support for the legislation is an important factor in the success of smoke-free legislation. Therefore, countries should actively aim to increase support for the legislation and attitudes about quitting, for example through accompanying media campaigns and media advocacy. 


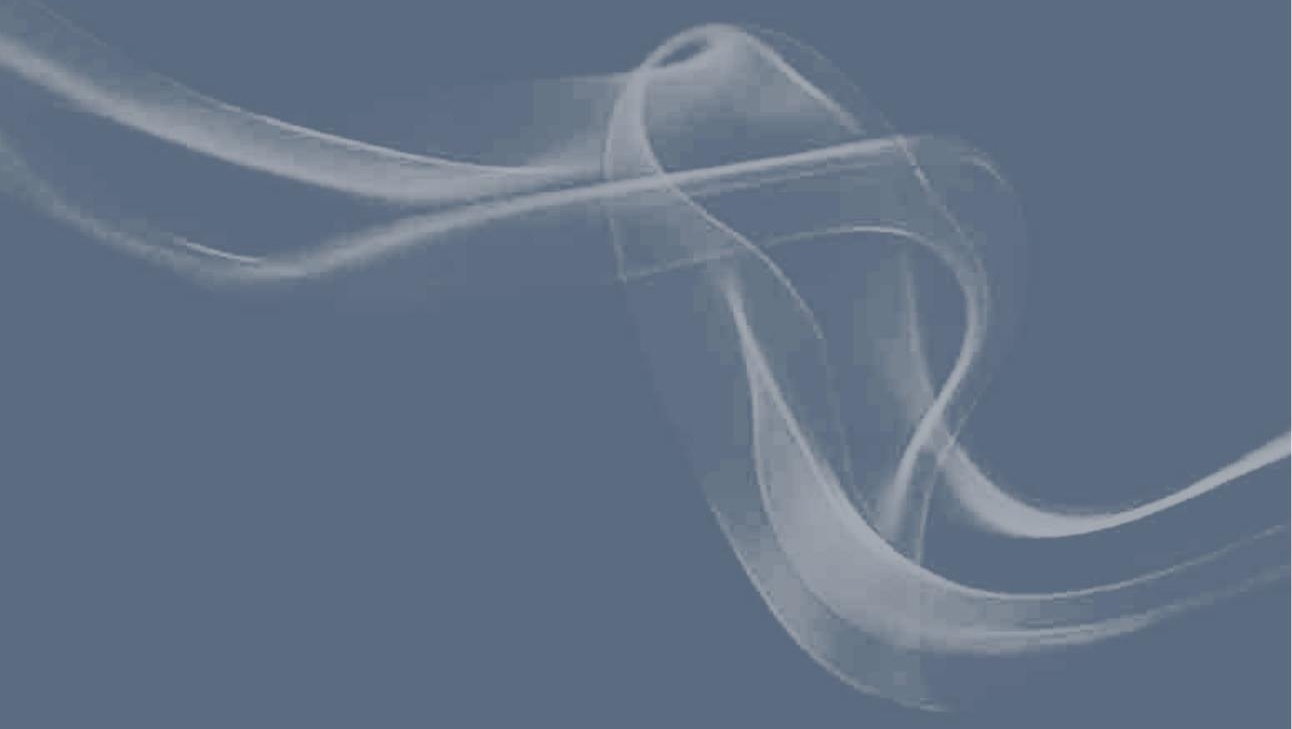

| 174 | 
Part 3

\section{Unintended consequences of smoke-free legislation}




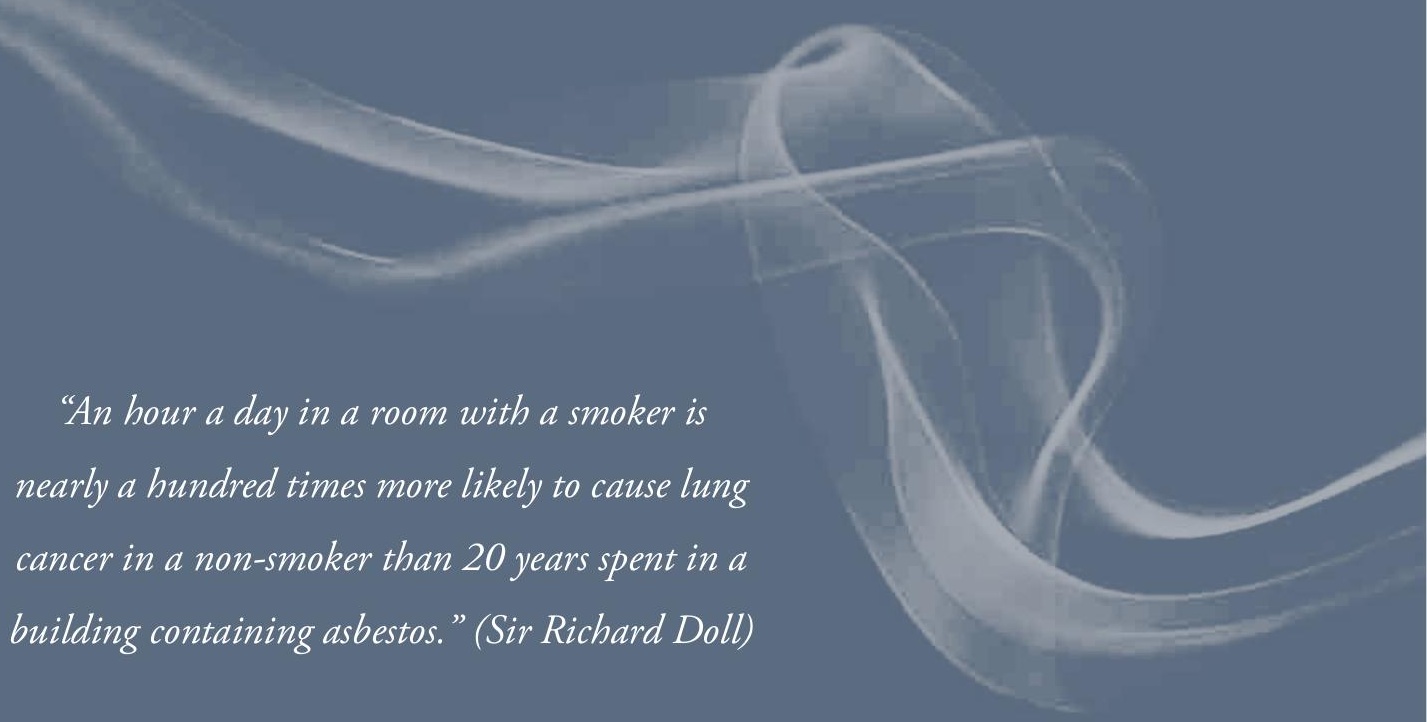




\section{Chapter 11}

\section{Smoke-free legislation and smoking in smokers' homes}

\section{Published as:}

Mons, U., Nagelhout, G. E., Allwright, S., Guignard, R., Van den Putte, B., Willemsen, M. C., Fong, G. T., Brenner, H., Pötschke-Langer, M., \& Breitling, L. P. Impact of national smoke-free legislation on home smoking bans: Findings from the International Tobacco Control (ITC) Policy Evaluation Project Europe Surveys. Tobacco Control. Published Online First: 13 February 2012. 
The aim of this study was to measure changes in prevalence and predictors of home smoking bans (HSB) among smokers in four European countries after the implementation of national smoke-free legislation. We used two waves of the International Tobacco Control Policy Evaluation Project (ITC Project) Europe Surveys, which is a prospective panel study. Pre- and post-legislation data was used from Ireland, France, Germany, and the Netherlands. Two pre-legislation waves from UK were used as control. 4,634 respondents from the intervention countries and 1,080 from the control country completed both baseline and follow-up, and were included in the present analyses. Multiple logistic regression models to identify predictors of having or of adopting a total HSB, and Generalised Estimating Equation (GEE) models to compare patterns of change after implementation of smoke-free legislation to a control country without such legislation. Most smokers had at least partial smoking restrictions in their home, but the proportions varied significantly between countries. After implementation of national smoke-free legislation, the proportion of smokers with a total HSB increased significantly in all four countries. Among continuing smokers the number of cigarettes smoked per day either remained stable or decreased significantly. Multiple logistic regression models indicated that having a young child in the household and supporting smoking bans in bars were important correlates of having a pre-legislation HSB. Prospective predictors of imposing a HSB between survey waves were planning to quit smoking, supporting a total smoking ban in bars, and the birth of a child. GEE models indicated that the change in total HSB in the intervention countries was greater than in the control country. The findings suggest that smoke-free legislation does not lead to more smoking in smokers' homes. On the contrary, our findings demonstrate that smoke-free legislation may stimulate smokers to establish total smoking bans in their homes. 


\section{INTRODUCTION}

For children, exposure to secondhand smoke (SHS) is an important health risk. SHS impairs their respiratory system and can cause severe and chronic diseases such as asthma and bronchitis (Cheraghi \& Salvi, 2009; Royal College of Physicians, 2010). Especially in early childhood, the home environment is usually the main source of exposure to SHS (Akhtar, Haw, Currie, Zachary, \& Currie, 2009). But while workplace and public smoking bans have been proven to be successful in reducing exposure to SHS in public areas (Callinan et al., 2010), private homes cannot be directly targeted by measures such as smoke-free legislation. They might nevertheless be indirectly affected.

Two competing hypotheses regarding possible influences of public smoking bans on smoking at home have been put forward (Borland, Yong, Cummings et al., 2006). According to the displacement hypothesis or 'last refuge model', smoking bans in public places would lead to more smoking in the home and hence to increased SHS exposure of non-smoking family members and children. Under this hypothesis, an increase in SHS-related diseases would be expected as an unintended detrimental consequence of smoke-free legislation. The social diffusion hypothesis, in contrast, suggests that more restrictive rules regarding smoking in public places would increase the likelihood of householders imposing voluntary home smoking restrictions.

Whereas two empirical studies from the US and from Hong Kong support the displacement hypothesis (Adda \& Cornaglia, 2010; Ho et al., 2010), recent studies from Scotland, Wales, Ireland, and New Zealand evaluating the effects of smoke-free legislation found no increase in exposure to SHS in non-smoking family members and children due to displacement of smoking into the private home, and no increase of smoking at home (Akhtar, Currie, Currie, \& Haw, 2007; Akhtar et al., 2009; Edwards et al., 2009; Edwards et al., 2008; Fong, Hyland et al., 2006; Haw \& Gruer, 2007; Holliday, Moore, \& Moore, 2009; Hyland, Hassan et al., 2009; Hyland et al., 2008; Jarvis, Sims, Gilmore, \& Mindell, 2012). Of these studies, only two are based on longitudinal data (Fong, Hyland et al., 2006; Hyland et al., 2008).

The recent implementation of pertinent legislation in several European countries provides an unprecedented opportunity to examine this topic in a broader European setting in order to allow better informed decisions by policymakers. Unique prospective data from the Europe Surveys of the International Tobacco Control Policy Evaluation Project (ITC Project) were analysed, based on representative surveys in Ireland, France, Germany, and the Netherlands conducted shortly before and after the implementation of smoke-free legislation. We examined the numbers of cigarettes smoked at home, and prevalence and predictors of home smoking 
bans (HSB) before and after implementation of smoke-free legislation. Additionally, the pattern of change in the rate of HSB in these countries was compared to prelegislation data from the United Kingdom (UK) as a control country.

\section{METHODS}

\section{Study design and study participants}

The ITC Europe Surveys are part of the ITC Project (www.itcproject.org), which is committed to evaluating the psychosocial and behavioural effects of tobacco control policies throughout the world. All ITC surveys are based on the same conceptual framework and methods and use standardised survey questionnaires (Fong, Cummings, Borland et al., 2006; Thompson et al., 2006).

The ITC Europe Surveys are conducted with probability samples of smokers aged 18 years and older, with smokers being defined as having smoked at least 100 cigarettes in their lifetime and currently smoking at least once per month. In Ireland, France and Germany, respondents were recruited and questioned using random digit dialling (RDD) and computer-assisted telephone interviews (CATI) only. In the Netherlands, the sample consisted of a small RDD CATI sample and a larger computer-assisted web interview sample (CAWI). The CAWI sample was drawn from a large probability-based database with potential respondents who had been recruited by phone or mail and who had indicated their willingness to participate in research on a regular basis. Whereas the two Dutch samples showed small differences in socio-demographics and smoking behaviour (Nagelhout et al., 2010), there were no significant differences with regard to HSB prevalence at prelegislation $\left(\chi^{2}=4.46, p=0.11\right)$ or post-legislation $\left(\chi^{2}=1.77, p=0.41\right)$; the samples were thus pooled for the analyses.

Respondents were first interviewed before implementation of the national smoke-free legislation (pre-legislation surveys). The fieldwork of the post-legislation measurements started about 8 months after implementation of the hospitality sector smoke-free legislation in Ireland, France and the Netherlands (Figure 1). As the starting date of the smoke-free legislation in Germany varied from state to state, the time gap between introduction of the state legislation and post-legislation survey varied from 12 to 23 months.

The analyses presented here were based on the longitudinal samples, i.e. only on those respondents who had been surveyed both pre- and post-legislation. Of 6,393 smokers interviewed pre-legislation, 4,634 (72.5\%) could be followed up after the implementation of the smoke-free legislation. Country-specific follow-up rates varied between 66 and 79 percent (Figure 1). For some analyses, sample sizes were smaller due to missing values for some covariates. 
In order to address the question of causality, we employed a quasi-experimental design in additional analyses. We chose UK as a control country, the only other European country in the ITC Project and the only one for which several pre-legislation waves are available. In the UK, Scotland introduced a comprehensive smoking ban in March 2006, Wales and Northern Ireland followed in April 2007, and England enacted its ban in July 2007. In order to have a pre-legislation observation period as comparable as possible to the pre- to post-legislation period in the other countries, we used waves 4 (October 2005 - January 2006) and 5 (October 2006 - February 2007) of the ITC UK survey, but excluded Scotland from the analyses, because they implemented their smoke-free legislation between these two waves. From 1,581 smoking non-Scotland respondents of ITC UK wave 4, 1,080 could be followed up at wave 5 and were used for the analyses (follow-up rate: $68.3 \%$ ).

In order to assess the potential effect of attrition bias, non-responder analyses were conducted by estimating logistic regression models with the full baseline samples, and with being lost to follow-up as dependent variable, and with home smoking restrictions and all covariates as independent variables. In the intervention countries, these analyses yielded higher odds of being lost to followup in younger age groups (age 18-24 versus age $55+$ : $\mathrm{OR}=1.79,95 \% \mathrm{Cl}=1.43-$ 2.24; age 25-39 versus age $55+$ : $\mathrm{OR}=1.54,95 \% \mathrm{Cl}=1.26-1.88$ ) and lower odds in married respondents $(\mathrm{OR}=0.68,95 \% \mathrm{Cl}=0.60-0.78)$. In the control country $\mathrm{UK}$, younger age groups also had comparably higher odds of being lost to follow-up (age 18-24 versus age 55+: $\mathrm{OR}=2.39,95 \% \mathrm{Cl}=1.41-4.03$; age 25-39 versus age $55+: \mathrm{OR}=1.46,95 \% \mathrm{Cl}=1.02-2.10)$. Additionally, higher odds were found among UK respondents with children aged 6 to $12(\mathrm{OR}=1.48,95 \% \mathrm{Cl}=1.05-2.07)$ and with children aged 13 to $17(\mathrm{OR}=1.74,95 \% \mathrm{Cl}=1.21-2.50)$, compared to respondents without children in the household. Furthermore, country-specific non-responder analyses showed that French respondents with home smoking restrictions prelegislation were less likely to be lost to follow-up (total HSB versus no restrictions: $\mathrm{OR}=0.56,95 \% \mathrm{Cl}=0.38-0.81$; partial restrictions versus no restrictions: $\mathrm{OR}=0.57$, $95 \% \mathrm{Cl}=0.42-0.77)$. 


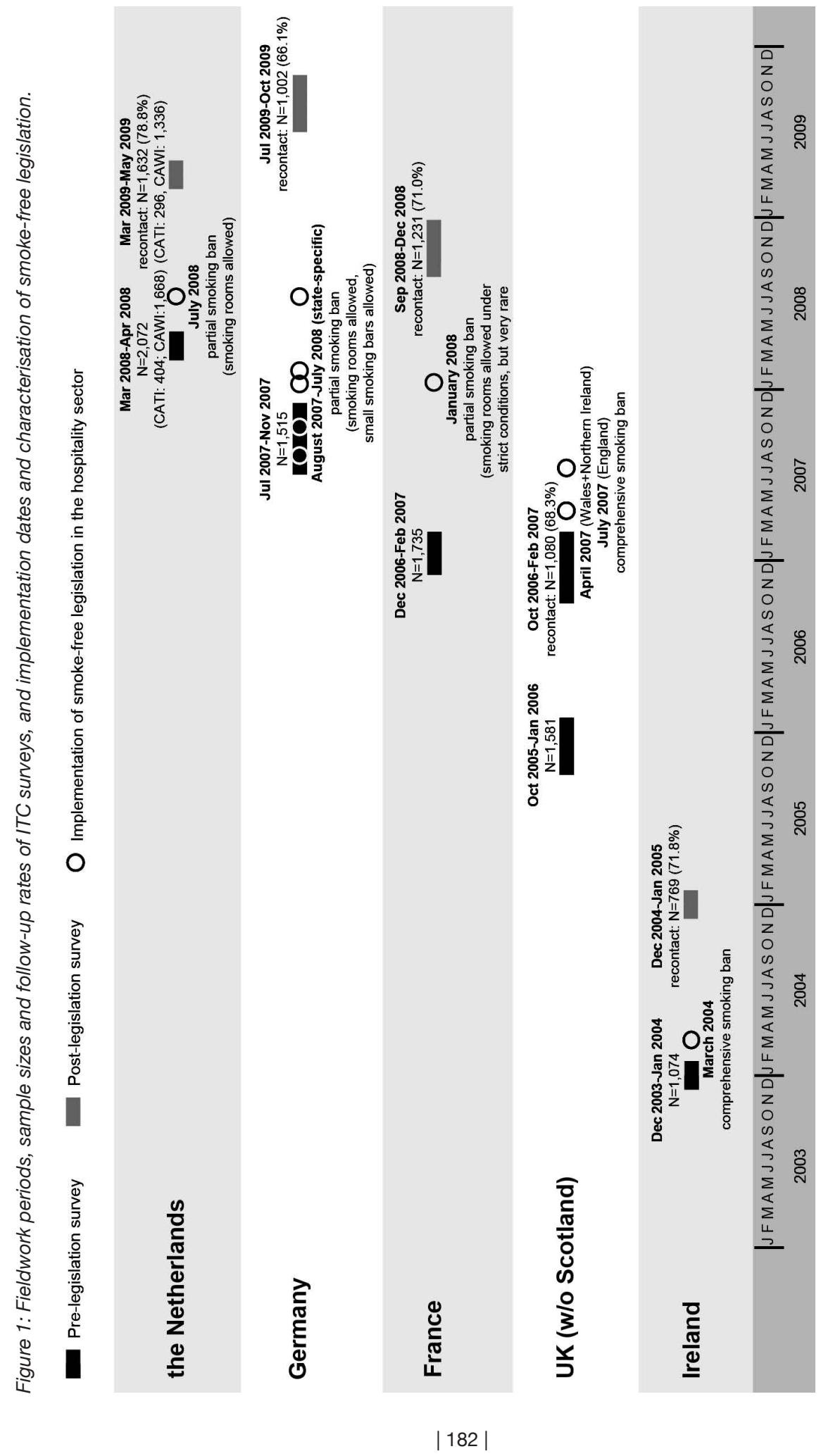




\section{Measures and outcomes}

The study included relevant socio-demographic variables, such as gender, age, marital status, education and the age of children living in the household. A binary variable referring to the birth of a child between the two survey waves was derived by using pre- and post-legislation information about the age of children living in the respondent's household. Because the Irish survey did not ask about children in the household at the first post-legislation survey, this item of information was derived from the second post-legislation survey (fieldwork period: February - March 2006, i.e. 14 months after the first post-legislation survey).

Smoking-related questions of particular relevance to the present analyses were cigarette consumption, the Heaviness of Smoking Index (HSI) (Heatherton et al., 1989), intention to quit smoking, and support for a bar smoking ban. The amount of cigarettes smoked at home was obtained with asking "When you are spending an evening at home, about how many cigarettes do you smoke inside your home during the evening?", and was used as a continuous variable. Unfortunately, this measure was not available for Ireland and UK. The frequency of bar visits was used to assess to what extent respondents would be affected by the smoke-free policy. Awareness of the harm of SHS was measured by reported agreement with the statement "Cigarette smoke is dangerous to non-smokers". For Ireland, the comparably phrased statement "Your cigarette smoke is dangerous to those around you" was used.

The rules for smoking at home were assessed by asking, "Which of the following statements best describes smoking inside your home (inside the home, not on the balcony or terrace)?" Response choices in France, Germany and the Netherlands were: "Smoking is allowed anywhere inside your home", "Smoking is allowed in some rooms inside your home", "Smoking is never allowed anywhere inside your home", and "Smoking is not allowed inside your home except under special circumstances". In Ireland and the UK the response choices were slightly different: "Smoking is allowed anywhere inside your home", "Smoking is never allowed anywhere inside your home", and "Something in between". For the bivariate analyses these statements were translated into three categories: total home smoking ban (HSB), partial restrictions, and no restrictions. For the multivariate analyses on having or adopting a HSB, a binary variable was constructed. The statement "Smoking is never allowed anywhere inside your home" qualified as having a HSB. Those respondents reporting having partial or no home smoking restrictions were regarded as having no HSB. 


\section{Statistical analyses}

Percentages reported for country-specific estimates of home smoking restrictions and arithmetic means of cigarette consumption were weighted by age and sex to each country's resident smoking population of the year of the respective survey. To assess whether changes in home smoking restrictions were due to smoking cessation between survey waves, the percentages were also reported for continuing smokers. McNemar-Bowker-tests of symmetry were used to test for changes in prevalence of home smoking restrictions. Paired t-tests were used to test for changes in mean cigarette consumption.

In order to identify factors associated with the presence or adoption of HSB in smokers, multiple logistic regression models were computed. For predictors of a HSB at the time of the pre-legislation survey, reporting a HSB at this survey was the dependent variable. For predictors of adopting a HSB, reporting a HSB at the post-legislation survey was the dependent variable, while the sample was restricted to those who had not implemented a HSB at the pre-legislation survey. Except for 'newborn child', all predictor variables refer to the pre-legislation measurement.

To test whether patterns of changes in HSB prevalence from pre- to postlegislation in the four countries examined differed from the control country (UK) in a comparable period of time, Generalised Estimating Equations (GEE) models (Hanley et al., 2003; Zeger \& Liang, 1986) predicting the presence of a HSB (binomial distribution; logit link function; exchangeable correlation structure) were computed separately for Ireland, France, Germany, and the Netherlands, each time including UK as control. The models were adjusted for socio-demographic timeinvariant covariates reported at baseline (age, gender, education, country) as well as for socio-demographic time-varying covariates reported at each measurement (wave, age of youngest child in the household, marital status). The inclusion of country $x$ wave-interaction allowed us to test whether the change in the presence of HSB over time significantly differed from the change in the UK as the no-legislation control country.

The statistical package SAS 9.2 was used for all analyses.

\section{RESULTS}

\section{Prevalence of home smoking restrictions}

Most smokers had at least partial smoking restrictions in their home at the prelegislation survey (Table 1). The proportion of smokers with no home smoking restrictions was lowest in Germany and in France; and both countries accordingly also had the highest proportion of smokers with a total HSB. By the post-legislation measurement, there was an increase in the proportion of total HSB in all four countries 
among the baseline smokers and a decrease in the proportion with no smoking restrictions. The relative increases of total HSB were $22 \%$ in the control country UK. In the intervention countries, it was $25 \%$ in Ireland, 17\% in France, 38\% in Germany, and $28 \%$ in the Netherlands. The changes in the proportions followed a similar pattern in the intervention countries when analysing only continuing smokers, albeit with somewhat smaller relative increases, suggesting that these changes were not merely a surrogate for smoking cessation occurring between the survey waves. The changes in proportions between the time points were statistically significant $(p<$ 0.05 ) in each country when analysing all baseline smokers, and in all countries but UK after restriction to continuing smokers. For UK, this suggests that the observed changes in home smoking restrictions in the overall sample mainly occurred among smokers who quit between the survey waves. 


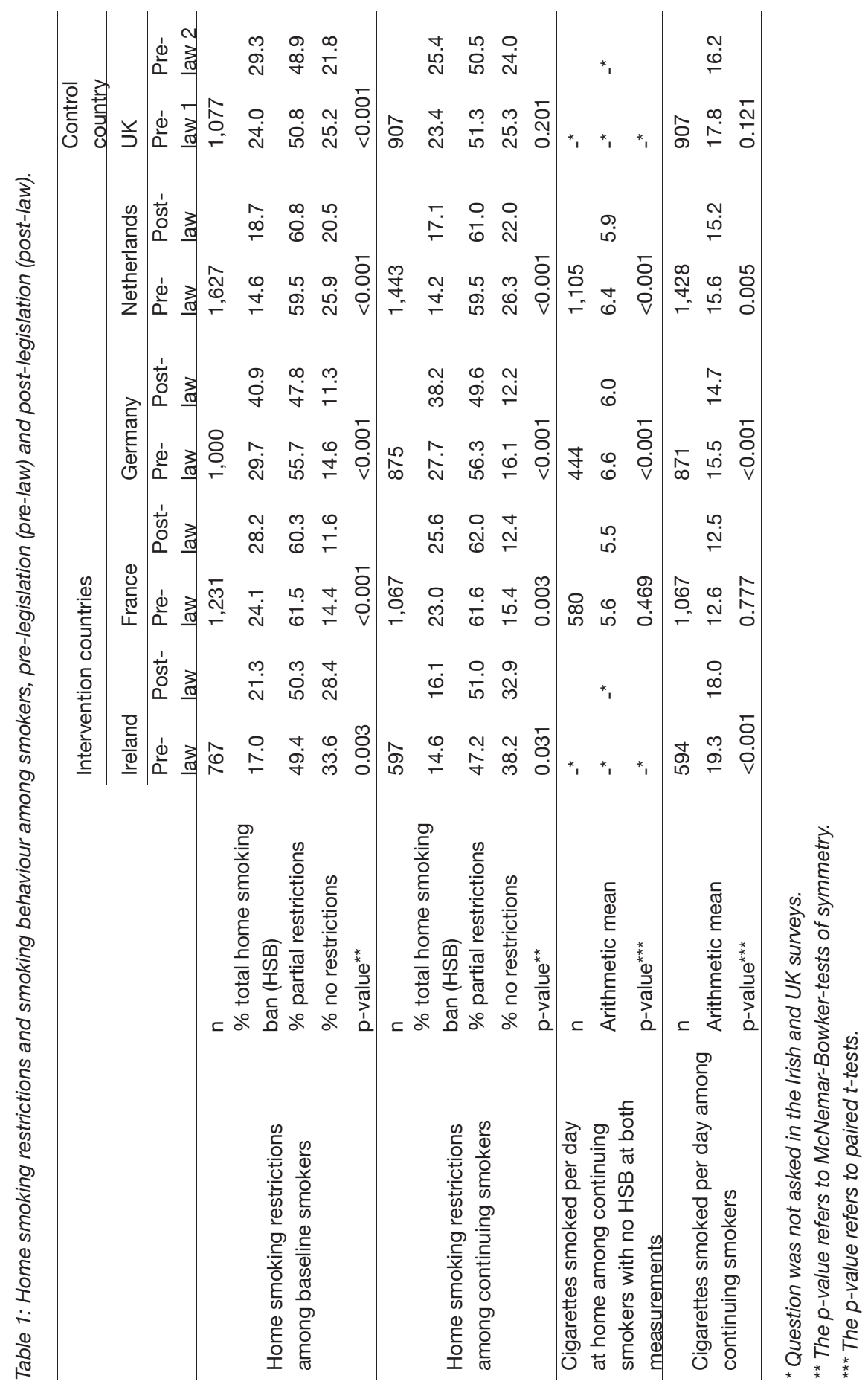




\section{Changes in smoking at home}

In order to test whether displacement took place among continuing smokers, we also tested for changes in cigarette consumption (Table 1). Among continuing smokers with no HSB at both time points, the average number of cigarettes smoked at home decreased significantly in Germany $(0.60,0.31-0.88)$ and the Netherlands (0.52, 0.34-0.69). Cigarette consumption per day decreased significantly $(p<0.05)$ in Ireland (mean decrease in cigarettes: $1.29,95 \% \mathrm{Cl}: 0.67-1.91)$, Germany (0.79, $0.45-1.13)$ and the Netherlands $(0.39,0.12-0.65)$.

\section{Predictors of home smoking bans}

Smokers who were male, younger, or married were more likely to report having a HSB at the pre-legislation survey (Table 2), and also smokers supporting a bar smoking ban, and those strongly agreeing that cigarette smoke is dangerous to others were more likely to report having a HSB. The presence of young children in the household was a strong predictor of HSB with a pronounced dose-response relationship with age of child: the younger the child, the greater the likelihood of having a HSB. Heaviness of smoking was inversely related to having a HSB. At pre-legislation, HSBs were significantly less likely among smokers from France, the Netherlands and Ireland than among smokers from Germany.

The prospective predictors of having adopted a HSB at the post-legislation survey (in subjects who did not have a HSB pre-legislation) were generally similar to the predictors of having a HSB at the pre-legislation survey (Table 2). Exceptions were the increased odds of newly adopting a HSB at the post-legislation survey among smokers who had reported at the pre-legislation survey an intention to quit within 1 or 6 months. Although the age of the youngest child at baseline was not related to the adoption of a $\mathrm{HSB}$, the birth of a child between waves was a strong predictor.

When the analysis of newly adopting a HSB was restricted to continuing smokers in order to rule out HSB adoption purely being a consequence of smoking cessation, the patterns were generally the same (Table 2). However, in this model only, smokers visiting bars on a monthly basis were significantly more likely to adopt a HSB than those rarely visiting bars. 


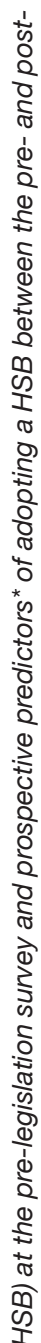

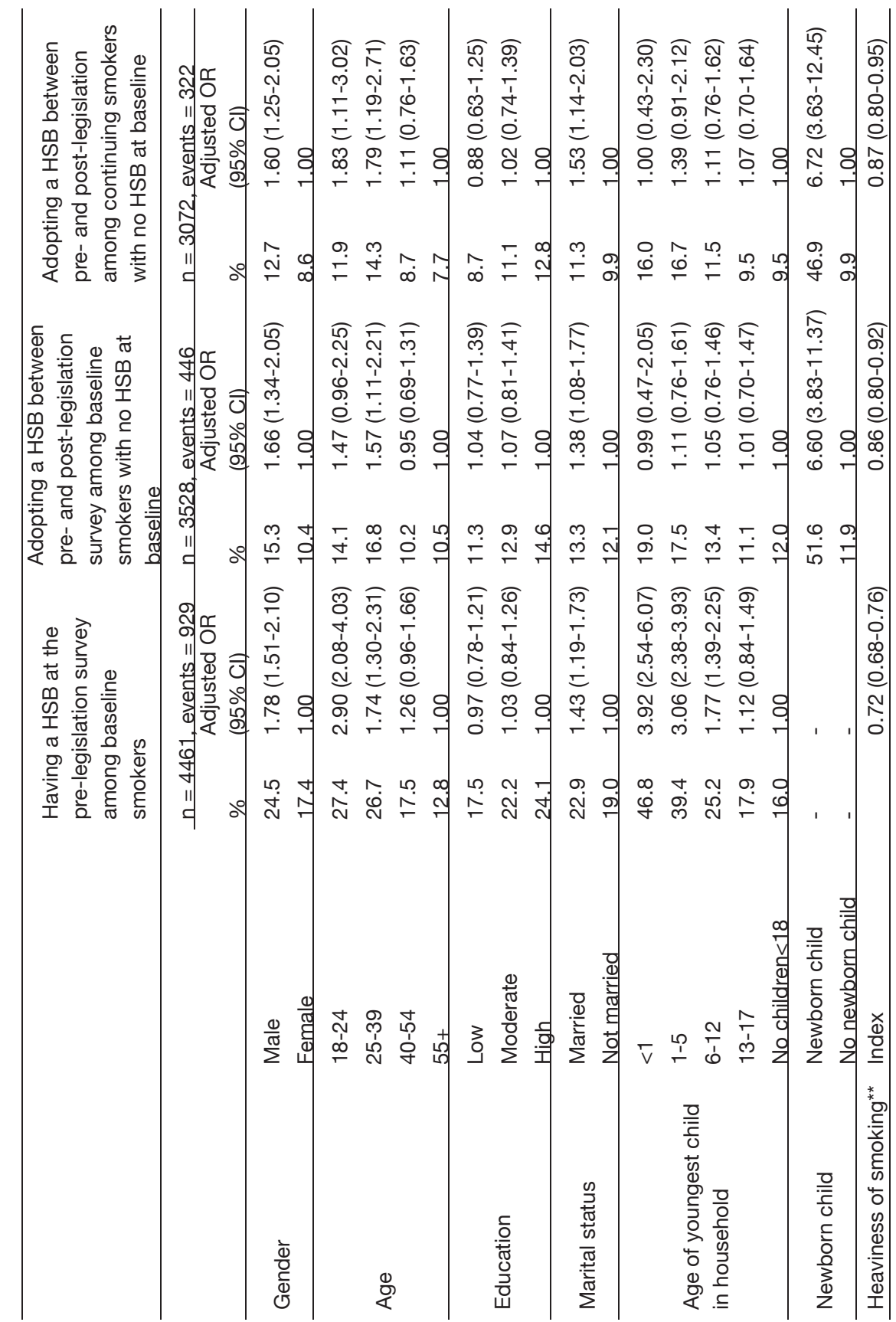




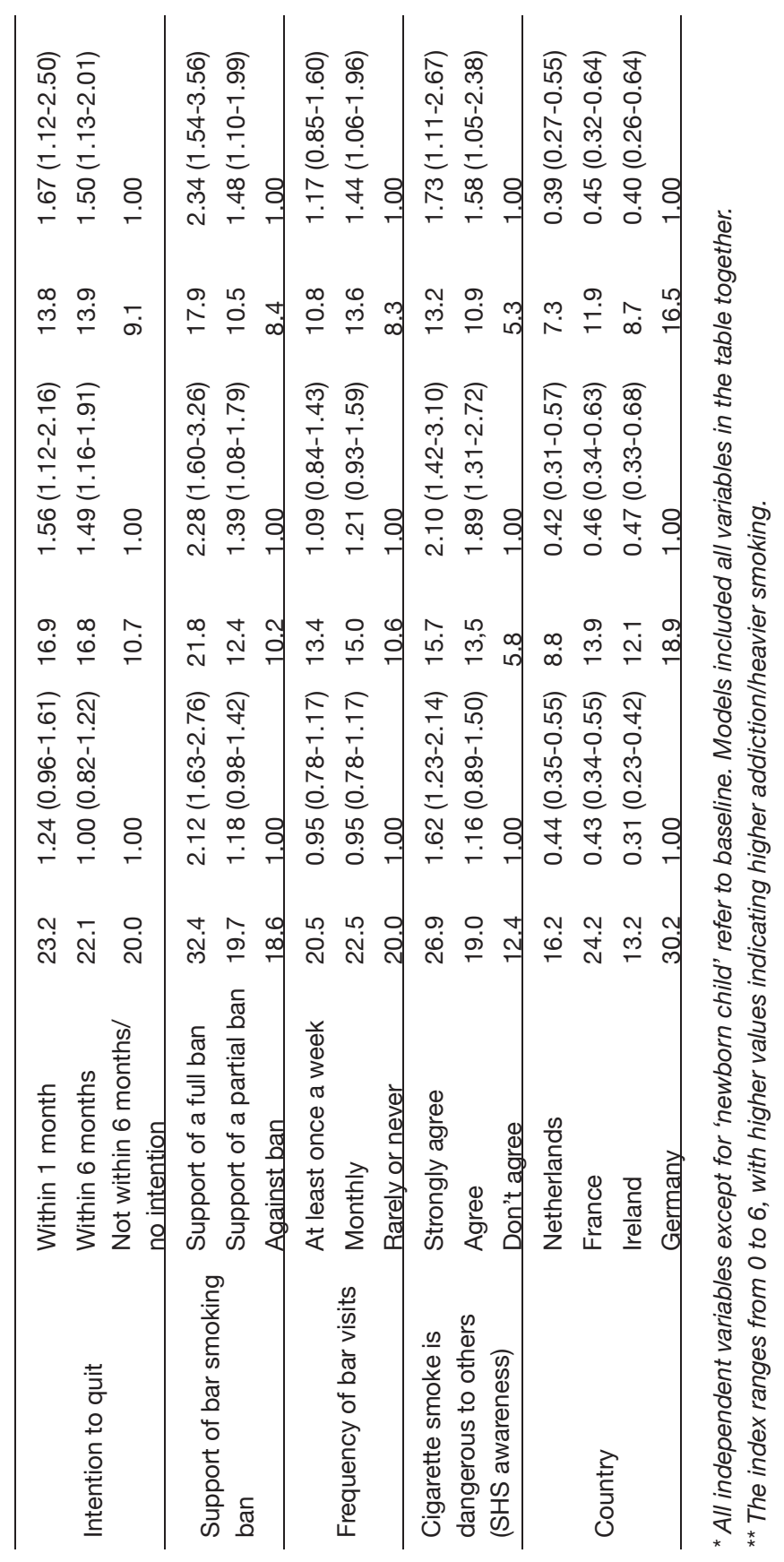




\section{Pattern of change over time and in comparison to control country}

Table 3 summarises the results of the GEE models comparing the intervention countries with the control country, separately for baseline smokers and for continuing smokers. The results for baseline smokers indicate that there was a significant increase in HSB prevalence from baseline to follow-up in all countries, i.e. in countries which introduced smoke-free legislation in the meantime as well as in the control country (UK). The increase was smaller in the control country compared to each of the four intervention countries. Nevertheless, the wave $x$ countryinteraction was only significant in the model comparing Germany to UK, indicating that the HSB prevalence increased to a significantly greater extent than it did in the control country.

In the models restricted to continuing smokers, the increase of HSB over time was significant in Germany, France, and the Netherlands, but not in Ireland nor in the control country. In Germany and France, the increase of HSB over time was statistically significantly greater than in the control country (as measured by the country $\mathrm{x}$ wave-interaction). 
Table 3: Results of GEE modelsa estimating the change in HSB prevalence for baseline smokers and for continuing smokers.

\begin{tabular}{|c|c|c|c|}
\hline & & $\begin{array}{l}\text { Presence of HSB } \\
\text { among baseline } \\
\text { smokers }\end{array}$ & $\begin{array}{l}\text { Presence of HSB } \\
\text { among continuing } \\
\text { smokers }\end{array}$ \\
\hline & & OR $(95 \% \mathrm{Cl})$ & OR $(95 \% \mathrm{Cl})$ \\
\hline \multirow{4}{*}{ Ireland vs. UK } & follow-up vs. baseline & & \\
\hline & Ireland & $1.53(1.24-1.90)$ & $1.26(0.97-1.65)$ \\
\hline & UK & $1.29(1.11-1.50)$ & $1.07(0.91-1.26)$ \\
\hline & Ireland $x$ wave-interaction & $1.19(0.92-1.54)$ & $1.16(0.86-1.61)$ \\
\hline \multirow{4}{*}{ France vs. UK } & follow-up vs. baseline & & \\
\hline & France & $1.53(1.32-1.78)$ & $1.40(1.18-1.66)$ \\
\hline & UK & $1.29(1.11-1.49)$ & $1.07(0.91-1.26)$ \\
\hline & France $x$ wave-interaction & $1.17(0.96-1.47)$ & $1.31(1.04-1.66)$ \\
\hline \multirow{4}{*}{ Germany vs. UK } & follow-up vs. baseline & & \\
\hline & Germany & $1.61(1.42-1.81)$ & $1.55(1.37-1.76)$ \\
\hline & UK & $1.29(1.11-1.50)$ & $1.07(0.91-1.26)$ \\
\hline & Germany $x$ wave-interaction & $1.25(1.03-1.51)$ & $1.45(1.17-1.79)$ \\
\hline \multirow{4}{*}{ Netherlands vs. UK } & follow-up vs. baseline & & \\
\hline & Netherlands & $1.34(1.20-1.51)$ & $1.22(1.08-1.38)$ \\
\hline & UK & $1.29(1.11-1.50)$ & $1.07(0.90-1.26)$ \\
\hline & Netherlands $x$ wave-interaction & $1.05(0.86-1.27)$ & $1.15(0.93-1.42)$ \\
\hline
\end{tabular}

a Models adjusted for socio-demographic time-invariant covariates (age, gender, education, country) and for time-varying covariates (age of youngest child in the household, marital status, wave), and included country $x$ wave-interaction terms. The odds ratios reported for each country estimate the change in HSB prevalence odds between the two waves. The interaction odds ratios are the ratios of these estimates and were used to assess if the change in the respective intervention country was statistically significantly different from the change in the no-legislation control country (UK w/o Scotland). In this table, an interaction $O R>1$ indicates that the change was greater in the intervention country compared to the control country. 


\section{DISCUSSION}

This large prospective dataset with pre- and post-smoke-free legislation observations from four European countries provided us with a uniquely comprehensive opportunity to assess effects of smoke-free legislation on home smoking in Europe. No evidence of displacement of smoking into the home after the implementation of national smoke-free legislation could be found. In all four countries, irrespective of the smoke-free legislation being comprehensive or allowing exceptions, the proportions of smokers having no or only partial home smoking restrictions either remained stable or even decreased, whereas the proportions of smokers with total home smoking bans increased. Among continuing smokers, the average number of cigarettes smoked per day decreased in three of the four countries examined, and there also was no rise in the average number of cigarettes smoked at home.

Regarding causality, it is important to assess whether the smoke-free legislation itself facilitated the adoption of home smoking bans, as the growth in the prevalence of home smoking bans could also be the manifestation of secular trends. GEE analyses comparing the patterns of change in the four countries which implemented smoke-free legislation with a control country without smokefree legislation at both time-points (UK) yielded some evidence that the increase in HSB prevalence could at least be partially attributable to the smoke-free legislation. Especially for continuing smokers the results indicated a significant (or borderline significant) increase in HSB among continuing smokers in Ireland, Germany, France, and the Netherlands, while there was no significant increase in HSB in the UK. Although the difference in patterns of change was significant only in the models comparing Germany to UK and France to UK, this is an important finding as it suggests the possibility of a causal link between the implementation of a national smoke-free legislation and imposition of individual home smoking restrictions among continuing smokers.

Furthermore, we found that positive attitudes towards smoking bans in bars were a significant prospective predictor of having adopted a HSB between pre- and post-legislation survey waves. This supports the social diffusion hypothesis and is suggestive of a causal relationship between smoking-related norms and attitudes and the adoption of a HSB. It is also known that the introduction of public smoking bans usually leads to an increase in support for such measures (Edwards et al., 2008; Rayens et al., 2007; Tang et al., 2003). Given the positive association between policy support and HSB observed in the present study, the prevalence of HSB may be expected to increase further in the future.

We also found that male, younger, married smokers, smokers with a young (or with a newborn) child in the household and smokers with a high awareness of 
the dangerous potential of SHS were more likely to have or to adopt a HSB. The gender effect could be an effect of household composition, which we could not control for as this variable was not recorded in all country surveys. Borland et al. reported that in their analyses, household composition accounted for the gender effect as male smokers were more likely to live in a home with non-smokers (Borland, Yong, Cummings et al., 2006). Previous cross-sectional studies (Borland, Mullins, Trotter, \& White, 1999; Ouedraogo, Turcotte, Ashley, Brewster, \& Ferrence, 2009; Pizacani et al., 2003), and a study analyzing ITC survey data from Australia, Canada, United Kingdom, and United States (Borland, Yong, Cummings et al., 2006), already showed that having a young child is one of the most important correlates of home smoking restrictions. In addition to this, our study found that also the birth of a child is a strong prospective predictor of adopting a HSB.

Some limitations need to be considered when interpreting our results. Due to different implementation dates of the national smoke-free legislation, the four country surveys were conducted in different years. The follow-up time and the time between implementation of the smoking ban and the post-legislation survey also varied between the countries, which probably affects the comparability of the relative increases in HSB prevalence. Such effects might explain why the comprehensiveness of the legislation seems to be unrelated to the extent of the policy effect in terms of an increase in HSB prevalence. In particular, that the relative increases in HSB prevalence is strongest in Germany could be partly due to the longer time between pre- and post-legislation measurements compared to the other countries, whereas the lower prevalence of home smoking restrictions in Ireland could partly be attributed to the surveys having been conducted about four years earlier than in the other countries. However, as additional single-country analyses of predictors of HSB yielded similar and consistent results (data not shown), it is unlikely that country differences in the study design would have distorted the findings from the multivariate analyses.

Between 21 and 34 percent of respondents were lost to attrition between pre- and post-legislation surveys. The non-responder analysis suggests only limited potential bias in the estimates of the multivariate analyses. The lower odds of being lost to follow-up among French respondents with pre-legislation home smoking restrictions might however lead to overestimated prevalence estimates for France.

UK (without Scotland) was chosen as a control country to give an estimate for the secular trend in HSB, and comparable baseline HSB prevalence implied that it was an appropriate choice for this purpose. In line with the diffusion hypothesis, it is nevertheless possible that the publicity around the plans for the enactment of the smoke-free legislation in UK has led to a steeper increase than would 
have been expected with the secular trend alone, which might have resulted in an overestimation of the secular trend. However, a similar effect could have led to a pre-legislation increase in the intervention countries already before the prelegislation measurements, which might have resulted in an underestimation of the policy effect in these countries. It thus appears quite possible that such effects might have lead to our estimates being altogether conservative.

We relied solely on self-reported information in this study, and our findings may be subject to social desirability bias. A study using data from a large household survey furthermore found inconsistencies in reports about strict HSB especially in multi-person households with smokers (Mumford, Levy, \& Romano, 2004). Recording more detailed information about the household composition and its members and biochemical validation would be an asset for any future study.

Regardless of the limitations outlined above, this study is characterised by several strengths. The surveys were based on large national probability samples from four European countries using standardised survey questions and a prospective study design. They were conducted at pre- and post-smoke-free legislation timepoints and thus exploited a historically unique situation. The prospective design, with replications across four countries, and with explicit analytic comparisons with a country in which smoke-free legislation had not yet been implemented, offers greater opportunities to examine alternatives to causality than cross-sectional studies. The greater internal validity accompanying the prospective design has been noted as a distinct advantage in evaluating the impact of tobacco control policies (International Agency for Research on Cancer, 2009b). Our findings also were consistent with results from ITC studies conducted elsewhere (Borland, Yong, Cummings et al., 2006), which suggests a broad generalisability of the findings for Western industrial nations.

Future research should be aimed at elucidating the mechanisms of how public smoking bans influence household smoking rules. Our study and some previous evidence support the social diffusion hypothesis, but the precise interrelations between smoke-free legislation, smoking-related norms and imposing household smoking bans have yet to be clarified. Additional ITC survey waves will provide an important resource in this regard.

Opponents of workplace or public smoking bans have argued that these policies - albeit intended to protect non-smokers from tobacco smoke - could lead to displacement of smoking into the home and hence even increase the SHS exposure of non-smoking family members and, most importantly, children. On the contrary, our findings strongly support the premise that smoke-free legislation does not lead to more smoking in smokers' homes. The data suggest rather that 
smoke-free legislation may stimulate smokers to establish total smoking bans in their homes. Policymakers in Europe and around the world thus do not need to fear an increase in SHS exposure among children as an unintended detrimental consequence of smoke-free legislation. In fact, converging evidence supports the notion that smoke-free legislation will lead to further benefits in reducing the harms of SHS beyond the limits of the legislation. 
"In the last half century the cigarette has been transformed.

The fragrant has become foul. . . . An emblem of attraction has become repulsive. A mark of sociability has become deviant. A public behaviour is now virtually private. Not only has the meaning of the cigarette been transformed but even more the meaning of the smoker (who) has become a pariah ... the object of scorn and hostility." (Allan Brandt) 


\section{Chapter 12}

\section{Smoke-free legislation and stigmatisation of smokers}

Accepted as:

Nagelhout, G. E., Willemsen, M. C., Gebhardt, W. A., Van den Putte,

B., Hichman, S. C., Crone, M. R., Fong, G. T., Van der Heiden, S., \& De Vries, H. Does smoke-free legislation and smoking outside bars increase feelings of stigmatisation among smokers? Findings from the International Tobacco Control (ITC) Netherlands Survey. Health \& Place. 
This study examined whether smokers' perceived level of stigmatisation changed after the implementation of smoke-free hospitality industry legislation and whether smokers who smoked outside bars reported more perceived stigmatisation. Longitudinal data from the International Tobacco Control (ITC) Netherlands Survey was used, involving a nationally representative sample of 1,447 smokers aged 15 years and older. Whether smoke-free legislation increases smokers' perceived stigmatisation depends on how smokers feel about smoking outside. The level of perceived stigmatisation did not change after the implementation of smoke-free hospitality industry legislation in the Netherlands, possibly because most Dutch smokers do not feel negatively judged when smoking outside. 


\section{INTRODUCTION}

Smoke-free legislation protects non-smokers from tobacco smoke pollution (also known as second-hand smoke) in public places. A possible unintended consequence of smoke-free legislation is that continuing smokers may experience increased feelings of stigmatisation. They may feel that not only their cigarette smoke is banned from public places, but that they are themselves banned and may thus think that others perceive smokers negatively.

Stigmatisation occurs "when elements of labelling, stereotyping, separating, status loss, and discrimination co-occur in a power situation that allows these processes to unfold" (Link \& Phelan, 2001). Because smoke-free legislation physically separates smokers from non-smokers by requiring smokers to smoke outside, it has been suggested that smoke-free legislation may increase feelings of stigmatisation (Gottlieb et al., 1992). Several qualitative studies that asked smokers whether they felt more stigmatised after the implementation of smoke-free legislation in workplaces and public places, found that smoke-free legislation indeed increased feelings of stigmatisation (Gottlieb et al., 1992; Hargreaves et al., 2010; Poland, 1998; Ritchie, Amos, \& Martin, 2010a, b; Thompson, Pearce, \& Barnett, 2007). In these studies, smokers report that they feel 'like a leper' (Ritchie, Amos, \& Martin, 2010a), 'an outcast' (Thompson, Pearce, \& Barnett, 2007), or 'ashamed' (Baha \& Le Faou, 2010) when they have to go outside to smoke. To our knowledge, only one quantitative study examined the association between exposure to smoke-free legislation and stigmatisation and this study found no association among smokers in New York City (Stuber et al., 2008).

In the current study, we used longitudinal data from two survey waves of the International Tobacco Control (ITC) Netherlands Survey. Smoke-free hospitality industry legislation was implemented in the Netherlands between these two survey waves, in July 2008. The implementation of the legislation was not comprehensive (smoking rooms were allowed) and there were high levels of non-compliance among bars (Nagelhout, Mons et al., 2011). We examined whether smokers' level of perceived stigmatisation changed after the implementation of smoke-free hospitality industry legislation, and whether smokers who smoked outside bars had stronger perceptions of stigmatisation. Also, we examined associations between perceived stigmatisation with feelings of shame, being judged, and being proud when smoking outside hospitality establishments after the smoke-free legislation. Finally, differences between smokers with low, moderate, and high education were investigated, because persons with lower socioeconomic status may be more vulnerable to the negative effects of stigmatisation (Major \& O'Brien, 2005). 


\section{METHODS}

\section{Sample}

Dutch smokers aged 15 years and older were recruited from a probability-based web database (Nagelhout et al., 2010). Potential respondents were identified as smokers (having smoked at least 100 cigarettes in their lifetime and currently smoking at least once per month) by means of a short screening survey in March 2008. In April 2008, 2,331 smokers were invited to participate in a web survey. Of these smokers, 1,820 participated in the first survey (78.1\%). In April and May 2009 all 1,820 smokers of the baseline survey were recontacted for the follow-up survey and 1,447 took part $(79.5 \%)$.

\section{Measurements}

Control variables were gender, age group, and heaviness of smoking in the 2008 survey. Age was categorised as 15 to 24,25 to 39,40 to 54, and 55 years and older. The Heaviness of Smoking Index (HSI) was created as the sum of two categorical measures: cigarettes per day and time before smoking the first cigarette of the day (Heatherton et al., 1989). HSI values ranged from 0 to 6 and are positively associated with nicotine dependence. Education was measured at the 2008 survey and categorised in three levels: low, moderate, and high.

Smoking outside bars was measured at the 2009 survey by asking continuing smokers who reported visiting a bar since the implementation of the smoke-free hospitality industry legislation in July 2008, whether they had smoked outside the bar at their last visit. Smokers who did not visit bars after the implementation of smoke-free hospitality industry legislation were categorised as not having smoked outside bars. We also controlled for bar visiting.

Feelings when smoking outside were measured at the 2009 survey by asking respondents how they feel when they are smoking outside the hospitality industry. Three statements about feeling negatively judged, ashamed, or proud were used, e.g. "You are ashamed if others see you smoking". Respondents could answer on a five-point Likert scale whether they agreed or disagreed with these statements.

Perceived stigmatisation of smokers was measured in both survey waves by asking respondents how they thought most Dutch people perceive smokers nowadays (Goldstein, 1991; Stuber et al., 2008). Respondents were asked to indicate on seven-point Likert bipolar scales whether they thought most people perceive smokers as nice versus not nice, strong versus weak, free versus not free, pathetic versus not pathetic, and persevering versus not persevering. A factor analysis showed that these items loaded on one factor, with factor loadings between 0.39 and 0.82. A mean score of these items (Cronbach's Alpha $=0.72$ ) was used 
as a measure of perceived stigmatisation that ranged from 1 (nice, strong, free, not pathetic, persevering) to 7 (not nice, weak, not free, pathetic, not persevering).

\section{Ethics}

The ITC Netherlands surveys were cleared for ethics by the Research Ethics Board of the University of Waterloo and the Central Committee on Research Involving Human Subjects in the Netherlands.

\section{Analyses}

All analyses were performed with SPSS version 17.0 and were weighted by age and gender to be representative of the smoker population in the Netherlands. More details on the weighting procedure can be found elsewhere (ITC Project, 2009b). Differences between respondents with low, moderate, and high educational level were tested with Chi-square tests and ANOVA F-tests.

Multivariate linear mixed model analysis was performed to assess whether the level of perceived stigmatisation changed between before (2008) and after (2009) the implementation of smoke-free hospitality industry legislation. This technique extends multivariate linear regression to longitudinal analyses of repeated measures. The two individual perceived stigmatisation scale scores were taken as dependent variable and survey wave was designated as the repeated measure variable, while controlling for gender, age group, educational level, and heaviness of smoking. Interactions of educational level with survey wave were added to the model to examine whether the change in perceived stigmatisation between 2008 and 2009 was the same for respondents from all educational levels.

Multivariate linear regression analysis was performed to determine whether smoking outside bars and feelings when smoking outside hospitality establishments predicted a change in perceived stigmatisation between 2008 and 2009. The dependent variable was the stigmatisation scale in 2009. The independent variables were gender, age group, educational level, heaviness of smoking, visited bars, smoking outside bars, feels ashamed when smoking outside, feels negatively judged when smoking outside, feels proud when smoking outside, and stigmatisation in 2008. Interactions of educational level with smoking outside bars and with feelings when smoking outside were added to the regression analysis to examine whether there were educational differences in the possible effect of smoking outside bars and feelings when smoking outside on perceived stigmatisation. 


\section{RESULTS}

Characteristics of respondents are shown in Table 1. Most respondents visited bars $(69.6 \%)$ and about half of smokers (46.5\%) had smoked outside the bar at their last visit. Few smokers felt ashamed when smoking outside hospitality establishments (6.4\%), one in five smokers felt negatively judged (20.1\%), and one in ten felt proud (10.4\%). High educated smokers visited bars more often $\left(\chi^{2}=44.91, p<0.001\right)$ and smoked more often outside the $\operatorname{bar}\left(\chi^{2}=10.64, p=0.005\right)$ than lower educated smokers. Low educated smokers felt more often proud when smoking outside ( 2 $=24.65, p<0.001)$ than higher educated smokers.

Table 1: Characteristics of study respondents $(n=1,447)$.

\begin{tabular}{|c|c|}
\hline & $\%$ \\
\hline \multicolumn{2}{|l|}{2008 Survey } \\
\hline \multicolumn{2}{|l|}{ Gender } \\
\hline Female (\%) & 46.2 \\
\hline Male (\%) & 53.8 \\
\hline \multicolumn{2}{|l|}{ Age group } \\
\hline $15-24$ years $(\%)$ & 12.3 \\
\hline $25-39$ years $(\%)$ & 27.7 \\
\hline $40-54$ years $(\%)$ & 35.0 \\
\hline 55 years and older $(\%)$ & 25.0 \\
\hline \multicolumn{2}{|l|}{ Educational level } \\
\hline Low $(\%)$ & 40.0 \\
\hline Moderate (\%) & 41.7 \\
\hline \multirow{2}{*}{\multicolumn{2}{|c|}{ Heaviness of smoking $\dagger$}} \\
\hline & \\
\hline Mean & 2.4 \\
\hline Standard deviation & 1.5 \\
\hline \multicolumn{2}{|l|}{2009 Survey } \\
\hline \multicolumn{2}{|l|}{ Visited bars } \\
\hline Yes (\%) & 69.6 \\
\hline No $(\%)$ & 30.4 \\
\hline \multicolumn{2}{|l|}{ Smoking outside bars } \\
\hline Yes (\%) & 46.5 \\
\hline No $(\%)$ & 53.5 \\
\hline \multicolumn{2}{|c|}{ Feels ashamed when smoking outside } \\
\hline Agree (\%) & 6.4 \\
\hline Disagree (\%) & 75.5 \\
\hline Neutral (\%) & 18.1 \\
\hline \multicolumn{2}{|c|}{ Feels negatively judged when smoking outside } \\
\hline Agree (\%) & 20.1 \\
\hline Disagree (\%) & 40.4 \\
\hline Neutral (\%) & 39.5 \\
\hline \multicolumn{2}{|c|}{ Feels proud when smoking outside } \\
\hline Agree (\%) & 10.4 \\
\hline Disagree (\%) & 43.7 \\
\hline Neutral (\%) & 46.0 \\
\hline
\end{tabular}

† Low dependence (0) - high dependence (6) 
The mean score of respondents on the perceived stigmatisation scale was 4 on a scale from 1 to 7 both before and after the implementation of smoke-free hospitality industry legislation (Table 2). This means that respondents thought that most other people perceive smokers as neutral. Low, moderate, and high educated smokers did not differ significantly in their perception of stigmatisation $(F=0.48, p=0.619)$. Respondents thought that most other people perceive smokers as weak $(M=5.12$, $S D=1.49)$ and not persevering $(M=5.16, S D=1.52)$, while they thought that most other people perceive smokers as neutral on the 'nice - not nice' ( $M=3.70, S D=$ 1.46), 'free - not free' $(M=4.21, S D=1.55)$, and 'pathetic - not pathetic' $(M=4.15$, $\mathrm{SD}=1.88)$ continuums.

Table 2: Mean scores on perceived stigma scale in 2008 and 2009 by smoking outside and feelings when smoking outside $(n=1,447)$.

\begin{tabular}{lll}
\hline & Perceived stigma† in 2008 & Perceived stigma in 2009 \\
\cline { 2 - 3 } & Mean (standard deviation) & Mean (standard deviation) \\
\hline All respondents & $4.46(1.09)$ & $4.41(1.10)$ \\
Smoking outside bars & & \\
$\quad$ Yes & $4.51(1.11)$ & $4.49(1.02)$ \\
No & $4.40(1.07)$ & $4.34(1.17)$ \\
Feels ashamed when smoking & & \\
outside & & $4.89(0.90)$ \\
Agree & $4.78(1.08)$ & $4.37(1.11)$ \\
$\quad$ Disagree & $4.41(1.09)$ & $4.44(1.07)$ \\
$\quad$ Neutral & $4.53(1.09)$ & \\
Feels negatively judged when & & $4.89(0.99)$ \\
smoking outside & & $4.19(1.09)$ \\
Agree & $4.84(1.00)$ & $4.39(1.09)$ \\
Disagree & $4.26(1.10)$ & \\
$\quad$ Neutral & $4.47(1.08)$ & $3.82(1.39)$ \\
Feels proud when smoking & & $4.67(0.98)$ \\
outside & & $4.30(1.07)$ \\
$\quad$ Agree & $3.97(1.26)$ & \\
Disagree & $4.64(1.01)$ & \\
Neutral & $4.40(1.09)$ &
\end{tabular}

† Low perceived stigma (1) - high perceived stigma (7)

A multivariate linear mixed model analysis (not shown in table) showed that the level of perceived stigmatisation did not change significantly after the implementation of smoke-free hospitality industry legislation (Beta of survey wave $=-0.02, p=$ 0.437 ). Educational level had no significant association with a change in perceived stigmatisation.

Table 2 shows that perceived stigmatisation was approximately the same for respondents who did and did not smoke outside bars, while perceived stigmatisation was relatively high for smokers who felt ashamed or negatively judged 
when smoking outside hospitality establishments. Also, perceived stigmatisation was relatively low for smokers who felt proud when smoking outside. A multivariate linear regression analysis (Table 3) confirmed that smoking outside bars in 2009 was not associated with perceived stigmatisation (Beta $=0.02, p=0.613$ ). However, feelings of being negatively judged when smoking outside were associated with an increase in perceived stigmatisation (Beta $=0.11, p<0.001$ ), while feelings of being proud when smoking outside were associated with a decrease in perceived stigmatisation (Beta $=-0.08, p=0.001$ ). There were no significant interactions of smoking outside bars or feelings when smoking outside with educational level (not shown in table).

Table 3: Multivariate linear regression analysis predicting perceived stigmatisation in $2009(n=1,264)$.

\begin{tabular}{|c|c|}
\hline & Beta $(95 \% \mathrm{Cl})$ \\
\hline Gender & \\
\hline $\begin{array}{l}\text { Female } \\
\text { Male }\end{array}$ & $\begin{array}{l}0.00(-0.05 \text { to } 0.05) \\
0.00\end{array}$ \\
\hline Age group & \\
\hline $15-24$ years & $0.04(-0.02$ to 0.13$)$ \\
\hline $25-39$ years & $0.08(0.02 \text { to } 0.15)^{\star \star}$ \\
\hline $40-54$ years & $0.08(0.02 \text { to } 0.14)^{\star *}$ \\
\hline 55 years and older & 0.00 \\
\hline Educational level & \\
\hline Low & $-0.07(-0.14 \text { to } 0.00)^{*}$ \\
\hline Moderate & $-0.03(-0.10$ to 0.03$)$ \\
\hline High & 0.00 \\
\hline Heaviness of smoking & $-0.03(-0.08$ to 0.02$)$ \\
\hline $\begin{array}{l}\text { VISIted Dars } \\
\text { Yes }\end{array}$ & $0.02(-0.04$ to 0.08$)$ \\
\hline No & 0.00 \\
\hline Smoking outside bars & \\
\hline $\begin{array}{l}\text { Yes } \\
\text { No }\end{array}$ & $\begin{array}{l}0.02(-0.05 \text { to } 0.08) \\
0.00\end{array}$ \\
\hline Feels ashamed when smoking outside & \\
\hline Agree & $0.02(-0.03$ to 0.08$)$ \\
\hline Disagree & $0.05(-0.01$ to 0.11$)$ \\
\hline Neutral & 0.00 \\
\hline Feels negatively judged when smoking outside & \\
\hline Agree & $0.11(0.06 \text { to } 0.17)^{\star \star \star}$ \\
\hline Disagree & $-0.07(-0.13 \text { to }-0.02)^{\star}$ \\
\hline Neutral & 0.00 \\
\hline Feels proud when smoking outside & \\
\hline $\begin{array}{l}\text { Agree } \\
\text { Disagree }\end{array}$ & $\begin{array}{l}-0.08(-0.14 \text { to }-0.03)^{\star \star} \\
0.08(0.03 \text { to } 0.14)^{\star \star}\end{array}$ \\
\hline Neutral & 0.00 \\
\hline Stigmatisation in 2008 & $0.42(0.39 \text { to } 0.49)^{\star \star \star}$ \\
\hline
\end{tabular}

${ }^{*} p<0.05$

${ }^{* *} p<0.01$

${ }^{* * *} p<0.001$ 


\section{DISCUSSION}

In our study, increased feelings of stigmatisation were found only among smokers who felt negatively judged by passers-by when smoking outside hospitality establishments. However, in the Netherlands, most smokers did not feel negatively judged when smoking outside. This explains why we found that the overall level of perceived stigmatisation did not change after the implementation of smokefree hospitality industry legislation and that smoking outside bars did not increase feelings of stigmatisation.

Earlier research (Stuber et al., 2008) found that lower educated smokers perceive lower levels of stigmatisation than higher educated smokers. In the current study, we did not find significant differences in perceived stigmatisation between educational levels. There are, however, concerns that lower educated smokers internalise the stigmatised identity more than higher educated smokers (Farrimond \& Joffe, 2006). This means that lower educated smokers may not only think that most other people perceive smokers as weak and not persevering, but they may also come to see themselves as weak and not persevering because they smoke. This may cause them to continue smoking despite high levels of perceived stigmatisation (Farrimond \& Joffe, 2006).

Our results suggest that smoke-free hospitality industry legislation may increase stigmatisation in countries where smokers feel negatively judged when smoking outside. Our study focused on smoking outside hospitality establishments after the implementation of smoke-free hospitality industry legislation, and findings may not generalise to effects of smoking outside workplaces. Also, specific characteristics of the Dutch legislation may have influenced the results.

A limitation of our study was that our measure of perceived stigmatisation may not capture the entire experience of smoker related stigmatisation. Although other studies have also measured perceived stigmatisation by asking respondents how they thought most others perceive smokers (Goldstein, 1991; Stuber et al., 2008), a study on HIV related stigma showed that this is only one dimension of perceived stigmatisation and that stigmatisation also includes personalised stigma, disclosure concerns, and a negative self-image (Berger, Ferrans, \& Lashley, 2001).

As argued by others (Ritchie et al., 2010a), we believe that policymakers should continue implementing smoke-free legislation despite possible unintended consequences such as stigmatisation. However, policymakers also have the moral responsibility to support individuals who experience negative consequences of smokefree legislation (Bayer, 2008). When these individuals are supported, the known benefits of smoke-free legislation for non-smokers and smokers who want to quit smoking will by far outweigh the possible unintended consequences for continuing smokers. 


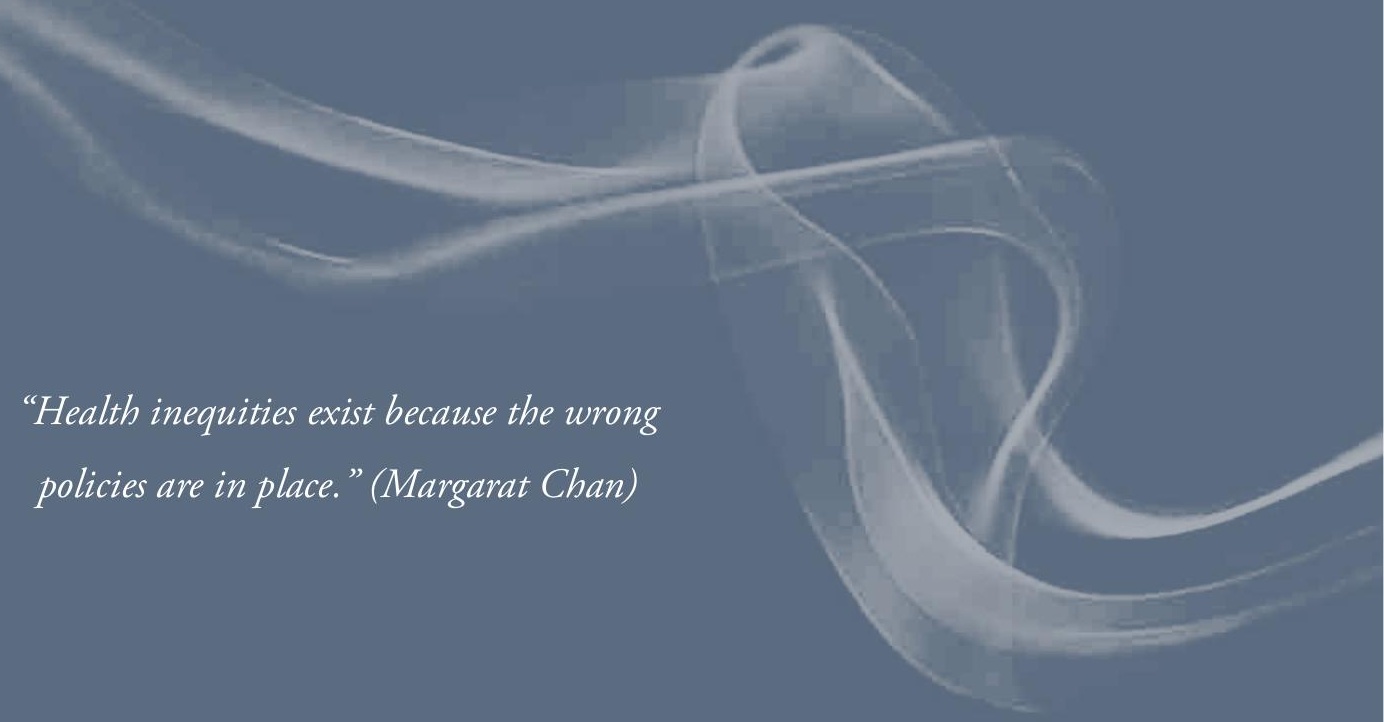




\section{Chapter 13}

\section{$\sim \sim \sim$ \\ Widening socioeconomic inequalities in smoking}

\section{Published as:}

Nagelhout, G. E., De Korte-de Boer, D., Kunst, A. E., Van der Meer, R. M., De Vries, H., Van Gelder, B. M., \& Willemsen, M. C. (2012). Trends in socioeconomic inequalities in smoking prevalence, consumption, initiation, and cessation between 2001 and 2008 in the Netherlands. Findings from a national population survey. BMC Public Health, 12, 303. 
Widening of socioeconomic status (SES) inequalities in smoking prevalence has occurred in several Western countries from the mid 1970's onwards. However, little is known about a widening of SES inequalities in smoking consumption, initiation and cessation. Repeated cross-sectional population surveys from 2001 to 2008 ( $n \approx 18,000$ per year) were used to examine changes in smoking prevalence, smoking consumption (number of cigarettes per day), initiation ratios (ratio of ever smokers to all respondents), and quit ratios (ratio of former smokers to ever smokers) in the Netherlands. Educational level and income level were used as indicators of SES and results were reported separately for men and women. Lower educated respondents were significantly more likely to be smokers, smoked more cigarettes per day, had higher initiation ratios, and had lower quit ratios than higher educated respondents. Income inequalities were smaller than educational inequalities and were not all significant, but were in the same direction as educational inequalities. Among women, educational inequalities widened significantly between 2001 and 2008 for smoking prevalence, smoking initiation, and smoking cessation. Among low educated women, smoking prevalence remained stable between 2001 and 2008 because both the initiation and quit ratio increased significantly. Among moderate and high educated women, smoking prevalence decreased significantly because initiation ratios remained constant, while quit ratios increased significantly. Among men, educational inequalities widened significantly between 2001 and 2008 for smoking consumption only. While inequalities in smoking prevalence were stable among Dutch men, they increased among women, due to widening inequalities in both smoking cessation and initiation. Both components should be addressed in equity-oriented tobacco control policies. 


\section{BACKGROUND}

Nowadays, mortality rates tend to be higher among lower socioeconomic status (SES) groups in most Western countries (Blais, Hamel, \& Rinfret, 2012; Mackenbach et al., 2003; Saydah \& Lochner, 2010). The higher prevalence of smoking in individuals from lower SES groups is the single most important cause of socioeconomic differences in mortality (Strand \& Tverdal, 2004; Stringhini et al., 2010). The smoking epidemic model describes the trends of smoking prevalence and smokingattributable mortality in populations over time (Lopez et al., 1994). In the first stage of the smoking epidemic, smoking prevalence and smoking-attributable mortality is low and rising. In the second stage, smoking prevalence among men rises rapidly, while smoking among women lags behind. Smoking prevalence rates are similar among different SES groups or may be higher among high SES groups. In the third stage, male prevalence declines and female prevalence remains stable. There is a rapid rise in smoking-attributable mortality among men. In the fourth stage of the smoking epidemic, smoking prevalence declines for both men and women and there is a rapid rise in smoking-attributable mortality among women. Smoking prevalence is higher among lower SES groups in this stage and a widening of SES inequalities in smoking prevalence may occur. A widening of SES inequalities in smoking has been found for several Western countries from the mid 1970's onwards, for example in most U.S. states (Harper \& Lynch, 2007; Pierce, Fiore, Novotny, Hatziandreu, \& Davis, 1989), Canada (Smith, Frank, \& Mustard, 2009), Australia (Bennett, 1995; White, Hill, Siahpush, \& Bobevski, 2003), New Zealand (Hill, Blakely, Fawcett, \& Howden-Chapman, 2005), and most European countries (Daponte-Codina, BolívarMuñoz, Ocaña-Riola, Toro-Cárdenas, \& Mayoral-Cortés, 2009; Giskes et al., 2005; Osler et al., 2000; Rasmussen, Due, Damsgaard, \& Holstein, 2009).

Studies that examined trends in SES differences in smoking focused mostly on differences in smoking prevalence (Schaap \& Kunst, 2009), i.e. the proportion of smokers in a population. These studies provide no information about how SES differences in smoking prevalence originate, because the smoking prevalence in a population is determined both by smoking initiation and by smoking cessation. The few studies that have examined trends in SES inequalities in both smoking initiation and cessation found mixed results (Federico, Costa, \& Kunst, 2007; Pierce et al., 1989). One study found that widening SES inequalities in cessation are mostly responsible for widening SES differences in smoking prevalence (Pierce et al., 1989), while the other study found that inequalities in initiation are a more important explanation (Federico, Costa, \& Kunst, 2007). Knowledge about trends in SES inequalities in initiation and cessation can potentially help to better inform future tobacco control interventions (Gilman, Abrams, \& Buka, 2003). Furthermore, 
it is important to examine SES differences in smoking consumption levels, as consumption levels have been found to relate in a dose-response manner to the risks and severity of many smoking-related diseases (U.S. Department of Health and Human Services, 2010). Therefore, information about trends in SES differences in smoking consumption, smoking initiation, and smoking cessation is required (Schaap \& Kunst, 2009).

In the current study, trends in SES differences in four smoking-related outcomes are examined for the Netherlands for the period 2001 to 2008. In this period, several tobacco control policies were implemented that could have influenced SES differences in smoking. In 2002, text warning labels for cigarette packages were implemented and a tobacco advertising ban was implemented (Nagelhout, Levy et al., 2012). In 2003, a youth access law was implemented (Nagelhout, Levy et al., 2012). In 2004, smoke-free workplace legislation was implemented, which was extended in 2008 so as to include the hospitality industry (Nagelhout, Willemsen et al., 2011). Tax increases were implemented in 2001, 2004, and 2008 and intensive national mass media smoking cessation campaigns ran in 2003, 2004, and 2008 (Nagelhout, Willemsen et al., 2011).

We aim to answer the following research questions: 1) Were there SES differences in smoking prevalence, smoking consumption, smoking initiation, and smoking cessation in the Netherlands in 2001 and 2008? and 2) Did these SES differences change in the period 2001 to 2008? These research questions are answered for both men and women.

\section{METHODS}

\section{Sample}

Data were obtained from the Dutch Continuous Survey of Smoking Habits (DCSSH). This is a cross-sectional population survey of respondents aged 15 years and older that is used to monitor smoking habits of the Dutch population, using weekly measurements. The DCSSH is conducted by market research company TNS NIPO for the Dutch expert centre on tobacco control (STIVORO). Respondents for the DCSSH were selected from TNS NIPObase, a database containing more than 140,000 potential respondents who participate in internet-based research on a regular basis. TNS NIPObase panel members are recruited actively by TNS NIPO using telephone and mail.

For the present study, DCSSH data from 2001 until 2008 were used. The questionnaire was sent to a stratified random sample of potential respondents by e-mail. Respondents completed the questionnaire at their own computer using software from TNS NIPO. Approximately 18,000 respondents participated in the 
survey each year, totaling 144,733 respondents in the period 2001 to 2008 . The respondents were representative of the Dutch population of 15 years and older after applying weights for gender, age, educational level, working hours, geographic region, urbanisation, and household size. Response data were weighted on the basis of stratum weights. Each respondent was provided a weight by TNS NIPO with DIANA software, using an iterative process until there was little deviation between the weighted data and the target strata.

The Central Committee on Research Involving Human Subjects in the Netherlands requires no ethical approval for non-medical survey research.

\section{Questionnaire}

The DCSSH questionnaire assessed demographic characteristics, smoking behaviour and use of smoking cessation aids and contained sections on tobacco control policies and campaigns. For the current study, we used questions about SES indicators, smoking status, smoking consumption, age, and gender.

Although educational level is seen as a key indicator of SES (Huisman, Kunst, \& Mackenbach, 2005a; Schaap \& Kunst, 2009), it has been recommended to include other indicators as well to account for other dimensions of SES that have shown to be independently related to smoking (Schaap \& Kunst, 2009). We, therefore, used both educational level and income level as indicators of SES. We categorised educational level into three groups: low (primary education and lower pre-vocational secondary education), moderate (middle pre-vocational secondary education and secondary vocational education) and high (senior general secondary education, (pre-)university education and higher professional education). Gross yearly household income level was also categorised into three equal sized groups: low (less than 28,500 Euro $=<25,600$ GBP), moderate (between 28,500 and 45,000 Euro $=25,600-40,430 \mathrm{GBP}$ ), and high (more than 45,000 Euro $=>$ 40,430 GBP).

In line with earlier studies (Nagelhout, Willemsen et al., 2011; Willemsen et al., 2002), current smoking status was assessed by asking 'do you (ever) smoke or do you not smoke at all?'. Respondents who answered that they smoke were defined as current smokers. Respondents who answered that they do not smoke were asked: 'have you smoked in the past?'. Respondents who answered that they had smoked in the past were defined as former smokers and respondents who answered that they had not smoked in the past were defined as never smokers. Smoking prevalence was defined as the proportion of all respondents who were current smokers (current smokers / all respondents * 100). In the regression analyses, smoking prevalence was treated as a binary outcome. 
Following recommendations from Schaap and Kunst (Schaap \& Kunst, 2009), smoking initiation and cessation were examined by calculating initiation ratios and quit ratios. Initiation ratio was defined as the ratio of all respondents who were ever smokers (current + former smokers / all respondents). Quit ratio was defined as the ratio of ever smokers who were former smokers (former smokers / current + former smokers). In the regression analyses, initiation and quit ratios were treated as binary outcomes.

Smoking consumption was measured by asking current smokers how many cigarettes (factory made and/or roll-your-own) they smoked on average per day. In the regression analyses, smoking consumption was treated as a continuous outcome.

Furthermore, age and gender were assessed. Age was categorised into four groups: 15-24 years, 25-39 years, 40-54 years, and 55 years and older.

\section{Analyses}

SES differences in smoking-related outcomes (research question 1) were examined by logistic regression analyses (for smoking prevalence, initiation, and cessation) and linear regression analyses (for smoking consumption). Dependent variables were smoking prevalence, smoking consumption, smoking initiation, and smoking cessation. Independent variables were educational level and income level (in separate analyses). Regression analyses were controlled for age group and reported separately for men and women in 2001 and 2008. Respondents who did not report their educational level $(n=665,0.5 \%)$ were excluded from the analyses with educational level. Respondents who did not report their income level $(n=30,661$, $21.2 \%)$ were excluded from the analyses with income level. Respondents who did not report their income level were significantly more likely to have a low educational level $\left(\chi^{2}(2)=413.08, p<0.001\right)$, to be younger $(F(1)=238.40, p<0.001)$, and to be a current smoker $\left(\chi^{2}(1)=61.52, p<0.001\right)$.

SES differences in trends in smoking-related outcomes (research question 2) were examined with the regression analyses described above for the survey years 2001 and 2008 taken together and with a dichotomous 'trends' variable ( 0 for 2001 and 1 for 2008) and the interaction between 'trends' and educational/income level (separate analyses per SES indicator) as independent variables. Regression analyses were controlled for age group and reported separately for men and women. Educational level and income level were treated as continuous variables in the interaction analyses so as to limit the number of interaction terms. In all other analyses, they were treated as categorical variables with high educational level and income level being the reference categories. Significant interactions between 
'trends' and educational level or income level indicated that the trends in smokingrelated outcomes differed for people with low, moderate, and high SES.

\section{RESULTS}

\section{Demographic characteristics}

Table 1 shows demographic characteristics of respondents per year. There were no significant differences in educational level, gender, and age group between years. However, income level differed significantly between years $\left(\chi^{2}(14)=669.19, p<\right.$ $0.001)$, which was due to an increase in respondents with higher incomes over time.

Table 1: Demographic characteristics from 2001 to 2008 (weighted data).

\begin{tabular}{lllllllll}
\hline & 2001 & 2002 & 2003 & 2004 & 2005 & 2006 & 2007 & 2008 \\
& $\begin{array}{l}\mathrm{n}= \\
\mathrm{n}=\end{array}$ & $\mathrm{n}=$ & $\mathrm{n}=$ & $\mathrm{n}=$ & $\mathrm{n}=$ & $\mathrm{n}=$ & $\mathrm{n}=$ \\
& 18,361 & 18,212 & 19,086 & 18,342 & 19,344 & 18,031 & 14,730 & 18,627 \\
\hline $\begin{array}{l}\text { Educational level } \\
\text { Low (\%) }\end{array}$ & 44.4 & 44.5 & 44.4 & 44.5 & 44.4 & 44.5 & 44.5 & 44.5 \\
$\quad$ Moderate (\%) & 33.6 & 33.6 & 33.6 & 33.6 & 33.6 & 33.6 & 33.6 & 33.6 \\
$\quad$ High (\%) & 22.0 & 22.0 & 22.0 & 21.9 & 21.9 & 21.9 & 21.9 & 21.9 \\
Income level & & & & & & & & \\
$\quad$ Low (\%) & 43.6 & 38.4 & 34.8 & 35.7 & 36.0 & 35.7 & 36.2 & 34.6 \\
$\quad$ Moderate (\%) & 34.8 & 37.1 & 34.2 & 35.1 & 34.7 & 37.3 & 35.5 & 36.3 \\
$\quad$ High (\%) & 21.5 & 24.6 & 31.0 & 29.2 & 29.2 & 27.0 & 28.3 & 29.2 \\
Gender & & & & & & & & \\
$\quad$ Men (\%) & 49.1 & 49.1 & 49.1 & 49.2 & 49.1 & 49.1 & 49.1 & 49.0 \\
$\quad$ Women (\%) & 50.9 & 50.9 & 50.9 & 50.8 & 50.9 & 50.9 & 50.9 & 51.0 \\
Age group & & & & & & & & \\
15-24 (\%) & 14.7 & 14.7 & 14.7 & 14.7 & 14.7 & 14.7 & 14.7 & 14.7 \\
25-39 (\%) & 29.9 & 30.3 & 30.3 & 30.6 & 30.3 & 30.3 & 30.7 & 30.8 \\
40-54 (\%) & 26.9 & 26.5 & 26.5 & 26.3 & 26.4 & 26.5 & 26.1 & 26.0 \\
55 and older & & & & & & & & \\
(\%) & 28.4 & 28.6 & 28.5 & 28.4 & 28.6 & 28.5 & 28.5 & 28.6 \\
\hline
\end{tabular}

\section{SES inequalities}

Figure 1 shows educational level differences and Figure 2 income level differences in smoking prevalence, consumption, initiation ratio, and quit ratio from 2001 to 2008. The figures show that smoking prevalence was higher among respondents with lower education (29\% in 2008) and income levels (28\%) than among respondents with higher education (20\%) and income levels (24\%). The regression analyses shown in Table 2 confirmed that the difference in smoking prevalence between respondents with higher and lower education and income was significant among both men and women in 2001 and 2008.

Smoking consumption levels were significantly higher among lower educated respondents than among higher educated respondents among both 
men and women in 2001 and 2008. Differences in smoking consumption between respondents with higher and lower income were smaller and only significant among women in 2001 and 2008.

The difference in initiation ratios between respondents with higher and lower education and income was significant among both men and women in 2001 and 2008, indicating that lower SES respondents more often started smoking than higher SES respondents.

Finally, quit ratios were significantly higher among respondents with higher education and income than among respondents with lower education and income among both men and women in 2001 and 2008, with the exception of differences between male respondents with higher and lower income levels in 2001.

Figure 1: Smoking characteristics of respondents by educational level from 2001 to 2008 (weighted data).
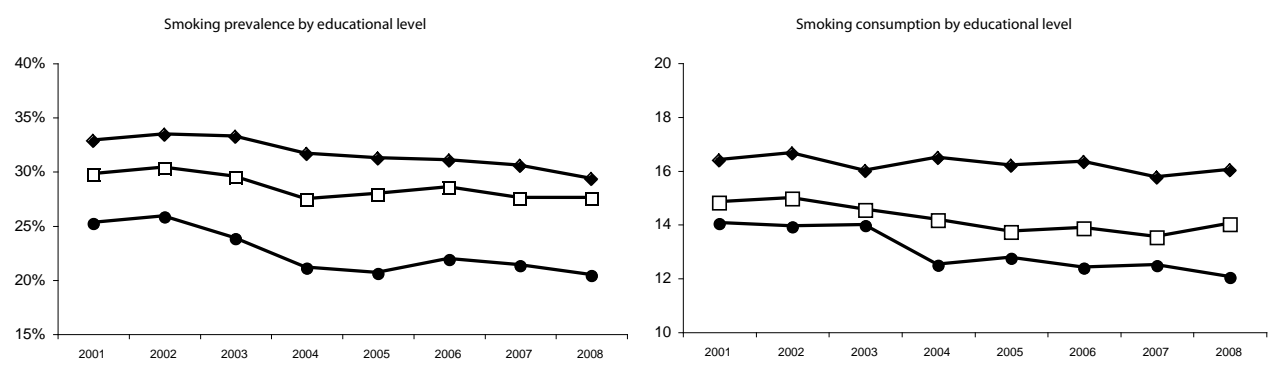

Initiation ratio by educational level

Quit ratio by educational level
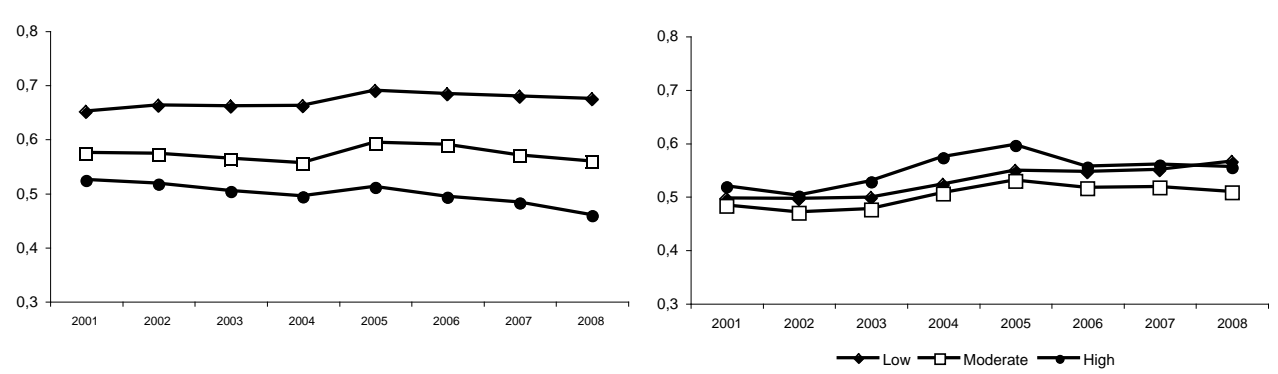
chapter 13 | Widening socioeconomic inequalities in smoking

Figure 2: Smoking characteristics of respondents by income level from 2001 to 2008 (weighted data).
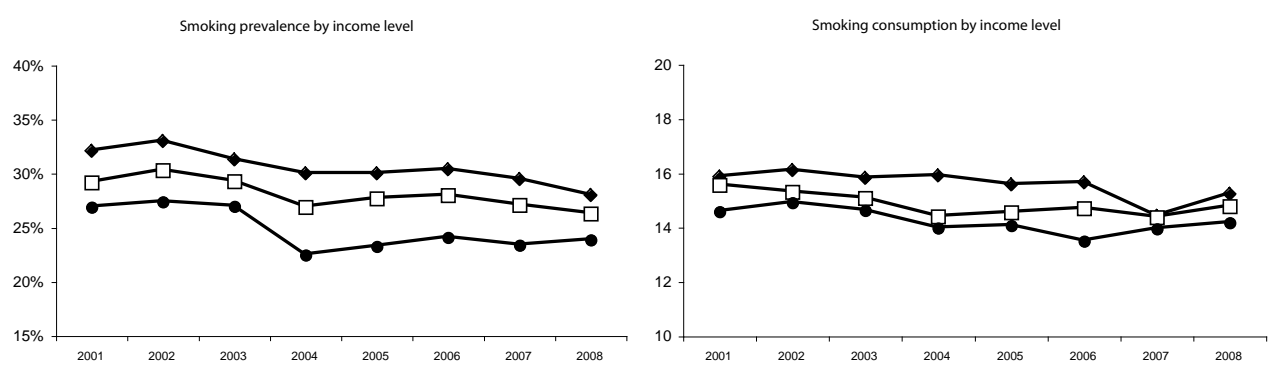

Initiation ratio by income level

Quit ratio by income level
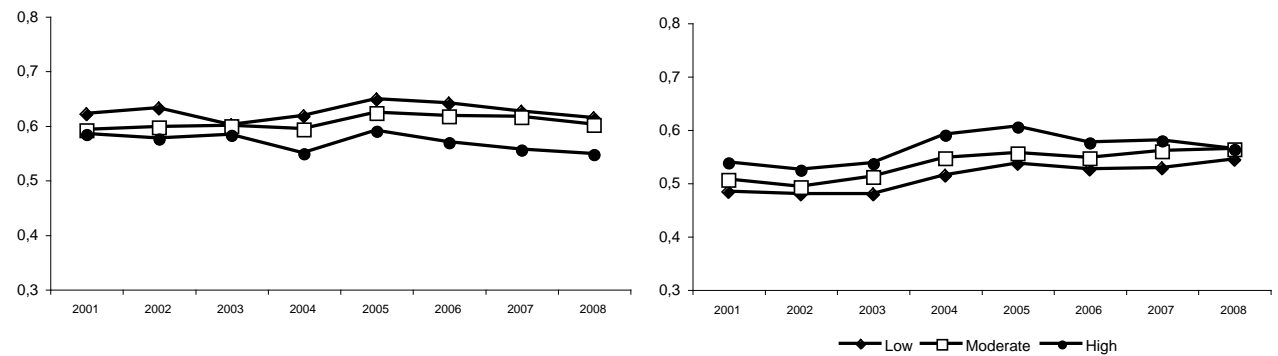
Table 2: Regression analysest in which educational level and income level predicted four smoking-related outcomes.

\begin{tabular}{|c|c|c|c|c|}
\hline & \multicolumn{2}{|l|}{ Men } & \multicolumn{2}{|l|}{ Women } \\
\hline & 2001 & 2008 & 2001 & 2008 \\
\hline \multicolumn{5}{|l|}{$\begin{array}{l}\text { Smoking } \\
\text { prevalence } \\
\text { Educational } \\
\text { level }^{*}\end{array}$} \\
\hline Low & 1.75 (1.55 to 1.97$)$ & 1.84 (1.62 to 2.09 ) & 1.79 (1.56 to 2.06$)$ & 2.26 (1.96 to 2.62 ) \\
\hline Moderate & $1.32(1.17$ to 1.49$)$ & 1.44 (1.27 to 1.64$)$ & 1.25 (1.09 to 1.44$)$ & $1.62(1.41$ to 1.87$)$ \\
\hline \multicolumn{4}{|l|}{ Income level } & 1.00 \\
\hline Low & $1.33(1.17$ to 1.51$)$ & 1.49 (1.31 to 1.70$)$ & 1.52 (1.33 to 1.74 & 1.83 (1.58 to 2.10$)$ \\
\hline Moderate & 1.13 (0.99 to 1.28$)$ & 1.11 (0.98 to 1.25$)$ & $1.12(0.97$ to 1.30$)$ & 1.39 (1.20 to 1.60$)$ \\
\hline High & 1.00 & 1.00 & 1.00 & 1.00 \\
\hline \multicolumn{5}{|l|}{$\begin{array}{l}\text { Smoking } \\
\text { consumption } \\
\text { Educational } \\
\text { level }\end{array}$} \\
\hline Low & 0.11 (0.06 to 0.17$)$ & 0.17 (0.11 to 0.23$)$ & 0.11 (0.05 to 0.17$)$ & $0.20(0.13$ to 0.26$)$ \\
\hline Moderate & 0.07 (0.02 to 0.13$)$ & 0.07 (0.01 to 0.13$)$ & 0.01 (-0.05 to 0.07$)$ & 0.12 (0.06 to 0.18$)$ \\
\hline $\begin{array}{l}\text { High } \\
\text { Income level }\end{array}$ & 0.00 & 0.00 & 0.00 & 0.00 \\
\hline Low & $0.06(0.00$ to 0.11$)$ & $0.00(-0.06$ to 0.06$)$ & $0.12(0.06$ to 0.17$)$ & 0.15 (0.08 to 0.20$)$ \\
\hline Moderate & 0.05 (-0.01 to 0.11$)$ & $-0.01(-0.06$ to 0.04$)$ & 0.06 (0.00 to 0.12$)$ & 0.08 (0.02 to 0.14$)$ \\
\hline High & 0.00 & 0.00 & 0.00 & 0.00 \\
\hline \multicolumn{5}{|l|}{$\begin{array}{l}\text { Educational } \\
\text { level }\end{array}$} \\
\hline Low & 1.87 (1.66 to 2.10$)$ & $2.24(1.99(2.52)$ & 1.41 (1.25 to 1.59$)$ & 1.73 (1.53 to 1.95$)$ \\
\hline Moderate & $1.43(1.27$ to 1.61$)$ & 1.47 (1.30 to 1.65$)$ & 1.19 (1.05 to 1.34$)$ & 1.45 (1.29 to 1.63$)$ \\
\hline High & 1.00 & 1.00 & 1.00 & 1.00 \\
\hline \multicolumn{5}{|l|}{ Income level } \\
\hline Low & $1.32(1.16$ to 1.51$)$ & 1.51 (1.32 to 1.73 ) & 1.25 (1.11 to 1.41$)$ & 1.32 (1.17 to 1.49$)$ \\
\hline Moderate & 1.14 (1.00 to 1.30$)$ & $1.27(1.13$ to 1.43$)$ & 1.01 (0.89 to 1.14$)$ & 1.21 (1.08 to 1.37$)$ \\
\hline High & 1.00 & 1.00 & 1.00 & 1.00 \\
\hline \multicolumn{5}{|l|}{$\begin{array}{l}\text { Quit ratio } \\
\text { Educational } \\
\text { level }\end{array}$} \\
\hline Low & 0.81 (0.70 to 0.94$)$ & 0.84 (0.71 to 0.98$)$ & 0.69 (0.58 to 0.82$)$ & 0.56 (0.47 to 0.67$)$ \\
\hline Moderate & 0.95 (0.81 to 1.11$)$ & 0.83 (0.70 to 0.98$)$ & 0.92 (0.77 to 1.10$)$ & 0.73 (0.61 to 0.87 ) \\
\hline $\begin{array}{l}\text { High } \\
\text { Income level }\end{array}$ & 1.00 & 1.00 & 1.00 & 1.00 \\
\hline Low & $0.86(0.74$ to 1.01$)$ & 0.76 (0.64 to 0.89$)$ & 0.72 (0.61 to 0.85$)$ & 0.56 (0.47 to 0.66$)$ \\
\hline Moderate & 0.96 (0.82 to 1.13$)$ & 1.05 (0.91 to 1.22$)$ & 0.88 (0.74 to 1.05$)$ & 0.78 (0.66 to 0.92$)$ \\
\hline High & 1.00 & 1.00 & 1.00 & 1.00 \\
\hline
\end{tabular}

† Odds Ratios and 95\% confidence intervals are given for smoking prevalence, initiation ratio, and quit ratio, Betas and 95\% confidence intervals for smoking consumption. All regression coefficients were adjusted for age group. Regression coefficients in italics were non-significant.

${ }^{*}$ Educational level and income level were entered as independent variables in separate analyses.

\section{Changes in SES inequalities}

Among women, educational differences changed significantly between 2001 and 2008 for smoking prevalence, smoking initiation, and smoking cessation (Table 3). Regression analyses stratified by educational level showed that smoking prevalence 
did not change between 2001 and 2008 among female respondents with low education (Odds Ratio $(\mathrm{OR})=0.95,95 \%$ confidence interval $(\mathrm{Cl})=0.86$ to 1.04 ), while smoking prevalence decreased among female respondents with moderate $(\mathrm{OR}=0.89,95 \% \mathrm{Cl}=0.79$ to 0.99$)$ and high education $(\mathrm{OR}=0.68,95 \% \mathrm{Cl}=0.58$ to 0.80$)$. Initiation ratios increased significantly among female respondents with low education $(\mathrm{OR}=1.19,95 \% \mathrm{Cl}=1.09$ to 1.30$)$, while remaining constant among female respondents with moderate $(\mathrm{OR}=1.04,95 \% \mathrm{Cl}=0.94$ to 1.15$)$ and high education $(\mathrm{OR}=0.88,95 \% \mathrm{Cl}=0.77$ to 1.01$)$. Quit ratios increased significantly among female respondents in all educational levels, but the increase was larger among female respondents with high education $(\mathrm{OR}=1.60,95 \% \mathrm{Cl}=1.30$ to 1.97$)$ than moderate $(\mathrm{OR}=1.21,95 \% \mathrm{Cl}=1.05$ to 1.40$)$ and low education $(\mathrm{OR}=1.16$, $95 \% \mathrm{Cl}=1.03$ to 1.30$)$.

Among men, educational inequalities widened significantly between 2001 and 2008 for smoking consumption and not for smoking prevalence, initiation, and cessation (Table 3). The mean number of cigarettes per day did not change between 2001 and 2008 among male smokers with low education $(\beta=-0.03,95 \% \mathrm{Cl}=$ -0.07 to 0.01 ), while the mean number of cigarettes per day decreased among male smokers with moderate $(\beta=-0.10,95 \% \mathrm{Cl}=-0.15$ to -0.06$)$ and high education ( $\beta$ $=-0.08,95 \% \mathrm{Cl}=-0.16$ to -0.01$)$.

Among both women and men, income differences in smoking-related outcomes did not change significantly between 2001 and 2008.

Table 3: Interactions $\uparrow$ of trends by educational level and income level on four smoking-related outcomes.

\begin{tabular}{lll}
\hline & Men & Women \\
\hline $\begin{array}{l}\text { Smoking prevalence } \\
\text { Trends * educational level }\end{array}$ & $0.99(0.91$ to 1.07$)$ & $0.86(0.79$ to 0.94$)$ \\
Trends * income level & $0.95(0.87$ to 1.04$)$ & $0.94(0.86$ to 1.04$)$ \\
\hline $\begin{array}{l}\text { Smoking consumption } \\
\text { Trends * educational level }\end{array}$ & $-0.08(-0.17$ to -0.01$)$ & $-0.04(-0.13$ to 0.04$)$ \\
Trends * income level & $0.05(-0.04$ to 0.14$)$ & $-0.02(-0.11$ to 0.07$)$ \\
\hline Initiation ratio & & \\
Trends * educational level & $0.94(0.87$ to 1.02$)$ & $0.86(0.79$ to 0.92$)$ \\
Trends * income level & $0.92(0.84$ to 1.01$)$ & $0.97(0.90$ to 1.06$)$ \\
\hline $\begin{array}{l}\text { Quit ratio } \\
\text { Trends * educational level }\end{array}$ & $0.99(0.90$ to 1.10$)$ & $1.14(1.02$ to 1.28$)$ \\
Trends * income level & $1.05(0.94$ to 1.18$)$ & $1.11(0.99$ to 1.25$)$ \\
\hline
\end{tabular}

† Odds Ratios and $95 \%$ confidence intervals are given for smoking prevalence, initiation ratio, and quit ratio, Betas and $95 \%$ confidence intervals are given for smoking consumption. All regression coefficients were adjusted for age group. Regression coefficients in italics were non-significant.

* Educational level and income level were entered as independent variables in separate analyses. 


\section{DISCUSSION}

We examined changes in socioeconomic inequalities in smoking prevalence, smoking consumption, smoking initiation, and smoking cessation between 2001 and 2008 in the Netherlands. In line with previous studies (Bennett, 1995; DaponteCodina et al., 2009; Giskes et al., 2005; Harper \& Lynch, 2007; Hill et al., 2005; Osler et al., 2000; Pierce et al., 1989; Rasmussen et al., 2009; Smith et al., 2009; White et al., 2003), we found that respondents with lower education and income were more likely to be smokers than respondents with higher education and income in 2001 and 2008. Socioeconomic inequalities in smoking consumption, smoking initiation, and smoking cessation are less well documented than inequalities in smoking prevalence (Schaap \& Kunst, 2009). We found that respondents with lower education smoked more cigarettes per day, had higher initiation ratios, and had lower quit ratios than respondents with higher education in 2001 and 2008. Therefore, it is important that tobacco control programs focus on decreasing smoking initiation and consumption and increasing smoking cessation among the lower educated. It seems that focusing only on either initiation or cessation is insufficient.

In this study, we found evidence that SES inequalities in smoking widened between 2001 and 2008 in the Netherlands, but this widening was not the same for women and men and it depended on which SES and smoking indicator was used. Among women, educational inequalities widened significantly for smoking prevalence, smoking initiation, and smoking cessation. Among men, educational inequalities widened significantly for smoking consumption. The widening pattern in smoking, initiation, and quitting among low educated women is especially worrying. In this group, smoking prevalence remained stable between 2001 and 2008 because both the initiation and quit ratio increased slightly. Among moderate and high educated women smoking prevalence decreased because initiation ratios remained constant, while quit ratios increased considerably. Other studies have also found that in countries in later stages of the smoking epidemic, SES inequalities in smoking prevalence are stable among men, while they are widening among women (Bennett, 1995; Giskes et al., 2005). Also, it was found earlier that SES inequalities in smoking consumption are stable among women and widening among men (Giskes et al., 2005).

According to the literature, advertising bans, smoking bans in workplaces, reimbursement of smoking cessation therapies, and increased tobacco taxes have the potential to reduce SES differences in smoking (Giskes et al., 2007). During our study period, smoke-free workplace legislation (2004), smoke-free hospitality industry legislation (2008), and tobacco tax increases (2001, 2004, and 2008) were implemented in the Netherlands. From our data, it looks like there was a change in 
SES inequalities in smoking prevalence and consumption between 2003 and 2004, when the smoke-free workplace legislation was implemented together with a tax increase. However, the SES inequalities seem to be widening instead of narrowing. An earlier study also showed that the workplace smoking ban in the Netherlands has increased SES differences in smoking cessation (Nagelhout, Willemsen et al., 2011). An explanation could be that the smoke-free legislation was not comprehensive: the hospitality industry was exempted (until 2008) and designated smoking rooms were allowed.

Our study had some important strengths. We used very large, representative samples of the Dutch population over a period of eight years. Therefore, changes in SES differences over time could be detected and generalised to the Dutch population. Also, we examined both educational level and income level differences in four smoking-related outcomes, including smoking initiation and cessation for both men and women. Our study thus provides a more detailed picture of SES differences in smoking than most studies. This study also had some limitations. First of all, we relied on self-reported smoking status. Since there can be differences in underreporting of smoking between SES groups, this could have influenced our results. Second, income levels were unknown for $21 \%$ of respondents. These respondents were excluded from the analyses and this may have introduced selection bias. However, since we also used another SES indicator (educational level) with only a few missing values resulting in comparable findings, we expect that the missing income data did not bias our results. Furthermore, we used initiation and quit ratios to estimate population level smoking initiation and cessation. These ratios may not be sensitive enough to reflect short-term changes in smoking initiation and cessation. However, initiation and quit ratios are suitable for understanding long-term population trends (Schaap \& Kunst, 2009).

\section{Conclusion}

This study exemplifies that inequalities in smoking prevalence among women and smoking consumption among men may widen in the fourth stage of the smoking epidemic. Although our study provides some insight in trends in SES differences in smoking in populations, more research is needed to find ways to successfully address these differences. While inequalities in smoking prevalence were stable among Dutch men, they increased among women, due to widening inequalities in both smoking cessation and initiation. Therefore, both components should be addressed in equity-oriented tobacco control policies. 


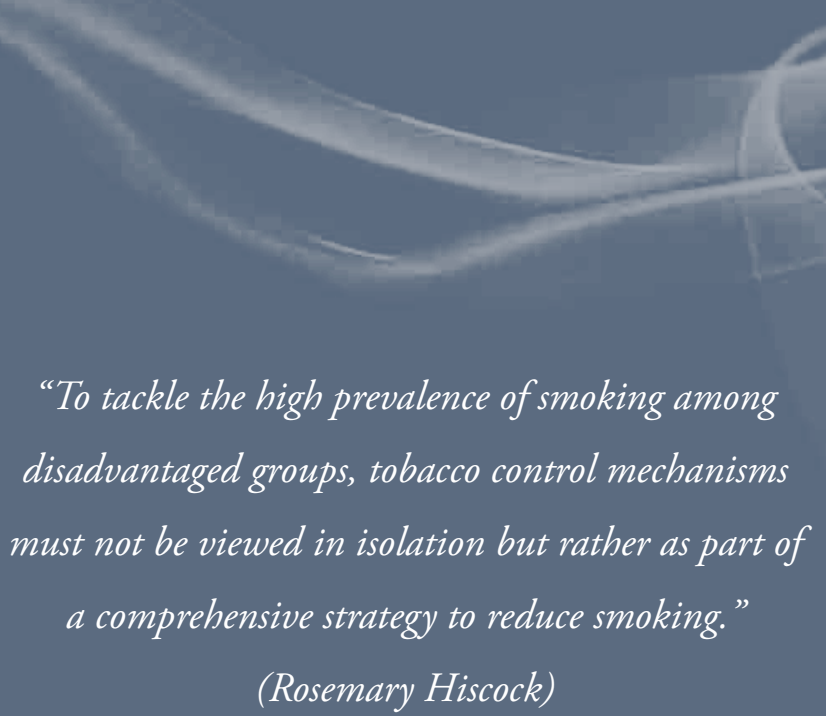

(Rosemary Hiscock) 


\section{Chapter 14}

\section{Inequalities in cessation after three tobacco control policies}

Resubmitted as:

Nagelhout, G. E., Crone, M. R., Van den Putte, B., Willemsen, M. C.,

Fong, G. T., \& De Vries, H. Age and educational inequalities in smoking cessation due to three population level tobacco control interventions. Findings from the International Tobacco Control (ITC) Netherlands Survey. 
This study aimed to examine age and educational inequalities in smoking cessation due to the implementation of a tobacco tax increase, smokefree legislation, and a cessation campaign. Longitudinal data from 962 smokers aged 15 years and older were used from three survey waves of the International Tobacco Control (ITC) Netherlands Survey. The 2008 survey was performed before the implementation of the interventions and the 2009 and 2010 surveys were performed after the implementation. No significant age and educational differences in successful smoking cessation were found after the implementation of the three tobacco control interventions, although smokers aged 15 to 39 years were more likely to attempt to quit. Of the three population level tobacco control interventions that were implemented simultaneously in the Netherlands, only the smoke-free legislation seemed to have increased quit attempts. The price increase of cigarettes may have been only effective in stimulating smoking cessation among younger smokers. Larger tax increases, stronger smokefree legislation, and media campaigns about the dangers of (second-hand) smoking are needed in the Netherlands. 


\section{INTRODUCTION}

The World Health Organization has introduced the MPOWER package, consisting of six effective population level tobacco control interventions (World Health Organization, 2008a). Three of these, tobacco tax increases, smoke-free legislation, and cessation campaigns, are thought to be most effective (Levy et al., 2004; Levy et al., 2005). Ideally, these interventions should not only be effective in reducing overall smoking rates, but also in decreasing smoking-related disparities. People with lower educational levels are more likely to become smokers and to become heavily addicted smokers (Huisman et al., 2005b; Siahpush et al., 2006). Previous research suggests that tax increases may have larger effects among smokers with lower educational levels (Chaloupka, Straif, \& Leon, 2011; Thomas et al., 2008) and that smoke-free legislation and cessation campaigns may have larger effects among smokers with higher educational levels (Niederdeppe et al., 2008; Thomas et al., 2008).

It is also preferred that population-level tobacco control interventions have equal or greater effects among young smokers, to prevent them from becoming established smokers (Huisman et al., 2005b). Tax increases on tobacco are known for their larger effects on young people (Chaloupka et al., 2011; Levy et al., 2004; World Health Organization, 2003), presumably because young people have lower incomes (Chaloupka et al., 1996). Potential differential effects of smoke-free legislation and cessation campaigns on young people are less well documented (Levy et al., 2004; Thomas et al., 2008).

Evidence about the differential effects of population-level tobacco control interventions generally comes from studies examining the effects of only one intervention (Levy et al., 2005), while the implementation of only one populationlevel tobacco control intervention at a time is rare (Chapman, 1993). Therefore, it is unclear whether differential effects of interventions across studies are really due to the differential strength of that particular intervention or to the presence of concurrent interventions whose impact was not explicitly considered in the evaluation.

In our study, we examine the differential effects of three tobacco control interventions: a tobacco tax increase, smoke-free hospitality industry legislation, and a mass media smoking cessation campaign. These three interventions were implemented during the same time period in the Netherlands in 2008 , providing a large opportunity to substantially decrease smoking prevalence and increase smoking cessation. However, smoking prevalence did not decrease significantly (Nagelhout, Willemsen et al., 2011) and the combination of the three interventions increased quit attempts only slightly from 24\% in 2007 to $26 \%$ in 2008 (Nagelhout, Willemsen et al., 2011). By using a longitudinal cohort study and classifying people 
according to their exposure to each of the three interventions, we attempt to disentangle the differential effects of the interventions.

In the Netherlands, tobacco taxes were increased by $€ 0.25$ for a pack of 20 cigarettes and by $€ 0.31$ for a 50 gram pouch of rolling tobacco from July 2008. This resulted in a mean price increase of $8 \%$, which reached the consumer in November 2008. Smoke-free hospitality industry legislation was implemented in July 2008. Workplaces were already smoke-free from January 2004. The smokefree hospitality industry legislation did not succeed in making all hospitality venues totally smoke-free due to weak legislation and problems with compliance (Gonzalez \& Glantz, 2011; Nagelhout, Mons et al., 2011). From April 2008 until January 2009, a mass media smoking cessation campaign 'There is a quitter in every smoker' ran on television, radio, print, and internet. This campaign was designed to stimulate smokers to quit smoking and had a special focus on smokers with low to moderate educational levels aged 20 to 50 years.

In the current study, we examine whether there were age or educational inequalities in smoking cessation after the implementation of the three interventions (research question 1), in exposure to the three interventions (research question 2), and in the effects of the three interventions on smoking cessation (research question 3 ).

\section{METHODS}

\section{Design}

The tobacco tax increase, smoke-free hospitality industry legislation, and the cessation campaign were all implemented on a national level in the Netherlands between April 2008 and January 2009. Longitudinal data from smokers from three survey waves of the International Tobacco Control (ITC) Netherlands Survey were used to evaluate the effects of the three interventions. The 2008 survey was performed before and the 2009 and 2010 surveys were performed after the implementation of the three interventions. The 2008 and 2009 surveys were used to assess exposure to the interventions and the 2010 survey was used to assess the effects of exposure on smoking cessation.

\section{Sample}

Dutch smokers aged 15 years and older were recruited from a probability-based web database (Nagelhout et al., 2010). Potential respondents were identified as smokers (having smoked at least 100 cigarettes in their lifetime and currently smoking at least once per month) by means of a short screening survey in March 2008. In April 2008, 2,331 smokers were requested to participate in a web survey. Of these smokers, 1,820 participated in the first survey (78.1\%). In April and May 
2009 all 1,820 smokers of the baseline survey were recontacted for the second survey and 1,447 took part (79.5\%). In May 2010 all baseline respondents were again recontacted and 1,275 respondents participated in the third survey $(70.1 \%)$.

The analyses for this paper were restricted to respondents who participated in all three survey waves $(n=1,176)$. Furthermore, respondents were excluded who had quit smoking between the 2008 and 2009 survey $(n=128)$. This enabled us to estimate the effects of exposure to the interventions between the 2008 and 2009 survey on smoking cessation between the 2009 and 2010 survey. Of the remaining 1,048 respondents 962 answered all questions that were used in the current study and were used in the analyses. These respondents $(n=962)$ were older $(t=4.83, p$ $<0.001)$, had higher scores on the Heaviness of Smoking Index $(t=2.81, p=0.005)$, and had less often the intention to quit smoking within the next 6 months $\left(\chi^{2}=8.18\right.$, $p=0.004)$ at the 2008 survey than respondents who did not answer all questions used in this study or did not participate in the 2010 survey $(n=858)$.

\section{Measurements}

\section{Control variables}

Control variables were gender, age group, educational level, heaviness of smoking, and intention to quit smoking. These variables were assessed at the 2008 survey. Age was categorised as 15 to 24,25 to 39,40 to 54 , and 55 years and older. Education was categorised in three levels: low (primary education and lower pre-vocational secondary education), moderate (middle pre-vocational secondary education and secondary vocational education), and high (senior general secondary education, (pre-)university education and higher professional education). The Heaviness of Smoking Index ( $\mathrm{HSI})$ was created as the sum of two categorical measures: number of cigarettes per day and time before smoking the first cigarette of the day (Heatherton et al., 1989). HSI values ranged from 0 to 6 and are positively associated with nicotine dependence. Intention to quit smoking was categorised as intending to quit within 6 months and not intending to quit within 6 months.

\section{Exposure to tobacco control interventions}

A tobacco tax increase will affect only those smokers who pay more for their cigarettes after the tax increase. Therefore, respondents were asked during the 2008 and 2009 survey how much they paid for their cigarettes at their last purchase. Following previous studies (Ross, Blecher, Yan, \& Hyland, 2011), the increase in reported prices between the 2008 and 2009 survey was used as an indicator of exposure to the price increase. Next, this variable was categorised into four levels: no price increase including price decreases (0), an increase in price of 1 to 2 cents per cigarette (1), 3 to 4 cents per cigarette (2), and 5 cents per cigarette or more (3). 
Not all smokers were exposed to the smoke-free hospitality industry legislation, because not all hospitality industry venues complied with the legislation and because not all smokers frequented hospitality industry venues. Therefore, we used both rules about smoking in bars (Cooper et al., 2010; Hammond et al., 2006) and frequency of visiting bars (Cooper et al., 2010; Nagelhout, Willemsen et al., 2011) at the 2009 survey as a measure for exposure to smoke-free legislation. The following questions were used: "Which of the following best describes the rules about smoking in drinking establishments such as bars or pubs where you live?" ("no rules or restrictions", "smoking is allowed only in some indoor areas", or "smoking is not allowed in any indoor area") and "Since the smoking ban in the hospitality industry (July 2008), how often have you visited a drinking establishment such as a bar or pub where you live?" ("never", "yearly", "monthly", or "weekly"). One exposure variable was created by multiplying the answers on the two questions, ranging from 0 (no rules or restrictions about smoking in drinking establishments and/or never visited drinking establishments since the ban) to 6 (smoking is not allowed in any indoor area in drinking establishments and weekly visited drinking establishments since the ban).

Recall of exposure to the cessation campaign was assessed at the 2009 survey by showing respondents pictures and texts from the campaigns. Smokers were asked how often they had seen the television commercial, the radio commercial, the poster, and how often they had seen anything on the internet from the 'There is a quitter in every smoker' campaign. Response categories were "never" (0), "rarely" (1), "sometimes" (2), and "often" (3). One exposure variable was created by computing a mean score of exposure to the four different parts of the campaign for every respondent.

Smoking cessation

Smoking cessation was assessed during the 2010 survey. Quit attempts were assessed by asking respondents: "Have you made any attempts to stop smoking since the last survey?"

Smokers who attempted to quit smoking since the last survey and who had not smoked in the past seven days at the 2010 survey were defined as successful quitters (seven-day point prevalence abstinence).

\section{Ethics}

The surveys were cleared for ethics by the Research Ethics Board of the University of Waterloo and the Central Committee on Research Involving Human Subjects in the Netherlands. 


\section{Analyses}

Age and educational inequalities in quit attempts and successful smoking cessation (research question 1) were examined with Chi-square tests. Age and educational inequalities in exposure to the interventions (research question 2) were examined with ANOVA F-tests. Exposure to the interventions was approximately normally distributed.

Age and educational inequalities in the effects of the three interventions (research question 3) were examined by performing logistic regression analyses (both bivariate and multivariate) predicting quit attempts and successful smoking cessation at the 2010 survey. Independent variables were the above mentioned control variables and exposure to the price increase, the smoke-free legislation, and the cessation campaign. Interactions of exposure to the interventions with age and education were simultaneously added to these regression analyses to examine whether there were age or educational inequalities in the effects of the interventions on smoking cessation. Simple slope analysis was conducted to decompose a significant interaction term (Aiken \& West, 1991). In the simple slopes analysis, low, moderate, and high values for each factor corresponded to one standard deviation (SD) below the mean, the mean, and one SD above the mean, respectively.

All analyses were weighted by age and gender to be representative of the adult smoker population in the Netherlands. More details on the weighting procedure can be found in Thompson et al. (2006).

\section{RESULTS}

\section{Inequalities in cessation}

Of the study sample, 281 out of 962 respondents (29.3\%) had tried to quit smoking between the 2009 and 2010 survey (Table 1). At the 2010 survey, 86 out of 962 respondents $(8.9 \%)$ had successfully quit smoking. Table 1 shows that there were no significant age or educational inequalities in successful smoking cessation. Smokers aged 15 to 39 years were more likely to attempt to quit smoking.

\section{Inequalities in exposure}

Most respondents were exposed to at least one of the three population-level tobacco control interventions. $82.4 \%$ reported having paid more for their cigarettes in the 2009 survey than in the 2008 survey, 65.6\% reported having visited a drinking establishment that had some form of smoking restriction, and $83.1 \%$ reported having experienced one or more parts of the campaign. Table 1 shows that smokers aged 15 to 24 years were more exposed to the smoke-free legislation, while smokers aged 25 to 39 years were more exposed to the cessation campaign. 
Higher educated smokers were more exposed to the price increase and the smokefree legislation.

\section{Inequalities in effects on cessation}

As can be seen in Table 2, exposure to the smoke-free legislation and to the cessation campaign had a significant positive association with attempting to quit smoking in the bivariate analyses, but not with successful smoking cessation. In the multivariate analyses, only the association between exposure to the smoke-free legislation with attempting to quit smoking remained significant (Odds Ratio $(\mathrm{OR})=$ $1.11,95 \%$ confidence interval $(\mathrm{Cl})=1.01$ to $1.22, \mathrm{p}=0.029$ ).

In additional analyses (not shown in table), interactions of exposure to the interventions with age and education were added. The interaction between age and exposure to the price increase on successful smoking cessation was significant (OR $=0.99,95 \% \mathrm{Cl}=0.97$ to $1.00, \mathrm{p}=0.046$ ). Decomposing this interaction by means of simple slopes analysis showed that exposure to the price increase only predicted successful smoking cessation among young respondents $($ Beta $=0.10,95 \% \mathrm{Cl}=$ 0.01 to $0.18, p=0.035$ ) and not among older respondents (Figure 1).

There were no significant interaction effects of age with the other two interventions (not shown in tables). Also, there were no significant interaction effects of education with any of the interventions. 
chapter $14 \mid$ Inequalities in cessation after three tobacco control policies

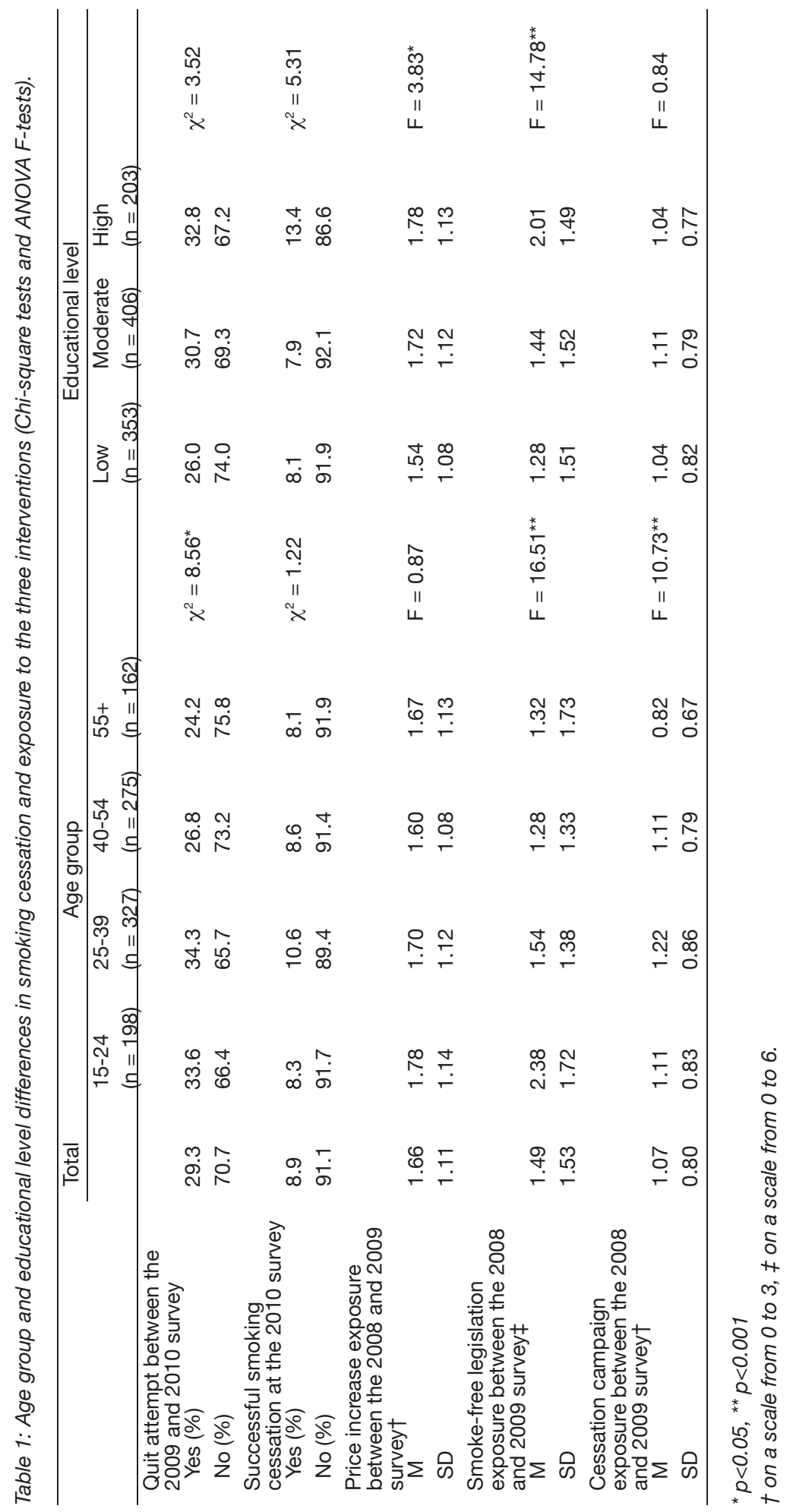




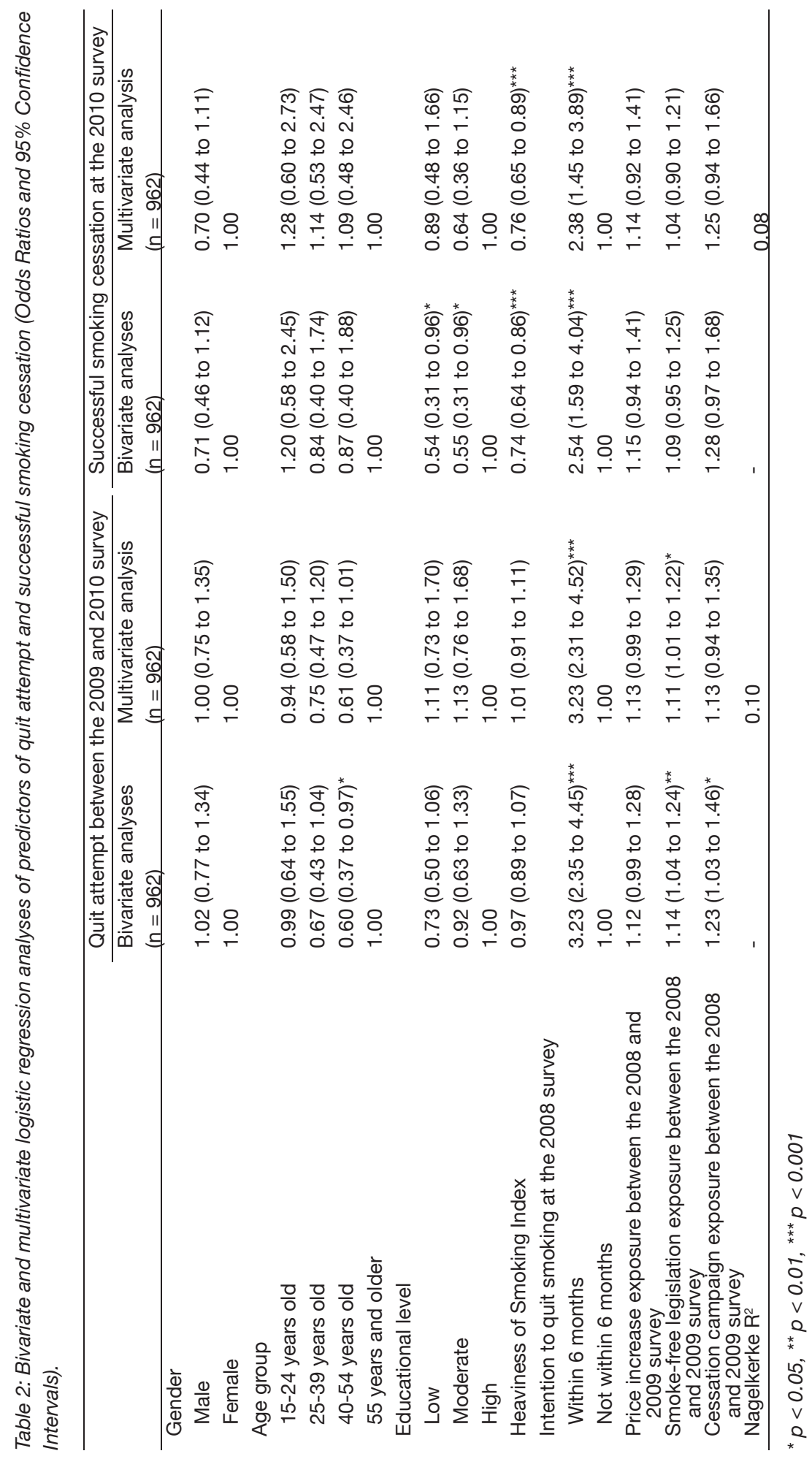


Figure 1: Simple slope analysis of the interaction between price increase exposure between the 2008 and 2009 survey and age on successful smoking cessation at the 2010 survey.

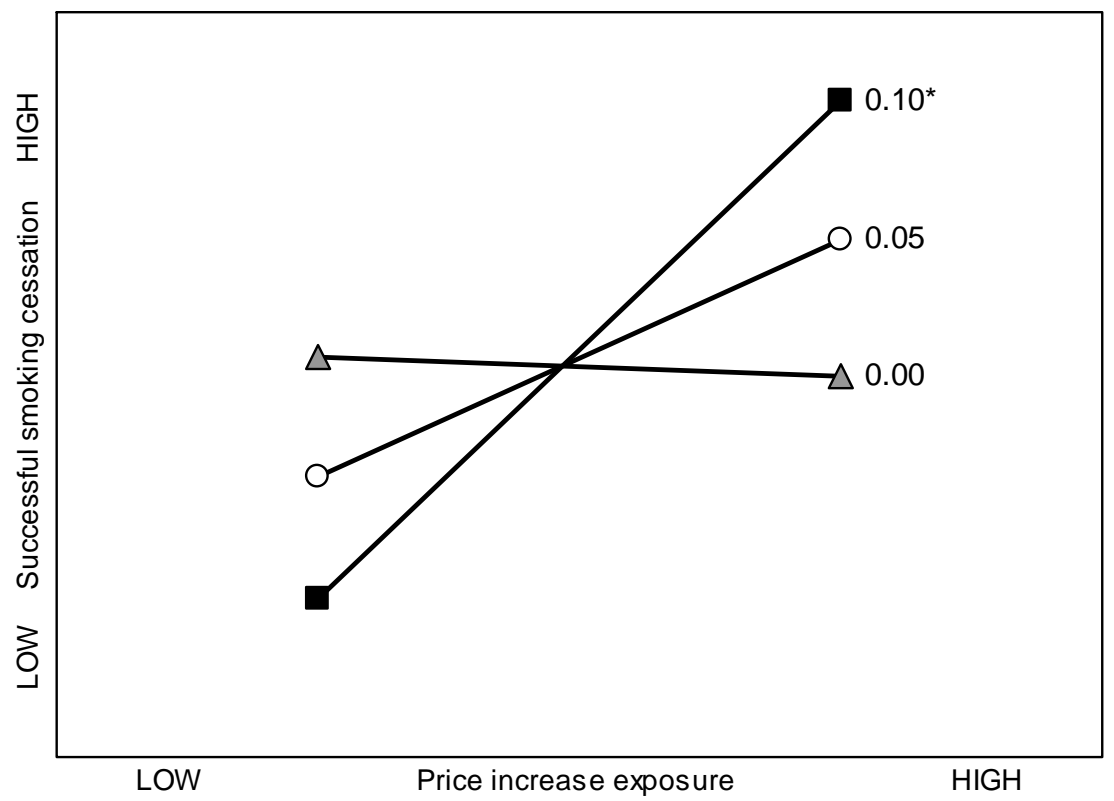

$\rightarrow$ Age 1 SD below the mean $-\infty-$ Mean age $\rightarrow$ Age 1 SD above the mean ${ }^{*} p<0.05$ 


\section{DISCUSSION}

In this study, we examined age and educational inequalities in smoking cessation after three population-level tobacco control interventions: a tobacco tax increase, smoke-free hospitality industry legislation, and a mass media cessation campaign. These three interventions were implemented during the same time period in the Netherlands in 2008. We found that only the smoke-free legislation seemed to have had a small effect on attempting to quit smoking among the whole group of smokers. The price increase may have been only effective in increasing successful smoking cessation among younger smokers. However, there were no overall age or educational differences in successful smoking cessation after the implementation of the three interventions.

We did not find significant effects of the price increase on smoking cessation for the whole group of smokers. This was probably caused by the fact that prices increased by only $8 \%$. Prices should rise substantial to increase smoking cessation (World Health Organization, 2010). Consistent with earlier findings (Chaloupka et al., 2011; Levy et al., 2004; World Health Organization, 2003), our findings suggest that the price increase was only effective in stimulating successful smoking cessation among younger smokers.

We found a small effect of the smoke-free hospitality industry legislation on quit attempts, but not on successful smoking cessation. This is consistent with a previous study that showed that quit attempts increased slightly in the Netherlands after the implementation of the three interventions, but smoking prevalence did not decrease significantly (Nagelhout, Willemsen et al., 2011). This previous study could not disentangle which of the three interventions caused this increase in quit attempts. In the current study, we controlled for the other two interventions, which strengthens conclusions that the found effect of exposure to the smoke-free legislation can actually be ascribed to this intervention. A possible explanation for the small size of the effect is that the legislation was weak, not well implemented, and that there were considerable problems with compliance (Gonzalez \& Glantz, 2011; Nagelhout, Mons et al., 2011). Another recent study showed that compared to two countries with comprehensive and well-enforced smoke-free legislation, Ireland and England, there were less quit attempts and there was less quit success in the Netherlands after the implementation (Nagelhout, De Vries, Boudreau et al., 2012).

The Dutch cessation campaign focused on smokers with low to moderate educational levels. However, we found no educational inequalities in exposure to the cessation campaign. The campaign did not succeed in reaching low to moderate educated smokers more than high educated smokers. But it may be considered an achievement that smokers from different educational levels were reached equally, 
because previous research found that cessation campaigns have a larger reach among smokers with higher educational levels (Niederdeppe et al., 2008; Thomas et al., 2008). Furthermore, smokers aged 25 to 39 years old were more often exposed to the campaign, which matches the focus of the campaign on smokers aged 20 to 50 years.

The strength of our study is that we compared the effects of three tobacco control interventions that were implemented during the same time period using three survey waves of a longitudinal cohort study. This study design allowed us to classify people according to their exposure to each of the three interventions, so we could disentangle the effects of the three interventions on smoking cessation. However, there were also some limitations. Our design with three survey waves has the drawback of being unable to account for short-term effects on smoking cessation and our results may therefore be conservative. The fact that we did not have a control region in the Netherlands where the three interventions were not implemented is a limitation of this study. Also, exposure to the interventions cannot be measured objectively by using self-report. Smokers who report that they have not seen or heard anything from the smoking cessation campaign, may have seen something from the campaign without remembering this at the time of the survey. Also, we used self-reported smoking cessation without biochemical validation. Finally, almost half of the sample was either lost to follow-up or did not answer all questions that were used in the current study. These respondents were younger, less addicted, and had more intention to quit smoking. Therefore, our results may not be fully generalisable to the broader population of Dutch smokers.

Our study has important implications for population-level tobacco control interventions. Based on our findings, we recommend increasing tobacco taxes at a higher rate such that there is a much larger resulting increase in price. Although raising taxes is widely recognised as the most potent tobacco control intervention (Glynn, Seffrin, Brawley, Grey, \& Ross, 2010; Levy et al., 2005), it is known from previous studies that in order for tax hikes to lead to substantial increases in cessation, the resulting price increase must also be substantial (World Health Organization, 2010). We also recommend implementing strong, comprehensive smoke-free legislation, because this protects non-smokers and may maximise quitting behaviour (Callinan et al., 2010; Nagelhout, De Vries, Boudreau et al., 2012). An accompanying media campaign should explain that smoke-free legislation is implemented to protect nonsmokers from exposure to second-hand smoke instead of only stimulating smoking cessation (European Commission, 2007; World Health Organization, 2007b). This is especially important in the Netherlands, were smokers are less knowledgeable or concerned about the harms of smoking and second-hand smoke than in other countries (Arnott et al., 2011). 


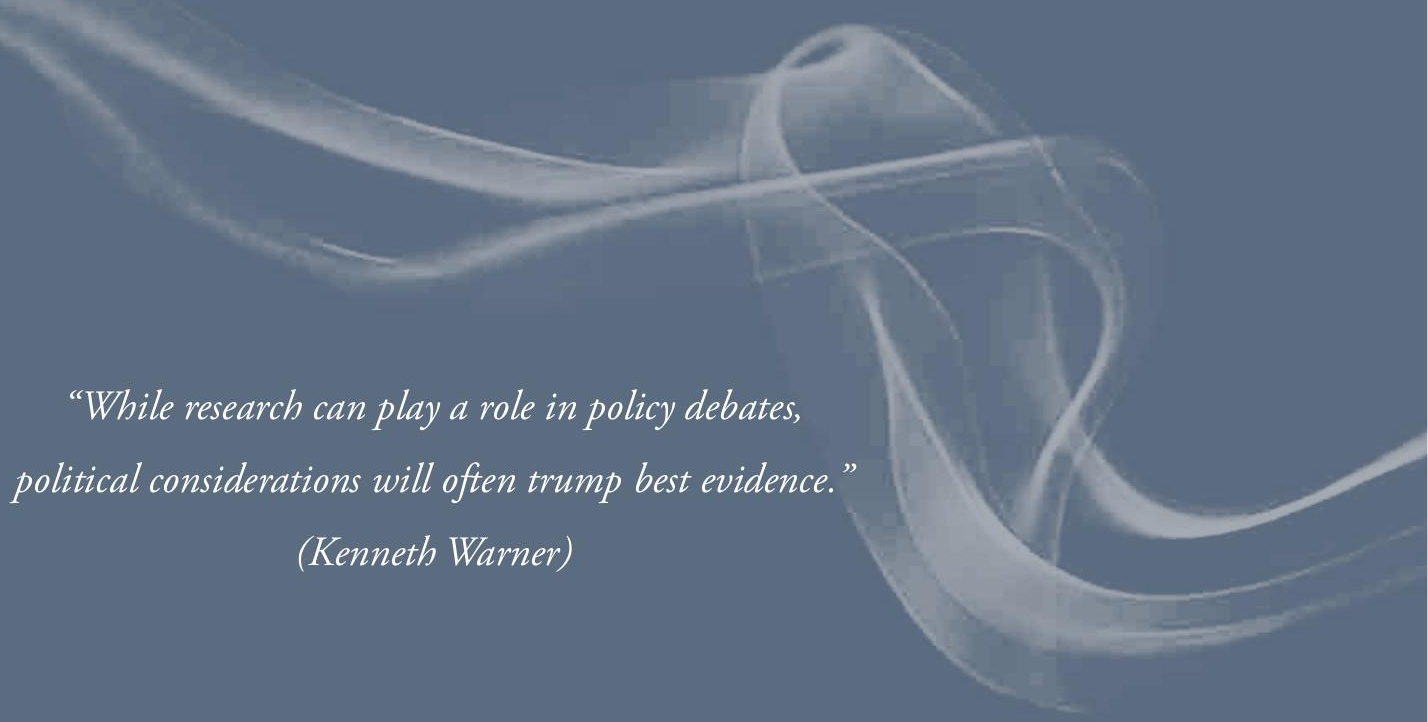


Chapter 15

\section{Discussion}




\section{Introduction}

The studies in this thesis focused on the impact of smoke-free legislation on smoking. Smoke-free legislation is a key policy under the World Health Organization (WHO) Framework Convention on Tobacco Control (FCTC). The FCTC is the first international public health treaty and has currently been ratified by more than 170 countries around the world. The International Tobacco Control Policy Evaluation Project (ITC Project) was specifically designed to evaluate the impact of FCTC policies. The founding researchers realised that the treaty provided a unique opportunity to evaluate the impact of tobacco control policies worldwide. ITC is the first-ever international cohort survey of tobacco use and is currently conducted in 20 countries. It is unique in its use of individual longitudinal cohort data within a quasi-experimental design. In this thesis, data from the ITC Project were used to evaluate the impact of smoke-free legislation in the Netherlands. The Netherlands is an interesting case study for smoke-free legislation because the emergence of smoke-free hospitality industry legislation was more controversial and problematic there than in many other countries.

The ITC Netherlands Survey was initiated in 2008 to evaluate the impact of Dutch FCTC policies. The following FCTC policies were implemented immediately after the first wave of the ITC Netherlands Survey in 2008: smoke-free hospitality industry legislation with an accompanying implementation campaign, a mass media smoking cessation campaign, and a small tax increase. The impact of all these policies are evaluated in this thesis, but the focus is on the impact of smoke-free hospitality industry legislation. The studies were grouped into three parts: 1) population impact of smoke-free legislation on smoking, 2) individual pathways of change after smokefree legislation, and 3) unintended consequences of smoke-free legislation.

In this chapter, we will discuss the main findings of our studies in relation to recent findings described in the international literature. Methodological limitations of the studies in this thesis will be discussed, as well as priorities for future research and recommendations for tobacco control policy.

\section{Overview of main findings}

Before the results of the studies are discussed separately, a short overview of the main findings is given. These findings are graphically displayed in Figure 1. The studies in this thesis focused mostly on the impact of smoke-free legislation on attempts to quit smoking. We found that support for smoke-free legislation was an important mediator of the relationship between smoke-free legislation and quit attempts. When smoke-free legislation succeeds in substantially increasing quit attempts, the legislation can cause a decrease in smoking prevalence. This 
eventually leads to a decrease in smoking-attributable deaths. Furthermore, smoke-free legislation can increase quit success. However, we found that smokefree workplace legislation in the Netherlands had a larger impact on quit success among higher educated that among lower educated smokers, thereby contributing to increased socioeconomic inequalities in smoking. Support for smoke-free legislation was not only important as a mediator of the relationship between smokefree legislation and quit attempts. Support was also important because it ensured compliance with smoke-free legislation and stimulated the implementation of voluntary home smoking bans. Media attention (about second-hand smoke) can have an impact on support, and may also directly influence compliance with smokefree legislation and the implementation of voluntary home smoking bans. Although this is not all explicitly studied in this thesis, it is to be expected that increased compliance with smoke-free legislation and more voluntary home smoking bans may reduce smoking-attributable deaths by decreasing both exposure to secondhand smoke and smoking consumption.

The results from three chapters in this thesis are not displayed in Figure 1. Chapter 2 described the methods of the ITC Netherlands Survey. The study in chapter 8 found that exposure to smoke-free legislation increased feelings of being uncomfortable about smoking and increased perceptions of societal disapproval of smoking. However, these associations were very small and are therefore not considered main findings. Finally, findings from chapter 12 revealed that perceived stigmatisation did not change after the implementation of smoke-free legislation. Because we did not find this unintended consequence, we did not display this in the summary figure of the main findings.

Figure 1: Summary figure of the main findings from the chapters in this thesis.

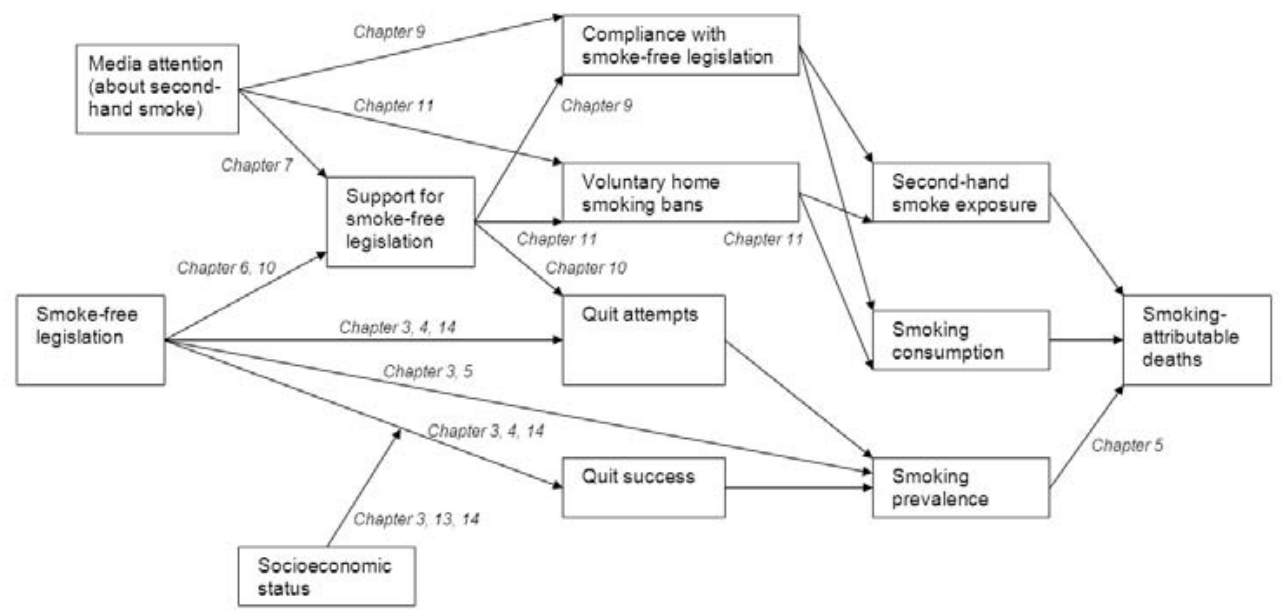




\section{Population impact of smoke-free legislation on smoking}

The main goal of smoke-free legislation is to protect non-smokers by reducing exposure to second-hand smoke. However, the largest impact on smokingattributable deaths may not come from the effects of smoke-free legislation on reduced exposure to second-hand smoke, but from its effects on reduced smoking consumption and reduced smoking prevalence (see Figure 1). The first part of this thesis focused on the population impact of smoke-free legislation on smoking cessation and smoking prevalence. Relatively few studies had addressed whether the population impact of smoke-free legislation on smoking was the same for smoke-free workplace legislation and hospitality industry legislation, whether the impact was the same for comprehensive and partial legislation, and how the impact of smoke-free legislation compared to the impact of other tobacco control policies. Moreover, few studies had examined the impact of national smoke-free legislation on smoking. The studies in the first part of this thesis were conducted to fill these gaps in the literature.

Findings from chapters 3,4 , and 5 demonstrated that national smoke-free legislation can have a population impact by reducing smoking prevalence, stimulating smoking cessation, and reducing smoking-attributable deaths. Furthermore, the findings suggested that the impact of smoke-free legislation on smoking prevalence and cessation was larger when it was implemented in all workplaces instead of only hospitality industry venues (chapter 3 ). Also, the impact on smoking cessation may be larger when the smoke-free legislation was comprehensive instead of partial (chapter 4). Extending partial smoke-free legislation to all public places and workplaces with full enforcement and publicity can substantially reduce smoking prevalence and smoking-attributable deaths (chapter 5). We found that the impact of comprehensive smoke-free legislation on reducing future smoking-attributable deaths ranked as the third most effective tobacco control policy, after increasing tobacco taxes and implementing cessation treatment policies (chapter 5).

A recent systematic review of the impact of smoke-free legislation reported that some studies found a positive effect on smoking cessation, whereas other studies did not (Callinan et al., 2010). Also, a study using data from 21 jurisdictions (countries, states, and provinces) that implemented smoke-free legislation found evidence of a decrease in smoking prevalence in eight jurisdictions but no change in the other 13 (Bajoga et al., 2011). This may suggest that smoke-free legislation has an impact on smoking cessation, but only under certain circumstances. Two of these circumstances were explicitly studied in this thesis: the scope of the legislation (workplace or hospitality industry) and the comprehensiveness of the legislation. We found that partial smoke-free workplace legislation in the Netherlands and 
comprehensive smoke-free workplace legislation in Ireland and England was more effective in increasing smoking cessation than partial smoke-free hospitality industry legislation in the Netherlands (chapters 3 and 4). The smoke-free hospitality industry legislation in the Netherlands only had a small impact on quit attempts, without significantly reducing smoking prevalence (chapter 3 ). It is unknown whether the smaller impact of smoke-free hospitality industry legislation in the Netherlands is due to its limited scope, to the fact that the legislation is not comprehensive (allowing smoking rooms and other exceptions), or to both. Additionally, the impact may have been larger in Ireland and England due to better enforcement, more publicity, and other policies already in place or implemented at the same time.

A study involving multiple countries that have different types of smoke-free legislation is needed to disentangle the factors determining the impact of smokefree legislation on smoking. At minimum, a two-by-two design of four countries would be needed to disentangle the two factors scope of the legislation and comprehensiveness. Yet if factors like enforcement and other policies or campaigns are also taken into account such a study may become practically unfeasible. Simulation studies, like the one described in chapter 5 , can be an alternative research strategy to answer these questions. Simulation studies combine information from different kinds of empirical studies and provide a useful tool for examining the effects of smoke-free legislation while controlling for secular trends, scope of the legislation, comprehensiveness, enforcement, publicity, and other policies or campaigns already in place or implemented at the same time (Levy et al., 2006). However, the reliability of simulation models is always limited by the quality of the empirical data that is used for model construction and validation. Therefore, more empirical studies are needed comparing countries with different types of smokefree legislation.

In conclusion, we found that national smoke-free legislation can reduce smoking prevalence, stimulate smoking cessation, and reduce smoking-attributable deaths. The impact is likely to be larger when the legislation is implemented in all workplaces, when it is comprehensive, and when there is full enforcement and publicity.

\section{Individual pathways of change after smoke-free legislation}

It is not only important to know whether policies have an impact on tobacco consumption; it is also important to understand how this process occurs. The ITC Conceptual Model (Fong et al., 2006) describes the individual pathways of change from tobacco control policies to smoking cessation. Before the start of the ITC Netherlands Survey, no published studies had tested the entire causal chain 
hypothesised in the ITC Conceptual Model. Therefore, it was unknown through which policy-specific variables and psychosocial mediators the individual impact of smoke-free legislation on smoking cessation occurred. This was examined in the studies in the second part of this thesis.

The studies in chapters 6 and 7 determined relevant policy-specific variables, the factors that are most proximal to the policy itself. It was found that comprehensive smoke-free legislation was associated with an increase in support for smoke-free legislation that was above the secular trend (chapter 6). Furthermore, awareness of the harm of second-hand smoking was a predictor of greater support for smoke-free legislation. The study in chapter 7 described the newspaper coverage about smoke-free hospitality industry legislation in the Netherlands. Most newspaper coverage was negative towards the smoke-free legislation and focused on economic aspects rather than health aspects. Exposure to this coverage had a small negative effect on support for smoke-free legislation, while exposure to the implementation campaign had a small positive effect on awareness of the harm of second-hand smoking. In sum, we found in chapters 6 and 7 that smoke-free legislation and accompanying media attention can have an influence on two policyspecific variables: support for smoke-free legislation and awareness of the harm of second-hand smoking.

In chapters 8 and 9 the role of psychosocial mediators was established. Chapter 8 focused on the social acceptability of smoking. Small associations between awareness of warning labels, anti-tobacco information, and smokefree legislation and the social acceptability of smoking were found. Exposure to smoke-free legislation increased feelings of being uncomfortable about smoking and increased perceptions of societal disapproval of smoking. However, the small associations suggest that smoke-free legislation may only have an impact on the social acceptability of smoking on the long term and/or the population level. Chapter 9 examined predictors of smoking in bars after the implementation of smoke-free legislation in Europe. Smokers who were more supportive of smokefree legislation and who were more aware of the harm of second-hand smoke were less likely to smoke in bars after the implementation. Attitudes and social norms about smoking partly mediated the relationship between support and harm awareness and smoking in bars post-ban. Concluding, the studies in chapters 8 and 9 found that exposure to smoke-free legislation, support for smoke-free legislation, and awareness of the harm of second-hand smoking can influence attitudes and social norms (psychosocial mediators) and compliance with smoke-free legislation (behavioural mediator). 
Chapter 10 tested the entire causal chain from individual exposure to smoke-free legislation through policy-specific variables and psychosocial mediators on smoking cessation. The effect of individual exposure to smoke-free legislation on smoking cessation was mediated by one pathway via support for smoke-free legislation, attitudes about quitting, and intention to quit smoking. Exposure to smoke-free legislation also influenced awareness of the harm of (second-hand) smoking, which in turn influenced the subjective norm about quitting. However, only attitudes about quitting were significantly associated with intention to quit smoking, whereas subjective norm and self-efficacy for quitting were not.

These studies point to the importance of support for smoke-free legislation in ensuring compliance with smoke-free legislation and in changing psychosocial determinants of smoking cessation. Other recent studies have also concluded that support for smoke-free legislation is an important mediator in the effect of smokefree legislation on intention to quit smoking (Brown et al., 2009; Macy et al., 2012). This may be caused by the fact that smokers first experience smoke-free legislation and come to appreciate it. Later, these changed perceptions about smoke-free legislation may have an impact on how they think about smoking and quitting. This may motivate them to quit smoking. It may be that for countries where smoke-free legislation had a positive effect on smoking cessation, support for the legislation also increased most or was highest. Anecdotal evidence from Ireland (Currie \& Clancy, 2010) and Greece (Tamvakas \& Amos, 2010) suggests that support for the legislation can be an important factor in explaining whether smoke-free legislation succeeds in reducing exposure to second-hand smoke.

In conclusion, we found that support for smoke-free legislation increased after the implementation when the legislation was comprehensive and/or when media attention was positive. Sufficient support is important, because it can contribute to increased levels of compliance with smoke-free legislation as well as increased smoking cessation.

\section{Unintended consequences of smoke-free legislation}

Most research has focused on the intended effects of smoke-free legislation: reduced exposure to second-hand smoke and increased smoking cessation. However, smoke-free legislation can also have unintended consequences. An important concern is that smoke-free legislation might lead to a displacement of smoking into private venues, thereby increasing second-hand smoke exposure among children. Another possible unintended consequence is increased stigmatisation of smokers. Furthermore, tobacco control policies sometimes have larger effects on smokers with a higher socioeconomic status (SES), thereby increasing socioeconomic 
inequalities (Niederdeppe et al., 2008; Thomas et al., 2008). Part three of this thesis examined possible unintended consequences of smoke-free legislation on smoking in the home, on stigmatisation of smokers, and on socioeconomic inequalities in smoking.

Findings from chapter 11 demonstrated that smoke-free hospitality industry legislation did not lead to more smoking in smokers' homes. In fact, smoke-free legislation seemed to reduce the number of cigarettes smoked per day and seemed to stimulate smokers to establish voluntary smoking bans in their homes. Smokers with young children, smokers who were supportive of smoke-free legislation, and who were planning to quit smoking were particularly likely to implement a voluntary home smoking ban. Consistent with our findings, a recent systematic review concluded that exposure to second-hand smoke does not increase in homes after the implementation of smoke-free legislation (Callinan et al., 2010).

Chapter 12 described that whether smoke-free legislation increased smokers' perceived stigmatisation depended on how smokers felt about smoking outside. Increased feelings of stigmatisation were found only among smokers who felt negatively judged by passers-by when smoking outside. The level of perceived stigmatisation did not change after the implementation of smoke-free hospitality industry legislation in the Netherlands, possibly because most Dutch smokers did not feel negatively judged when smoking outside. However, it is unclear whether our results are generalisable to other countries that implemented comprehensive smoke-free legislation in both workplaces and the hospitality industry at the same time. Evidence from other recent studies is inconsistent (Hargreaves et al., 2010; Ritchie, Amos, \& Martin, 2010a; Stuber et al., 2008). Therefore, more research is warranted.

In the Netherlands, there is a widening of educational inequalities in smoking (chapter 13). While smoking prevalence remained stable among low educated women between 2001 (29\%) and 2008 (26\%), there was a significant decrease in smoking prevalence among high educated women in the same period (from 23\% to $17 \%)$. Similarly, smoking consumption remained stable among low educated men, while there was a decrease in smoking consumption among high educated men. There are concerns that tobacco control policies contributed to this widening of socioeconomic inequalities by having larger effects on smokers with a higher SES. Our findings revealed that the smoke-free hospitality industry legislation in the Netherlands did not have differential effects on lower or higher educated people (chapters 3 and 14). However, the smoke-free workplace legislation did have differential effects, with more effects on smoking cessation among higher educated smokers than among lower educated smokers (chapters 3 and 13). A possible 
explanation is that smoke-free workplace legislation has larger effects on higher educated smokers because they are more likely to be employed (Verdonk-Kleinjan, Candel, Knibbe, Willemsen, \& De Vries, 2011). However, a recent review of the international literature concluded that there is inconsistent evidence about whether the impact of smoke-free legislation on smoking behaviour differs between people from different socioeconomic groups (Amos et al., 2011). Thus, more research is still needed to determine whether smoke-free legislation increases socioeconomic differences in smoking.

Possible unintended consequences of tobacco control policies are explicitly modeled in the ITC Conceptual Model to provide a more complete picture of the effects of policies (Fong et al., 2006). Determining possible unintended consequences can help in developing a comprehensive tobacco control strategy. For example, because smoke-free workplace legislation can increase educational inequalities in smoking cessation (chapters 3 and 13), the implementation could be combined with a tobacco tax increase or an educational campaign specifically targeted at lower educated smokers to stimulate lower educated smokers to quit smoking too (Giskes et al., 2007; Hiscock, Bauld, Amos, Fidler, \& Munafò, 2012). However, when unintended negative consequences are found, this does not imply that countries should not implement smoke-free legislation (Ritchie et al., 2010a). Smoke-free legislation remains paramount for the protection of non-smokers. It may imply, however, that policymakers have the moral responsibility to support individuals who experience negative consequences (Bayer, 2008; Willemsen, 2011). For example, France implemented a reimbursement policy for smoking cessation aids simultaneously with the implementation of smoke-free legislation to support those who want to quit but cannot do this without help (ITC Project, 2009a).

In sum, we found that smoke-free hospitality industry legislation did not increase smoking in smokers' homes, did not increase Dutch smokers' perceived stigmatisation, and did not increase socioeconomic inequalities in smoking in the Netherlands. However, smoke-free workplace legislation did increase socioeconomic inequalities in smoking in the Netherlands, because it was more effective in stimulating smoking cessation among higher educated smokers than among lower educated ones. 


\section{Conceptual model of individual impact of smoke-free legislation on smoking cessation}

Based on the findings from this thesis and on the ITC Conceptual Model (Fong et al., 2006), we developed a model of the individual impact of smoke-free legislation on smoking cessation (Figure 2). Smoke-free legislation is often accompanied by media attention, and both have the potential to increase support for smoke-free legislation and awareness of the harm of (second-hand) smoking. Increases in support and harm awareness result in more favourable attitudes and social norms about quitting. These attitudes and social norms can in turn increase intention to quit and smoking cessation. Support and harm awareness, as well as attitudes and social norms about quitting, also influence compliance with smoke-free legislation and whether people implement voluntary smoking bans, for example in their home. These behavioural mediators may also increase intention to quit and smoking cessation.

The ITC Conceptual Model does not specify which policy-specific and psychosocial mediators can be expected to mediate the impact of policies on behaviour separately for each tobacco control policy. Our model applied the ITC Conceptual Model on smoke-free legislation in order to determine which policyspecific variables and psychosocial mediators were important in explaining the impact of smoke-free legislation on smoking cessation (chapter 10). It is important that such mediational models are also applied to other policies, such as tax increases, tobacco advertising bans, and health warnings on cigarette packages. This can help future theory building concerning the working mechanisms of these policies.

In our model, we added the category of behavioural mediators to the ITC Conceptual Model, consisting of two intermediate behaviours that relate to the implementation of smoke-free legislation: complying with smoke-free legislation (chapter 9) and implementing voluntary smoking bans (chapter 11). Some smokers may not immediately intend to quit smoking after they change their attitudes about smoke-free legislation and quitting. These smokers may first perform intermediate behaviours such as complying with smoke-free legislation and implementing voluntary smoking bans in their home, which may ultimately cause them to intend to quit smoking and attempt to quit. Future research should not only examine psychosocial mediators, but should also take behavioural mediators into account. 
Figure 2: Conceptual model of individual impact of smoke-free legislation on smoking cessation.

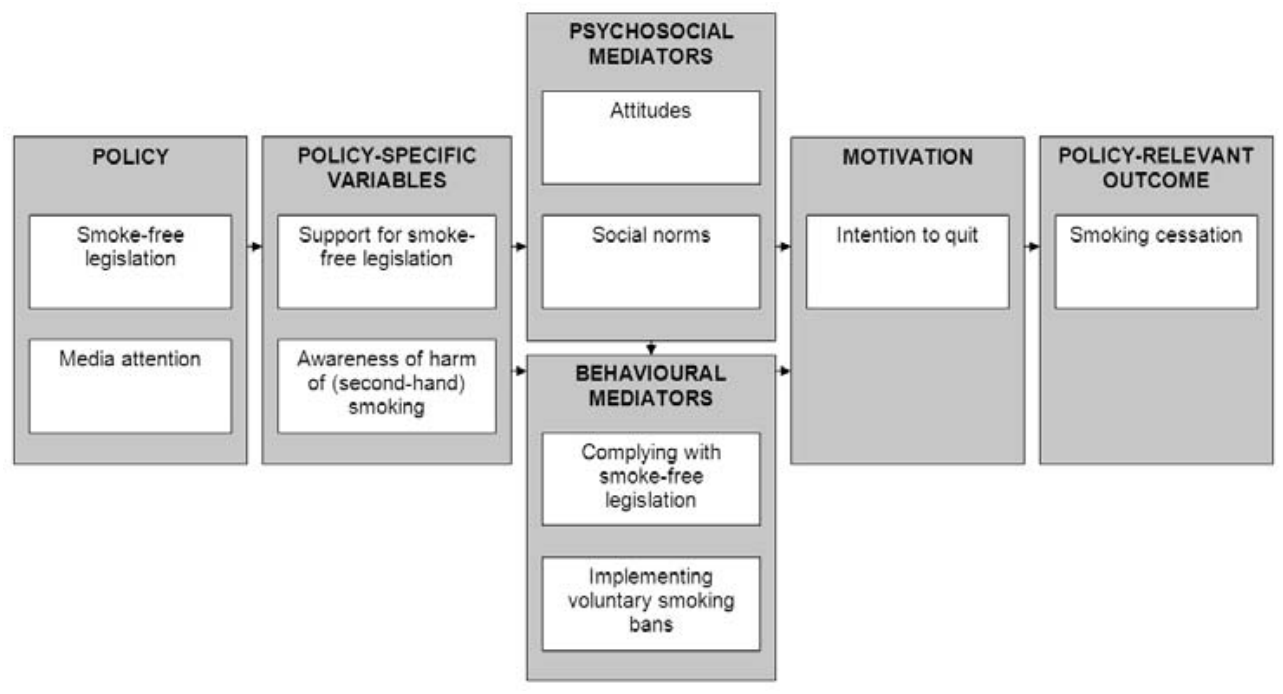

\section{Generalisability of findings to other countries}

Most findings in this thesis resulted from research in the Netherlands. The Netherlands is a high-income country with moderately strong tobacco control policies compared to other European countries (Joossens \& Raw, 2011). The Netherlands is currently in the fourth stage of the tobacco epidemic (chapter 13). Smoking prevalence is slightly lower than average in Europe as a whole (European Commission, 2010).

Despite the fact that the implementation of some tobacco control interventions in the Netherlands was quite successful (Mudde \& De Vries, 1999; Willemsen, 2005), the implementation of smoke-free legislation in Dutch bars was considerably less successful in reducing exposure to second-hand smoke than in other countries. This is evidenced by more smokers reporting smoking inside bars after the implementation in the Netherlands (chapter 9). In Ireland, reports of other people smoking dropped from $98 \%$ before to $5 \%$ one year after and $4 \%$ two years after implementation (ITC Project, 2010b). In the Netherlands, however, reports of other people smoking dropped from $93 \%$ before to $30 \%$ five months after the implementation and increased each year after the implementation to reach $49 \%$ three years later (Figure 3). 
Figure 3: Reported smoking inside bars before and after the implementation of smoke-free hospitality industry legislation in July 2008 in the Netherlands (source: wave 1-5 of the ITC Netherlands Survey).

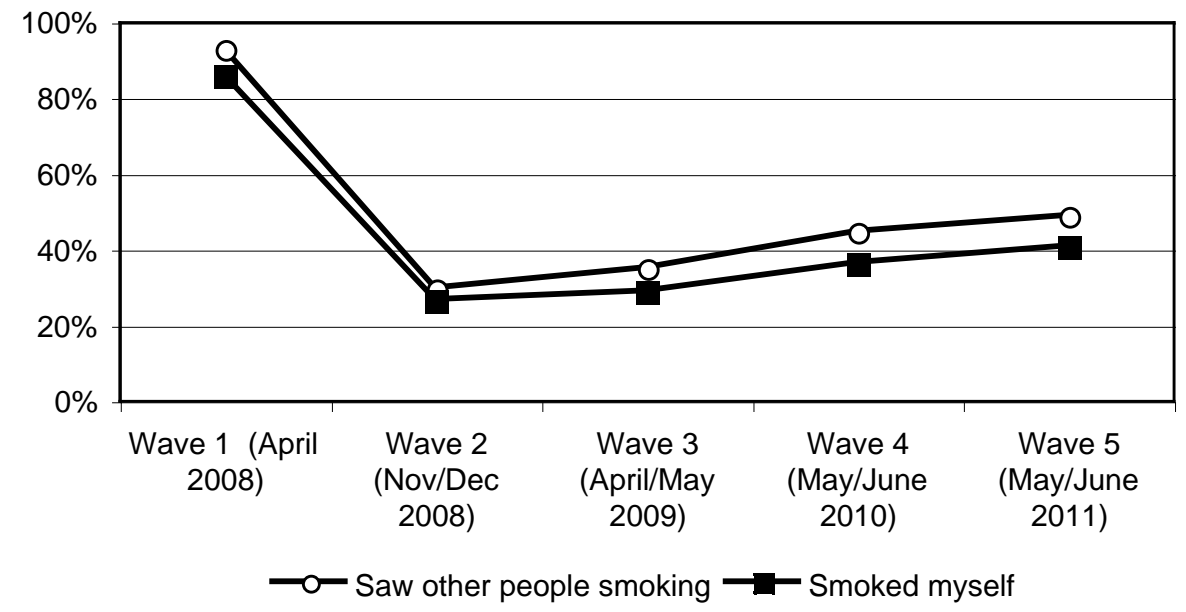

An important question is whether the failure of smoke-free bars in the Netherlands is the result of a difference between smokers and the political context in the Netherlands and those found in other countries, or whether it is mainly the result of weak implementation. The first possibility would imply that the results of tobacco control research in the Netherlands are not generalisable to other countries. The second would imply that with proper implementation smoke-free legislation can be successful everywhere, and results from the Netherlands can assist other countries by learning from the Dutch failure.

We have some evidence that smokers in the Netherlands are different from smokers in other countries. Findings from the ITC Netherlands Project showed that smokers in the Netherlands have less negative attitudes about smoking, are less supportive of smoke-free legislation and of government interference with smoking, and have less awareness of the harm of (second-hand) smoking than smokers in other countries (ITC Project, 2010b, 2011). This may be the result of a lack of educational campaigns about the harm of (second-hand) smoking and weak implementation of existing tobacco control policies. Clearly, the smoke-free legislation in the Netherlands was not properly implemented (chapter 9). The Netherlands complied with none of the four smoke-free policy recommendations from the WHO (Figure 4). Prompted by a press release about the results of our study in chapter 9 , questions were asked in Dutch parliament of the Minister of Health about the reasons for not following the WHO recommendations (Wiegman-van Meppelen Scheppink, 2011). The Minister answered that decisions should be made at the national political level 
and that this freedom must not be delegated to the WHO (Schippers, 2011). Further, the Minister indicated that the implementation campaign did not mention the harm of second-hand smoking because the government wanted a humorous campaign with a positive feeling.

Although the Dutch Minister of Health claimed that political considerations guided decisions about the implementation of smoke-free legislation, there is emerging evidence that the weak implementation may also be the result of tobacco industry influence (Gonzalez \& Glantz, 2011; Sheldon, 2011; Van den Bos, 2010). Investigative journalism confirmed ties between the organisation 'Red de Kleine Horeca Ondernemer' ('Save the small hospitality industry entrepreneur') which lobbied against the legislation and the tobacco industry (Baltesen \& Rosenberg, 2009). Tobacco industry attempts to prevent and undermine smoke-free legislation are not typical for the Netherlands (Gonzalez \& Glantz, 2011; Hyland, Barnoya, \& Corral, 2012; Schneider, Sebrie, \& Fernandez, 2011). However, the success of these efforts may have been caused by the Dutch political context in which interest groups have a relatively strong influence on policy-making (Andeweg \& Irwin, 2009). Coupled with the Dutch culture of tolerance and consensus (Andeweg \& Irwin, 2009; Social \& Cultural Planning Office, 2001), it may have been more difficult in the Netherlands to ignore the calls of the hospitality and tobacco industries for a partial smoke-free policy instead of comprehensive legislation.

Findings from studies in this thesis suggest that following the WHO recommendations about smoke-free legislation has a positive effect on smoking cessation (chapters 3 and 4), support for smoke-free legislation (chapter 6), and compliance with the legislation (chapter 9) (Figure 4). Therefore, it is plausible that the smoke-free legislation would have been successful in the Netherlands had the WHO policy recommendations been followed through. As long as there are no countries that followed these recommendations and were not successful, there is no reason not to believe than with proper implementation "it can be done everywhere" (Smoke Free Partnership, 2006). 
Figure 4: The various effects that full adherence to the smoke-free policy recommendations from the WHO (World Health Organization, 2007b) may have on smoking cessation, support for smoke-free legislation, and compliance with the legislation.

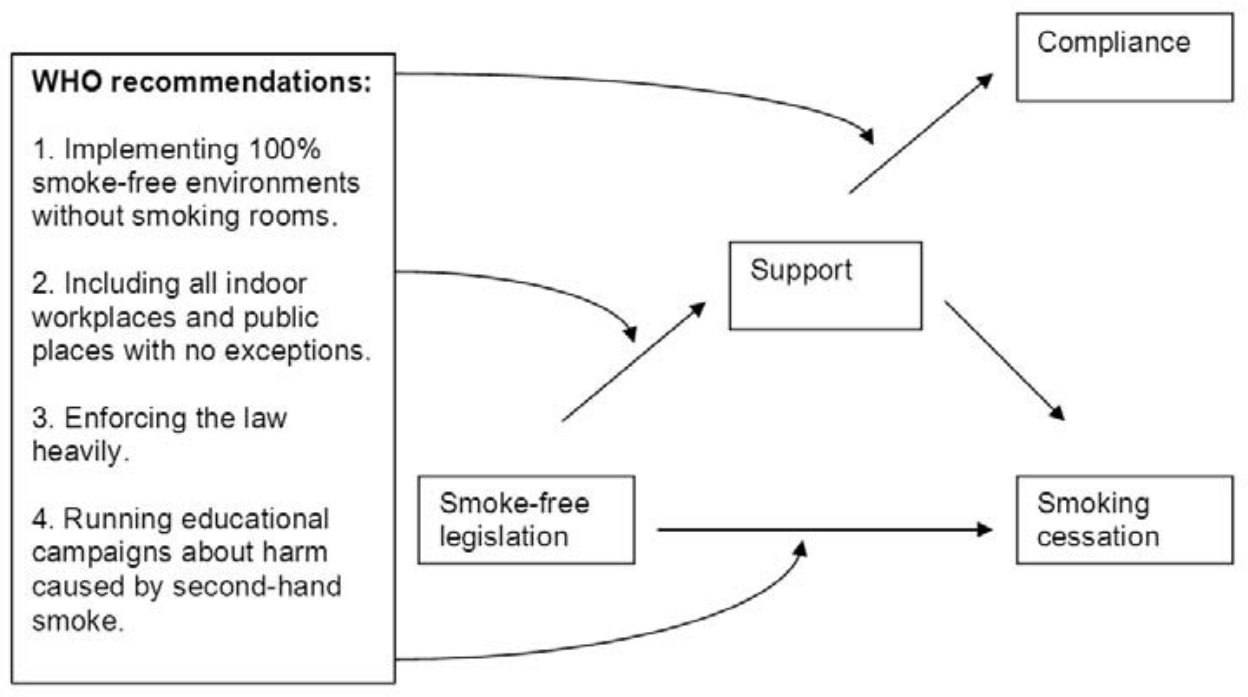

\section{Methodological issues}

Methodological limitations of the studies in this thesis have been reported separately in each study. The most important issues are discussed here.

Disentangling the effects of interventions that are implemented at the same time is difficult. In the Netherlands, smoke-free legislation was implemented simultaneously with a smoking cessation campaign and a tobacco tax increase. The effects of these interventions cannot be disentangled with the cross-sectional data from the Dutch Continuous Survey of Smoking Habits (DCSSH). In principle, it is possible to separate effects from different interventions with longitudinal data from the ITC Project by classifying respondents according to their exposure to different interventions. However, more factors influence smoking than only the interventions that are measured in these studies and it is impossible to control for all these influences (Chapman, 1993). The SimSmoke simulation model controls for the most important tobacco control influences, but because empirical studies often evaluate the effect of only one intervention (Levy et al., 2005), there is little evidence about how policies depend on other policies already in place or about the synergistic effects of policies implemented simultaneously (Levy et al., 2006). Therefore, the SimSmoke model makes the conservative assumption that the effects of most policies are independent of other policies. The SimSmoke model does assume that the effects of policies are magnified by publicity about the policies and 
media campaigns (U.S. Department of Health and Human Services, 2000), but more empirical studies are needed that explicitly take publicity and media campaigns into account when evaluating the effects of policies.

Second, it is important to take secular trends into account when examining smoking behaviour. The ITC surveys in the Netherlands, Germany, France, and Ireland only had one survey wave before the implementation of smoke-free legislation and could therefore not control for secular trends in the same country. The studies in chapters 4, 6, and 11 used a control country as an attempt to control for secular trends, but secular trends may have been different in that country. Also, different survey months and years between countries and different time intervals between survey waves and between the implementation of smoke-free legislation and postban waves complicate comparisons of trends across countries. Although we could take secular trends into account using data from the DCSSH study, a change in the sampling strategy of the survey from 2009 prevented us from examining longterm trends after the implementation of smoke-free hospitality industry legislation in 2008.

The ITC Project measures many aspects of smoking and tobacco control. All FCTC policies are examined by using several policy-specific questions per policy in the ITC Surveys. The downside is that the surveys become very lengthy and compromises have to be made with respect to the number of items used to measure one concept. For example, social acceptability of smoking was measured with three items, while it was clear that each item measured a very different aspect of the social acceptability of smoking (chapter 8). Also, ITC researchers in different countries make different choices about which items to include in their ITC Surveys. Therefore, we could not always include every country in our analyses when we wanted to compare specific items. Moreover, we could not always include every potentially relevant item when we wanted to compare specific countries.

Each study in this thesis was based on survey research that used selfreported measures. Self-reported measures are sometimes biased because of social desirability and recall problems (Adams, Soumerai, Lomas, \& Ross-Degnan, 1999). For example, smoking inside bars and homes can be considered socially undesirable, which may cause underreporting. Also, exposure to smoke-free legislation and campaigns may not always be remembered at the time of the survey. Although this may cause underreporting of exposure to smoke-free legislation, it will probably not affect results about the impact of exposure to smoke-free legislation on smoking cessation and the pathways of change.

Finally, in the ITC Netherlands Survey we were only able to retain half of the baseline respondents in wave 5 of the survey which could introduce selection bias 
into the inferences from the survey. Respondents lost to follow-up were more likely to be younger, female, more highly educated, and less heavy smokers. Therefore, results from follow-up waves may not be fully generalisable to the broader population of Dutch smokers. This is handled by the ITC methodology of replenishing the sample after attrition to ensure a generalisable sample with a constant sample size across waves (Thompson et al., 2006).

\section{Research priorities}

Both the Population Model of Tobacco Control (Willemsen, 2011) and the ITC Conceptual Model (Fong et al., 2006) assume that social norms are an important mediator of the effect of tobacco control policies on smoking cessation. However, only a few studies have empirically tested this mediating role of social norms. The studies in chapters 8 and 10 have begun to explore this research area, but further research is warranted. Findings from chapter 8 demonstrate that there are different aspects to the social norms or social acceptability of smoking. Future research should attempt to measure these aspects separately with validated measures and further determine the role of social norms and denormalisation in reducing smoking in the population. The study in chapter 10 is the first to examine the full causal chain from individual exposure to tobacco control policy through policy-specific variables and psychosocial mediators (like social norms) on smoking cessation. The role of social norms in the full causal chain from exposure to policies on smoking cessation should also be explored for policies other than smoke-free legislation. Furthermore, social norms should not only be studied on the individual level, but also on the macro level. For example, the relatively tolerant attitude in the Netherlands towards smokers may have its roots in the broader socio-cultural and political environment. Ecological studies that examine these macro-level determinants may provide insights into the possible consequences of including a denormalisation strategy in the national tobacco control strategy in the Netherlands.

As socioeconomic inequalities in smoking are widening (chapter 13), it is important to find effective ways to prevent low SES groups from initiating smoking and to stimulate low SES smokers to quit smoking. Tobacco tax increases are the only tobacco control policy which we know with sufficient certainty to be more effective among low SES groups (Amos et al., 2011; Chaloupka, Straif, \& Leon; Thomas et al., 2008). Only a small amount of studies about the impact of tobacco control interventions have examined socioeconomic differences, and most examined individual-level cessation support rather than population-level tobacco control interventions (Amos et al., 2011). More research is therefore needed on the differential effectiveness of various tobacco control policies. Research should focus 
not only on educational inequalities (as was primarily the case in this thesis), but also on income inequalities (Schaap \& Kunst, 2009). Furthermore, tobacco control policies' effects on socioeconomic inequalities in smoking should be studied in different countries and cultural contexts to assist policymakers in prioritising which policies should be implemented in their country. Such research can also assist in developing effective new interventions for low SES groups. For example, it has been suggested that media campaigns specifically targeted at low SES groups can be effective in reducing socioeconomic inequalities, and that a tobacco control strategy that uses a combination of interventions is likely to be most effective (Hiscock, Bauld, Amos, Fidler, \& Munafò, 2012). More specifically, it has been proposed that media campaigns should contain emotionally evocative and personal stories to reduce socioeconomic inequalities in smoking (Durkin, Biener, \& Wakefield, 2009). More research is needed to test these assumptions.

The total impact of implementing several tobacco control policies simultaneously is probably greater than the sum of the impact of implementing each policy separately. However, few studies have examined synergies between tobacco control policies (Levy et al., 2006). An example of synergy is the fact that publicity and campaigns about policies are expected to magnify the effect of policies. Chapter 7 has begun to explore the effects of publicity and campaigns about the smoke-free hospitality industry legislation in the Netherlands. Publicity and campaigns are expected to contribute to the success of smoke-free legislation, but the effects of publicity and campaigns are rarely evaluated in such a way that they can be separated from the effects of the legislation (Kosir \& Gutierrez, 2009; Thrasher et al., 2011). More knowledge about synergies from publicity and campaigns with tobacco control policies can be very important for tobacco control advocates. Tobacco control advocates often have little direct influence on policy implementation, but they can advocate for policy change by using the media (Dorfman, 2003). Also, evidence about synergies between various tobacco control policies can be important for policymakers who want to develop a comprehensive tobacco control strategy.

\section{Policy recommendations}

Support for smoke-free legislation among smokers is a crucial factor in ensuring compliance with smoke-free legislation, in stimulating the implementation of voluntary home smoking bans and in changing psychosocial determinants of smoking cessation. Therefore, policymakers should plan upfront how to ensure that smokers are more supportive of smoke-free legislation. Because media attention can both help and hinder in creating support for smoke-free legislation and the 
tobacco industry will also attempt to win over public opinion, a coordinated media advocacy strategy is needed (Crosbie, Sebrié, \& Glantz; Currie \& Clancy, 2010; Fahy et al., 2009). The timing of the implementation of smoke-free legislation is also important. If few smokers support smoke-free legislation it is likely to fail. As Kagan and Skolnick comment: "Like surfers, legislators and corporate officials who wish to change everyday social norms must wait for signs of a rising wave of cultural support, catching it at just the right time. Legislate too soon and they will be swamped by the swells of public resistance. Legislate too late and they will be irrelevant. Legislate at the right moment and an emerging cultural norm still tentatively struggling for authority . . . acquires much greater social force." (Kagan \& Skolnick, 1993).

Countries without smoke-free legislation in public places and workplaces should implement smoke-free legislation according to the recommendations from the WHO (World Health Organization, 2007b): 100\% smoke-free legislation without smoking rooms, without exceptions, with adequate enforcement, and with a campaign that educates the public about the harms of second-hand smoke. Ireland implemented national comprehensive smoke-free legislation in all workplaces in one legislative action without exceptions for the hospitality industry. Despite the Irish 'pub culture', compliance rates were excellent and a large majority of the Irish population supported the legislation (Allwright, 2004). At the end of $2008,80 \%$ of the Irish population supported smoke-free bars, whereas in the Netherlands only $44 \%$ of the population was supportive of smoke-free bars (European Commission, 2009).

Countries that currently have partial smoke-free legislation should acknowledge that the policy is not effectively protecting non-smokers from secondhand smoke and should announce the implementation of new comprehensive smokefree legislation. Spain is an example of a country that implemented comprehensive smoke-free legislation as recommended by the WHO (Fernández \& Nebot, 2011) after policy makers recognised that the partial smoke-free legislation that was in place was not working (López et al., 2011). The partial smoke-free legislation in Germany was based on the old 'Spanish model' that was, according to the tobacco industry, working well for everyone (Schneider, Sebrie, \& Fernandez, 2011). In turn, the Dutch exemption for small bars is based on the 'German model' (VVD-CDA, 2010). However, the new 'Spanish model' and the example of the German federal state, Bavaria, which implemented comprehensive smoke-free legislation despite the weak national law demonstrate that partial smoke-free legislation is not working and should be strengthened. The Netherlands should follow the examples of Spain and Bavaria and implement comprehensive smoke-free legislation. If it can be done elsewhere, it can be done everywhere. 


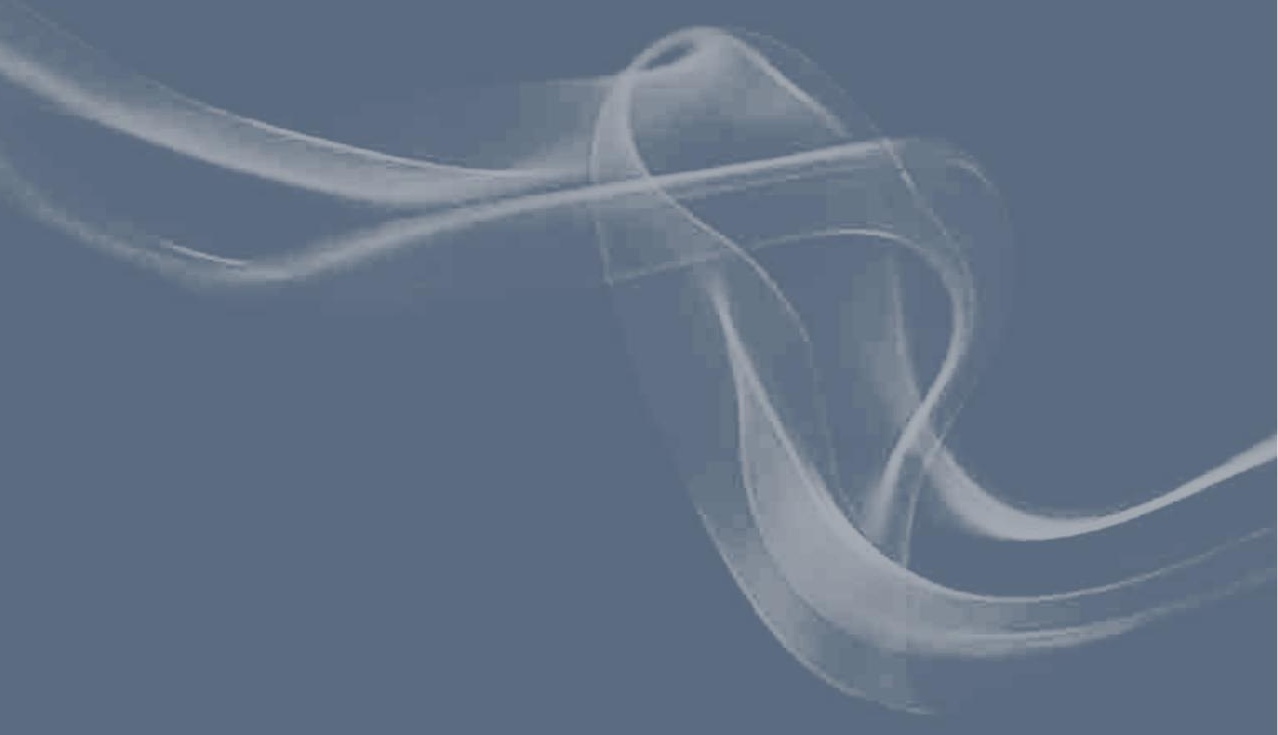

| 254 | 
References

$\sim \sim \sim$ 


\section{References}

Adams, A., Soumerai, S., Lomas, J., \& Ross-Degnan, D. (1999). Evidence of self-report bias in assessing adherence to guidelines. International Journal for Quality in Health Care, 11, 187-192.

Adda, J., \& Cornaglia, F. (2010). The effect of bans and taxes on passive smoking. American Economic Journal: Applied Economics, 2, 1-32.

Ahmad, S. (2005). Increasing excise taxes on cigarettes in California: A dynamic simulation of health and economic impacts. Preventive Medicine, 41, 276-283.

Ahmad, S., \& Billimek, J. (2005). Estimating the health impacts of tobacco harm reduction policies: A simulation modeling approach. Risk Analysis, 25, 801-812.

Aiken, L., \& West, S. (1991). Multiple Regression: Testing and Interpreting Interactions. Newbury Park, CA: Sage Publications.

Ajzen, I. (1991). The Theory of Planned Behavior. Organizational Behavior Human Decision Processes, 50, 179-211.

Akhtar, P. C., Haw, S. J., Currie, D. B., Zachary, R., \& Currie, C. E. (2009). Smoking restrictions in the home and secondhand smoke exposure among primary schoolchildren before and after introduction of the Scottish smoke-free legislation. Tobacco Control, 18, 409-415.

Alamar, B., \& Glantz, S. A. (2006). Effect of increased social unacceptability of cigarette smoking on reduction in cigarette consumption. American Journal of Public Health, 96, 1359-1363.

Albers, A. B., Siegel, M., Cheng, D. M., Biener, L., \& Rigotti, N. A. (2004). Relation between local restaurant smoking regulations and attitudes towards the prevalence and social acceptability of smoking: A study of youths and adults who eat out predominantly at restaurants in their town. Tobacco Control, 13, 347-355.

Alesci, N. L., Forster, J. L., \& Blaine, T. (2003). Smoking visibility, perceived acceptability, and frequency in various locations among youth and adults. Preventive Medicine, 36, 272-281.

Allwright, S. (2004). Republic of Ireland's indoor workplace smoking ban. British Journal of General Practice, 54, 811-812.

American Cancer Society (2003). Tobacco control strategy planning guide \#1. Strategy planning for tobacco control advocacy. American Cancer Society \& International Union Against Cancer.

Amos, A., Bauld, L., Clifford, D., Fidler, J., Hill, S., Hiscock, R. et al. (2011). Tobacco control, inequalities in health and action at the local level in England. York: Public Health Research Consortium.

Andeweg, R. B., \& Irwin, G. A. (2009). Governance and politics of the Netherlands. Houndmills, Basingstoke, Hampshire: Palgrave Macmillan.

Andreou, G., Gourgoulianis, K., \& Galantomos, I. (2010). The "language" of the unsuccessful anti-smoking campaign in Greece: Examples from Greek newspaper headlines. Preventive Medicine, 51, 336-337.

Armitage, C. J., \& Conner, M. (2001). Efficacy of the Theory of Planned Behaviour: A meta-analytic review. British Journal of Social Psychology, 40, 471-499.

Arnott, D., Berteletti, F., Britton, J., Cardone, A., Clancy, L., Craig, L. et al. (2011). Can the Dutch government really be abandoning smokers to their fate? The Lancet, 379(9811), 121-122.

Baha, M., \& Le Faou, A. L. (2010). Smokers' reasons for quitting in an anti-smoking social context. Public Health, 124, 225-231.

Bajoga, U., Lewis, S., McNeill, A., \& Szatkowski, L. (2011). Does the introduction of comprehensive smokefree legislation lead to a decrease in population smoking prevalence? Addiction, 106, 
1346-1354.

Baltesen, F., \& Rosenberg, E. (2009). Tabakssector betaalt verzet rookverbod [Big tobacco pays Dutch opposition to smoking ban]. NRC Handelsblad, p. 1.

Bandura, A. (1986). Social foundations of thought and action: A Social Cognitive Theory. New York: Prentice Hall.

Bauld, L. (2011). The impact of smokefree legislation in England: Evidence review. Bath: University of Bath.

Bayer, R. (2008). Stigma and the ethics of public health: Not can we but should we. Social Science \& Medicine, 67, 463-472.

Bell, K., McCullough, L., Salmon, A., \& Bell, J. (2010). 'Every space is claimed': Smokers' experiences of tobacco denormalisation. Sociology of Health \& IIIness, 32, 914-929.

Bennett, S. (1995). Cardiovascular risk factors in Australia: Trends in socioeconomic inequalities. Journal of Epidemiology and Community Health, 49, 363-372.

Berger, B. E., Ferrans, C. E., \& Lashley, F. R. (2001). Measuring stigma in people with HIV: Psychometric assessment of the HIV stigma scale. Research in Nursing \& Health, 24, 518-529.

Bettcher, D., \& Subramaniam, C. (2001). The necessity of global tobacco regulations. JAMA, $286,2737$.

Blake, K. D., Viswanath, K., Blendon, R. J., \& Vallone, D. (2010). The role of tobacco-specific media exposure, knowledge, and smoking status on selected attitudes toward tobacco control. Nicotine \& Tobacco Research, 12, 117-126.

Bledsoe, L. K. (2006). Smoking cessation: An application of Theory of Planned Behavior to understanding progress through stages of change. Addictive Behaviors, 31, 1271-1276.

Borland, R., Yong, H.-H., Cummings, K. M., Hyland, A., Anderson, S., \& Fong, G. T. (2006). Determinants and consequences of smoke-free homes: Findings from the International Tobacco Control (ITC) Four Country Survey. Tobacco Control, 15(Suppl 3), 42-50.

Borland, R., Yong, H.-H., Siahpush, M., Hyland, A., Campbell, S., Hastings, G. et al. (2006). Support for and reported compliance with smoke-free restaurants and bars by smokers in four countries: Findings from the International Tobacco Control (ITC) Four Country Survey. Tobacco Control, 15(Suppl 3), 34-41.

Braverman, M. T., Aaro, L. E., Bontempo, D. E., \& Hetland, J. (2010). Bar and restaurant workers' attitudes towards Norway's comprehensive smoking ban: A growth curve analysis. Tobacco Control, 19, 240-247.

Braverman, M. T., Aaro, L. E., \& Hetland, J. (2008). Changes in smoking among restaurant and bar employees following Norway's comprehensive smoking ban. Health Promotion International, 23, 5-15.

Brooks, D., \& Mucci, L. (2001). Support for smoke-free restaurants among Massachusetts adults, 19921999. American Journal of Public Health, 91, 300-303.

Brown, A., Moodie, C., \& Hastings, G. (2009). A longitudinal study of policy effect (smoke-free legislation) on smoking norms: ITC Scotland/United Kingdom. Nicotine \& Tobacco Research, 11, 924-932.

Brownson, R. C., Eriksen, M. P., Davis, R. M., \& Warner, K. E. (1997). Environmental tobacco smoke: Health effects and policies to reduce exposure. Annual Review of Public Health, 18, 163-185.

California Department of Health Services (1998). A model for change: The California experience in tobacco control. California: California Department of Health Services / Tobacco Control Section.

Callinan, J. E., Clarke, A., Doherty, K., \& Kelleher, C. (2010). Legislative smoking bans for reducing 
secondhand smoke exposure, smoking prevalence and tobacco consumption. Cochrane Database of Systematic Reviews, Issue 4.

Capannesi, M., Boshuizen, H. C., Willemsen, M. C., \& Van Houwelingen, H. C. (2009). How to obtain long term projections for smoking behaviour: A case study in the Dutch population.

Computational and Mathemethical Methods in Medicine, 10, 155-164.

Chaloupka, F. J., Grossman, M., Pacula, R., Wechsler, H., Saffer, H., Tauras, J. et al. (1996). Price, tobacco control policies and youth smoking. ImpacTeen Reports Paper Series. Chicago: University of Illinois.

Chaloupka, F. J., Straif, K., \& Leon, M. E. (2011). Effectiveness of tax and price policies in tobacco control. Tobacco Control, 20, 235-238.

Chan, S. S. C., Wong, D. C. N., Fong, D. Y. T., Leung, A. Y. M., Mak, Y.-W., Lam, D. O. B. et al. (2009). Short-term impact of new smoke-free legislation on the utilization of a quitline in Hong Kong. Nicotine \& Tobacco Research, 11, 356-361.

Chandola, T., Head, J., \& Bartley, M. (2004). Socio-demographic predictors of quitting smoking: How important are household factors? Addiction, 99, 770-777.

Chandra, S., \& Chaloupka, F. J. (2003). Seasonality in cigarette sales: Patterns and implications for tobacco control. Tobacco Control, 12, 105-107.

Chapman, S. (1993). Unravelling gossamer with boxing gloves: Problems in explaining the decline in smoking. BMJ, 307(6901), 429-432.

Chapman, S., Borland, R., Scollo, M., Brownson, R. C., Dominello, A., \& Woodward, S. (1999). The impact of smoke-free workplaces on declining cigarette consumption in Australia and the United States. American Journal of Public Health, 89, 1018-1023.

Chapman, S., \& Freeman, B. (2008). Markers of the denormalisation of smoking and the tobacco industry. Tobacco Control, 17, 25-31.

Cheraghi, M., \& Salvi, S. (2009). Environmental tobacco smoke (ETS) and respiratory health in children. European Journal of Pediatrics, 168, 897-905.

Christakis, N. A., \& Fowler, J. H. (2008). The collective dynamics of smoking in a large social network. The New England Journal of Medicine, 358, 2249-2258.

Cilcote, S. (1985). Public Smoking: The Problem (SDC Introduction). Tobacco Institute, Bates Range TIMN0014552/4597. http://legacy.library.ucsf.edu/tid/yai76b00 (Accessed 14 Sep 2011).

Clegg-Smith, K., Siebel, C., Pham, L., Cho, J., Singer, R. F., Chaloupka, F. J. et al. (2008). News on tobacco and public attitudes towards smokefree air policies in the United States. Health Policy, 86, 42-52.

Cooper, J., Borland, R., Yong, H. H., \& Hyland, A. (2010). Compliance and support for bans on smoking in licensed venues in Australia: Findings from the International Tobacco Control Four-Country Survey. Australian and New Zealand Journal of Public Health, 34, 379-385.

Currie, L. M., \& Clancy, L. (2010). The road to smoke-free legislation in Ireland. Addiction, 106, 15-24.

De Vries, H., \& Mudde, A. N. (1998). Predicting stage transitions for smoking cessation applying the attitude-social influence-efficacy model. Psychology \& Health, 13, 369-385.

De Vries, H., Mudde, A. N., Dijkstra, A., \& Willemsen, M. C. (1998). Differential beliefs, perceived social influences, and self-efficacy expectations among smokers in various motivational phases. Preventive Medicine, 27, 681-689.

Doll, R., \& Hill, B. (1950). Smoking and carcinoma of the lung: Preliminary report. British Medical Journal, 2(4682), 739-748. 
Doll, R., Peto, R., Boreham, J., \& Sutherland, I. (2004). Mortality in relation to smoking: 50 years' observations on male British doctors. BMJ, 328, 1519.

Dorfman, L. (2003). Studying the news on public health: How content analysis supports media advocacy. American Journal of Health Behavior, 27(Suppl 3), 217-226.

Dunlop, S. M., \& Romer, D. (2010). Relation between newspaper coverage of 'light' cigarette litigation and beliefs about 'lights' among American adolescents and young adults: The impact on risk perceptions and quitting intentions. Tobacco Control, 19, 267-273.

Durkin, S. J., Biener, L., \& Wakefield, M. A. (2009). Effects of different types of antismoking ads on reducing disparities in smoking cessation among socioeconomic subgroups. American Journal of Public Health, 99, 2217-2223.

Eadie, D., Heim, D., MacAskill, S., Ross, A., Hastings, G., \& Davies, J. (2008). A qualitative analysis of compliance with smoke-free legislation in community bars in Scotland: Implications for public health. Addiction, 103, 1019-1026.

Edwards, R., Thomson, G., Wilson, N., Waa, A., Bullen, C., O'Dea, D. et al. (2008). After the smoke has cleared: Evaluation of the impact of a new national smoke-free law in New Zealand. Tobacco Control, 17, e2.

Elton, P. J., \& Campbell, P. (2008). Smoking prevalence in a north-west town following the introduction of Smoke-free England. Journal of Public Health, 30, 415-420.

ENSP (2009). European trends towards smoke-free provisions. Brussels: European Network for Smoking Prevention.

Eriksen, M. P., \& Gottlieb, N. H. (1998). A review of the health impact of smoking control at the workplace. American Journal of Health Promotion, 13, 83-104.

Etter, J.-F., \& Perneger, T. V. (2001). A comparison of cigarette smokers recruited through the Internet or by mail. International Journal of Epidemiology, 30, 521-525.

European Commission (2007). Green paper. Towards a Europe free from tobacco smoke: Policy options at EU level. Brussels: European Commission.

European Commission (2009). Survey on tobacco: Analytical report. Eurobarometer \#253. Hungary: The Gallup Organisation.

European Commission (2010). Tobacco. Eurobarometer \#332. Brussels: TNS Opinion \& Social.

Ezzati, M., \& Lopez, A. D. (2003). Estimates of global mortality attributable to smoking in 2000. Lancet, 362, 847-852.

Fahy, D., Trench, B., \& Clancy, L. (2009). Communicating contentious health policy: Lessons from Ireland's workplace smoking ban. Health Promotion Practice. Published Online First: 8 October 2009.

Farkas, A. J., Gilpin, E. A., Distefan, J. M., \& Pierce, J. P. (1999). The effects of household and workplace smoking restrictions on quitting behaviours. Tobacco Control, 8, 261-265.

Farrelly, M., Pechacek, T., \& Chaloupka, F. (2003). The impact of tobacco control program expenditures on aggregate cigarette sales: 1981-2000. Journal of Health Economics, 22, 843-849.

Farrelly, M. C., Evans, W. N., \& Sfekas, A. E. S. (1999). The impact of workplace smoking bans: Results from a national survey. Tobacco Control, 8, 272-277.

Farrimond, H. R., \& Joffe, H. (2006). Pollution, peril and poverty: A British study of the stigmatization of smokers. Journal of Community \& Applied Social Psychology, 16, 481-491.

Federico, B., Costa, G., \& Kunst, A. E. (2007). Educational inequalities in initiation, cessation, and prevalence of smoking among 3 Italian birth cohorts. American Journal of Public Health, 97, 
838-845.

Fernández, E., Fu, M., Pascual, J. A., Lopéz, M. J., Pérez-Ríos, M., Schiaffino, A. et al. (2009). Impact of the Spanish smoking law on exposure to second-hand smoke and respiratory health in hospitality workers: A cohort study. PLoS ONE, 4, e4244.

Fernández, E., \& Nebot, M. (2011). Spain: Beyond the 'Spanish model' to a total ban. Tobacco Control, 20, 6-7.

Ferrante, D., Linetzky, B., Virgolini, M., Schoj, V., \& Apelberg, B. (2011). Reduction in hospital admissions for acute coronary syndrome after the successful implementation of $100 \%$ smoke-free legislation in Argentina: A comparison with partial smoking restrictions. Tobacco Control. Published Online First: 20 May 2011.

Fichtenberg, C. M., \& Glantz, S. A. (2002). Effect of smoke-free workplaces on smoking behaviour: Systematic review. BMJ, 325(7357), 188.

Fong, G. T., Cummings, K. M., \& Shopland, D. R. (2006). Building the evidence base for effective tobacco control policies: The International Tobacco Control Policy Evaluation Project (the ITC Project). Tobacco Control, 15(Suppl 3), 1-2.

Fong, G. T., Cummings, M., Borland, R., Hastings, G., Hyland, A., Giovino, G. et al. (2006). The conceptual framework of the International Tobacco Control (ITC) Policy Evaluation Project. Tobacco Control, 15(Suppl 3), 3-11.

Fong, G. T., Hyland, A., Borland, R., Hammond, D., Hastings, G., McNeill, A. et al. (2006). Reductions in tobacco smoke pollution and increases in support for smoke-free public places following the implementation of comprehensive smoke-free workplace legislation in the Republic of Ireland: Findings from the ITC Ireland/UK Survey. Tobacco Control, 15(Suppl 3), 51-58.

Fowkes, F. J. I., Stewart, M. C. W., Fowkes, F. G. R., Amos, A., \& Price, J. F. (2008). Scottish smoke-free legislation and trends in smoking cessation. Addiction, 103, 1888-1895.

Galán, I., Mata, N., Estrada, C., Díez-Gañán, L., Velázquez, L., Zorrilla, B. et al. (2007). Impact of the «Tobacco control law» on exposure to environmental tobacco smoke in Spain. BMC Public Health, 7, 224.

Galeone, D., Laurendi, G., Vasselli, S., Spizzichino, L., D’Argenio, P., \& Greco, D. (2006). Preliminary effects of Italy's ban on smoking in enclosed public places. Tobacco Control, 15, 143.

Gallus, S., Zuccaro, P., Colombo, P., Apolone, G., Pacifici, R., Garattini, S. et al. (2007). Smoking in Italy 2005-2006: Effects of a comprehensive national tobacco regulation. Preventive Medicine, 45, 198-201.

German Constitutional Court (2008). Decision of the First Senate from July 30th 2008. Karlsruhe: German Constitutional Court.

Gilman, S. E., Abrams, D. B., \& Buka, S. L. (2003). Socioeconomic status over the life course and stages of cigarette use: Initiation, regular use, and cessation. Journal of Epidemiology and Community Health, 57, 802-808.

Giskes, K., Kunst, A. E., Ariza, C., Benach, J., Borrell, C., Helmert, U. et al. (2007). Applying an equity lens to tobacco-control policies and their uptake in six Western-European countries. Journal of Public Health Policy, 28, 261-280.

Giskes, K., Kunst, A. E., Benach, J., Borrell, C., Costa, G., Dahl, E. et al. (2005). Trends in smoking behaviour between 1985 and 2000 in nine European countries by education. Journal of Epidemiology and Community Health, 59, 395-401.

Gleich, F., Mons, U., \& Pötschke-Langer, M. (2011). Air contamination due to smoking in German 
restaurants, bars, and other venues - Before and after the implementation of a partial smoking ban. Nicotine \& Tobacco Research, 13, 1155-1160.

Goffman, E. (1974). Frame analysis: An essay on the organization of experience. New York: Harper University Press.

Goldstein, J. (1991). The stigmatization of smokers: An empirical investigation. Journal of Drug Education, $21,167-182$.

Gonzalez, M., \& Glantz, S. A. (2011). Failure of policy regarding smokefree bars in the Netherlands. European Journal of Public Health. Published Online First: 5 December 2011.

Gottlieb, N. H., Lovato, C. Y., Weinstein, R., Green, L. W., \& Eriksen, M. P. (1992). The implementation of a restrictive worksite smoking policy in a large decentralized organization. Health Education \& Behavior, 19, 77-100.

Hackshaw, L., McEwen, A., West, R., \& Bauld, L. (2010). Quit attempts in response to smoke-free legislation in England. Tobacco Control, 19, 160-164.

Hahn, E. J., Rayens, M. K., Butler, K. M., Zhang, M., Durbin, E., \& Steinke, D. (2008). Smoke-free laws and adult smoking prevalence. Preventive Medicine, 47, 206-209.

Hamilton, W. L., Biener, L., \& Brennan, R. T. (2008). Do local tobacco regulations influence perceived smoking norms? Evidence from adult and youth surveys in Massachusetts. Health Education Research, 23, 709-722.

Hammond, D. (2011). Health warning messages on tobacco products: A review. Tobacco Control, 20, 327-337.

Hammond, D., Fong, G. T., Zanna, M. P., Thrasher, J. F., \& Borland, R. (2006). Tobacco denormalization and industry beliefs among smokers from four countries. American Journal of Preventive Medicine, 31, 225-232.

Hanley, J. A., Negassa, A., Edwardes, M. D., \& Forrester, J. E. (2003). Statistical analysis of correlated data using Generalized Estimating Equations: An orientation. American Journal of Epidemiology, 157, 364-375.

Hardin, J. W., \& Hilbe, J. M. (2003). Generalized Estimating Equations. Boca Raton, FL: Chapman \& Hall/ CRC.

Harper, S., \& Lynch, J. (2007). Trends in socioeconomic inequalities in adult health behaviors among U.S. states, 1990-2004. Public Health Reports, 122, 177-189.

Harris, J. K., Shelton, S. C., Moreland-Russell, S., \& Luke, D. A. (2010). Tobacco coverage in print media: The use of timing and themes by tobacco control supporters and opposition before a failed tobacco tax initiative. Tobacco Control, 19, 37-43.

Haw, S. J., \& Gruer, L. (2007). Changes in exposure of adult non-smokers to secondhand smoke after implementation of smoke-free legislation in Scotland: National cross sectional survey. BMJ, 335, 549-552.

Heatherton, T. F., Kozlowski, L. T., Frecker, R. C., Rickert, W., \& Robinson, J. (1989). Measuring the heaviness of smoking: Using self-reported time to the first cigarette of the day and number of cigarettes smoked per day. British Journal of Addiction, 84, 791-800.

Heironimus, J. (1992). Impact of workplace restrictions on consumption and incidence (memo to Louis Suwarna). Philip Morris, Bates Range 2045447779/7806. http://legacy.library.ucsf.edu/tid/ ytw44e00 (Accessed 14 Sep 2011).

Hill, S. E., Blakely, T. A., Fawcett, J. M., \& Howden-Chapman, P. (2005). Could mainstream anti-smoking programs increase inequalities in tobacco use? New Zealand data from 1981-96. Australian 
and New Zealand Journal of Public Health, 29, 279-284.

Hirayama, T. (1981). Non-smoking wives of heavy smokers have a higher risk of lung cancer: A study from Japan. British Medical Journal, 282(6259), 183-185.

Hiscock, R., Bauld, L., Amos, A., Fidler, J. A., \& Munafò, M. (2012). Socioeconomic status and smoking: A review. Annals of the New York Academy of Sciences, 1248, 107-123.

Hitchman, S. C., Mons, U., Nagelhout, G. E., Guignard, R., Mcneill, A., Willemsen, M. C. et al. (2011). Effectiveness of the European Union text-only cigarette health warnings: Findings from four countries. European Journal of Public Health. Published Online First: 15 September 2011.

Ho, S. Y., Wang, M. P., Lo, W. S., Mak, K. K., Lai, H. K., Thomas, G. N. et al. (2010). Comprehensive smoke-free legislation and displacement of smoking into the homes of young children in Hong Kong. Tobacco Control, 19, 129-133.

Homer, J. B., \& Hirsch, G. B. (2006). System dynamics modeling for public health: Background and opportunities. American Journal of Public Health, 96, 452-458.

Hoogenveen, R. T., Van Baal, P. H., Boshuizen, H. C., \& Feenstra, T. L. (2008). Dynamic effects of smoking cessation on disease incidence, mortality and quality of life: The role of time since cessation. Cost Effectiveness and Resource Allocation, 6, 1.

Hopkins, D. P., Briss, P. A., Ricard, C. J., Husten, C. G., Carande-Kulis, V. G., Fielding, J. E. et al. (2001). Reviews of evidence regarding interventions to reduce tobacco use and exposure to environmental tobacco smoke. American Journal of Preventive Medicine, 20(Suppl 1), 16-66.

Hosking, W., Borland, R., Yong, H.-H., Fong, G., Zanna, M., Laux, F. et al. (2009). The effects of smoking norms and attitudes on quitting intentions in Malaysia, Thailand and four Western nations: A cross-cultural comparison. Psychology and Health, 24, 95-107.

Hoving, E., Mudde, A., \& De Vries, H. (2006). Smoking and the Phi-pattern; predictors of transitions through the stages of change. Health Education Research, 21(3), 305-314.

Howell, F. (2004). Ireland's workplaces, going smoke free. BMJ, 328, 847-848.

Howell, F., \& Allwright, S. (2005). Smoke-free public places in Ireland: How was it achieved and what has been learnt? In Royal College of Physicians Tobacco Advisory Group (Ed.), Going smokefree. The medical case for clean air in the home, at work and in public places. (pp. 185-196). London: Royal College of Physicians.

Hox, J. J., \& Bechger, T. M. (1998). An introduction to Structural Equation Modeling. Family Science Review, 11, 354-373.

Hu, T. W., Sung, H. Y., \& Keeler, T. E. (1995a). Reducing cigarette consumption in California: Tobacco taxes vs an anti-smoking media campaign. American Journal of Public Health, 85, 1218-1222.

Hu, T. W., Sung, H. Y., \& Keeler, T. E. (1995b). The state antismoking campaign and the industry response: The effects of advertising on cigarette consumption in California. The American Economic Review, 85, 85-90.

Hublet, A., Schmid, H., Clays, E., Godeau, E., Gabhainn, S. N., Joossens, L. et al. (2009). Association between tobacco control policies and smoking behaviour among adolescents in 29 European countries. Addiction, 104, 1918-1926.

Huisman, M., Kunst, A. E., \& Mackenbach, J. P. (2005a). Educational inequalities in smoking among men and women aged 16 years and older in 11 European countries. Tobacco Control, 14, 106-113.

Huisman, M., Kunst, A. E., \& Mackenbach, J. P. (2005b). Inequalities in the prevalence of smoking in the European Union: Comparing education and income. Preventive Medicine, 40, 756-764.

Hyland, A., Borland, R., Li, Q., Yong, H.-H., McNeill, A., Fong, G. T. et al. (2006). Individual-level predictors 
of cessation behaviours among participants in the International Tobacco Control (ITC) Four Country Survey. Tobacco Control, 15(Suppl 3), 83-94.

Hyland, A., Hassan, L. M., Higbee, C., Boudreau, C., Fong, G. T., Borland, R. et al. (2009). The impact of smokefree legislation in Scotland: Results from the Scottish ITC Scotland/UK longitudinal surveys. European Journal of Public Health, 19, 198-205.

Hyland, A., Higbee, C., Borland, R., Travers, M., Hastings, G., Fong, G. T. et al. (2009). Attitudes and beliefs about secondhand smoke and smoke-free policies in four countries: Findings from the International Tobacco Control Four Country Survey. Nicotine \& Tobacco Research, 11, 642-649.

Hyland, A., Li, Q., Bauer, J., Giovino, G., Bauer, U., \& Cummings, K. (2006). State and community tobacco-control programs and smoking-cessation rates among adult smokers: What can we learn from the COMMIT intervention cohort? American Journal of Health Promotion, 20, 272-281.

International Agency for Research on Cancer (2004). IARC monographs on the evaluation of carciongenic risks to humans, vol. 83: Tobacco smoke and involuntary smoking. Lyon: World Health Organization, International Agency for Research on Cancer.

International Agency for Research on Cancer (2009a). IARC handbooks of cancer prevention, tobacco control, vol. 13: Evaluating the effectiveness of smoke-free policies. Geneva: WHO Press.

International Agency for Research on Cancer (2009b). IARC handbooks of cancer prevention, tobacco control, vol. 12: Methods for evaluating tobacco control policies. Geneva: WHO Press.

ITC Project (2009a). ITC France National Report. Waterloo, Paris: University of Waterloo, Institut national de prévention et d'éducation pour la santé (INPES), Institut national du cancer (INCa), and Observatoire francais des drogues et des toxicomanies (OFDT).

ITC Project (2009b). ITC Netherlands Survey Waves 1-3 (2008-2009) Technical Report. Waterloo, Ontario, Canada.

ITC Project (2010a). ITC Germany National Report. Waterloo, Heidelberg: University of Waterloo, German Cancer Research Center.

ITC Project (2010b). ITC Netherlands National Report. Waterloo, The Hague: University of Waterloo, STIVORO.

ITC Project (2011). ITC Netherlands Survey. Report on smokers' awareness of the health risks of smoking and exposure to second-hand smoke. Waterloo: University of Waterloo.

Jaccard, J. (2001). Interaction effects in logistic regression. Sage university paper series on quantitative applications in the social sciences, series no. 07-135. Thousand Oaks, CA: Sage.

Janz, N., \& Becker, M. (1984). The Health Belief Model: A decade later. Health Education Quarterly, 11, $1-47$.

Jha, P., \& Chaloupka, F. (1999). Curbing the epidemic: Government and the economics of tobacco control. Washington, DC: World Bank.

Joossens, L., \& Raw, M. (2007). Progress in tobacco control in 30 European countries, 2005 to 2007. Bern: Swiss Cancer League.

Joossens, L., \& Raw, M. (2011). The Tobacco Control Scale 2010 in Europe. Paper presented at the fifth European Conference on Tobacco or Health, Amsterdam, the Netherlands.

Kagan, R. A., \& Skolnick, J. H. (1993). Banning smoking: Compliance without enforcement. In R. L. Rabin \& S. D. Sugarman (Eds.), Smoking policy: Law, politics \& culture (pp. 69-94). New York: Oxford University Press. 
Kluger, R. (1996). Ashes to ashes: America's hundred-year cigarette war, the public health, and the unabashed triumph of Philip Morris. New York: Alfred A. Knopf.

Kosir, M., \& Gutierrez, K. (2009). Lessons learned globally: Secondhand smoke mass media campaigns. Saint Paul, Minnesota, United States: Global Dialogue for Effective Stop Smoking Campaigns.

Krasnegor, N. A. (1979). Cigarette smoking as a dependence process. Rockville, Maryland: U.S.

Department of Health, Eduction, and Welfare, Public Health Service, Alcohol, Drug Abuse, and Mental Health Administration, National Institute on Drug Abuse.

Kunst, A., Giskes, K., \& Mackenbach, J. (2004). Socio-economic inequalities in smoking in the European Union. Applying an equity lens to tobacco control policies. Rotterdam: Erasmus Medical Center Rotterdam.

Larsson, M., Boethius, G., Axelsson, S., \& Montgomery, S. M. (2008). Exposure to environmental tobacco smoke and health effects among hospitality workers in Sweden - before and after the implementation of a smoke-free law. Scandinavian Journal of Work, Environment \& Health, 34, 267-277.

Lavack, A. M. (1999). De-normalization of tobacco in Canada. Social Marketing Quarterly, 5, 82-85.

Lee, J. T., Glantz, S. A., \& Millett, C. (2011). Effect of smoke-free legislation on adult smoking behaviour in England in the 18 Months following implementation. PLOS ONE, 6(6), e20933.

Lemstra, M., Neudorf, C., \& Opondo, J. (2008). Implications of a public smoking ban. Canadian Journal of Public Health, 99, 62-65.

Lennox, A. (1992). Determinants of outcome in smoking cessation. British Journal of General Practice, 42, 247-252.

Levin, M., Goldstein, H., \& Gerhardt, P. (1950). Cancer and tobacco smoking. JAMA, 143, 336-338.

Levy, D., Blackman, K., Currie, L., Clancy, L., \& Willemsen, M. (2011). The Netherlands SimSmoke: The effect of tobacco control policies on smoking prevalence and tobacco attributable deaths in the Netherlands. Soon available at www.PPACTE.eu.

Levy, D. T., Bauer, J., Ross, H., \& Powell, L. (2007). The role of public policies in reducing smoking prevalence and deaths caused by smoking in Arizona: Results from the Arizona tobacco policy simulation model. Journal of Public Health Management and Practice, 13, 59-67.

Levy, D. T., Bauer, J. E., \& Lee, H.-R. (2006). Simulation modeling and tobacco control: Creating more robust public health policies. American Journal of Public Health, 96, 494-498.

Levy, D. T., Benjakul, S., Ross, H., \& Ritthiphakdee, B. (2008). The role of tobacco control policies in reducing smoking and deaths in a middle income nation: Results from the Thailand SimSmoke simulation model. Tobacco Control, 17, 53-59.

Levy, D. T., Chaloupka, F., \& Gitchell, J. (2004). The effects of tobacco control policies on smoking rates: A tobacco control scorecard. Journal of Public Health Management and Practice, 10, 338-353.

Levy, D. T., Chaloupka, F., Gitchell, J., Mendez, D., \& Warner, K. E. (2002). The use of simulation models for the surveillance, justification and understanding of tobacco control policies. Health Care Management Science, 5, 113-120.

Levy, D. T., Cho, S., Kim, Y.-M., Park, S., Suh, M.-K., \& Kam, S. (2010). An evaluation of the impact of tobacco control policies in Korea using the SimSmoke model: The unknown success story. American Journal of Public Health, 100, 1267-1273.

Levy, D. T., \& Friend, K. B. (2003). The effects of clean indoor air laws: What do we know and what do we need to know? Health Education Research, 18, 592-609.

Levy, D. T., Hyland, A., Higbee, C., Remer, L., \& Compton, C. (2007). The role of public policies in 
reducing smoking prevalence in California: Results from the California tobacco policy simulation model. Health Policy, 82, 153-166.

Levy, D. T., Nikolayev, L., \& Mumford, E. (2005). Recent trends in smoking and the role of public policies: Results from the SimSmoke tobacco control policy simulation model. Addiction, 100, 1526-1536.

Levy, D. T., Tworek, C., Hahn, E., \& Davis, R. (2008). The Kentucky SimSmoke tobacco policy simulation model: Reaching healthy people 2010 goals through policy change. Southern Medical Journal, 101, 503-507.

Lewis, S. A., Haw, S. J., \& McNeill, A. (2008). The impact of the 2006 Scottish smoke-free legislation on sales of nicotine replacement therapy. Nicotine \& Tobacco Research, 10, 1789-1792.

Li, X., Li, Q., Dong, L., Sun, B., Chen, J., Yuan, J. et al. (2010). Risk factors associated with smoking behavior in recreational venues: Findings from the International Tobacco Control (ITC) China Survey. Tobacco Control, 19(Suppl 2), 30-39.

Liang, K. Y., \& Zeger, S. L. (1986). Longitudinal data using Generalized Linear Models. Biometrika, 73, 13-22.

Ling, P. M., \& Glantz, S. A. (2002). Nicotine addiction, young adults, and smoke-free bars. Drug and Alcohol Review, 21, 101-104.

Link, B. G., \& Phelan, J. C. (2001). Conceptualizing stigma. Annual Review of Sociology, 27, 363-385.

Longo, D. R., Johnson, J. C., Kruse, R. L., Brownson, R. C., \& Hewett, J. E. (2001). A prospective investigation of the impact of smoking bans on tobacco cessation and relapse. Tobacco Control, 10, 267-272.

Lopez, A. D., Collishaw, N. E., \& Piha, T. (1994). A descriptive model of the cigarette epidemic in developed countries. Tobacco Control, 3, 242-247.

López, M. J., Nebot, M., Schiaffino, A., Pérez-Ríos, M., Fu, M., Ariza, C. et al. (2011). Two-year impact of the Spanish smoking law on exposure to secondhand smoke: Evidence of the failure of the 'Spanish model'. Tobacco Control. Published Online First: June 92011.

Lund, K. E. (2006). The introduction of smoke-free hospitality venues in Norway. Impact on revenues, frequency of patronage, satisfaction and compliance (vol. 2). Oslo: The Norwegian Institute for Alcohol and Drugs Research.

Macy, J. T., Middlestadt, S. E., Seo, D.-C., Kolbe, L. J., \& Jay, S. J. (2012). Applying the Theory of Planned Behavior to explore the relation between smoke-free air laws and quitting intentions. Health Education \& Behavior, 39, 27-34.

Magzamen, S., Charlesworth, A., \& Glantz, S. A. (2001). Print media coverage of California's smokefree bar law. Tobacco Control, 10, 154-160.

Magzamen, S., \& Glantz, S. (2001). The new battleground: California's experience with smoke-free bars. American Journal of Public Health, 91, 245-252.

Major, B., \& O’Brien, L. T. (2005). The social psychology of stigma. Annual Review of Psychology, 56, 393-421.

Mamudu, H. M., Hammond, R., \& Glantz, S. (2008). Tobacco industry attempts to counter the World Bank report curbing the epidemic and obstruct the WHO Framework Convention on Tobacco Control. Social Science \& Medicine, 67, 1690-1699.

Martínez-Sánchez, J. M., Fernández, E., Fu, M., Gallus, S., Martínez, C., Sureda, X. et al. (2010). Smoking behaviour, involuntary smoking, attitudes towards smoke-free legislations, and tobacco control activities in the European Union. PLoS ONE, 5, e13881. 
McNabb, J., \& Hearns, N. (2005). The smoking ban in hospitality: A cross-border perspective from Ireland. International Journal of Contemporary Hospitality Management, 17, 191-190.

McNicholas, W. T. (2004). Controlling passive smoking through legislation in Ireland: An attack on civil liberty or good public health policy? European Respiratory Journal, 24, 337-338.

Mendez, D., \& Warner, K. E. (2004). Adult cigarette smoking prevalence: Declining as expected (not as desired). American Journal of Public Health, 94, 251-252.

Mendez, D., Warner, K. E., \& Courant, P. N. (1998). Has smoking cessation ceased? Expected trends in the prevalence of smoking in the United States. American Journal of Epidemiology, 148, 249-258.

Moher, M., Hey, K., \& Lancaster, T. (2005). Workplace interventions for smoking cessation. Cochrane Database of Systematic Reviews, Issue 2, CD003440.

Momperousse, D., Delnevo, C. D., \& Lewis, M. J. (2007). Exploring the seasonality of cigarette-smoking behaviour. Tobacco Control, 16, 69-70.

Mons, U., Nagelhout, G. E., Guignard, R., McNeill, A., Van den Putte, B., Willemsen, M. C. et al. (2012). Comprehensive smoke-free policies attract more support from smokers in Europe than partial policies. European Journal of Public Health, 22(Suppl 1), 10-16.

Moskowitz, J., Lin, Z., \& Hudes, E. (2000). The impact of workplace smoking ordinances in California on smoking cessation. American Journal of Public Health, 90, 757-761.

Mullally, B. J., Greiner, B. A., Allwright, S., Paul, G., \& Perry, I. J. (2009). The effect of the Irish smoke-free workplace legislation on smoking among bar workers. European Journal of Public Health, 19, 206-211.

Mumford, E. A., Levy, D. T., \& Romano, E. O. (2004). Home smoking restrictions: Problems in classification. American Journal of Preventive Medicine, 27, 126-131.

Muthén, L. K., \& Muthén, B. O. (2007). Mplus user’s guide. Los Angeles: Muthén \& Muthén.

Nagelhout, G. E., De Vries, H., Boudreau, C., Allwright, S., McNeill, A., Van den Putte, B. et al. (2012). Comparative impact of smoke-free legislation on smoking cessation in three European countries. European Journal of Public Health, 22(Suppl 1), 4-9.

Nagelhout, G. E., De Vries, H., Fong, G. T., Candel, M. J. J. M., Thrasher, J. F., Van den Putte, B. et al. (2012). Pathways of change explaining the effect of smoke-free legislation on smoking cessation in the Netherlands. An application of the International Tobacco Control Conceptual Model. Nicotine \& Tobacco Research. Published Online First: 5 April 2012.

Nagelhout, G. E., Levy, D. T., Blackman, K., Currie, L., Clancy, L., \& Willemsen, M. C. (2012). The effect of tobacco control policies on smoking prevalence and smoking-attributable deaths. Findings from the Netherlands SimSmoke Tobacco Control Policy Simulation Model. Addiction, 107, 407-416.

Nagelhout, G. E., Mons, U., Allwright, S., Guignard, R., Beck, F., Fong, G. T. et al. (2011). Prevalence and predictors of smoking in "smoke-free" bars. Findings from the International Tobacco Control (ITC) Europe Surveys. Social Science \& Medicine, 72, 1643-1651.

Nagelhout, G. E., Van den Putte, B., De Vries, H., Crone, M., Fong, G. T., \& Willemsen, M. C. (2012). The influence of newspaper coverage and a media campaign on smokers' support for smokefree bars and restaurants and on secondhand smoke harm awareness: Findings from the International Tobacco Control (ITC) Netherlands Survey. Tobacco Control, 21, 24-29.

Nagelhout, G. E., Willemsen, M. C., \& De Vries, H. (2011). The population impact of a workplace smoking ban and a hospitality industry smoking ban on smoking behaviour. Findings from a national 
population survey. Addiction, 106, 816-823.

Nagelhout, G. E., Willemsen, M. C., Thompson, M. E., Fong, G. T., Van den Putte, B., \& De Vries, H. (2010). Is web interviewing a good alternative to telephone interviewing? Findings from the International Tobacco Control (ITC) Netherlands Survey. BMC Public Health, 10, 351.

Naiman, A., Glazier, R., \& Moineddin, R. (2011). Is there an impact of public smoking bans on selfreported smoking status and exposure to secondhand smoke? BMC Public Health, 11, 146.

National Cancer Institute (2006). Evaluating ASSIST: A Blueprint for Understanding State-level Tobacco Control. Tobacco Control Monograph No. 17. Bethesda, MD: U.S. Department of Health and Human Services, National Institutes of Health, National Cancer Institute.

National Cancer Institute (2008). The role of the media in promoting and reducing tobacco use. Tobacco Control Monograph No. 19. Bethesda, MD: U.S. Department of Health and Human Services, National Institutes of Health, National Cancer Institute.

Niederdeppe, J., Kuang, X., Crock, B., \& Skelton, A. (2008). Media campaigns to promote smoking cessation among socioeconomically disadvantaged populations: What do we know, what do we need to learn, and what should we do now? Social Science \& Medicine, 67, 1343-1355.

Öberg, M., Jaakkola, M. S., Woodward, A., Peruga, A., \& Prüss-Ustün, A. (2011). Worldwide burden of disease from exposure to second-hand smoke: A retrospective analysis of data from 192 countries. The Lancet, 377(9760), 139-146.

Office of Tobacco Control (2010). Ireland: Current trends in cigarette smoking. Retrieved May 23, 2011 from http://www.otc.ie/research.asp.

Osypuk, T. L., \& Acevedo-Garcia, D. (2010). Support for smoke-free policies: A nationwide analysis of immigrants, US-born, and other demographic groups, 1995-2002. American Journal of Public Health, 100, 171-181.

Palmersheim, K. A., Remington, P. L., \& Gundersen, D. F. (2006). The impact of a smoke-free ordinance on the health and attitudes of bartenders. Madison, USA: Tobacco Surveillance and Evaluation Program, University of Wisconsin Comprehensive Center.

Peto, R., Lopez, A. D., Boreham, J., Health, C., \& Thun, M. (1992). Mortality from tobacco in developed countries: Indirect estimation from national vital statistics. Lancet, 339, 1269-1278.

Pierce, J. P., Fiore, M. C., Novotny, T. E., Hatziandreu, E. J., \& Davis, R. M. (1989). Trends in cigarette smoking in the United States. Educational differences are increasing. JAMA: The Journal of the American Medical Association, 261, 56-60.

Preacher, K. J., \& Hayes, A. F. (2004). SPSS and SAS procedures for estimating indirect effects in simple mediation models. Behavior Research Methods, Instruments, \& Computers, 36, 717-731.

Preacher, K. J., \& Hayes, A. F. (2010). SPSS Sobel macro syntax reference. Retrieved January 13, 2011 from http://www.comm.ohio-state.edu/ahayes/SPSS\%20programs/Sobel\%20syntax.pdf.

Public Health Service (1979). Healthy people: Surgeon General's report on health promotion and disease prevention. Washington, DC: US Department of Health, Education and Welfare.

Pursell, L., Allwright, S., O’Donovan, D., Paul, G., Kelly, A., Mullally, B. J. et al. (2007). Before and after study of bar workers' perceptions of the impact of smoke-free workplace legislation in the Republic of Ireland. BMC Public Health, 7, 131.

Rayens, M. K., Hahn, E. J., Langley, R. E., Hedgecock, S., Butler, K. M., \& Greathouse-Maggio, L. (2007). Public opinion and smoke-free laws. Policy Politics Nursing Practice, 8, 262-270.

Reda, A. A., Kaper, J., Fikretler, H., Severens, J. L., \& Schayck, C. P. v. (2009). Healthcare financing systems for increasing the use of tobacco dependence treatment. Cochrane Database of 
Systematic Reviews 2009, Issue 2, CD004305.

Ritchie, D., Amos, A., \& Martin, C. (2010a). "But it just has that sort of feel about it, a leper" - Stigma, smoke-free legislation and public health. Nicotine \& Tobacco Research, 12, 622-629.

Ritchie, D., Amos, A., \& Martin, C. (2010b). Public places after smoke-free--A qualitative exploration of the changes in smoking behaviour. Health \& Place, 16, 461-469.

Ross, H., Blecher, E., Yan, L., \& Hyland, A. (2011). Do cigarette prices motivate smokers to quit? New evidence from the ITC survey. Addiction, 106, 609-619.

Royal College of Physicians (2010). Passive smoking and children: A report by the Tobacco Advisory Group of the Royal College of Physicians. London: Royal College of Physicians.

Schaap, M. M., \& Kunst, A. E. (2009). Monitoring of socio-economic inequalities in smoking: Learning from the experiences of recent scientific studies. Public Health, 123, 103-109.

Schaap, M. M., Kunst, A. E., Leinsalu, M., Regidor, E., Ekholm, O., Dzurova, D. et al. (2008). Effect of nationwide tobacco control policies on smoking cessation in high and low educated groups in 18 European countries. Tobacco Control, 17, 248-255.

Schippers, E. I. (2011). Kamervragen betere uitleg rookvrije horeca [Parliamentary questions about a better explanation about smoke-free hospitality industry legislation]. The Hague: Ministry of Health.

Schneider, N., Sebrie, E., \& Fernandez, E. (2011). The so-called "Spanish model" - Tobacco industry strategies and its impact in Europe and Latin America. BMC Public Health, 11, 907.

Sheldon, T. (2010). Netherlands is told to get tough on smokers as cancer mortality stagnates. BMJ, 340, c3309.

Sheldon, T. (2011). Dutch health minister is quizzed about "intensive" contact with tobacco industry. $B M J, 343, \mathrm{~d} 7137$.

Siahpush, M., McNeill, A., Borland, R., \& Fong, G. T. (2006). Socioeconomic variations in nicotine dependence, self-efficacy, and intention to quit across four countries: Findings from the International Tobacco Control (ITC) Four Country Survey. Tobacco Control, 15(Suppl 3), 71-75.

Siegel, M., \& Skeer, M. (2003). Exposure to secondhand smoke and excess lung cancer mortality risk among workers in the " 5 B's": Bars, bowling alleys, billiard halls, betting establishments, and bingo parlours. Tobacco Control, 12, 333-338.

Smith, P., Frank, J., \& Mustard, C. (2009). Trends in educational inequalities in smoking and physical activity in Canada: 1974-2005. Journal of Epidemiology and Community Health, 63, 317-323.

Smoke Free Partnership (2006). Lifting the smokescreen. 10 reasons for a smoke free Europe. Brussels: European Respiratory Society Brussels Office.

Social \& Cultural Planning Office (2001). The Netherlands in a European perspective. Social \& cultural report 2000. The Hague: Social \& Cultural Planning Office.

Steering Committee of the National Strategy to Reduce Tobacco Use in Canada (1999). New directions for tobacco control in Canada: A national strategy. Ottawa: Health Canada.

Stuber, J., Galea, S., \& Link, B. G. (2008). Smoking and the emergence of a stigmatized social status. Social Science \& Medicine, 67, 420-430.

Szatkowski, L., Coleman, T., McNeill, A., \& Lewis, S. (2011). The impact of the introduction of smokefree legislation on prescribing of stop-smoking medications in England. Addiction, 106, 1827-1834.

Tamvakas, I., \& Amos, A. (2010). 'These things don't happen in Greece': A qualitative study of Greek young people's attitudes to smoking, secondhand smoke and the smokefree legislation. 
Health Education Research, 25, 955-964.

Tang, H., Cowling, D. W., Lloyd, J. C., Rogers, T., Koumjian, K. L., Stevens, C. M. et al. (2003). Changes of attitudes and patronage behaviors in response to a smoke-free bar law. American Journal of Public Health, 93, 611-617.

Tang, H., Cowling, D. W., Stevens, C. M., \& Lloyd, J. C. (2004). Changes of knowledge, attitudes, beliefs, and preference of bar owner and staff in response to a smoke-free bar law. Tobacco Control, 13, 87-89.

Tengs, T. O., Osgood, N. D., \& Chen, L. L. (2001). The cost-effectiveness of intensive national schoolbased anti-tobacco education: Results from the Tobacco Policy Model. Preventive Medicine, 33, 558-570.

The American Association for Public Opinion Research (2009). Standard definitions: Final dispositions of case codes and outcome rates for surveys. Deerfield, Illinois: AAPOR.

Thomas, S., Fayter, D., Misso, K., Ogilvie, D., Petticrew, M., Sowden, A. et al. (2008). Population tobacco control interventions and their effects on social inequalities in smoking: Systematic review. Tobacco Control, 17, 230-237.

Thompson, L., Pearce, J., \& Barnett, J. R. (2007). Moralising geographies: Stigma, smoking islands and responsible subjects. Area, 39, 508-517.

Thompson, M. E., Fong, G. T., Hammond, D., Boudreau, C., Driezen, P., Hyland, A. et al. (2006). Methods of the International Tobacco Control (ITC) Four Country Survey. Tobacco Control, 15(Suppl 3), 12-18.

Thrasher, J. F., Besley, J. C., \& González, W. (2010). Perceived justice and popular support for public health laws: A case study around comprehensive smoke-free legislation in Mexico City. Social Science \& Medicine, 70, 787-793.

Thrasher, J. F., Boado, M., Sebrié, E. M., \& Bianco, E. (2009). Smoke-free policies and the social acceptability of smoking in Uruguay and Mexico: Findings from the International Tobacco Control Policy Evaluation Project. Nicotine \& Tobacco Research, 11, 591-599.

Thrasher, J. F., Huang, L., Pérez-Hernández, R., Niederdeppe, J., Arillo-Santillán, E., \& Alday, J. (2011). Evaluation of a social marketing campaign to support Mexico City's comprehensive smokefree law. American Journal of Public Health, 101, 328-335.

Thrasher, J. F., Pérez-Hernández, R., Swayampakala, K., Arillo-Santillán, E., \& Bottai, M. (2010). Policy support, norms, and secondhand smoke exposure before and after implementation of a comprehensive smoke-free law in Mexico City. American Journal of Public Health, 100, 1789-1798.

Thrasher, J. F., Swayampakala, K., Arillo-Santillán, E., Sebrié, E., Walsemann, K. M., \& Bottai, M. (2010). Differential impact of local and federal smoke-free legislation in Mexico: A longitudinal study among adult smokers. Salud Pública de México, 52(Suppl 2), 244-253.

Thun, M., Myers, D. G., Day-Lally, C., Namboodiri, N. M., Calle, E. E., Flanders, W. D. et al. (1997). Age and the exposure-response relationships between cigarette smoking and premature death in Cancer Prevention Study II. In National Cancer Institute (Ed.), Changes in cigarette related disease risks and their implication for prevention and control. Smoking and tobacco control monograph 8, NIH publication no. 97-4213 (pp. 383-475). Bethesda, MD: National Cancer Institute.

Tichenor, P. J., Donohue, G. A., \& Olien, C. N. (1970). Mass media flow and differential growth in knowledge. Public Opinion Quarterly, 34, 159-170. 
Trotter, L., Wakefield, M., \& Borland, R. (2002). Socially cued smoking in bars, nightclubs, and gaming venues: a case for introducing smoke-free policies. Tobacco Control, 11, 300-304.

U.S. Department of Health and Human Services (1986). The health consequences of involuntary smoking: A report of the Surgeon General. Rockville, Maryland: U.S. Department of Health and Human Services, Center for Disease Control and Prevention, National Center for Chronic Disease Prevention and Health Promotion, Office on Smoking and Health.

U.S. Department of Health and Human Services (2000). Reducing tobacco use: A report of the Surgeon General. Atlanta, Georgia: U.S. Department of Health and Human Services, Centers for Disease Control and Prevention, National Center for Chronic Disease Prevention and Health Promotion, Office on Smoking and Health.

U.S. Department of Health and Human Services (2006). The health consequences of involuntary exposure to tobacco smoke: A report of the Surgeon General. Atlanta, GA: U.S. Department of Health and Human Services, Centers for Disease Control and Prevention, Coordinating Center for Health Promotion, National Center for Chronic Disease Prevention and Health Promotion, Office on Smoking and Health.

U.S. Department of Health and Human Services (2010). How tobacco smoke causes disease: The biology and behavioral basis for smoking-attributable disease: A report of the Surgeon General Atlanta, GA: U.S. Department of Health and Human Services, Centers for Disease Control and Prevention, National Center for Chronic Disease Prevention and Health Promotion, Office on Smoking and Health.

U.S. Department of Health Education and Welfare (1964). Smoking and health: Report of the Advisory Committee to the Surgeon General of the Public Health Service. Washington, DC: U.S. Public Health Service.

Van den Bos, A. (2010). From controversy to courtesy: Tobacco industry's tactics to prevent workplace smoking restrictions in the Netherlands [Master's thesis]. Amsterdam: Vu University Amsterdam.

Van den Putte, B., Yzer, M. C., \& Brunsting, S. (2005). Social influences on smoking cessation: A comparison of the effect of six social influence variables. Preventive Medicine, 41, 186-193.

Van den Putte, B., Yzer, M. C., Brunsting, S., \& Willemsen, M. C. (2005). Sociale invloeden op stoppen met roken [social influences on smoking cessation]. Tijdschrift voor Communicatiewetenschap, 33, 262-272.

Van Genugten, M. L., Hoogenveen, R. T., Mulder, I., Smit, H. A., Jansen, J., \& De Hollander, A. E. (2003). Future burden and costs of smoking-related disease in the Netherlands: A dynamic modeling approach. Value in Health, 6, 494-499.

Verdonk-Kleinjan, W. M. I., Candel, M. J. J. M., Knibbe, R. A., Willemsen, M. C., \& De Vries, H. (2011). Effects of a workplace-smoking ban in combination with tax increases on smoking in the Dutch population. Nicotine \& Tobacco Research, 13, 412-418.

Verdonk-Kleinjan, W. M. I., Knibbe, R. A., Tan, F. E. S., Willemsen, M. C., de Groot, H. N., \& De Vries, H. (2009). Does the workplace-smoking ban eliminate differences in risk for environmental tobacco smoke exposure at work? Health Policy, 92, 197-202.

VVD-CDA (2010). Vrijheid en verantwoordelijkheid. Regeerakkoord VVD-CDA [Freedom and responsibility. Coalition agreement VVD-CDA]. The Hague: VVD, CDA.

VWA (2010). Inventarisatie naleefniveau rookvrije horeca winter 2009/2010 [Inventarisation level of compliance smoke-free hospitality industry legislation winter 2009/2010]. Voedsel en Waren 
Autoriteit \& Intraval.

Wakefield, M., \& Chaloupka, F. (2000). Effectiveness of comprehensive tobacco control programmes in reducing teenage smoking in the USA. Tobacco Control, 9, 177-186.

Wakefield, M., Roberts, L., \& Owen, N. (1996). Trends in prevalence and acceptance of workplace smoking bans among indoor workers in South Australia. Tobacco Control, 5, 205-208.

Warren, C. W., Lee, J., Lea, V., Goding, A., O'Hara, B., Carlberg, M. et al. (2009). Evolution of the Global Tobacco Surveillance System (GTSS) 1998-2008. Global Health Promotion, 16(Suppl 2), 4-37.

White, J., \& Froeb, H. (1980). Small-airways dysfunction in nonsmokers chronically exposed to tobacco smoke. New England Journal of Medicine, 302, 720-723.

White, V., Hill, D., Siahpush, M., \& Bobevski, I. (2003). How has the prevalence of cigarette smoking changed among Australian adults? Trends in smoking prevalence between 1980 and 2001. Tobacco Control, 12(Suppl 2), 67-74.

Wiegman-van Meppelen Scheppink (2011). Vragen van het lid Wiegman-van Meppelen Scheppink (ChristenUnie) aan de minister van Volksgezondheid Welzijn en Sport over betere uitleg van de overheid over rookvrije horeca [Questions from parliament member Wiegman-van Meppelen Scheppink (ChristenUnie) to the Minister of Health about a better explanation from the government about smoke-free hospitality industry legislation]. The Hague: ChristenUnie.

Willems, P., Brown, M., Van Ossenbruggen, R., \& Vonk, T. (2006). The effects of panel recruitment and management on research results. Dutch online panel study NOPVO. Barcelona: ESOMAR.

Willemsen, M. C. (2011). Roken in Nederland. De keerzijde van tolerantie. Oratie [Smoking in the Netherlands. The downside of tolerance. Inaugural lecture]. Maastricht: Maastricht University.

Willemsen, M. C., Hoogenveen, R. T., \& Van der Lucht, F. (2002). New smokers and quitters. Transitions in smoking status in a national population. European Journal of Public Health, 12, 136-138.

Wilson, N., Thomson, G., Grigg, M., \& Afzal, R. (2005). New smoke-free environments legislation stimulates calls to a national Quitline. Tobacco Control, 14, 287-288.

World Bank (2003). Tobacco control at a glance. Washington, DC: World Bank.

World Health Organization (1998). Guidelines for controlling and monitoring the tobacco epidemic.

Geneva: World Health Organization.

World Health Organization (2003). WHO Framework Convention on Tobacco Control. Geneva: World Health Organization.

World Health Organization (2007a). Guidelines on protection from exposure to tobacco smoke. Geneva: World Health Organization.

World Health Organization (2007b). Protection from exposure to second-hand tobacco smoke. Policy recommendations. Geneva: World Health Organization.

World Health Organization (2008a). Report on the global tobacco epidemic, 2008: the MPOWER package. Geneva: World Health Organization.

World Health Organization (2008b). Tobacco industry interference with tobacco control. Geneva: World Health Organization.

World Health Organization (2010). WHO Technical manual on tobacco tax administration. Geneva: World Health Organization.

World Health Organization, Health and Welfare Canada, \& Canadian Public Health Association (1986). Ottawa charter for health promotion. Canadian Journal of Public Health, 77, 425-430.

Yong, H.-H., Foong, K., Borland, R., Omar, M., Hamann, S., Sirirassamee, B. et al. (2010). Support for and reported compliance among smokers with smoke-free policies in air-conditioned 
hospitality venues in Malaysia and Thailand: Findings from the International Tobacco Control Southeast Asia Survey. Asia-Pacific Journal of Public Health, 22, 98-109.

Zeger, S. L., \& Liang, K. Y. (1986). Longitudinal data analysis for discrete and continuous outcomes. Biometrics, 42, 121-130.

Zhang, X., Cowling, D. W., \& Tang, H. (2010). The impact of social norm change strategies on smokers' quitting behaviours. Tobacco Control, 19(Suppl 1), 51-55. 


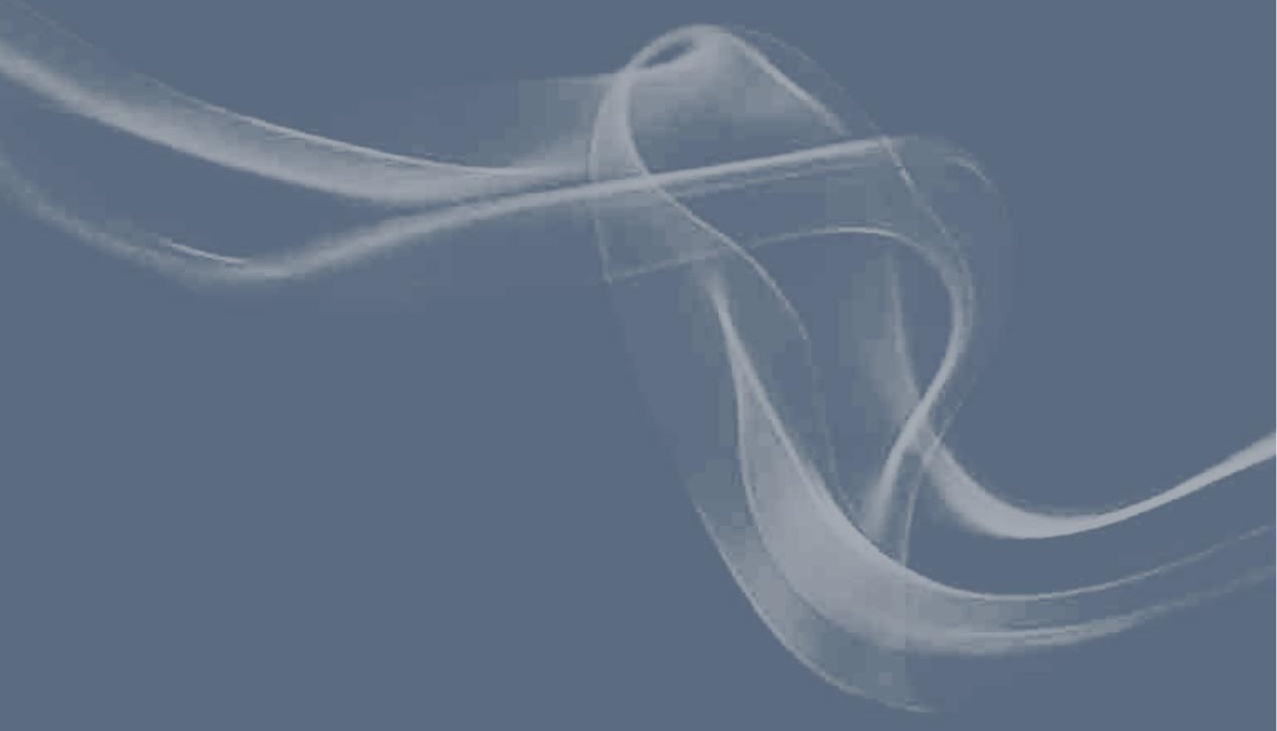

| 274 | 
Summary 


\section{Summary}

Exposure to tobacco smoke from others (second-hand smoking) is dangerous for non-smokers. To protect them from these risks, many countries have implemented smoke-free legislation that bans smoking in indoor workplaces and public places. We examined the impact of smoke-free legislation on smokers instead of nonsmokers in this thesis. The expectation is that the largest public health gain from smoke-free legislation comes from the effect on smokers. This effect can set a flywheel in motion that eventually causes smoking to reduce further and further. This thesis mainly focused on the impact of the implementation of smoke-free hospitality industry legislation in the Netherlands in July 2008.

It was unknown in 2008 whether smoke-free legislation in the hospitality industry had a similar impact on the population as smoke-free legislation in workplaces. We also did not know enough about differences in impact between comprehensive and partial smoke-free legislation and between smoke-free legislation and other tobacco control policies. Furthermore, it was unclear how smoke-free legislation influenced smoking cessation. Finally, more research was needed on unintended consequences of smoke-free legislation on smoking in smokers' homes, perceived stigmatisation of smokers, and socioeconomic inequalities in smoking.

For this thesis, we mostly used data from the International Tobacco Control Policy Evaluation Project (ITC Project). ITC is an international survey study among smokers and is currently conducted in 20 countries. The methods of the ITC Netherlands Project are described in chapter 2.

\section{Part 1: What is the impact of smoke-free legislation on smoking?}

Findings from chapters 3,4 , and 5 demonstrated that national smoke-free legislation can reduce smoking prevalence, stimulate smoking cessation, and reduce smoking-attributable deaths. Furthermore, the findings suggested that the impact of smoke-free legislation on smoking prevalence and cessation was larger when it was implemented in all workplaces instead of only hospitality industry venues (chapter 3). Also, the impact on smoking cessation may be larger when the smokefree legislation was comprehensive instead of partial (chapter 4). Extending partial smoke-free legislation to all public places and workplaces can substantially reduce smoking prevalence and smoking-attributable deaths provided that there is full enforcement and publicity (chapter 5). We found that the impact of comprehensive smoke-free legislation on reducing future smoking-attributable deaths ranked as the third most effective tobacco control policy in the Netherlands, after increasing tobacco taxes and implementing cessation treatment policies (chapter 5). 


\section{Part 2: How do the individual pathways of change after smoke-free legislation look like?}

According to the ITC Conceptual Model, tobacco control policy can have an impact on smoking cessation through certain individual pathways of change. First, the policy influences opinions and thoughts that are strongly related to the policy (policy-specific variables). These opinions and thoughts then influence more general psychological factors that are less related with the policy and more with smoking cessation (psychosocial mediators). Finally, these psychosocial mediators can have an influence on actual smoking cessation.

In the studies in chapters 6 and 7 we determined relevant policy-specific variables of smoke-free legislation. It was found that there was a larger increase in support for smoke-free legislation among smokers than normal in countries that implemented comprehensive smoke-free legislation (chapter 6). Smokers who were more aware of the harm of second-hand smoking were more often supportive of smoke-free legislation. The study in chapter 7 described the newspaper coverage about smoke-free hospitality industry legislation in the Netherlands. Most newspaper coverage was negative towards the smoke-free legislation and focused on economic aspects rather than health aspects. Exposure to this coverage had a small negative effect on support for smoke-free legislation, while exposure to the implementation campaign had a small positive effect on awareness of the harm of second-hand smoking.

The studies in chapters 8 and 9 focused on the impact of smoke-free legislation on psychosocial mediators. In chapter 8 we examined the impact on the social acceptability of smoking. Exposure to smoke-free legislation was associated with increased feelings of being uncomfortable about smoking and increased perceptions of societal disapproval of smoking. However, these associations were small, which suggests that smoke-free legislation may only have an impact on the long term and on the population level. In chapter 9 we described which smokers smoked inside bars after the implementation of smoke-free legislation. Smokers who were more supportive of smoke-free legislation and who were more aware of the harm of second-hand smoke were less likely to smoke in bars after the implementation. Smokers in the Netherlands and Germany, countries with partial smoke-free legislation, smoked more often inside bars after the implementation of smoke-free legislation than smokers in Ireland and France, where the implementation of smoke-free legislation was comprehensive.

In chapter 10 we tested the entire causal chain from individual exposure to smoke-free legislation on smoking cessation, through policy-specific variables and psychosocial mediators. The effect of individual exposure to smoke-free 
legislation on smoking cessation could be explained by an effect on support for smoke-free legislation (policy-specific variable), and an impact of this on attitudes about quitting and intention to quit smoking (psychosocial mediators). Exposure to smoke-free legislation also created more awareness of the harm of (second-hand) smoking (policy-specific variable), which in turn increased positive social norms about quitting (psychosocial mediator).

\section{Part 3: Are there unintended consequences of smoke-free legislation?}

It was demonstrated in chapter 11 that smoke-free hospitality industry legislation did not lead to more smoking in smokers' homes. In fact, smoke-free legislation seemed to reduce the number of cigarettes smoked per day and seemed to stimulate smokers to establish voluntary smoking bans in their homes. In chapter 12 we described that whether smoke-free legislation increased smokers' perceived stigmatisation depended on how smokers felt about smoking outside. Feelings of stigmatisation did not increase after the implementation of smoke-free hospitality industry legislation in the Netherlands, possibly because most Dutch smokers did not feel negatively judged when smoking outside. Finally, we found that there is a widening of educational inequalities in smoking in the Netherlands (chapter 13). We did not find that the implementation of smoke-free hospitality industry legislation contributed to this (chapters 3 and 14). However, the smoke-free workplace legislation did have larger effects on smoking cessation among higher educated smokers than among lower educated smokers (chapters 3 and 13).

\section{What can we conclude from this?}

In this thesis we found that smoke-free legislation can reduce smoking prevalence, stimulate smoking cessation, and reduce smoking-attributable deaths. Support for smoke-free legislation among smokers proved to be very important, because support contributes to more compliance with the legislation, because support can lead to more smoking cessation by influencing attitudes and intentions to quit smoking, and because support for smoke-free legislation stimulates smokers to establish voluntary home smoking bans. Smoke-free legislation did not lead to more smoking in smokers' homes and the smoke-free hospitality industry legislation in the Netherlands did not lead to an increase in feelings of stigmatization. Only the smoke-free workplace legislation and not the smoke-free hospitality industry legislation increased socioeconomic differences in smoking.

Based on the findings from this thesis and on the ITC Conceptual Model, we developed a model of the individual impact of smoke-free legislation on smoking cessation (chapter 15). Smoke-free legislation is often accompanied by media 
attention and both have the potential to increase support for smoke-free legislation and awareness of the harm of (second-hand) smoking. Increases in support and harm awareness result in more favourable attitudes and social norms about quitting. These attitudes and social norms can in turn increase intention to quit and smoking cessation. Support and harm awareness, as well as attitudes and social norms about quitting, also influence compliance with smoke-free legislation and whether people implement voluntary smoking bans in their home. Compliance with smokefree legislation and voluntarily implementing home smoking bans may also increase intention to quit and smoking cessation.

The World Health Organization recommends implementing 100\% smokefree environments without smoking rooms and exceptions, to enforce the law heavily, and to run an educational campaign about the harm caused by secondhand smoke. Several studies in this thesis found evidence that it is important to follow these recommendations. It seems that following these recommendation has a positive effect on smoking cessation (chapters 3 and 4), support for smokefree legislation (chapter 6), and compliance with the legislation (chapter 9). The Netherlands did not follow any of these recommendations, which is the most likely cause of less smoking cessation after the implementation in the Netherlands than in other countries, a lower increase in support for smoke-free legislation, and more smoking inside bars. It is plausible that the smoke-free legislation would have been successful in the Netherlands when the World Health Organization policy recommendations had been followed through. As long as there are no countries that followed these recommendations and were not successful, we can assume that with proper implementation it can succeed everywhere. "It has been done elsewhere, it can be done everywhere".

\section{What should be studied further?}

Future research should further determine the role of social norms and denormalisation in reducing smoking in the population. More research is also needed on the differential effectiveness of various tobacco control policies on different socioeconomic groups. Finally, it is important to study synergies between tobacco control policies and publicity about this.

\section{Which recommendations do we have for practice?}

Policymakers in countries that do not have smoke-free legislation should plan upfront how they are going to ensure that enough smokers are supportive of smoke-free legislation. A coordinated media advocacy strategy is therefore needed. These countries should implement smoke-free legislation according to the 
recommendations from the World Health Organization (100\% smoke-free legislation without smoking rooms, without exceptions, with adequate enforcement, and with an educational campaign about the harms of second-hand smoke).

The Netherlands and other countries that still have partial legislation should acknowledge that the policy is not effectively protecting non-smokers from secondhand smoke and are advised to implement comprehensive smoke-free legislation. The Netherlands should reverse the exemption for small bars without employees, should ban smoking rooms, should enforce the law more heavily, and should run an educational campaign which explains that smoke-free legislation is necessary to protect non-smokers from the harm of second-hand smoke. 


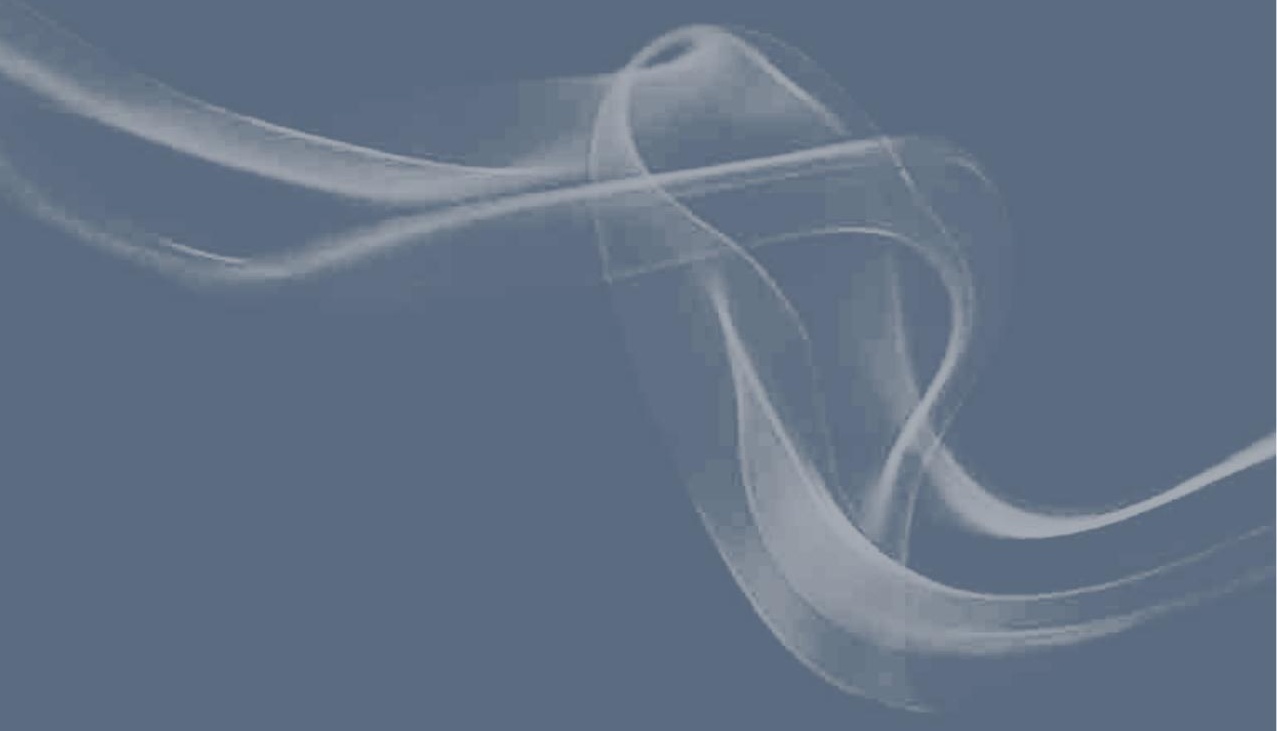

| 282 | 


\section{Samenvatting}




\section{Samenvatting}

Blootstelling aan tabaksrook van anderen (meeroken) is gevaarlijk voor niet-rokers. Om hen hiertegen te beschermen, voeren veel landen rookverboden in voor werkplekken en openbare gebouwen. In dit proefschrift is gekeken naar het effect van rookverboden op rokers in plaats van niet-rokers. De verwachting is namelijk dat de grootste gezondheidswinst door rookverboden ontstaat door het effect op rokers. Dit effect kan een vliegwiel in beweging brengen dat er uiteindelijk voor zorgt dat roken steeds verder teruggedrongen wordt in de samenleving. In dit proefschrift is vooral onderzoek gedaan naar het effect van de invoering van de rookvrije horeca in Nederland in juli 2008.

Het was in 2008 nog onbekend of rookverboden in de horeca een vergelijkbare invloed hadden op de populatie als rookverboden op de werkplek. Ook wisten we onvoldoende over de verschillen in effect tussen volledige en gedeeltelijke rookverboden en tussen rookverboden en ander tabaksontmoedigingsbeleid. Verder was nog onduidelijk hoe rookverboden stoppen met roken beïnvloeden. Ten slotte was meer onderzoek nodig naar mogelijke ongewenste effecten van rookverboden op roken in het eigen huis, gevoelens van stigmatisering onder rokers en op sociaaleconomische verschillen in roken.

In dit proefschrift is voornamelijk gebruik gemaakt van data uit het International Tobacco Control Policy Evaluation Project (ITC project). ITC is een internationaal vragenlijstonderzoek onder rokers en wordt momenteel uitgevoerd in 20 landen. De methode van het ITC Nederland project is beschreven in hoofdstuk 2.

\section{Deel 1: Wat is het effect van rookverboden op roken?}

Resultaten uit hoofdstuk 3, 4 en 5 lieten zien dat landelijke rookverboden het percentage rokers kunnen doen dalen, stoppen met roken kunnen stimuleren en het aantal aan roken gerelateerde sterfgevallen (tabaksdoden) kunnen reduceren. Verder wezen de resultaten erop dat het effect van rookverboden groter is als een rookverbod op alle werkplekken wordt ingevoerd in plaats van alleen in de horeca (hoofdstuk 3). Ook leek het erop dat het effect van volledige rookverboden groter was dan het effect van gedeeltelijke rookverboden (hoofdstuk 4). Het uitbreiden van een gedeeltelijk rookverbod naar alle openbare gebouwen en werkplekken kan het percentage rokers en het aantal tabaksdoden sterk doen dalen, mits er sprake is van volledige handhaving en voldoende publiciteit over het verbod (hoofdstuk 5). De meest effectieve maatregelen om het aantal tabaksdoden terug te dringen in Nederland zijn het verhogen van de tabaksaccijns en het invoeren van beleid voor stoppen-met-rokenbehandeling, gevolgd door volledige rookverboden (hoofdstuk 5). 


\section{Deel 2: Hoe zien de individuele paden van verandering na rookverboden eruit?}

Volgens het conceptuele model van ITC kan tabaksontmoedigingsbeleid een effect hebben op stoppen met roken via bepaalde individuele paden van verandering. Eerst beïnvloed het beleid meningen en gedachten die sterk met het beleid te maken hebben (beleidsspecifieke variabelen). Deze meningen en gedachten beïnvloeden vervolgens algemenere psychologische factoren die minder met het beleid zelf en meer met stoppen met roken te maken hebben (psychosociale mediatoren). Ten slotte kunnen deze psychosociale mediatoren een invloed hebben op daadwerkelijk stoppen met roken.

In de studies in hoofdstuk 6 en 7 onderzochten we beleidsspecifieke variabelen van rookverboden. Gevonden werd dat er een grotere stijging dan normaal in draagvlak voor rookverboden onder rokers was in landen die een volledig rookverbod invoerden (hoofdstuk 6). Rokers die zich meer bewust waren van de schade van meeroken waren vaker voorstander van rookverboden. In hoofdstuk 7 werd de krantenberichtgeving over de rookvrije horeca in Nederland beschreven. De berichtgeving was overwegend negatief over het rookverbod en ging voornamelijk in op economische aspecten in plaats van gezondheidsaspecten. Blootstelling aan deze berichtgeving had een klein negatief effect op draagvlak voor rookverboden, terwijl blootstelling aan de implementatiecampagne van de overheid een klein positief effect had op bewustzijn van de schade van meeroken.

De studies in hoofdstuk 8 en 9 waren vooral gericht op het effect van rookverboden op psychosociale mediatoren. In hoofdstuk 8 onderzochten we het effect op de sociale acceptatie van roken. Blootstelling aan rookverboden ging samen met het zich ongemakkelijk voelen over roken en meer denken dat de samenleving het roken afkeurt. Deze associaties waren echter klein, wat doet vermoeden dat het effect van rookverboden op de sociale acceptatie van roken vooral op de lange termijn en op het populatieniveau optreedt. In hoofdstuk 9 beschreven we welke rokers binnen in cafés rookten na de invoering van rookverboden. Rokers die voorstander waren van rookverboden en die zich meer bewust waren van de gevaren van meeroken waren minder geneigd om te roken binnen in cafés na de invoering van een rookverbod. Rokers in Nederland en Duitsland, landen met een gedeeltelijk rookverbod, rookten vaker binnen in cafés na de invoering van het rookverbod dan rokers in lerland en Frankrijk, waar het rookverbod volledig was ingevoerd.

In hoofdstuk 10 onderzochten we de totale oorzakelijke keten van individuele blootstelling aan rookverboden op stoppen met roken, via beleidsspecifieke variabelen en psychosociale mediatoren. Het effect van individuele blootstelling aan rookverboden op stoppen met roken kon verklaard worden door een effect 
van rookverboden op draagvlak voor rookverboden (beleidsspecifieke variabele) en vervolgens een effect daarvan op attitudes over stoppen met roken en intenties om te stoppen (psychosociale mediatoren). Blootstelling aan rookverboden zorgde ook voor meer bewustzijn van de schade van (mee)roken (beleidsspecifieke variabele), wat zorgde voor positievere sociale normen over stoppen met roken (psychosociale mediator).

\section{Deel 3: Zijn er ongewenste effecten van rookverboden?}

In hoofdstuk 11 werd aangetoond dat rookvrije horeca wetgeving niet leidt tot meer roken in het eigen huis. Het leek er zelfs op dat rookverboden zorgden voor een daling in het aantal gerookte sigaretten per dag en een rookverbod leek rokers te stimuleren om hun huis vrijwillig rookvrij te maken. In hoofdstuk 12 lieten we zien dat een eventueel effect van rookverboden op gevoelens van stigmatisering afhing van hoe rokers zich voelen over buiten roken. Gevoelens van stigmatisering namen niet toe na de invoering van de rookvrije horeca in Nederland. Nederlandse rokers voelen zich dan ook meestal niet negatief beoordeeld als ze buiten roken. Ten slotte vonden we dat de sociaaleconomische verschillen in roken steeds meer toenamen in Nederland (hoofdstuk 13). Het leek er niet op dat de invoering van de rookvrije horeca hieraan heeft bijgedragen (hoofdstuk 3 en 14). Echter, de invoering van de rookvrije werkplek had wel een groter effect op stoppen met roken onder hoogopgeleiden dan onder lager opgeleiden (hoofdstuk 3 en 13).

\section{Wat kunnen we hieruit concluderen?}

In dit proefschrift vonden we dat rookverboden het percentage rokers kunnen doen dalen, stoppen met roken kunnen stimuleren en zodoende het aantal tabaksdoden kunnen reduceren. Draagvlak voor rookverboden onder rokers bleek erg belangrijk te zijn, omdat draagvlak zorgt voor meer naleving van het verbod, omdat het door het beïnvloeden van attitudes en intenties om te stoppen met roken kan leiden tot meer stoppogingen en omdat het stimuleert om het eigen huis vrijwillig rookvrij te maken. Rookverboden zorgden niet voor meer roken in het eigen huis en in Nederland heeft de rookvrije horeca niet geleid tot een toename in gevoelens van stigmatisering. Alleen de rookvrije werkplek en niet de rookvrije horeca heeft in Nederland geleid tot een vergroting van de sociaaleconomische verschillen in roken.

Op basis van de bevindingen in dit proefschrift en het conceptuele model van ITC hebben we een model ontwikkeld dat het individuele effect van rookverboden op stoppen met roken beschrijft (hoofdstuk 15). Rookverboden gaan vaak samen met media-aandacht en beide hebben de potentie om te zorgen voor meer draagvlak voor rookverboden en meer bewustzijn over de schade van (mee)roken. 
Meer draagvlak en bewustzijn van schade kunnen leiden tot positievere attitudes en sociale normen over stoppen met roken. Deze attitudes en normen kunnen vervolgens leiden tot meer intentie om te stoppen met roken en meer stoppogingen. Zowel draagvlak en bewustzijn van schade als attitudes en sociale normen over stoppen met roken kunnen beïnvloeden of rokers het rookverbod naleven en of ze hun eigen huis vrijwillig rookvrij maken. Naleving van het rookverbod en het vrijwillig invoeren van thuisrookverboden kunnen ook leiden tot een hogere stopintentie en meer stoppen met roken.

De Wereldgezondheidsorganisatie beveelt aan om rookverboden $100 \%$ in te voeren zonder rookruimtes en uitzonderingen, om te zorgen voor goede handhaving en om een voorlichtingscampagne te voeren over de schade van meeroken. Verschillende studies in dit proefschrift hebben aanwijzingen gevonden dat het belangrijk is om deze aanbevelingen te volgen. Het lijkt erop dat het volgen van deze aanbevelingen een positief effect heeft op stoppen met roken (hoofdstuk 3 en 4), draagvlak voor rookverboden (hoofdstuk 6) en naleving van het rookverbod (hoofdstuk 9). Nederland heeft geen van deze aanbevelingen opgevolgd, wat de meest waarschijnlijke oorzaak is voor het feit dat er na de invoering minder gestopt werd met roken dan in andere landen, dat het draagvlak voor rookverboden minder steeg en dat er meer gerookt werd binnen in cafés. Het is aannemelijk dat het rookverbod in Nederland succesvol was geweest als de aanbevelingen van de Wereldgezondheidsorganisatie waren gevolgd. Zolang er geen landen zijn die deze aanbevelingen volgen en niet succesvol zijn, kunnen we ervan uitgaan dat het met een goede invoeringsstrategie overal kan lukken. "It has been done elsewhere, it can be done everywhere".

\section{Wat moet er verder nog onderzocht worden?}

Toekomstig onderzoek zou meer inzicht moeten geven in de rol van sociale normen en denormalisatie in het terugdringen van roken in de populatie. Ook is meer onderzoek nodig naar de effecten van verschillend tabaksontmoedigingsbeleid op sociaaleconomische verschillen in roken. Ten slotte is het belangrijk om onderzoek te doen naar de synergie tussen tabaksontmoedigingsbeleid en publiciteit hierover.

\section{Welke aanbevelingen doen we voor de praktijk?}

Beleidsmakers in landen die nog geen rookverbod hebben ingevoerd, moeten vóór tot invoering van rookverboden wordt overgegaan, nadenken over hoe ze draagvlak voor rookverboden onder rokers kunnen realiseren. Daarvoor is een gecoördineerde mediastrategie nodig. Deze landen zouden rookverboden in moeten voeren volgens de aanbevelingen van de Wereldgezondheidsorganisatie (100\% rookvrij zonder 
rookruimtes en uitzonderingen, goede handhaving en een voorlichtingscampagne over de schade van meeroken).

Nederland en andere landen die nog een gedeeltelijk rookverbod hebben, moeten onderkennen dat dit beleid niet effectief is in het beschermen van niet-rokers tegen de schade van meeroken en worden geadviseerd een volledig rookverbod in te voeren. Nederland zou de uitzondering voor kleine cafés zonder personeel moeten terugdraaien, rookruimtes moeten verbieden, beter moeten handhaven en alsnog een voorlichtingscampagne moeten voeren waarin wordt uitgelegd dat een rookverbod noodzakelijk is om niet-rokers te beschermen tegen de schade van meeroken. 


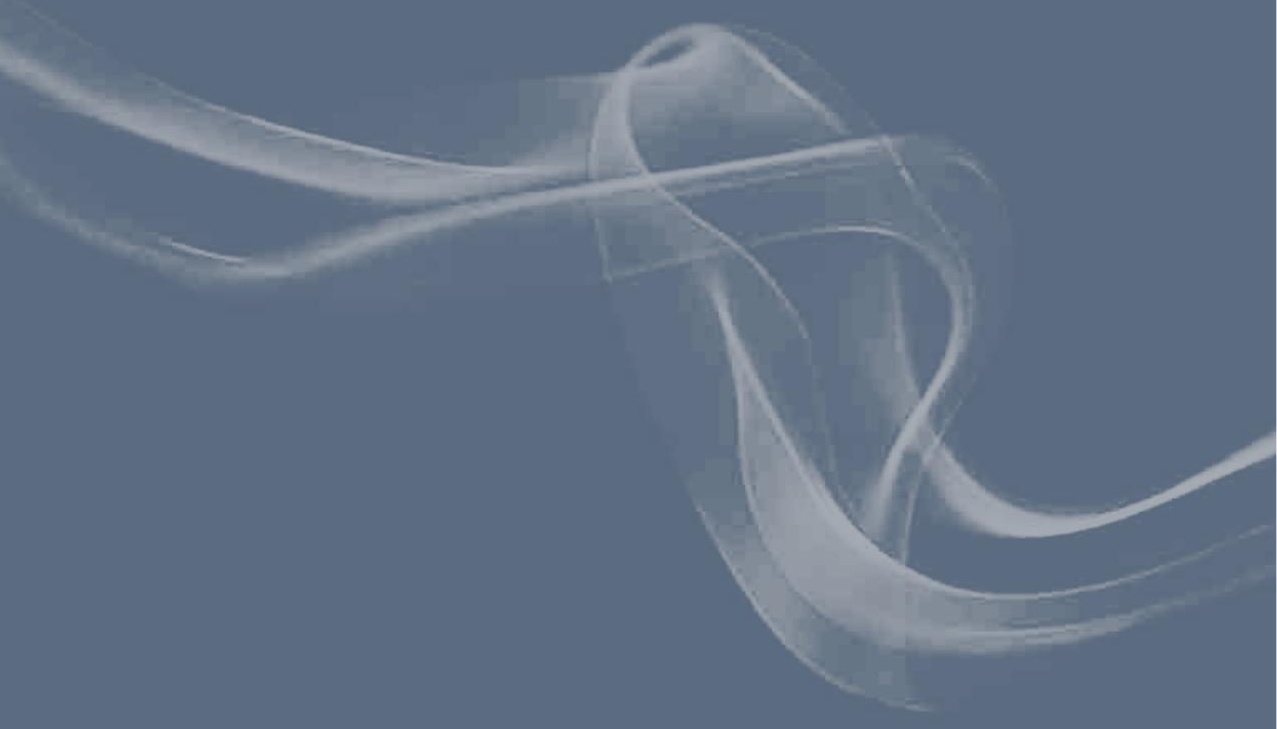

| 290 | 


\section{Dankwoord}<smiles>[3H][IH]</smiles> 


\section{Dankwoord}

Het schrijven van dit proefschrift heb ik zeker niet alleen gedaan. Daarom wil ik iedereen bedanken die hieraan heeft bijgedragen. Als eerste wil ik mijn promotoren, Marc en Hein, bedanken. Marc, dankjewel voor de vele uren die je gestoken hebt in mijn begeleiding, het brainstormen over de implicaties van mijn bevindingen en het becommentariëren van alle artikelen. Ik denk dat ik heel veel geluk heb gehad met een promotor waar ik altijd bij binnen kan lopen en die heel geïnteresseerd is en zeer deskundig op mijn onderzoeksterrein. Ook bedankt voor de gezelligheid tijdens onze tripjes naar lerland, Engeland en (de jungle van) Singapore. Hein, dankjewel voor je opbouwende kritieken en goede adviezen. Het is fijn om een promotor te hebben die geroutineerd is in het begeleiden van promovendi en je vanaf de eerste dag dwingt te kijken naar het grote geheel van het proefschrift en de planning die daarbij hoort. Ik wil jullie beiden ook bedanken voor jullie geduld toen bleek dat het schrijven van de inleiding en discussie van mijn proefschrift me minder makkelijk afging dan het schrijven van artikelen.

Ook wil ik natuurlijk de andere twee leden van het 'ITC Netherlands team', Bas en Matty, bedanken voor hun bijdrages. Bas, dankjewel voor je bijdrages aan bijna alle artikelen in mijn proefschrift. Je co-auteurschap is altijd zeer verdiend en je commentaren bijzonder nuttig (ook al is het vaak ook even slikken hoe kritisch je bent). Ik wil je vooral bedanken voor je enthousiasme en begeleiding bij ons 'krantenproject'. Ook wil ik je bedanken voor alle tijd die je in ITC steekt. Super dat je elk jaar de gehele vragenlijst doorloopt om mij te helpen met testen. Matty, ook jou wil ik bedanken voor je bijdrage aan ITC en mijn proefschrift. Ik heb het erg leuk gevonden om samen te puzzelen op de analyses van ons 'jongerenartikel' (van Structural Equation Modelling, naar Growth Modelling, naar uiteindelijk 'gewoon' regressie analyses). Ik hoop dat we in de toekomst samen kunnen blijven werken op onderzoek naar meeroken en Rookvrij Opgroeien.

My PhD project would not have been possible without the help of the ITC team at the University of Waterloo in Canada. Many of you have worked on ITC Netherlands and helped us with project management, survey development, research coordination, data cleaning, and statistical analyses. In particular, I want to thank Geoff and Lorraine. Geoff, thanks very much for critically revising my papers, coming up with ideas for survey questions, and for your inspiring leadership on the project. It is unbelievable that with all the work that you do, you still make the time to fly to the Netherlands to talk to our national media and help us in our battle to save tobacco control in the Netherlands. Lorraine, thanks for your terrific work on the ITC 
Netherlands National Report and Health Risk Report. I dare to say that these reports have been more important for tobacco control in the Netherlands than any of the scientific papers in my thesis. Also, many thanks for making me feel so welcome on the project and helping me with so many things. As a young researcher, it is great to be part of the ITC Project and immediately having a large international network and seeing lots of familiar faces at your first conferences. Finally, I want to thank you for the opportunity of being involved in ITC journal supplements and ITC conference symposia. Thank you, Lorraine, for organising many of these events and getting us involved.

ITC has also brought me new friends. In one of the first conference calls with Canada, Geoff told us that there was a PhD student in Germany, Ute, who was "also young, ambitious, and fun". And he was right! Later on, a PhD student from Canada, Sara, became ITC Europe Student Project Manager. Ute and Sara, thanks for the nice company during the conferences in Ireland, England, Amsterdam, and Singapore. I hope we will meet many more times in the future, but anyway, we will keep in touch through Facebook. Of course, I also owe you thanks for working together on some interesting papers. It's great that we never had any problems, although Ute and I were both doing a PhD Project on the same topic and with the same data.

Furthermore, I had the privilege of being involved in another international study: SimSmoke. Many thanks, David, for giving me the opportunity to work with the model that you developed and to write a paper about it. And thank you for your enthusiasm whenever we use SimSmoke Netherlands for national media advocacy purposes. I hope to work with you and with the SimSmoke model more often in the future.

Obviously, none of the papers in my $\mathrm{PhD}$ thesis were written by me alone. Many thanks to all my co-authors (in alphabetical order): Ann, Anton, Bas, Boukje, Christian, David, Dianne, Els, Eva, François, Geoff, Hein, Hermann, Jim, Kenneth, Laura, Luke, Lutz, Marc, Martina, Mary, Math, Matty, Mike, Regina, Romain, Sander, Sara, Shane, Ute, and Winnie. Ann, thanks for organising a journal supplement and conference symposia for ITC Europe and involving us in these efforts. Christian and Math, your help with some complex statistical modelling is much appreciated. Shane, thanks for proofreading the introduction of my thesis.

Een ontzettend leuk onderdeel van het promoveren, vond ik het begeleiden van twee masterstudenten. Els en Mariëtte, bedankt voor jullie inzet, enthousiasme 
en gezelligheid. Ik ben erg trots dat er uit beide projecten een mooi artikel is voortgekomen (hoofdstuk 8 en 12 uit dit proefschrift). Ik heb het volste vertrouwen dat we beide artikelen binnenkort in een wetenschappelijk tijdschrift geplaatst krijgen.

Ik wil graag mijn (ex-)collega's bij STIVORO bedanken voor de prettige werksfeer en gezelligheid. In het bijzonder Dagmar en Annegré, die beiden begonnen als kamergenoten en al snel lunchwandelmaatjes werden, later vriendinnen zijn geworden en nu mijn paranimfen zijn. Natuurlijk ben ik jullie ook dank verschuldigd voor jullie bijdrage aan mijn proefschrift: het lezen en coderen van 1.068 artikelen over de rookvrije horeca! Dagmar, dankjewel voor het kritisch lezen en becommentariëren van de inleiding van mijn proefschrift. Verder wil ik Dewi bedanken voor het zijn van een hele leuke baas, voor de wijze adviezen tijdens voortgangsgesprekken en voor het leesbaarder maken van de Nederlandse samenvatting van mijn proefschrift. Graag wil ik ook mijn mede-promovendi bij STIVORO, Regina en Frederieke, bedanken voor de steun na een afgewezen artikel, de felicitaties bij een geaccepteerd artikel en natuurlijk voor jullie gezelligheid als (ex-)kamergenoten. Frederieke, dankjewel voor het becommentariëren van de inleiding van mijn proefschrift. Ten slotte wil ik Lies, Grieto en Fleur bedanken voor het vertalen van mijn onderzoeksbevindingen naar de pers en politiek.

Natuurlijk wil ik ook mijn (ex-)collega's bij de Universiteit Maastricht bedanken, ook al ben ik daar niet erg vaak te vinden. Ik wil iedereen van de PhD lunch meetings hartelijk bedanken voor het kritisch lezen en bespreken van de artikelen in hoofdstuk 2, 3, 7 en 10 van mijn proefschrift. Ik heb daar enorm veel van geleerd! Ik wil Roy bedanken voor het bieden van een plek, een theemok en een gezellig praatje als ik een keer geen vertraging had met de trein en daardoor te vroeg in Maastricht was. Eline, Nicola, Daniel, Iman en Carolien, bedankt voor de gezelligheid tijdens het congres in Turkije.

Tijdens mijn promotieproject had ik de luxe dat ik het werven van respondenten, het programmeren van vragenlijsten en het uitvoeren van het veldwerk niet zelf hoefde te doen, maar dat dit uitgevoerd werd door TNS NIPO. Hanneke, Yvette, Noortje, Danielle, Anneloes en Kevin: bedankt voor jullie inzet en interesse in het onderzoek.

Dit proefschrift was niet mogelijk geweest zonder de subsidiegevers: ZonMw (voor ITC Nederland), het Ministerie van VWS (voor het COR) en de Europese Commissie 
(voor SimSmoke). Ook zijn subsidies verleend door de Amsterdam School of Communication Research ASCoR en STIVORO voor de inhoudsanalyse van de krantenberichtgeving over de rookvrije horeca. En niet te vergeten: een subsidie van maar liefst 2 Singapore dollars van Bas voor het WCToH-congres. Bedankt!

Ten slotte wil ik vrienden, familie en Jaap bedanken voor de afleiding en ontspanning die ook erg hard nodig zijn tussen het schrijven van het proefschrift door. Mama, dankjewel voor je hulp bij het leesbaarder maken van de Nederlandse samenvatting van mijn proefschrift. Roos, dankjewel voor de prachtige vormgeving van mijn proefschrift. Jaap, dankjewel dat je me meestal hebt 'gedwongen' om thuis te ontspannen en leuke dingen (met jou) te doen, maar dat je me ook af en toe m'n gang hebt laten gaan als dat nodig was. 


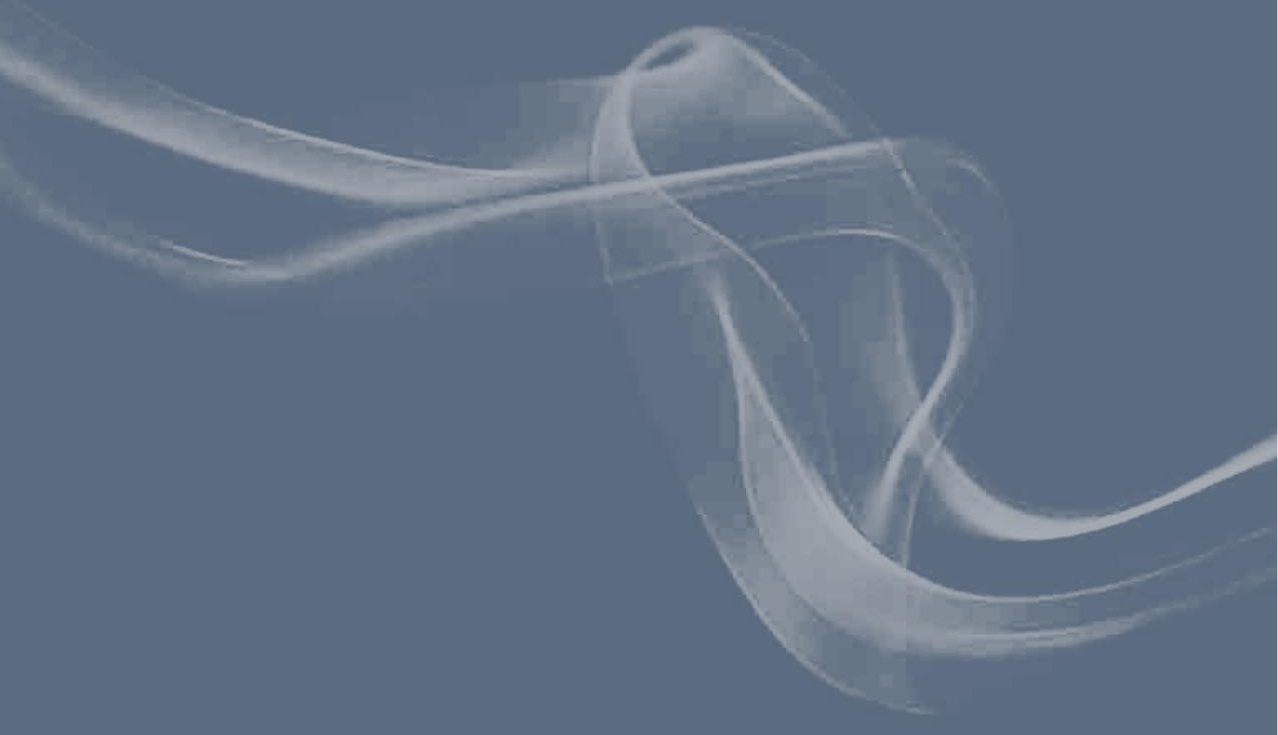

| 296 | 
Curriculum Vitae 


\section{Curriculum Vitae}

Gera Nagelhout was born on January 30, 1985, in Hattem, the Netherlands. After having graduated from secondary school in 2003, she started studying Communications at Radboud University Nijmegen. Her goal was to learn about commercial communication and public relations. However, after a project on organ donation in her first year, she became more interested in health communication than in commercial communication. During her time in Nijmegen, she also participated in a multidisciplinary extracurricular Honours Program, where she learned about evolution, literature, nutrition, and religion. Although she secretly thought that statistics were fun, Gera thought research was not something she wanted to do after graduation. Therefore, she went to the University of Twente in Enschede for a master in Applied Communications with the specialisation Health Promotion and Government Communication. Her master thesis was about smoking cessation counselling by oncologists and physician assistants, which was commissioned by the knowledge centre for the implementation of the clinical guideline on tobacco addiction. This knowledge centre was a collaboration between the Dutch expert centre on tobacco control STIVORO in The Hague and the Radboud University Nijmegen's Scientific Institute for Quality of Healthcare (IQ Healthcare). After receiving her MSc degree in August 2007, she worked on a research project at IQ Healthcare in which she evaluated a quality improvement program for mental health care and addiction care. In 2007, she also started working at STIVORO one day a week, where she wrote Dutch reports on trends in smoking in the Netherlands. Gera then realised that research was what she wanted to do after all and started her $\mathrm{PhD}$ project in May 2008, employed at the department of Health Promotion of Maastricht University (CAPHRI), but working from the office of STIVORO in The Hague. Gera will continue her work on the impact of tobacco control policies on smoking as a post-doctoral researcher at Maastricht University and STIVORO.

\section{Publications in this thesis}

Nagelhout, G. E., Willemsen, M. C., Thompson, M. E., Fong, G. T., Van den Putte, B. \& De Vries, H. (2010). Is web interviewing a good alternative to telephone interviewing? Findings from the International Tobacco Control (ITC) Netherlands Survey. BMC Public Health, 10, 351.

Nagelhout, G. E., Willemsen, M. C., \& De Vries, H. (2011). The population impact of smoke-free workplace and hospitality industry legislation on smoking behaviour. Findings from a national population survey. Addiction, 106, 816-823.

Nagelhout, G. E., De Vries, H., Allwright, S., McNeill, A., Van den Putte, B., Boudreau, 
C., Fong, G. T. \& Willemsen, M. C. (2012). Comparative impact of smokefree legislation on smoking cessation in three European countries. European Journal of Public Health, 22(Suppl 1), 4-9.

Nagelhout, G. E., Levy, D. T., Blackman, K., Currie, L., Clancy, L., \& Willemsen, M. C. (2012). The effect of tobacco control policies on smoking prevalence and smoking-attributable deaths. Findings from the Netherlands SimSmoke Tobacco Control Policy Simulation Model. Addiction, 107, 407-416.

Mons, U., Nagelhout, G. E., Guignard, R., McNeill, A., Van den Putte, B., Willemsen, M. C., Brenner, H., Pötschke-Langer \& M., Breitling, L. P. (2012).

Comprehensive smoke-free policies attract more support from smokers in Europe than partial policies. European Journal of Public Health, 22(Suppl 1), 10-16.

Nagelhout, G. E., Van den Putte, B., De Vries, H., Crone, M., Fong, G. T., \& Willemsen, M. C. (2012). The influence of newspaper coverage and a media campaign on smokers' support for smoke-free bars and restaurants and on secondhand smoke harm awareness. Findings from the International Tobacco Control (ITC) Netherlands Survey. Tobacco Control, 21, 24-29.

Rennen, E., Nagelhout, G. E., Van den Putte, B., Janssen, E., Mons, U., Guignard, R., Beck, F., De Vries, H., Thrasher, J. F., \& Willemsen, M. C. The effects of tobacco control policy awareness on smoking cessation by reducing the social acceptability of smoking. Findings from the International Tobacco Control (ITC) Europe Surveys. Submitted.

Nagelhout, G. E., Mons, U., Allwright, S., Guignard, R., Beck, F., Fong, G. T., De Vries, H., \& Willemsen, M. C. (2011). Prevalence and predictors of smoking in "smoke-free" bars. Findings from the International Tobacco Control (ITC) Europe Surveys. Social Science \& Medicine, 72, 1643-1651.

Nagelhout, G. E., De Vries, H., Fong, G. T., Candel, M. J. J. M., Thrasher, J. F., Van den Putte, B., Thompson, M. E., Cummings, K. M., \& Willemsen, M. C. Pathways of change explaining the effect of smoke-free legislation on smoking cessation in the Netherlands. An application of the International Tobacco Control (ITC) Conceptual Model. Nicotine \& Tobacco Research. Published Online First: 5 April 2012.

Mons, U., Nagelhout, G. E., Allwright, S., Guignard, R., Van den Putte, B., Willemsen, M. C., Fong, G. T., Brenner, H., Pötschke-Langer \& M., Breitling, L. P. Impact of national smoke-free legislation on home smoking bans: Findings from the International Tobacco Control (ITC) Policy Evaluation Project Europe Surveys. Tobacco Control. Published Online First: 13 February 2012. 
Nagelhout, G. E., Willemsen, M. C., Gebhardt, W. A., Van den Putte, B., Hichman, S. C., Crone, M. R., Fong, G. T., Van der Heiden, S., \& De Vries, H. Does smoke-free legislation and smoking outside bars increase feelings of stigmatisation among smokers? Findings from the International Tobacco Control (ITC) Netherlands Survey. Accepted for publication in Health \& Place.

Nagelhout, G. E., De Korte-de Boer, D., Kunst, A. E., Van der Meer, R. M., De Vries, H., Van Gelder, B. M., \& Willemsen, M. C. (2012). Trends in socioeconomic inequalities in smoking prevalence, consumption, initiation, and cessation between 2001 and 2008 in the Netherlands. Findings from a national population survey. BMC Public Health, 12, 303.

Nagelhout, G. E., Crone, M. R., Van den Putte, B., Willemsen, M. C., Fong, G. T., \& De Vries, H. Age and educational inequalities in smoking cessation after three population level tobacco control interventions. Findings from the International Tobacco Control (ITC) Netherlands Survey. Resubmitted.

\section{Other international publications}

Van der Heiden, S., Gebhardt, W.A., Willemsen, M. C., Nagelhout, G. E. \& Dijkstra, A. Behavioral and psychological responses of lower educated smokers to smoke-free legislation in Dutch hospitality venues. Accepted for publication in Psychology \& Health.

Willems, R. A., Willemsen, M. C., Nagelhout, G. E., \& De Vries, H. Understanding smokers' motivations to use evidence-based smoking cessation aids. Nicotine \& Tobacco Research. Published Online First: 9 May 2012.

Hitchman, S. C., Guignard, R., Nagelhout, G. E., Mons, U., Beck, F., Van den Putte, B., Crone, M., De Vries, R., Hyland, A., \& Fong, G. T. (2012). Predictors of car smoking rules among smokers in France, Germany and the Netherlands. European Journal of Public Health, 22(Suppl 1), 17-22.

Hitchman, S. C., Mons, U., Nagelhout, G. E., Guignard, R., Mcneill, A., Willemsen, M. C., Driezen, P., Wilquin, J.-L., Beck, F., Du-Roscöat, E., Pötschke-Langer, M., Hammond, D., \& Fong, G. T. Effectiveness of the European Union text-only cigarette health warnings: Findings from four countries. European Journal of Public Health. Published Online First: 15 September 2011.

Nagelhout, G. E. \& Fong, G. T. (2011). Netherlands: Plan to cut all health education (News Analysis). Tobacco Control, 20, 253-254.

\section{Other national publications}

Nagelhout, G. E., Willemsen, M. C., \& De Vries, H. (2012). Een écht rookvrije horeca is ook mogelijk in Nederland. Tijdschrift voor Gezondheidswetenschappen, 
90, 344-346.

Nagelhout, G. E., Van den Putte, B., De Vries, H., \& Willemsen, M. C. (2011).

Krantenberichtgeving over het rookverbod in de horeca: Een inhoudsanalyse.

Tijdschrift voor Communicatiewetenschap, 39, 4-16.

Nagelhout, G. E., Willemsen, M. C., Van den Putte, B., Crone, M., Segaar, D. \& De

Vries, H. (2011). Campagnes over schade van roken zijn absoluut noodzakelijk. Tijdschrift voor Gezondheidswetenschappen, 89, 258-260.

Nagelhout, G. E., Van den Burg, I., Muller, D. S. C. M., Adriaanse, M. C., \& Crone, M. R. (2011). Rookvrij Opgroeien. Voorlichting over meeroken door de Jeugdgezondheidszorg. Tijdschrift voor Jeugdgezondheidszorg, 43, 58-60.

Crone, M. R., Nagelhout, G. E., Van den Burg, I., \& Hirasing, H. A. (2010). Meeroken door kinderen in Nederland sinds 1996 sterk gedaald. Nederlands Tijdschrift voor Geneeskunde, 154, A1658. 